\author{
Universidade de São Paulo
}

Instituto de Física

\title{
Identificação e Localização de Ondas de Alfvén Excitadas no Plasma de um Tokamak
}

\author{
Paulo Giovane Paschoali Pereira Puglia
}

Orientador: Prof. Dr. Artour Elfimov

Tese apresentada ao Instituto de Física da Universidade de São Paulo para a obtenção do título de Doutor em Ciências.

Comissão examinadora:

Prof. Dr. Artour Elfimov (IFUSP)

Prof. Dr. Munemasa Machida (UNICAMP)

Prof. Dr. Francisco E. Mendonça da Silveira (UFABC)

Prof. Dr. José Helder Facundo Severo (IFUSP)

Prof. Dr. Zwinglio Guimarães (IFUSP)

São Paulo 
FICHA CATALOGRÁFICA

Preparada pelo Serviço de Biblioteca e Informação do Instituto de Física da Universidade de São Paulo

Puglia, Paulo Giovane Paschoali Pereira

Identificação e localização de ondas de Alfvén excitadas no plasma de um tokamak. São Paulo, 2015.

Tese (Doutorado) - Universidade de São Paulo. Instituto de Física. Depto. de Física Aplicada.

Orientador: Prof. Dr. Artour Elfimov

Área de Concentração: Física de Plasmas.

Unitermos: 1. Física de plasmas; 2. Eletromagnetismo; 3. Tokamak; 4. Física. 


\section{Resumo}

O objetivo deste trabalho é a investigação da excitação e detecção de ondas globais de Alfvén no plasma do tokamak TCABR para fins diagnósticos. As ondas são excitadas com o uso de uma ou duas antenas localizadas dentro do vaso do TCABR. Para excitar o modo global de Alfvén, as antenas são alimentadas com corrente de radio-frequência de até $15 \mathrm{~A}$ cada, na faixa de frequência de $2-4 M H z$. O esquema apresentado nos permitiu estimar o valor da massa efetiva no centro do plasma, que tem seu valor afetado pela concentração de impurezas. O amplificador de corrente para as antenas é baseado no chaveamento de MOSFETs. As ondas são excitadas com o uso de baixa potência, assim não causam perturbação nos parâmetros básicos do plasma.

Foi verificada a variação da frequência de ressonância do modo global de Alfvén com a densidade do plasma. A localização da ressonância do modo é identificada na parte central do plasma, devido ao batimento da amplitude da onda com oscilações dente de serra, de modo que a inversão de fase entre o batimento e a oscilação dente de serra melhora a precisão da determinação da condição ressonante. A paridade toroidal dos modos excitados é determinada com o uso de duas antenas localizadas em posição toroidal oposta na câmara do TCABR e com diferença de fase na corrente de radiofrequência. O conhecimento do número de onda toroidal é importante para a correta estimativa da localização do modo excitado e do valor da massa efetiva do plasma.

O valor obtido para a estimativa da massa efetiva, primeiramente, foi mais alto que nossa expectativas e não era bem relacionado com estimativas da condutividade do plasma. O valor obtido foi de $A_{e f f} \approx 1.60$, com um erro sistemático. Para calibrar a densidade central do plasma usamos dados do reflectômetro e realizamos disparos com gás hélio, que tem a mesma massa efetiva que a maioria das impurezas do TCABR. Finalmente, estimamos a massa efetiva como $A_{e f f}=1.40 \pm 0.07$, valor compatível com a estimativa de $Z_{\text {eff }}$. 


\section{Abstract}

The goal of this study is experimental detection of global Alfvén waves in the plasma of TCABR tokamak for diagnostic. The waves are excited by the use of one or two antennas posed within the shadow of the limiter within the TCABR vessel. To excite the global Alfvén eigenmode the antennas are fed with radio-frequency current of up to $15 \mathrm{~A}$ each, in the frequency range of $2-4 \mathrm{MHz}$. The presented scheme allows us to estimate the value of the effective mass in the centre of the plasma, which has its value affected by the concentration of impurities in the plasma. The amplifier of the antenna current is based on electronically switching MOSFETs. The waves are excited in the plasma with low power, thus it does not cause perturbation of the basic plasma parameters.

The variation of the resonance frequency of the global Alfvén eigenmode with density is verified. The location of the resonance is identified in the central part of the plasma due to the wave amplitude beating with sawtooth oscillations, so that the phase inversion between the beating and the sawtooth oscillation improves the accuracy of determining the resonant condition. The toroidal parity of the excited modes is determined with use of two antennas oppositely located within the TCABR chamber and established by phase difference between their radio-frequency current. Knowledge of the toroidal wave number is important for a correct estimate of both the excited mode location and the plasma effective ion mass value.

The value of the initially found effective mass was $A_{\text {eff }} \approx 1.60$, higher than our expectations at first and did not agree with plasma conductivity estimates, and we proposed that it had a systematic error of approximately $10 \%$. To calibrate the central plasma density, it was used data from a reflectometer and some plasma discharges performed with helium gas, which has the same effective mass as most TCABR impurities. Finally, we estimate the effective mass as $A_{e f f}=1.40 \pm 0.07$, that is consistent with the $Z_{\text {eff }}$ estimation. 


\section{Agradecimentos}

Agradeço primeiramente a minha mãe e pai, minha família, namorada e meus amigos e colegas, pessoas que sem o incentivo não teria completado este projeto.

Agradeço ao Prof. Dr. Artour Elfimov e ao Dr. Leonid Ruchcko, pela orientação, disponibilidade, a amizade e o convívio por todos esses anos. Sem o qual o apoio e orientação não teria sido possível realizar este projeto.

Agradeço também toda a equipe do TCABR pelo suporte e apoio em todos os momentos. Especialmente a Gilson Ronchi e Wanderley Pires pela ajuda no sistema de aquisição; Edson Sanada pelo empenho na operação do TCABR, sendo responsável por todos os disparos usados neste trabalho; Prof. Dr. Zwinglio Guimarães pela ajuda com analise de dados; Alex Andriatti pelo auxílio com a análise de dados do reflectômetro; Prof. Dr. Ricardo Galvão pelo auxílio e apoio com o projeto.

Por fim, agradeço a FAPESP (Fundação de Amparo a Pesquisa do Estado de São Paulo) pelo apoio financeiro a este projeto. 


\section{Sumário}

1 Introdução $\quad 9$

1.1 Fusão termonuclear controlada . . . . . . . . . . . . . . . . . . . . . . . 9 9

1.2 Tokamaks . . . . . . . . . . . . . . . . . . . . . 10

1.2 .1 TCABR ............................ 12

1.3 Ondas de Alfvén . . . . . . . . . . . . . . . . . . . . . . . . . . . . . . . . . . . . . . . 14

1.3.1 O contínuo de Alfvén . . . . . . . . . . . . . . . . . . . 14

1.3.2 Automodos das Ondas de Alfvén . . . . . . . . . . . . . . . . 19

1.3.3 O modo global de Alfvén . . . . . . . . . . . . . . . . . 20

1.3.4 Definição de massa efetiva e o contínuo de Alfvén com impurezas 23

1.4 Excitação de modos no plasma por uma fonte de RF de baixa potência 25

1.5 Proposta da tese . . . . . . . . . . . . . . . 26

2 Os equipamentos usados para o sistema de diagnóstico de Alfvén 29

2.1 Modulo de antenas . . . . . . . . . . . . . . . . . . . . . . . . . . . 30

2.2 Sondas magnéticas e BALUN . . . . . . . . . . . . . . . 33

2.2.1 Testes do equipamento usando oscilação da ilha magnética . . . 36

2.3 Gerador RF com varredura de frequência . . . . . . . . . . . . . . . . . 37

2.4 NI USB-5133 - Diferença entre os módulos . . . . . . . . . . . . . . . . . . . . . 40

2.5 Interferômetro . . . . . . . . . . . . . . . . . . . . . . 41

2.6 Raio-X mole e identificação do fator de segurança por oscilações dentes de serra . . . . . . . . . . . . . . . . . . 45

2.7 Reflectometro . . . . . . . . . . . . . . . . . 47

3 Experimentos de excitação de ondas globais de Alfvén $\quad 55$

3.1 Método de análise dos sinais . . . . . . . . . . . . . . . . 56

3.2 Ressonância da onda de Alfvén induzida por campo RF com varredura de frequência . . . . . . . . . . . . . . . . . 57

3.2.1 Análise do sinal das sondas magnéticas em um disparo com densidade estável . . . . . . . . . . . . . . . . 57

3.2.2 Análise do sinal das sondas magnéticas em um disparo com forte variação da densidade . . . . . . . . . . . . . . . . . . .

3.3 Ressonância do ondas de Alfvén com frequência de RF fixa em um plasma com rampa de densidade . . . . . . . . . . . . . . . . 62

3.3.1 O efeito da oscilação dente de serra nas ressonâncias de Alfvén . 63

3.4 Comportamento geral das ressonâncias . . . . . . . . . . . . . . 67

3.5 Identificação da paridade toroidal dos modos $G A W \ldots$. . . . . . . . . 69 
3.5.1 Escolha de paridade com duas antenas . . . . . . . . . . . . 70

3.5.2 Excitação de corrente de RF nas duas antenas . . . . . . . . . . . . 72

3.5.3 Excitação preferencial do modo $N=1$. . . . . . . . . . . 73

3.5.4 Excitação preferencial do modo $N=2 \ldots \ldots$. . . . . . 76

3.5.5 Conclusão . . . . . . . . . . . . . . . . . . . . 80

4 Discussão dos resultados $\quad 83$

4.1 Número de onda dos modos excitados . . . . . . . . . . . . . . . . . 84

4.1.1 Determinação do valor da massa efetiva . . . . . . . . . . . . 86

4.1.2 Comparação com estimativa da carga efetiva . . . . . . . . . . . 90

4.1.3 Deslocamento de Shafranov e medida de densidade com interferômetro . . . . . . . . . . . . . . . 90

4.1.4 Estimativa da massa efetiva com densidade corrigida pelo deslocamento de Shafranov . . . . . . . . . . . . . . . . . . . 94

4.2 Excitação de $G A W$ com plasma de Hélio . . . . . . . . . . . . . . . . . . 97

4.2.1 Correção pelo termo íon-cíclotron . . . . . . . . . . . . . . 99

4.2.2 Ressonâncias detectadas . . . . . . . . . . . . . . . . . . . . 100

4.2.3 Comparação com plasma de hidrogênio . . . . . . . . . . . . . . 103

4.3 Excitação de modos de Alfvén com números de onda elevados . . . . . 105

4.4 Oscilação da massa efetiva por dentes de serra . . . . . . . . . . . . . . 107

4.5 O perfil de densidade com impurezas . . . . . . . . . . . . . 108

5 Conclusão $\quad 111$

5.1 Propostas para trabalhos futuros . . . . . . . . . . . . . . . 113

A Detalhes do sistema de diagnóstico por ondas de Alfvén 115

B Código em LabVIEW para aquisição de dados 123

$\begin{array}{ll}\text { C Códigos em Matlab usados para a análise de dados } & 129\end{array}$

$\begin{array}{ll}\text { Referências Bibliográficas } & 147\end{array}$ 


\section{Capítulo 1}

\section{Introdução}

\subsection{Fusão termonuclear controlada}

Esse trabalho tem como base o estudo de plasmas de tokamak, uma máquina de confinamento magnético de plasma. O incentivo para a pesquisa do plasma de tokamaks é a busca de fusão termonuclear controlada para geração de energia elétrica. Se houver sucesso, podemos ter uma alternativa para a geração de energia elétrica ecologicamente viável e praticamente inesgotável [1]. A reação de fusão entre o trítio e deutério é pretendida para a geração de energia, pois a seção de choque desta reação é maior para baixas energias do que as reações dos outros isótopos do hidrogênio. O produto dessa reação é um núcleo de hélio (partícula alfa) e um nêutron energético.

$$
D+T \quad \rightarrow \quad H e(3.5 \mathrm{MeV})+n(14.1 \mathrm{MeV})
$$

Partindo desse ponto, o processo para gerar energia é análogo ao de uma usina nuclear, que também envolve nêutrons energéticos. Para se atingir fusão termonuclear foram desenvolvidos diversos tipos de máquinas de confinamento de plasmas e o maior progresso, até hoje, foi obtido com o dispositivo chamado tokamak. 


\subsection{Tokamaks}

Os melhores resultados para se atingir a fusão nuclear foram atingidos por tokamaks, que são máquinas toroidais de confinamento magnético. A proposta da máquina se originou na antiga União Soviética pelos físicos A. D. Sakharov e I. E. Tamm nos anos $1950[2,3,4]$. No começo, projetos sobre fusão nuclear e plasma eram confidenciais, estando ligados a pesquisas nucleares e bélicas [5]. Posteriormente, descobriu-se que havia a possibilidade de produzir energia elétrica com o tokamak, e então os trabalhos deixaram, progressivamente, de ser confidenciais. Ainda na década de 1950, um laboratório russo, chefiado por L. A. Artsimovich no Instituto Kurchatov, em Moscou, começou a fazer pesquisas com tokamaks. Para determinar se o plasma criado no disparo de um tokamak tem a condição necessária para a fusão usamos o critério de Lawson [6]

$$
\hat{n} \tau_{e} \hat{T}>5 \times 10^{21} m^{-3} s \quad k e V
$$

onde $\hat{n}$ é a densidade no centro do plasma, $\hat{T}$ é a temperatura iônica no centro do plasma e $\tau_{e}$ é o tempo de confinamento de energia, que é

$$
\tau_{e}=\frac{\int \frac{3 n}{2}\left(T_{i}+T_{e}\right) d V}{P}
$$

Sendo $\mathrm{P}$ a potência total depositada no plasma, vemos que $\tau_{e}$ é a razão da energia térmica do plasma pela potência necessária para manter essa energia. Esse fator aumenta com o tamanho do tokamak. Quanto maior o volume, melhor o confinamento.

O tríplice produto da (eq. 1.2) apresenta um aumento grande ao longo dos anos, sendo comparável com a evolução do processamento dos computadores até o começo da década de 90. A partir dessa década houve uma maior estagnação na área, pois deixou-se de construir tokamaks maiores. Apenas recentemente iniciou-se a construção de um tokamak de grande porte (ITER) [7], que deve servir como base para um futuro protótipo de reator por fusão termonuclear (DEMO) [8]. 
O tokamak é uma máquina em que o plasma é confinado por campos magnéticos. A geometria do tokamak é toroidal, assim o plasma tem uma configuração na forma de anel, fazendo um loop. Para o confinamento do plasma são usados dois campos principais: o campo toroidal, criado por bobinas colocadas no entorno da câmara de vácuo, e o campo poloidal, criado pela corrente do próprio plasma. Assim, se tem linhas de campo com trajetórias helicoidais. Na figura 1.1 apresentamos os principais componentes dos campos de um tokamak.

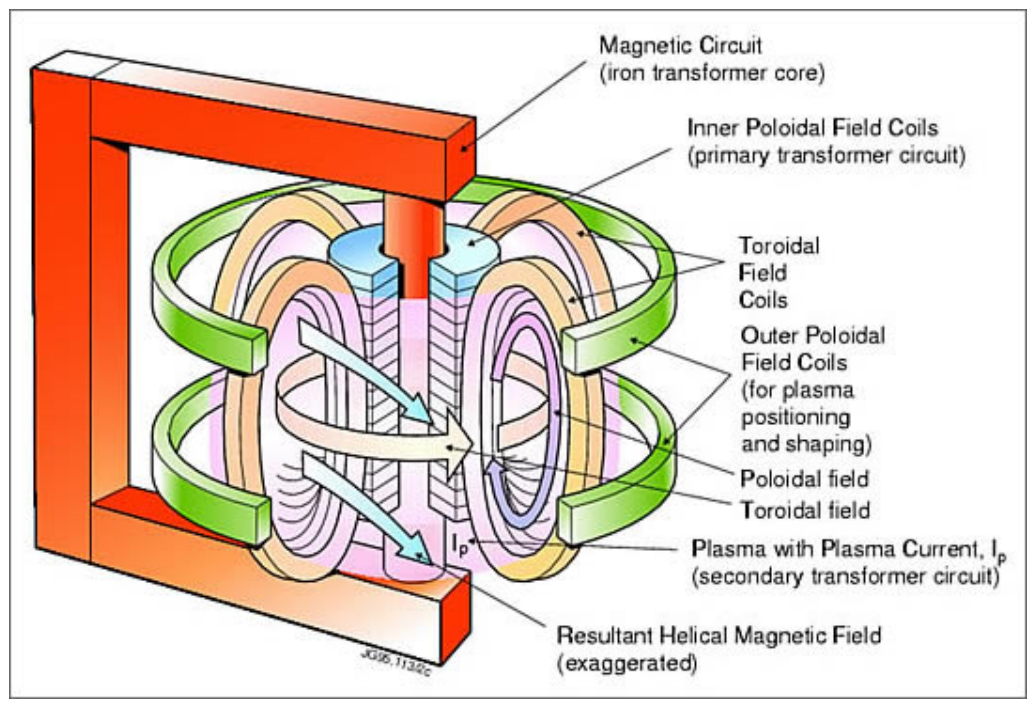

Figura 1.1: Esquema representativo de um tokamak [9].

No tokamak, o plasma pode ser criado por um disparo ôhmico, induzido por um campo elétrico indutivo criado por um transformador central, com a corrente na direção ao longo do toroide. O campo elétrico ioniza o gás neutro e cria o plasma. Uma vez criado, o plasma será aquecido até uma temperatura de poucos $k e V$, valor que depende do tempo de confinamento e tamanho do tokamak.

Como é necessária uma corrente variável não oscilatória no transformador central para se ter o plasma em um tokamak, o tempo de duração do disparo não é muito longo, limitado pelo armazenamento de energia. Outros métodos de geração de correntes auxiliares existem, como Lower Hybrid Current Drive. Mas, por causa desse fator limitante, os tokamaks funcionam em regime pulsado. Esse regime de funcionamento não é ideal para um reator e cria problemas devido à alta potência envolvida, havendo 
chance de danos aos equipamentos e a necessidade de manutenção constante.

Apenas com o regime ôhmico não é possível aquecer o plasma a uma temperatura que seja alta o suficiente para iniciar as reações de fusão, pois a resistência do plasma diminui com a temperatura na forma $T^{-3 / 2}[10]$. A temperatura iônica mínima necessária para haver fusão é de $10 \mathrm{keV}\left(\sim 10^{8} \mathrm{~K}\right)$ [11]. Em uma descarga puramente ôhmica o plasma atinge temperaturas da ordem de $\sim 1 \mathrm{keV}$. Assim, métodos auxiliares de aquecimento são necessários para se atingir o regime de fusão, como injeção de partículas energéticas e/ou campos eletromagnéticos de radio frequência ou microondas. Esses campos aceleram as partículas ressonantes no plasma, que por sua vez transferem a energia por colisões com o resto do plasma.

Apesar das dificuldades, já houve experimentos com sucesso em produção de fusão nuclear de modo modesto. No JET (Joint European Torus), o maior tokamak em operação hoje, localizado na Inglaterra, assim como no TFTR (Tokamak Fusion Test Reactor), que não está mais em funcionamento e operou nos Estados Unidos da América, já foi realizada fusão nuclear [12]. Chegou a ser produzido $16 M W$ por reações de fusão. Nesse caso, a energia liberada era menor que a usada para produzir a fusão e insuficiente para a produção de energia elétrica, mas o experimento demonstrou a viabilidade da fusão em um tokamak.

\subsubsection{TCABR}

O TCABR é o tokamak do laboratório instalado no laboratório de física de plasmas do IFUSP. Ele foi trazido para a São Paulo no final da década de 1990. Este tokamak foi construído em Lausanne, na Suíça, para experimentos de excitação de ondas de Alfvén [13, 14], onde era chamado de TCA (Tokamak Chauffage Alfvén). No TCABR foi obtido sucesso parcial no aquecimento de elétrons do plasma [15]. Seu objetivo de construção era investigar ondas de Alfvén e como elas podem ser utilizadas para aquecer o plasma. Através de antenas instaladas na câmara de vácuo [16] é possível excitar tais ondas. Hoje, o estudo é concentrado no uso de ondas de Alfvén para diagnósticos do 
plasma.

Tabela 1.1: Parâmetros do TCABR

\begin{tabular}{|c|c|}
\hline \hline raio maior & $61,5 \mathrm{~cm}$ \\
\hline raio menor & $18,0 \mathrm{~cm}$ \\
\hline raio da parede do vaso & $24,0 \mathrm{~cm}$ \\
\hline raio da antena & $20 \mathrm{~cm}$ \\
\hline campo magnético toroidal & $1,07 \mathrm{~T}$ \\
\hline fator de segurança na borda & $3-4$ \\
\hline densidade no centro do plasma & $\leq 4 \times 10^{13} \mathrm{~cm}^{-3}$ \\
\hline densidade na borda do plasma & $\sim 1 \times 10^{11} \mathrm{~cm}^{-3}$ \\
\hline temperatura de elétrons no centro do plasma & $\leq 500 \mathrm{eV}$ \\
\hline temperatura de elétrons na borda do plasma & $\sim 20 \mathrm{eV}$ \\
\hline corrente de plasma & $60-100 \mathrm{kA}$ \\
\hline duração do disparo & $\sim 100-150 \mathrm{~ms}$ \\
\hline
\end{tabular}

Por ser um tokamak pequeno, o TCABR apresenta vantagens se comparado com tokamaks maiores. Ele pode ser ultilizado para treinamento de pessoal e, pela sua simplicidade, é mais fácil instalar algum equipamento novo e realizar diversos disparos para realização de testes, pois o tempo de funcionamento de máquina é mais barato. O acesso à máquina em si é mais fácil e é preciso uma equipe com um número pequeno de pessoas para operá-la. Alguns parâmetros do TCABR estão apresentados na tabela 1.1.

Sobre os sistemas de diagnósticos do TCABR, tem-se para a medida de temperatura de elétrons os detectores de emissão ciclotrônica de elétrons (ECE) e espalhamento Thomson. Para medidas de densidade, há um interferômetro, com dois canais em funcionamento, e um reflectômetro. Outros diagnósticos são: detectores de emissão de raio-X mole para medida da radiação de Bremsstrahlung, medidas de linhas espectrais óticas para medida de rotação e temperatura de íons do plasma, bobinas de Mirnov para medidas de oscilações MHD, sondas eletrostáticas para medidas das características da borda do plasma e estudo de turbulência, e bolômetro para uma medida total da radiação emitida pelo plasma. 


\subsection{Ondas de Alfvén}

Em um gás neutro apenas há a oscilação de ondas de pressão, que são ondas sonoras, e a única força restauradora presente é a pressão térmica. Em um fluido ionizado, como o plasma, na presença de um campo magnético, há mais duas forças de restauração das perturbações de pressão: a tensão associada às linhas de força do campo magnético e a pressão associada à densidade de energia do campo magnético. Por causa disso, na teoria magneto-hidrodinâmica (MHD), ao invés de haver um único tipo de onda, há três tipos de ondas, as magnetossônicas, rápida e lenta, e mais uma onda chamada agora como "onda de Alfvén"[17].

As ondas de Alfvén foram propostas por Hannes Alfvén, físico sueco ao qual devem seu nome, num artigo de 1942 onde trata-se ondas aplicadas à física solar [18]. No mesmo trabalho, ele também introduziu a teoria MHD. Este trabalho lhe rendeu um prêmio Nobel de física, até hoje ele é único Nobel referente a física de plasma.

\subsubsection{O contínuo de Alfvén}

A onda de Alfvén é incompressível, sendo assim, não é afetada pela pressão cinética do plasma. Já as outras duas ondas envolvem a compressão do plasma e do campo magnético, sendo chamadas de ondas magnetossônica rápida e lenta, devido a suas velocidades em relação a velocidade da onda de Alfvén, que é de valor intermediário. Essas ondas MHD envolvem movimento conjunto de íons e elétrons, sendo que a frequência de plasma é muito mais alta e envolve apenas o movimento dos elétrons. Vale ressaltar que a frequência da onda de Alfvén é baixa se comparada à frequência de ciclotron dos íons.

Ondas de Alfvén ocorrem quando o campo magnético sofre uma perturbação [11, 19, 20]. A velocidade da oscilação do plasma é perpendicular à propagação, por isto este tipo de onda também recebe o nome de onda de Alfvén cisalhada (shear Alfvén wave), pois tem o movimento paralelo de duas camadas do plasma 1.2. A força restauradora 
é produzida pela tensão das linhas do campo magnético. O movimento das partículas do plasma faz com que o campo magnético oscile junto com a onda, e a curvatura da oscilação cria uma força de tensão magnética $\vec{B} \cdot \vec{\nabla} B$ na direção oposta à do movimento do plasma.

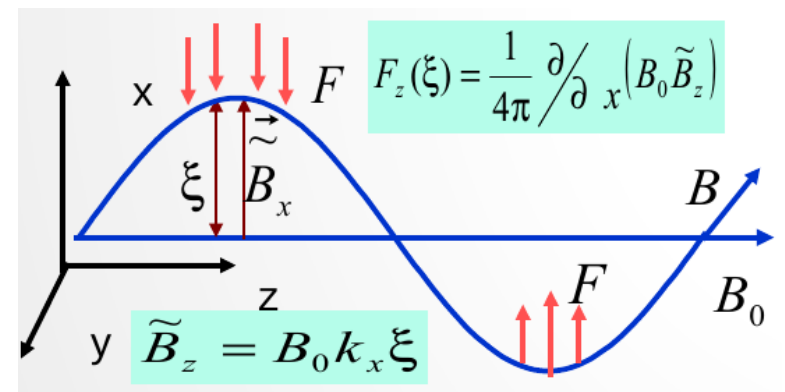

Figura 1.2: Perturbação de campo magnético por onda de Alfvén.

Para calcular a expressão para o contínuo de Alfvén e a razão da formação do modo global de Alfvén (GAE), começamos indicando o cálculo do tensor dielétrico do plasma. Vamos supor um plasma inserido em um campo magnético na direção $\hat{z}$. Partimos da lei de Ohm no limite MHD, considerando um plasma sem pressão. Como as ondas de Alfvén são ondas incompressíveis, essa aproximação é válida. No caso temos [21]

$$
\vec{E}+\vec{v} \times \vec{B}+\frac{m_{i}}{e} \frac{d \vec{v}}{d t}=\eta \vec{j}
$$

onde mantivemos o termo referente ao efeito Hall $\left(\frac{m_{i}}{e} \frac{d \vec{v}}{d t}\right)$. Esse termo é responsável pelo aparecimento de termos não diagonais no tensor dielétrico. Temos também a equação da conservação do momento, usada para o cálculo das componentes da velocidade

$$
\rho \frac{d \vec{v}}{d t}=\frac{1}{c} \vec{j} \times \vec{B}
$$

O tensor dielétrico do plasma é definido nas equações de Maxwell pela da condutividade. Temos as equações de Maxwell

$$
\vec{\nabla} \times \vec{B}=\frac{1}{c} \overleftrightarrow{\epsilon} \frac{d \vec{E}}{d t} \quad ; \quad \vec{\nabla} \times \vec{E}=-\frac{1}{c} \frac{d \vec{B}}{d t}
$$


com o tensor dielétrico $(\overleftrightarrow{\epsilon})$ dado por

$$
4 \pi \vec{j}=(\overleftrightarrow{\delta}-\overleftrightarrow{\epsilon}) \frac{d \vec{E}}{d t}
$$

Onde $\overleftrightarrow{\delta}$ é o tensor unitário. Para os cálculos das componentes do tensor dielétrico é preciso calcular as componentes da corrente perturbada. Para isso supomos perturbações da forma $A=A_{0} e^{(i \vec{k} \cdot \vec{r}-i \omega t)}$. As componentes do tensor dielétrico são

$$
\left[\begin{array}{ccc}
\epsilon_{11} & i \epsilon_{12} & 0 \\
-i \epsilon_{12} & \epsilon_{11} & 0 \\
0 & 0 & \epsilon_{33}
\end{array}\right]=\left[\begin{array}{ccc}
1+\sum_{\alpha} \frac{\omega_{p \alpha}^{2}}{\omega_{c \alpha}^{2}} \frac{\omega_{c \alpha}^{2}}{\omega_{c \alpha}^{2}-\omega^{2}} & \sum_{\alpha} \frac{\omega_{p \alpha}^{2}}{\omega_{c \alpha} \omega} \frac{\omega_{c \alpha}^{2}}{\omega_{c \alpha}^{2}-\omega^{2}} & 0 \\
-\sum_{\alpha} \frac{\omega_{p \alpha}^{2}}{\omega_{c \alpha} \omega} \frac{\omega_{c \alpha}^{2}}{\omega_{c \alpha}^{2}-\omega^{2}} & 1+\sum_{\alpha} \frac{\omega_{p \alpha}^{2}}{\omega_{c \alpha}^{2}} \frac{\omega_{c \alpha}^{2}}{\omega_{c \alpha}^{2}-\omega^{2}} & 0 \\
0 & 0 & 1+\sum_{\alpha} \frac{\omega_{p \alpha}^{2}}{\omega^{2}}
\end{array}\right]
$$

onde somamos para todos as espécies $\alpha$ do plasma. Temos $\omega_{p \alpha}$ e $\omega_{c \alpha}$ as frequências de plasma e ciclotrônica da espécie $\alpha$, respectivamente. No caso MHD, quando $\omega<\omega_{c i}$, temos as componentes do tensor simplificadas para:

$$
\epsilon_{11}=\frac{\omega_{p i}^{2}}{\omega_{c i}^{2}-\omega^{2}} \quad ; \quad \epsilon_{12}=i \epsilon_{11} \frac{\omega}{\omega_{c i}}
$$

Sendo este último definido como termo de efeito Hall. A componente $\epsilon_{33}$ do tensor dielétrico representa a oscilação de plasma, paralela ao campo magnético e, assim, não é afetada pelo mesmo. Na aproximação MHD trataremos o componente $\epsilon_{33}$ como infinito, isso implica que temos a componente $z$ do campo elétrico nula $E_{z}=0$, condutividade infinita ao longo do campo magnético.

Com o tensor dielétrico definido, podemos aplicá-lo na equação Maxwell. Combinando as equações (1.6) obtemos para perturbações de uma onda

$$
\vec{\nabla} \times \vec{\nabla} \times \vec{E}=\frac{1}{c^{2}} \overleftrightarrow{\epsilon} \frac{d^{2} \vec{E}}{d t^{2}} \quad \rightarrow \quad k^{2} \vec{E}-\vec{k}(\vec{k} \cdot \vec{E})=\frac{\omega^{2}}{c^{2}} \overleftrightarrow{\epsilon} \vec{E}
$$

Para prosseguirmos, precisamos definir as componentes do campo elétrico e do 
vetor de onda $\vec{k}$. No caso, já definimos $E_{z}=0$. Para o vetor de onda, vamos o separar em duas componentes, uma paralela ao campo magnético e outra perpendicular, que podemos chamar, já adiantando o caso de um tokamak, de componente radial. Sendo assim, $k^{2}=k_{\|}^{2}+k_{r}^{2}$ é reduzido a um caso bidimensional, no nosso caso $k_{\|} \equiv k_{z}$ e $k_{r}$ é definido como uma perturbação na forma eikonal, proporcional à $\exp \left(i \int_{0}^{r} k_{r} d r\right)$. A (eq. 1.10) fica

$$
\begin{aligned}
k^{2} E_{r}-k_{r}^{2} E_{r} & =k_{\|}^{2} E_{r}=\frac{\omega^{2}}{c^{2}}\left(\epsilon_{11} E_{r}+i \epsilon_{12} E_{b}\right) \\
k^{2} E_{b} & =\frac{\omega^{2}}{c^{2}}\left(\epsilon_{11} E_{\theta}-i \epsilon_{12} E_{r}\right)
\end{aligned}
$$

A partir da (eq. 1.11) obtemos

$$
E_{r}=-\frac{\omega^{2}}{c^{2}} \frac{\epsilon_{12}}{A} E_{\theta} \quad ; \quad A \equiv \frac{\omega^{2}}{c^{2}} \epsilon_{11}-k_{\|}^{2}
$$

Usando essa relação em (eq. 1.12) obtemos

$$
k_{r}^{2}=A+\frac{\frac{\omega^{4}}{c^{4}} \epsilon_{12}^{2}}{A}
$$

Essa expressão representa a relação de dispersão para as ondas rápida e de Alfvén. Conseguimos identificar o contínuo de Alfvén como a condição $A=0$. Com essa condição temos um valor de $k_{r}^{2}$ muito alto, tendendo ao infinito. Isso indica um comprimento de onda muito pequeno. Por isso também recebe o nome de onda de Alfvén local ou ressonância local.

Fora do contínuo de Alfvén, temos duas soluções para a (eq. 1.14). Uma das soluções é a onda magnetossônica rápida, que tem um valor de frequência elevado. A outra solução é o GAE, ou modo discreto de Alfvén, quando $A \lesssim 0$, que tem uma frequência menor que a onda rápida. O GAE possui um valor pequeno para a vetor de onda $k_{r}$, implicando em um comprimento de onda grande. Porém, o comprimento de onda radial não pode ser indefinidamente grande, sendo limitado pelas dimensões do 
plasma. O comprimento de onda paralelo, dada a geometria do plasma, é maior que o comprimento de onda radial $k_{r} \gg k_{\text {parallel }}$. O valor da frequência de ressonância desse modo é abaixo do mínimo do contínuo de Alfvén, evitando a singularidade.

No caso de um tokamak temos, em uma aproximação, $k_{r}=\frac{p \pi}{a}$, sendo $p$ o número de nós da onda e a o raio menor do plasma. Como temos valores discretos tanto para $k_{r}$ quanto para $k_{\|} \approx N / R$, esses modos de Alfvén também são chamados de modos discretos de Alfvén.

No caso de um tokamak temos o vetor de onda paralelo ao campo magnético de equilíbrio como

$$
k_{\|}=\frac{1}{R_{0}}\left(N+\frac{M}{q}\right)
$$

onde $q=\frac{r B_{0}}{R_{0} B_{0_{\theta}}}$ o fator de segurança, $R_{0}$ o raio maior do plasma, $N$ o número toroidal de onda e $M$ o número poloidal de onda. $\mathrm{O}$ valor de $B_{0_{\theta}}$ é determinado pela corrente do plasma. A relação de dispersão para o contínuo de Alfvén $(A=0)$, fica da forma

$$
\omega^{2}=v_{A}^{2} k_{\|}^{2}=\frac{v_{A}^{2}}{R_{0}^{2}}\left(N+\frac{M}{q}\right)^{2}
$$

onde $v_{A}=\frac{B_{t}}{\sqrt{4 \pi A_{e f f} n_{e}}}$ a velocidade de Alfvén, $n_{e}$ a densidade de elétrons e $A_{e f f}$ a massa efetiva; que é melhor definida na seção 1.3.4. O contínuo de Alfvén tem esse nome pois há um contínuo de frequências, ao longo do raio do plasma, em que temos satisfeita a relação da ressonância local (eq. 1.16). Essa relação se diferencia dos automodos das ondas de Alfvén, que tem valores de frequência discretos, devido a relação de dispersão de $k_{r}^{2}$.

No caso de um tokamak, devido a inomogeneidade do plasma, as ondas não se propagam no contínuo de Alfvén. Essas ondas são fortemente amortecidos localmente, por causa da conversão em de ondas de Alfvén cinéticas (KAW), quando considerados os mecanismos de amortecimento de Landau ou colisões elétron-íon [22, 23]. 


\subsubsection{Automodos das Ondas de Alfvén}

Na seção anterior foi apresentada a onda cisalhada de Alfvén que forma o contínuo de Alfvén, ou ressonância local de Alfvén. Há também os automodos de Alfvén, que podem ocorrer tanto em um extremo quanto em uma brecha formada no contínuo, por causa da intersecção de modos poloidais vizinhos devido a geometria toroidal. Ao redor da frequência da brecha pode haver um automodo, já que não há amortecimento das perturbações pelo contínuo. Na figura 1.3a apresentamos o comportamento dos diferentes modos de de Alfvén que podem ser excitados no plasma e o comportamento da perturbação causada no plasma.
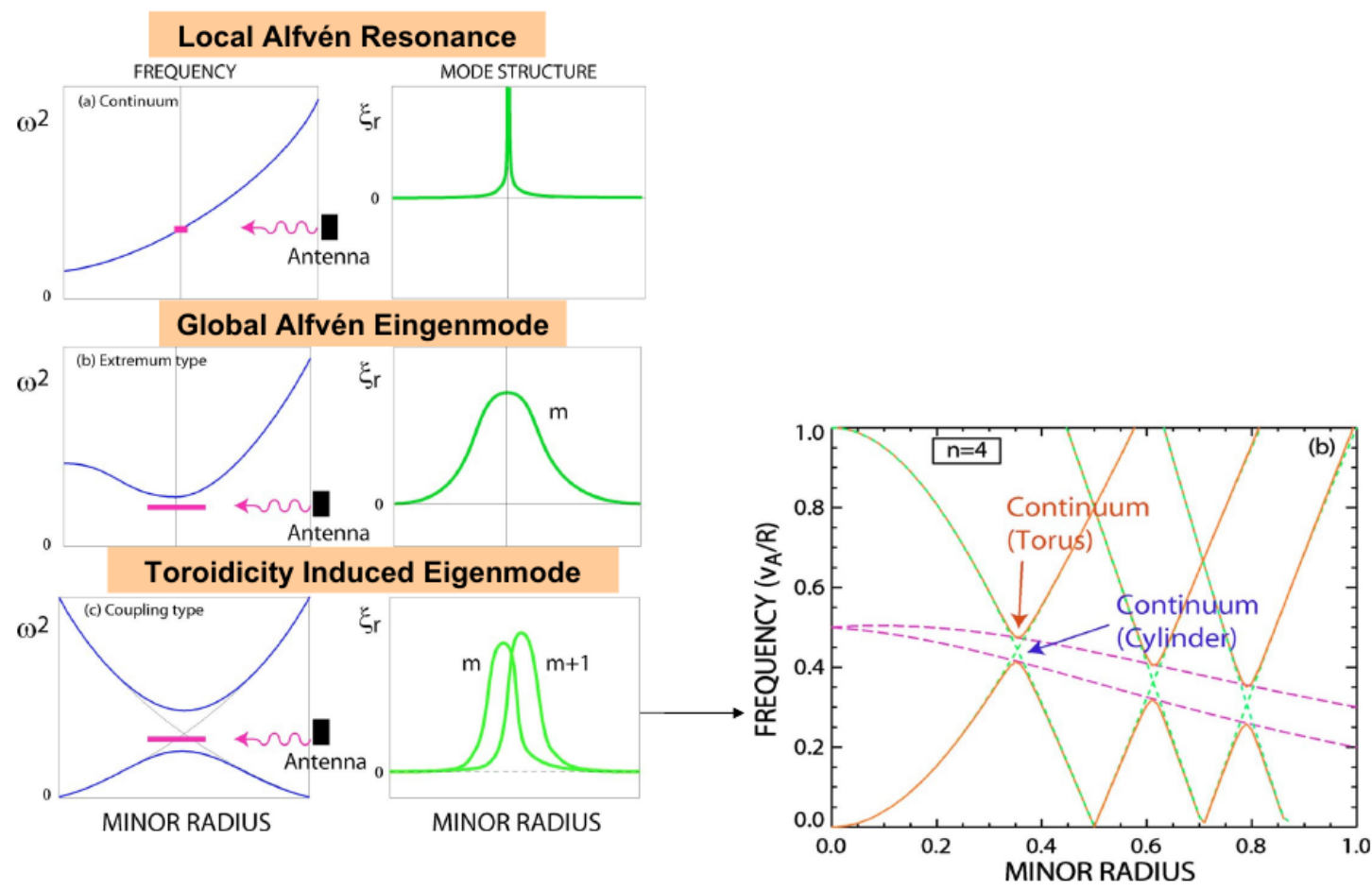

Figura 1.3: Diferentes tipos de ressonância que podem ocorrer em um plasma de tokamak.[24]

Neste trabalho nos focamos no modo global de Alfvén. O modo global ocorre em um mínimo do contínuo de Alfvén que também existe no modelo cilíndrico. O mesmo tipo de onda, chamado de automodo toroidal de Alfvén (TAE), ocorre em uma brecha formada no contínuo devido a geometria toroidal do plasma, ligando dois modos poloidais vizinhos. Como temos uma geometria fechada, aparecem brechas análogas 
às que ocorrem com elétrons em sólidos, chamadas de bandas proibidas. No caso de um tokamak estas bandas não são proibidas e há uma onda que pode se propagar na brecha. Na figura 1.3b é possível ver o efeito da geometria toroidal no contínuo de Alfvén. Além destes modos podem ocorrer outros [24] que ocorrem em outras brechas do contínuo causadas pela geometria toroidal.

\subsubsection{O modo global de Alfvén}

O modo global de Alfvén (GAE ou GAW) [25], que também pode ser chamado de modo discreto de Alfvén (DAW) [22] ocorre logo abaixo do mínimo do contínuo de Alfvén e, por não se encontrar no contínuo de Alfvén, evita o amortecimento no contínuo. A distância do modo para o mínimo do contínuo pode variar dependendo dos parâmetros do plasma, mas como regra, podemos considerar que se localiza em uma frequência menor que $10 \%$ do mínimo do contínuo para o TCABR. Uma dedução e análise detalhada da teoria por trás da excitação destes modos pode ser encontrada na minha dissertação de mestrado [26] ou em [27, 28, 29]. A relação de dispersão simplificada, mas que contem informação necessária para entender o aparecimento do GAE, foi apresentada na (eq. 1.14), porém agora usamos cálculos com código cinético [27] para avançar na descrição do GAE.

Originalmente os estudos sobre esses modos foram conduzidos pelo grupo de plasma de Lausanne, no tokamak TCA [30, 25], tendo um enfoque no aquecimento do plasma por ondas de Alfvén, tema também explorado no TCABR [31, 32]. Porém, trabalhos sobre ondas de Alfvén sendo usadas para diagnósticos também foram realizados no TCA [33]. Com os resultados foi proposto o uso do modo global de Alfvén para determinação da massa efetiva de grandes tokamaks em [34]. Resultados obtidos sobre ondas de Alfvén no TCABR podem ser encontrados em [35]. Aqui iremos apresentar somente as principais características desse tipo de modo.

Uma outra forma de entender a formação dos automodos das ondas de Alfvén é os considerar como modos de cavidade. Supomos um potencial e uma equação análoga a 


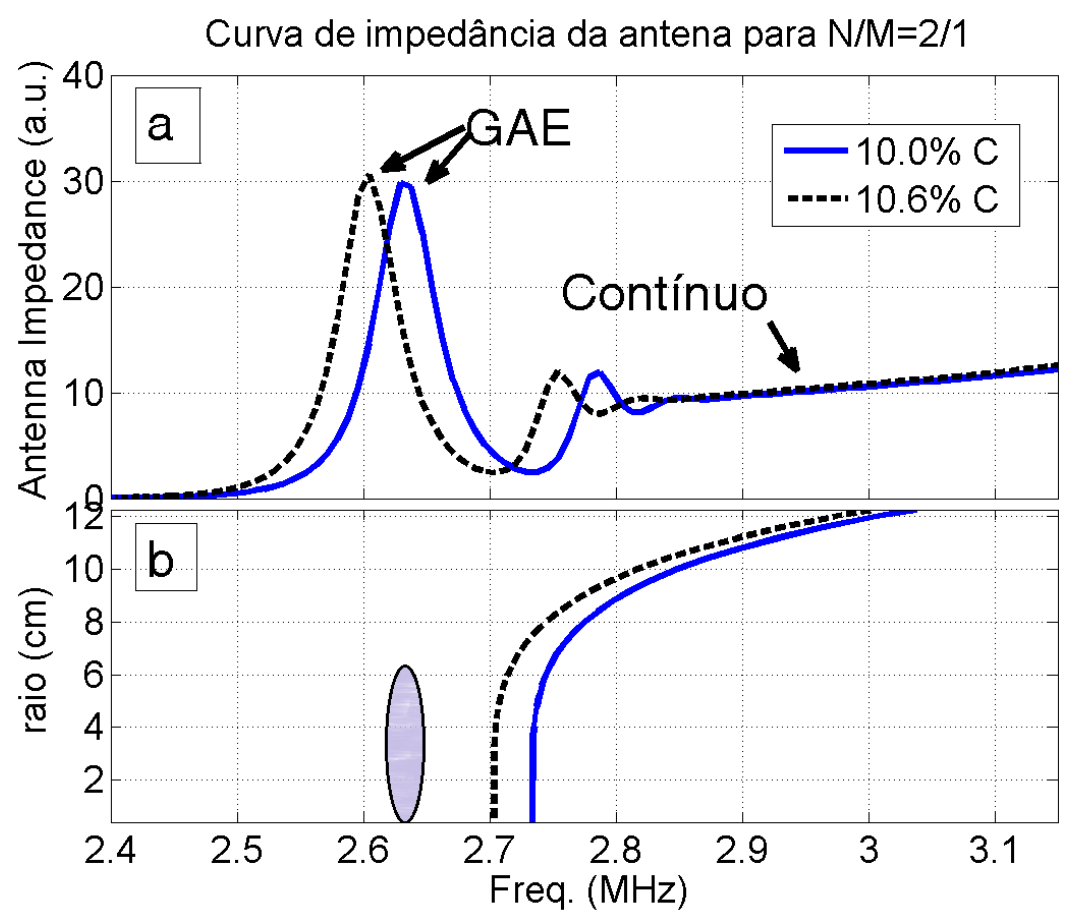

Figura 1.4: (a) Dependência da impedância de uma antena externa ao plasma pela frequência da corrente de RF. Calculado para o modo $N / M=2 / 1$ e parâmetros do plasma típicos para o TCABR e diferentes concentrações de carbono. Com densidade de elétrons no centro de $n_{0}=2.5 \times 10^{13} / \mathrm{cm}^{3}$ e concentração de $10.0 \% 10.6 \%$ de carbono relativa a concentração de hidrogênio. (b) Cálculo do contínuo de Alfvén pelo raio do plasma para os mesmos parâmetros, a região em destaque é a largura radial do GAE.

de Schrödinger, que nos leva a existência de modos discretos no plasma [36, 37]. Para haver esses modos, necessariamente, é preciso que, além do campo magnético toroidal, exista um campo magnético poloidal, criado por uma corrente no plasma.

Como mostrado em [25], o GAE é localizado no raio de um mínimo do contínuo de Alfvén tanto no centro do plasma quanto em uma posição mais afastada (eq. 1.16). Para apresentar o comportamento da frequência de ressonância do GAE temos a figura 1.4. Nessa figura apresentamos uma curva de impedância da antena pela frequência da corrente de RF calculada com código cinético. Nela é possível identificar o GAE como um pico na impedância da antena, em uma frequência inferior à do contínuo de Alfvén. Apresentamos também, na parte inferior da figura 1.4, o contínuo de Alfvén em relação ao raio do plasma. Para os cálculos, foram usados valores típicos do tokamak TCABR, com a densidade central de elétrons de $n_{0}=2.5 \times 10^{13} / \mathrm{cm}^{3}$ considerando uma mistura 
de hidrogênio com carbono. Vemos em destaque, abaixo do contínuo, uma estimativa da largura radial para o modo GAE.

Na figura 1.4, ainda, observamos uma mudança da ressonância GAE e do contínuo por uma diferença no nível de concentração das impurezas. No caso consideramos $10.0 \%$ e $10.6 \%$ de carbono completamente ionizado como impureza. Mais detalhes sobre o comportamento do contínuo de Alfvén com a presença de impurezas são apresentadas na próxima seção.

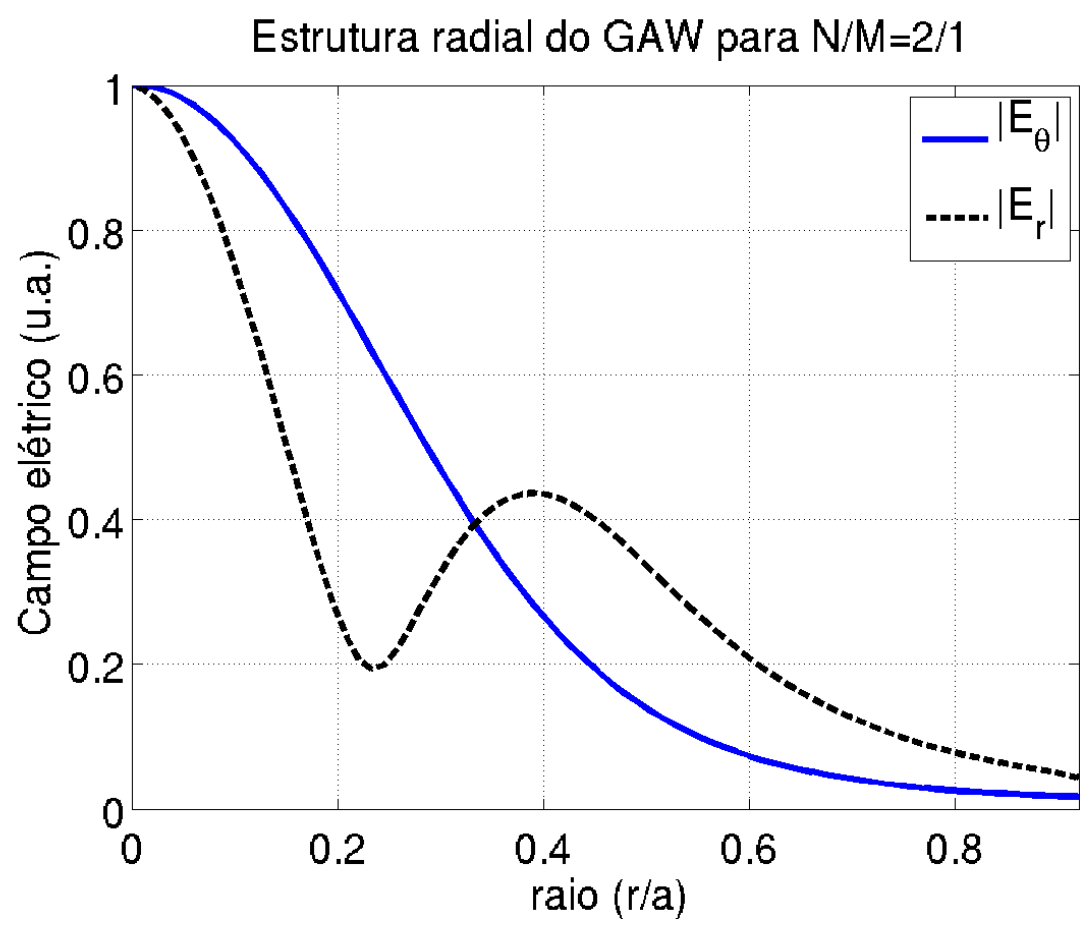

Figura 1.5: Gráfico do perfil radial dos campos elétricos poloidal e radial para o GAE com o número de onda $N / M=2 / 1$.

A ressonância do GAE, posicionado abaixo do mínimo do contínuo, não tem restrições por amortecimento pelo contínuo. O modo excitado se espalha pelo raio do plasma, criando uma oscilação que ocupa grande parte dele. Por isso seu nome, modo global de Alfvén. A estrutura radial do campo elétrico perturbado do GAE é apresentado na figura 1.5, onde vemos os perfis radiais do módulo do campo elétrico radial e poloidal para o modo $N / M=2 / 1$, o pico que aparece no campo radial representa uma inversão de fase. No caso, temos a ressonância no centro do plasma, sendo assim, o máximo dos campos perturbados está no centro também. 


\subsubsection{Definição de massa efetiva e o contínuo de Alfvén com impurezas}

Como nosso objetivo é determinar a concentração de impurezas no TCABR com medidas das ressonâncias de Alfvén, temos que demonstrar como é o contínuo de Alfvén com impurezas e definir a massa efetiva. A equação do contínuo de Alfvén para plasma com mais de uma espécie nos dá [26, 28]

$$
k_{\|}^{2}-\frac{\omega^{2}}{c^{2}} \epsilon_{11}=0
$$

que é equivalente a

$$
k_{\|}^{2}=\frac{\omega^{2}}{c^{2}} \sum_{i} \frac{\omega_{p i}^{2}}{\left(\omega_{c i}^{2}-\omega^{2}\right)}
$$

Podemos desconsiderar o termo proveniente dos elétrons pois $\omega_{c e}>>\omega_{c i}$.

Sendo

$$
\omega_{c i}=\frac{e Z_{i} B}{m_{i} c} \quad ; \quad \omega_{p i}^{2}=\frac{4 \pi n_{i} Z_{i}^{2} e^{2}}{m_{i}}
$$

Podemos escrever o contínuo como

$$
\frac{\omega^{2}}{c^{2}} \sum_{i} \frac{4 \pi n_{i} Z_{i}^{2} e^{2}}{m_{i}} \frac{m_{i}^{2} c^{2}}{e^{2} Z_{i}^{2} B^{2}} \frac{1}{1-\frac{\omega^{2}}{\omega_{c i}^{2}}}=\sum_{i} \frac{4 \pi n_{i} m_{i}}{B^{2}} \frac{\omega^{2}}{1-\frac{\omega^{2}}{\omega_{c i}^{2}}}=k_{\|}^{2}
$$

Para chegarmos a definição da massa efetiva, temos que desprezar o termo da ressonância de ciclotron dos íons $\frac{\omega^{2}}{\omega_{c i}^{2}}$. Podemos, em uma aproximação, desconsiderar este termo, pois, no caso do TCABR, temos a frequência de Alfvén $\sim 3 M H z$ e a frequência de ciclotron do hidrogênio $\sim 16 M H z$. Assim, obtemos

$$
\omega^{2}=\frac{k_{\|}^{2} B^{2}}{4 \pi \sum_{i}\left(n_{i} m_{i}\right)}
$$

Sendo $m_{i}$ dado em unidades da massa de um núcleo de hidrogênio, definimos a massa efetiva como 


$$
A_{e f f} \equiv \sum_{i}\left(\frac{n_{i} m_{i}}{n_{e}}\right)
$$

Que é a massa efetiva baseada na densidade dos elétrons. Pode ser escrita em termo da densidade de elétrons, usando $Z_{i} n_{i}=n_{e_{i}}$, sendo $n_{e_{i}}$ a densidade de elétrons proveniente dos íons da iésima espécie, como

$$
A_{e f f}=\sum_{i}\left(\frac{n_{i} m_{i}}{Z_{i} n_{e_{i}}}\right)
$$

Vemos que as espécies de íons podem ser agrupadas de acordo com a razão $\frac{m_{i}}{Z_{i}}$. E realmente é essa razão que determina o valor da massa efetiva.

O contínuo de Alfvén fica da forma

$$
\omega=V_{A} k_{\|}=\frac{B}{\sqrt{4 \pi n_{e} A_{e f f}}} k_{\|}
$$

Equivalente à fórmula tradicional. Vale ressaltar que a aproximação de desconsiderar o termo de efeito Hall acaba por diminuir a precisão dos cálculos. No capítulo de discussão dos resultados elaboraremos mais sobre essa diferença.

Podemos traçar um análogo entre a massa efetiva e a carga efetiva. Como ambos os valores são dependentes das impurezas no plasma é interessante compará-los. A carga efetiva é definida como

$$
Z_{e f f}=\frac{\sum_{i} n_{i} Z_{i}^{2}}{\sum_{i} Z_{i} n_{i}}=\frac{\sum_{i} n_{i} Z_{i}^{2}}{n_{e}}
$$

A $Z_{\text {eff }}$ depende do quadrado das cargas das partículas pois depende da colisão entre as partículas, que por sua vez depende do quadrado da carga. A carga efetiva será usada para comparar e validar a estimativa da massa efetiva.

O valor da carga efetiva $Z_{\text {eff }}$ pode ser obtido com a condutividade de Spitzer ou com uma análise da emissão de linhas óticas. No caso do TCABR, usamos uma fórmula empírica para a condutividade de Spitzer validada no TCA em Lausanne [38], 


$$
Z_{\text {eff }}(0)=1.84 V_{\text {loop }} T_{e}^{1.5} / B_{0}-0.755
$$

Com diagnósticos ópticos podemos, também, estimar a carga efetiva e nível de impureza em um tokamak. Para isso, é necessário medir a radiação de uma faixa do espectro em que não temos emissão de linhas espectrais das impurezas, e sim a emissão, somente, da radiação de bremsstrahlung. Como a emissão de bremsstrahlung depende do valor de $Z_{\text {eff }}$ e de parâmetros globais do plasma (temperatura dos elétrons e densidade), é possível estimar $Z_{\text {eff }}$ deste modo [39].

\subsection{Excitação de modos no plasma por uma fonte de RF de baixa potência}

Por causa da dependência simples na (eq. 1.16) da frequência de Alfvén com o campo magnético e a densidade de massa, as medidas dos modos de Alfvén podem ser usadas para diagnóstico do plasma. Se houver a excitação de um modo com uma antena externa e esse modo for detectado e bem caracterizado, é possível determinar características do plasma, como a massa efetiva dos íons e o perfil do campo magnético poloidal via o fator de segurança [40,41]. Tal método é chamado de espectroscopia MHD ou diagnóstico MHD [42]. Para que esse sistema de excitação de modos de Alfvén não perturbe o plasma, as ondas têm que ser excitadas com baixa potência, ou seja, uma potência bem menor que a potência total do plasma.

Ondas globais de Alfvén já foram propostas e usadas como diagnósticos para plasmas nos tokamaks TCA [43], PETULA [44] e TEXTOR [45]. Seu uso também foi proposto para tokamaks maiores [34]. Porém, suspeita-se que em tokamaks maiores há uma deformação do mínimo do contínuo, que inibe a excitação do modo global de Alfvén [46]. Porém, outros tipos de automodos das ondas de Alfvén podem ser usados [47, 48]. No JET são usados TAE para diagnóstico, usando geradores de radio-frequência com baixa potência para excitação de ondas.

Recentemente o interesse da pesquisa foi voltado para os automodos das ondas de 
Alfvén devido a sua excitação por partículas energéticas. Com os modos excitados é possível usar a sua detecção para objetivos diagnósticos. Outro interesse é a diminuição da eficiência energética em um futuro reator de fusão, dada a perda da energia das partículas no plasma no processo de excitação dos modos de Alfvén.

No caso do TCABR, não temos partículas energéticas excitando ondas, por isso usamos antenas externas ao plasma. O objetivo é a excitação do GAE para estudo do nível de impurezas. No TCABR temos um limitador de carbono, mas apesar de ser um plasma formado com a injeção de hidrogênio puro, acabamos obtendo um alto nível de impureza de carbono. Além disso, há impureza de ferro produzida por espalhamento na parede da câmara de vácuo. Em experimentos anteriores no TCA houve um maior foco em uma mistura de gases, de hidrogênio e deutério.

A proposta do método de excitação de modos de Alfvén é baseada no uso de antenas, para lançamento de ondas, que já estão disponíveis no TCABR. É necessário apenas o desenvolvimento de geradores de RF de baixa potência. No caso, foram feitos geradores de RF baseado em MOSFETs, que também já estão disponíveis no TCABR [49].

\subsection{Proposta da tese}

O objetivo deste trabalho é um estudo das ondas de Alfvén no tokamak TCABR. Pretendemos realizar a excitação e caracterização dos modos de Alfvén. Com base nisso, iremos usar os resultados obtidos para caracterizar as impurezas e a massa efetiva no TCABR. Para facilitar as contas e o entendimento, as equações para os cálculos analíticos estão escritas no sistema gaussiano de unidades e as grandezas estão no sistema internacional de unidades.

Esta tese tem como base as publicações:

[35] P. G. P. P. Puglia et. al., Externally driven global Alfvén eigenmodes applied for effective mass number measurement on TCABR, Phys. Plasmas 21, 122509, 2014 
[49] P. G. P. P. Puglia et. al., Alfvén and Helicon Wave Resonances Measured with Demodulator Circuit in TCABR, J. Phys.: Conf. Ser. 511 012038, 2014.

[50] P. G. P. P. Puglia et. al., Excitation of Global Alfvén Waves by Low RF Power on TCABR, J. Phys.: Conf. Ser. 591012002 , 2015;

A estrutura da tese é:

- O capítulo 1 mostra uma breve introdução sobre tokamaks e ondas de Alfvén. Os tópicos pautados servirão para embasar a discussão sobre os dados obtidos no TCABR;

- O capítulo 2 apresenta os equipamentos e diagnósticos, usados para as medidas experimentais, que são relevantes para a interpretação dos dados sobre excitação de ondas de Alfvén;

- O capítulo 3 apresenta os resultados obtidos nos experimentos de excitação de ondas de Alfvén, usando tanto uma quanto duas antenas. Nele mostramos a identificação da paridade de dois dos modos excitados;

- O capítulo 4 apresenta a discussão sobre os resultados obtidos. Inicialmente, fazemos uma estimativa da massa efetiva, que se mostra muito alta. Para calibrar o sistema usamos plasma de gás hélio. Uma vez com o sistema calibrado, obtemos valores inferiores que estão de acordo com a estimativa da carga efetiva. 


\section{Capítulo 2}

\section{Os equipamentos usados para o sistema de diagnóstico de Alfvén}

Neste capítulo fazemos a descrição do arranjo experimental do TCABR, que é relevante para os experimentos de excitação e detecção de ondas de Alfvén no plasma. O arranjo experimental dedicado consiste de dois amplificadores de frequência variável [51], antenas e sondas magnéticas [31]. Para a aquisição de dados usamos um par de equipamentos da National Instruments (NI-USB 5133), que têm uma alta taxa de amostragem, chegando à até $100 \mathrm{MS} / \mathrm{s}$. Esse equipamento se comunica com o computador (PC) de aquisição de dados pela porta USB.

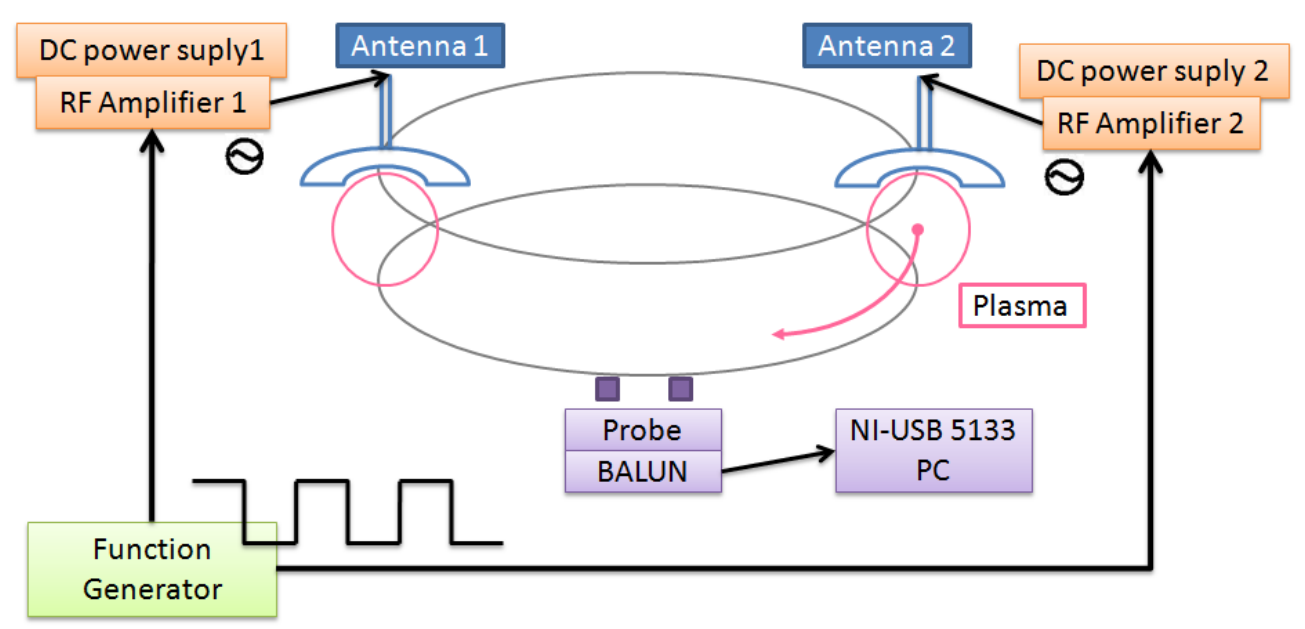

Figura 2.1: Representação esquemática do sistema de detecção e excitação de ondas de Alfvén do TCABR. Sentido de propagação do modo global de Alfvén na direção toroidal (a favor da corrente e contrário ao campo magnético) devido a efeito Hall $\left(\sim \omega / \omega_{c i}\right)$ é indicado pela flecha.

O computador de aquisição de dados se localiza em um gabinete próximo do to- 
kamak. Todos os sinais relevantes são levados ao gabinete por cabos BNC ou BNO, dependendo da forma de aterramento do sinal. Na Figura 2.1 o esquema geral de aquisição de dados é apresentado e será detalhado ao longo deste capítulo.

\subsection{Modulo de antenas}

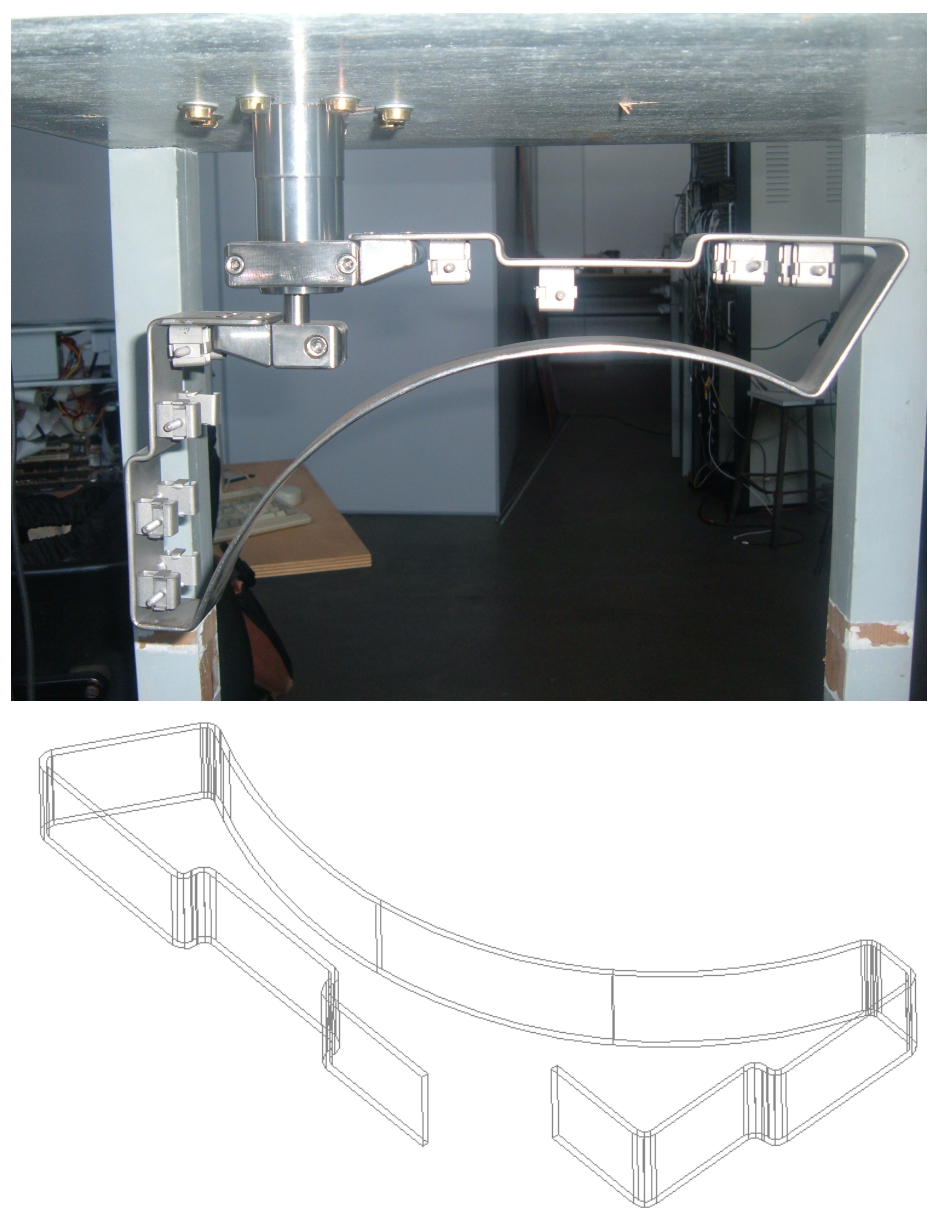

Figura 2.2: Detalhe de um strap da antena de aço inox.

No TCABR há dois módulos de antenas instaladas e sua operação é exclusivamente dedicada a excitação de ondas de Alfvén no plasma. Como a frequência das ondas de Alfvén que buscamos excitar é na faixa de rádio frequência ( $\mathrm{RF} 2-4 M H z)$, as antenas operam com correntes nesta faixa de frequência. O acoplamento das antenas com os modos de Alfvén se dá de forma indutiva; isso permite que ignoremos os campos eletrostáticos para a excitação das ondas. Os dois módulos estão instalados dentro do 
vaso de vácuo do TCABR e colocados em posições toroidalmente opostas, conforme mostrados na figura 2.1. Cada módulo consiste de quatro straps (tiras), cada strap sendo uma alça metálica, conforme mostrado na figura 2.2. As antenas são robustas e podem ser ligadas com alta potência, como quando foram utilizadas para aquecimento do plasma [31], suportando até $100 \mathrm{~kW}$ e correntes de até $100 \mathrm{~A}$ para o tempo característico do TCABR $(\sim 100 \mathrm{~ms})$. Neste trabalho temos como objetivo usar ondas de Alfvén para diagnóstico do plasma. Para isso, podemos usar baixa potência e apenas dois straps simétricos, um de cada módulo de antenas. Para gerar a corrente que passa nas antenas usamos um amplificador de frequência variável, que é descrito na seção 2.3

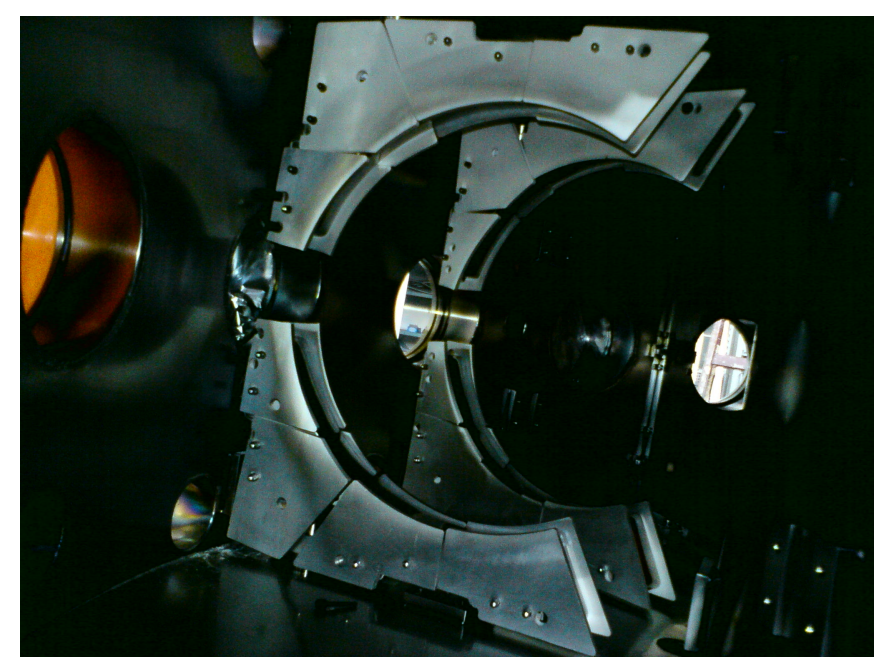

Figura 2.3: Foto da antena dentro do vaso, com a proteção de nitreto de boro.

Os dois módulos da antena não são idênticos. Um deles possui straps de aço inox e placas laterais de proteção de nitreto de boro para evitar exposição da antena ao plasma, figura 2.3. O outro módulo possui straps de cobre e tem como proteção uma gaiola de Faraday de aço inox, como mostrado na figura 2.4. Como já foi mencionado, campos eletrostáticos, produzidos pela voltagem nas antenas, podem produzir interferência e ruído no sistema de diagnóstico. Essa interferência é eliminada pela gaiola de Faraday. Como o campo eletrostático produzido pelas voltagens nas antenas não acopla com as ressonâncias globais de Alfvén, a presença da gaiola de Faraday não prejudica a excitação destes modos no plasma. 
Os conectores (feedthrough) da antena na flange do vaso do TCABR podem ser uma fonte de radiação parasítica quando se passa corrente de RF por eles, já que ficam expostos na parte de fora do vaso. Essa radiação de RF emitida pode causar interferência nos sinais de outros diagnósticos do TCABR. Por isso, usamos uma blindagem de alumínio na parte dos conectores que ficam externos ao vaso.

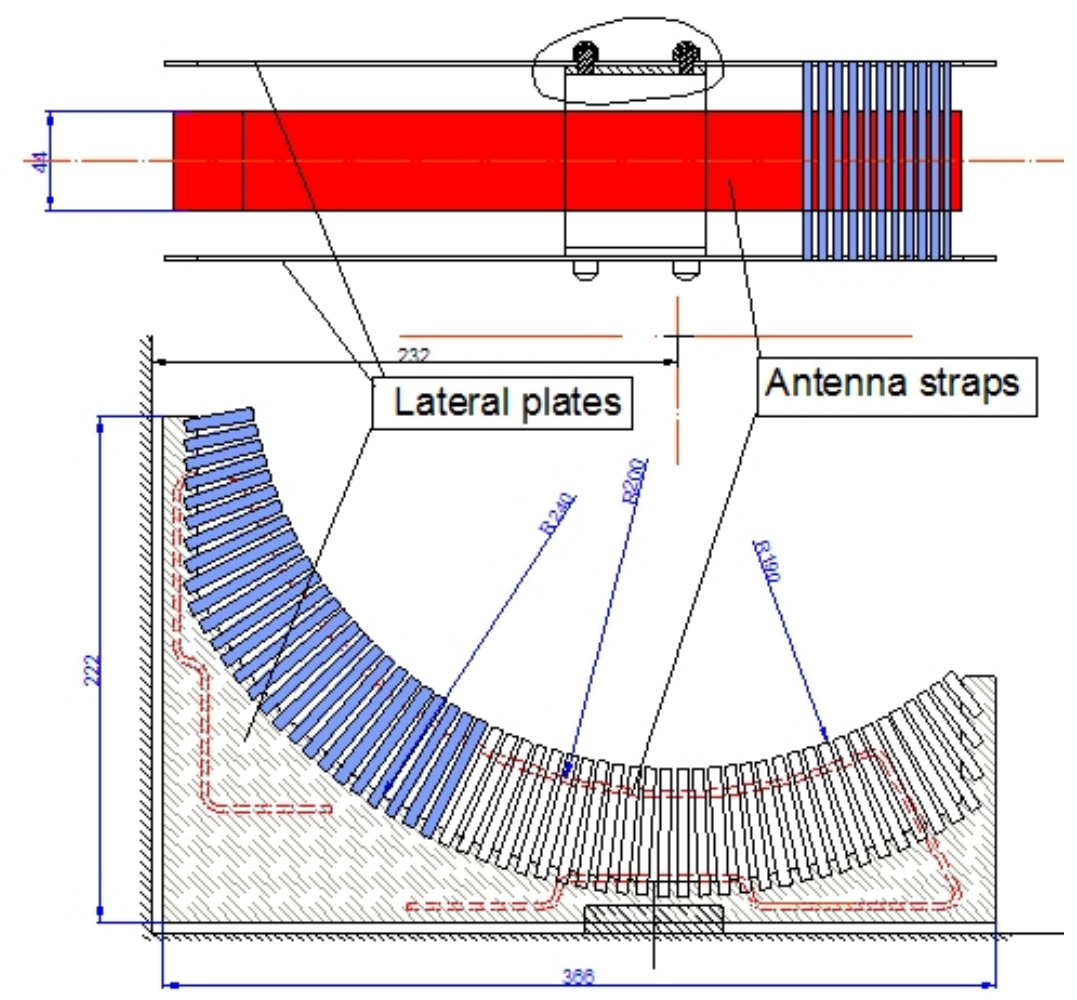

Figura 2.4: Esquema da gaiola de Faraday para proteção da antena.

Para fazer um teste de blindagem, colocamos uma proteção de alumínio em cima de um dos feedthrough e passamos corrente apenas na antena cujo conector foi blindado. $\mathrm{O}$ nível de interferência detectado foi mais de dez vezes menor. Na figura 2.5 apresentamos os sinais de bolometria e raio-x mole (SXR), que demonstram a melhora obtida no nível de interferência parasítica. 

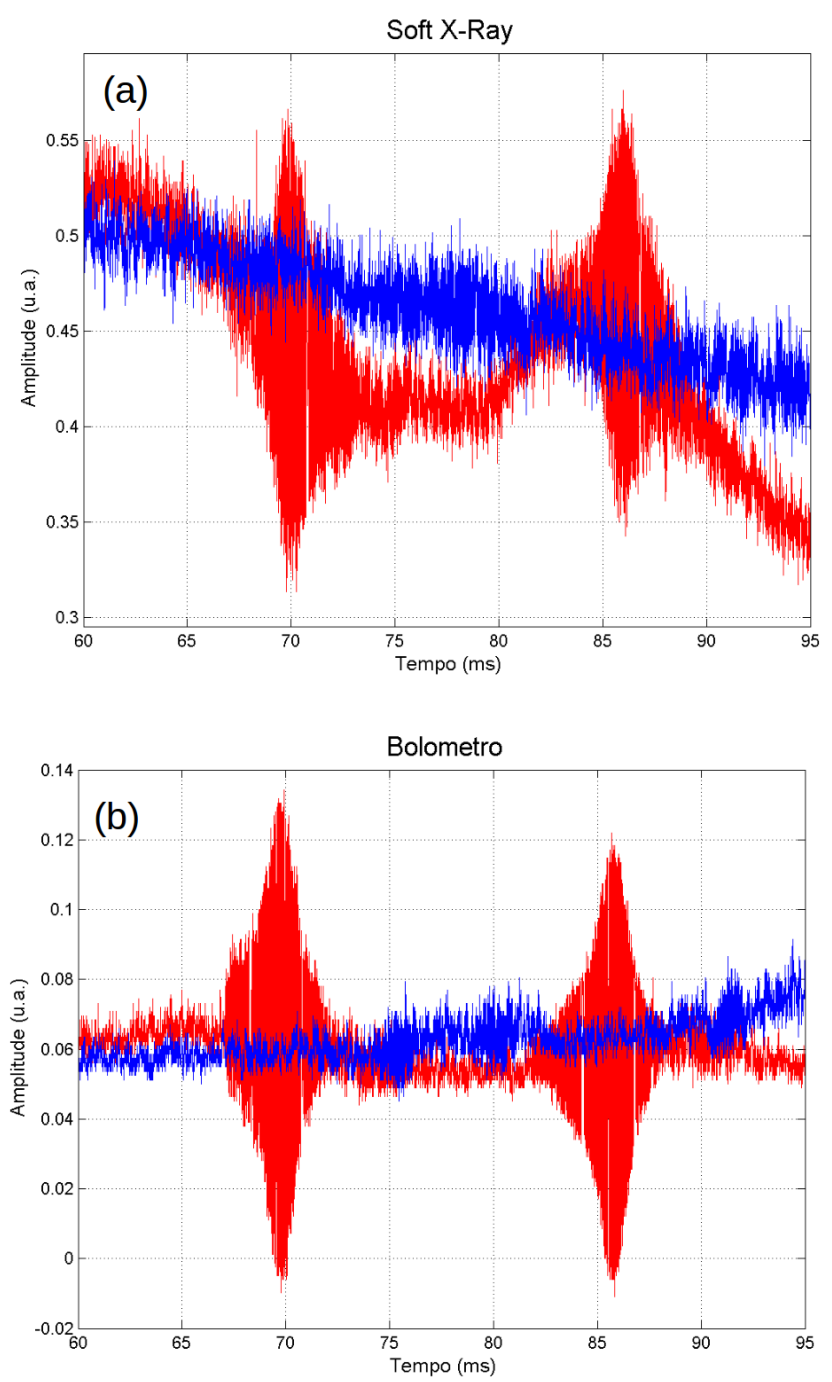

Figura 2.5: Comparação do sinal de dois disparos diferentes, um sem a blindagem do feedthrough (\# 26536, vermelho) e outro com a blindagem do feedthrough (\# 26556, azul). São apresentados sinais do soft $x$-ray (a) e do bolometro (b).

\subsection{Sondas magnéticas e BALUN}

Para medir as oscilações dos campos magnéticos, referentes às ondas de Alfvén excitadas pela corrente que passa pela antena, temos disponível um par de sondas magnéticas dedicadas. As sondas estão instaladas a uma distância de $\sim 1 m$ da antena, deslocadas na direção toroidal (fig. 2.1). Na direção radial, estão a uma distância de $23 \mathrm{~cm}$ do centro geométrico da câmara de vácuo. Devido a seu desenho, figura 2.6, é possível detectar tanto o campo magnético toroidal como o poloidal. Cada sonda é 


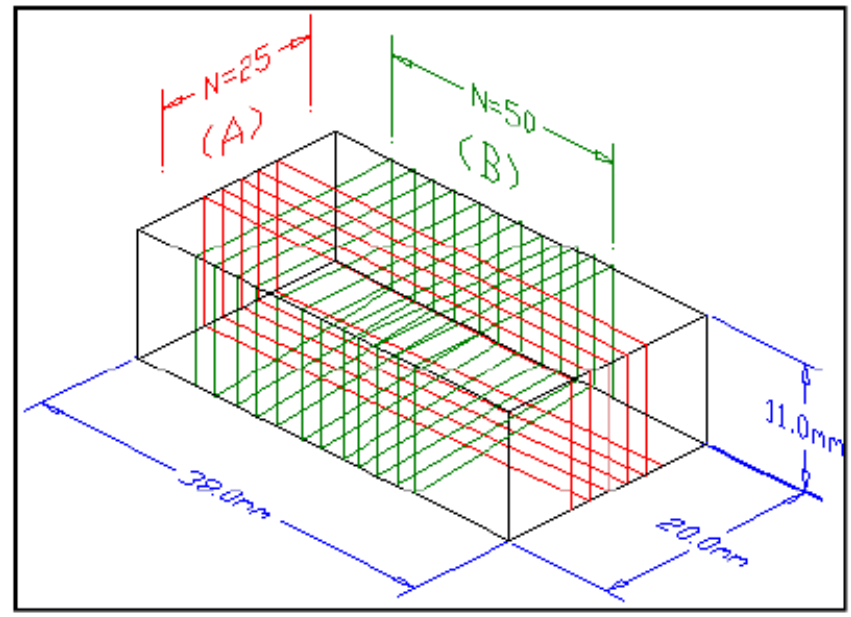

Figura 2.6: Esquema das bobinas ortogonais da sonda magnética usada para fazer as medidas do campo magnético [31]

composta de duas bobinas, (A) e (B). A bobina (A) mede o campo poloidal e tem seção de $11 \times 36 \mathrm{~mm}$, a $(\mathrm{B})$ mede o campo toroidal e tem seção de $10 \times 20 \mathrm{~mm}$. A distância angular entre as sondas magnéticas é de aproximadamente $25^{\circ}$. A estrutura metálica para montagem da sonda é a mesma que foi usada, quando experimentos de ondas de Alfvén foram realizados, no TCA, em Lausanne.

Para adquirir o sinal da sonda magnética utilizamos dois digitalizadores da National Instruments (NI) NI USB-5133, de 8 bits com taxa de aquisição de até $100 M S / s$. No entanto, comumente usamos uma taxa de aquisição de $50 \mathrm{MS} / \mathrm{s}$. Como não excitamos ressonâncias de Alfvén, com frequência superior à $5 M H z$, a taxa de aquisição citada é suficiente para satisfazer a condição de Nyquist. Essa condição determina que temos que ter, pelo menos, uma taxa de aquisição com o dobro do valor da frequência que desejamos detectar.

Esse equipamento da NI possui uma entrada single-ended; assim, um dos lados do canal de aquisição tem que ser aterrado, como em um osciloscópio convencional. Como estamos lidando com a detecção do sinal de uma bobina, temos um sinal diferencial entre os terminais da sonda. Neste caso, é necessário que não se aterre um lado da sonda, porque como o terra é comum, isso geraria um curto entre as duas sondas.

A sonda não poderia ser aterrada diretamente porque o terra do vaso do tokamak 
e o terra do sistema de aquisição são diferentes. Haveria um potencial entre a sonda magnética e o plasma, podendo danificar a sonda ou criar um regime de sonda eletrostática, sinal que não representa a excitação de ondas de Alfvén no plasma. Para sanar esse problema foi usado um BALUN (figura 2.7), que é um transformador de linha de transmissão usado para fazer a transformação de sinais bipolares ou diferenciais (BALanced) para unipolares (UNbalanced), com um dos lados aterrados. A vantagem é que o BALUN também funciona como uma bobina de proteção (choke), eliminando modos comuns.

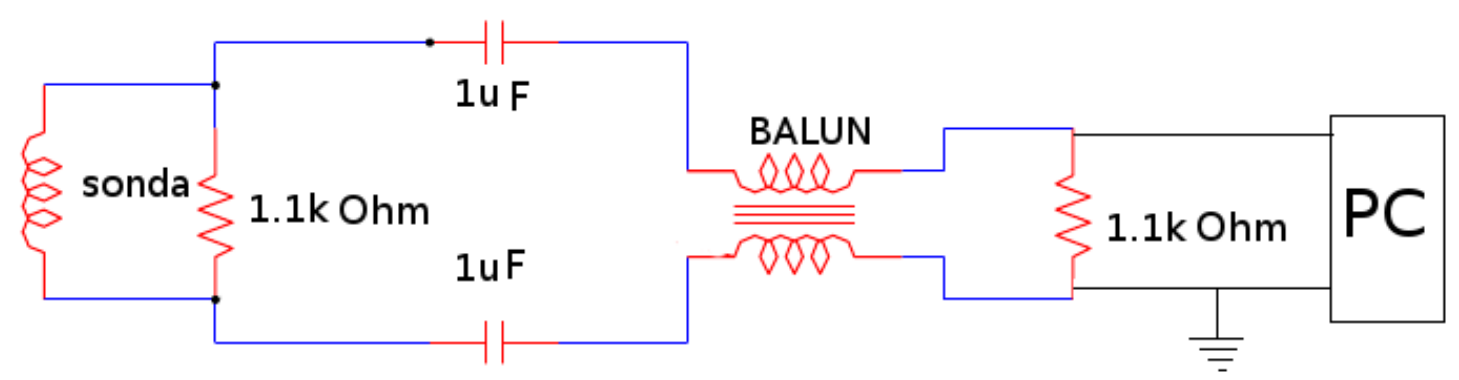

Figura 2.7: Esquema de ligação do PC à sonda magnética via BALUN. Usamos uma indutância de $1 m H$ para o BALUN.

Os modos comuns são sinais que se propagam em uma linha de transmissão, como um cabo coaxial, sem serem diferenciais, se propagando apenas de um lado da linha ou igual nos dois lados. A linha de transmissão deve carregar sinais que são opostos em cada lado (no cabo coaxial temos o pino central e a malha de terra). O ruído comumente se comporta como um modo comum, se propagando em apenas um dos lados da linha de transmissão. No nosso caso, os modos comuns são devido a interferência da corrente que passa pela antena. Em teoria, com os modos comuns suprimidos, medimos apenas o sinal diferencial da sonda no NI-USB 5133. No fundo, o BALUN é um cabo coaxial enrolado em um ferrite, com uma indutância de $1 \mathrm{mH}$ para os modos comuns, enquanto para o sinal diferencial funciona como um cabo coaxial comum. O importante para seu funcionamento correto é ter a sua impedância $(\omega L)$ bem maior que a do medidor e da sonda, para os modos comuns. 
Na conexão, como podemos ver na figura 2.7, colocamos também capacitores de $1 \mu F$. Eles são necessários pois o BALUN só cria isolação para altas frequências, onde sua impedância é alta. Para baixas frequências $(<1 k H z)$ o isolamento se dá pelo capacitor. Para a conexão das sondas magnéticas até o gabinete com o computador de aquisição, foram usados cabos tipo BNO (twinaxial cabling). Este tipo de cabo tem dois canais internos entrelaçados e com uma malha externa, aumentando a blindagem do sistema e é próprio para sinais diferenciais.

\subsubsection{Testes do equipamento usando oscilação da ilha magné- tica}

Com o intuito de testar o funcionamento da sonda magnética com o BALUN, realizamos uma análise das oscilações magnéticas (MHD) no plasma do TCABR. Essas oscilações são em frequência próxima de $15 \mathrm{KHz}$ e, além de serem bem conhecidas, são bem caracterizadas [52], com modo toroidal $\mathrm{N}=1$ e poloidal $\mathrm{M}=2$ ou 3 . Os resultados são apresentados na figura 2.8 .

Podemos ver que a oscilação aparece bem clara no sinal das sondas magnéticas. A diferença de fase observada se refere ao modo toroidal $N=1$, e a defasagem entre os sinais das sondas é de $\approx 25^{\circ}$, o mesmo valor da distância angular entre as duas sondas. Esse teste confirma que as sondas magnéticas estão em bom funcionamento e conseguem detectar oscilações magnéticas do plasma, além de servir como um método para verificar a defasagem entre as sondas.

É mais confiável encontrar o valor da defasagem das oscilações MHD do que dos modos de Alfvén, pois temos um sinal detectado forte e que não sofre interferência da corrente de RF nos conectores da antena, pois está em outra faixa de frequência, além do sinal produzido pela onda na borda do plasma e no vácuo. As oscilações MHD também apresentam uma frequência baixa, se comparada a das ondas de Alfvén. Dada essas diferenças, não conseguimos obter de modo satisfatório a diferença de fase para os modos de Alfvén, apesar de os identificar claramente no sinal da sonda. Mesmo assim o esquema de ligação das sondas magnéticas serve para detectar, de maneira 
satisfatória, as oscilações magnéticas ligadas à excitação de ondas de Alfvén no plasma. Como mencionado, vamos usar duas antenas toroidalmente opostas para determinar a paridade dos modos de Alfvén excitados, suprindo a falta da identificação do número toroidal dos modos com as sondas magnéticas.

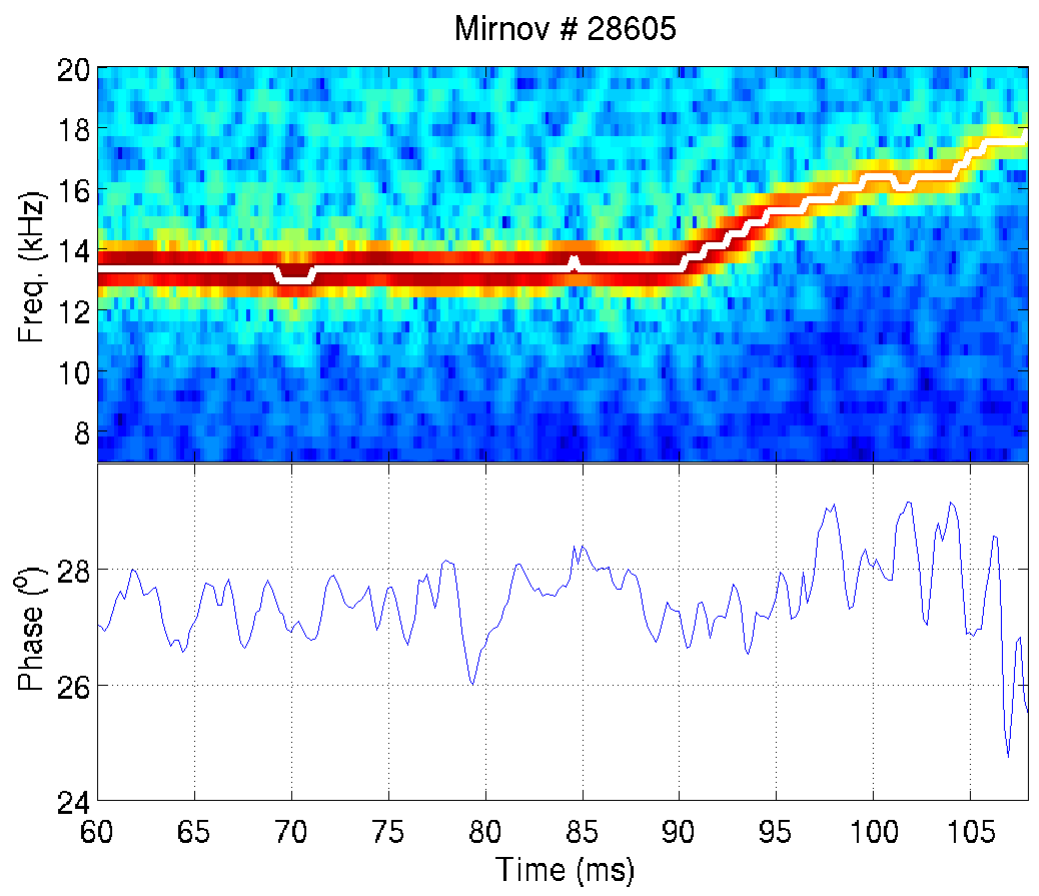

Figura 2.8: Detecção das oscilações da ilha magnética do TCABR com as sondas magnéticas de Alfvén, para o disparo\# 28605. Temos o espectrograma com o máximo destacado em branco e, a defasagem entre o sinal duas sondas, referente a frequência que segue a linha branca. A defasagem é de $\approx 27^{\circ}$.

\subsection{Gerador RF com varredura de frequência}

Para alimentar a antena com potência, foram empregados geradores de radio frequência $(\mathrm{RF})$ produzidos no próprio Laboratório de Física de Plasmas em colaboração com a empresa Politron (projetos da CNPq 478304/2006-4 e 475985/2009-5). Usualmente, temos disponíveis no mercado amplificadores que operam com cargas puramente resistivas. No nosso caso, temos uma carga que não é resistiva e como o amplificador opera em uma larga faixa de frequência $\left(\frac{\Delta f}{f} \gtrsim 1\right)$, precisa apresentar resistência a reflexões por toda a faixa de frequência. Para construir um amplificador que suprisse as nossas 
necessidades, foi desenvolvido um módulo RF de potência. O módulo de RF produz uma onda senoidal com a eliminação de harmônicos de uma onda quadrada, esta criada pelo chaveamento de MOSFETs.

O amplificador por chaveamento de MOSFETs facilita o casamento de impedância com a carga, tornando possível uma varredura em uma banda de frequência larga. Os MOSFETs usados para a construção do módulo do sistema de RF podem gerar potência de pelo menos $1 k W$, suportando a variação da frequência de chaveamento de $f=2-4 M H z$

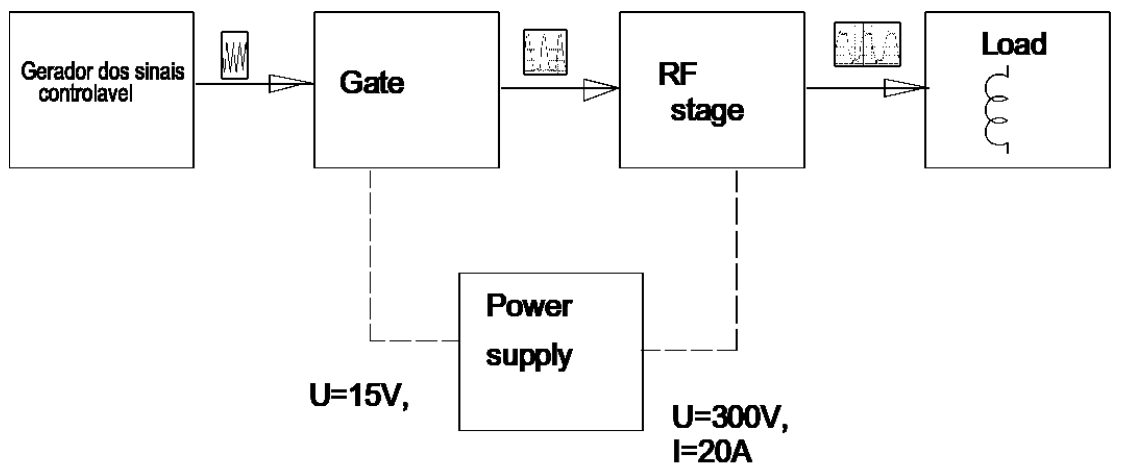

Figura 2.9: Esquema de blocos do gerador de potência com varredura de frequência. [51]

O esquema de blocos do gerador de potência de RF pode ser visto na figura 2.9. A frequência e a fase do sinal de saída do módulo RF são controladas pelo gerador de sinais comercial AGILENT 33220A $20 \mathrm{MHz}$ - Arbitrary Waveform Generator, que fornece como sinal de entrada uma onda quadrada na frequência desejada.

A onda quadrada é amplificada pelo driver do MOSFET (Gate driver) chaveando uma fonte $\mathrm{DC}$ de $15 \mathrm{~V}$. Após este estágio, temos potência suficiente para chavear o MOSFET de potência (RF stage). A potência chaveada vem de uma fonte DC regulável de até $20 \mathrm{~A}$ e $300 \mathrm{~V}$. Normalmente operamos em $V_{D C} \approx 100 \mathrm{~V}$, já que com essa tensão obtemos a corrente máxima de saída. Depois dessa etapa, temos uma onda quadrada como saída do MOSFET, embora o sinal não seja uma onda quadrada devido à carga indutiva na fonte. Como queremos uma onda senoidal na saída, filtramos os harmônicos utilizando um filtro $\pi$ de 2 estágios. Após o sinal de potência estar filtrado, 

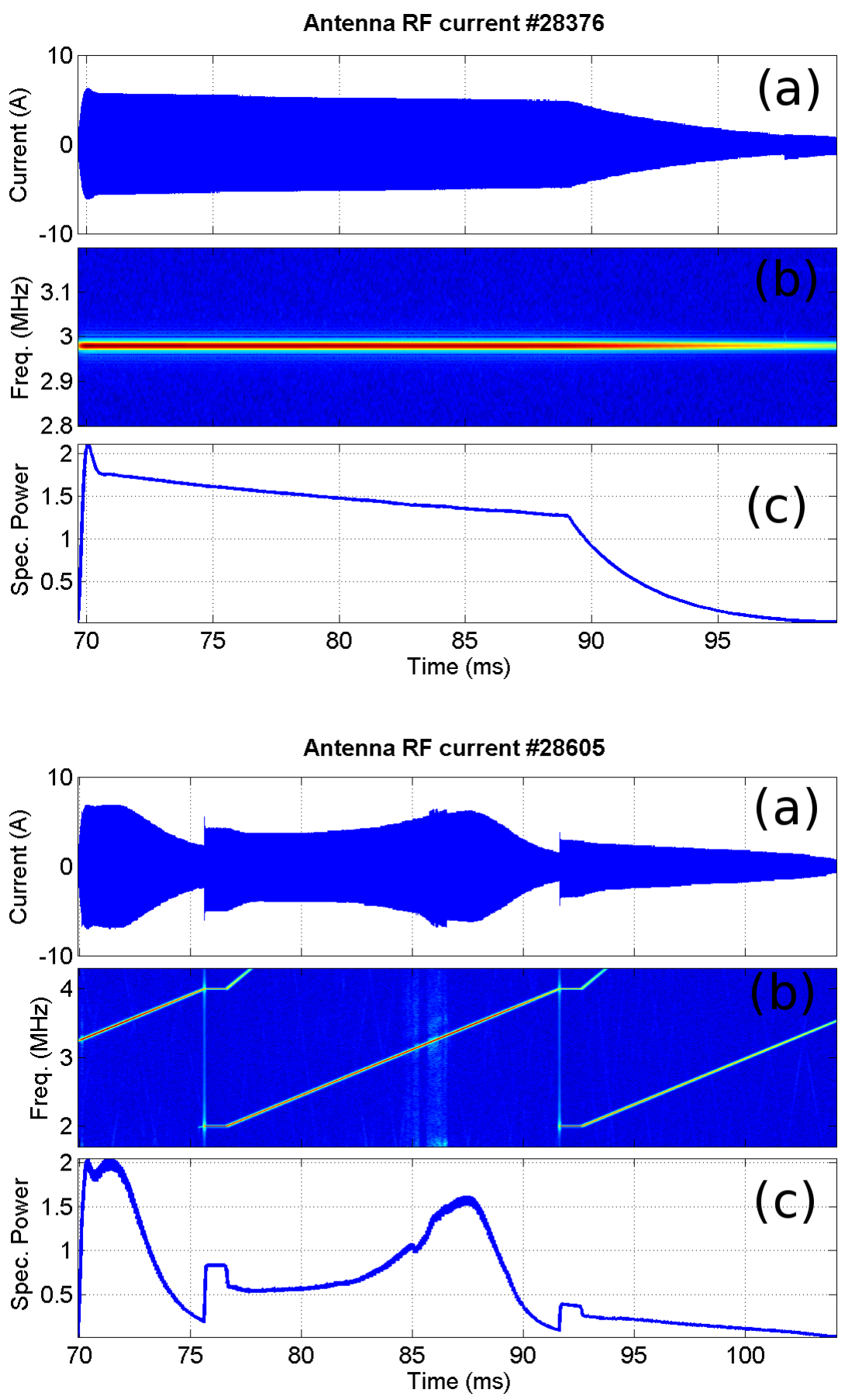

Figura 2.10: Performance do amplificador de RF, com a corrente em modo de frequência fixa (\#28376) e em modo de varredura de frequência (\#28605). Podemos ver, para os dois disparos diferentes, o sinal da corrente de RF que passa pela antena obtido com uma bobina de Rogowski (a), o espectrograma desse sinal (b) e a potencia espectral na frequência da corrente de RF (c).

podemos injetá-lo na antena (load/carga).

A corrente passa pela antena por um tempo $t \approx 20 \mathrm{~ms}$. Esse tempo é limitado pela 
fonte DC de potência e serve para proteger os MOSFETs de super aquecimento. Como eles operam em regime pulsado, puderam ser subdimensionados, barateando o custo de construção. Na figura 2.10 temos o sinal da corrente na antena com frequência fixa e com varredura de frequência. Na figura vemos que a corrente pode chegar a até $5 A$, dependendo da frequência e voltagem da fonte DC. Com um amplificador feito com outro MOSFET, mais potente, chegamos a até $15 \mathrm{~A}$.

\subsection{NI USB-5133 - Diferença entre os módulos}

Como já foi mencionado, para fazer a aquisição de dados usamos dois módulos NIUSB 5133. Entre os dois módulos há uma pequena diferença na taxa de aquisição. Essa diferença causa uma defasagem entre os sinais medidos pelos diferentes módulos e dificulta a comparação entre dados obtidos em módulos diferentes.

(a)

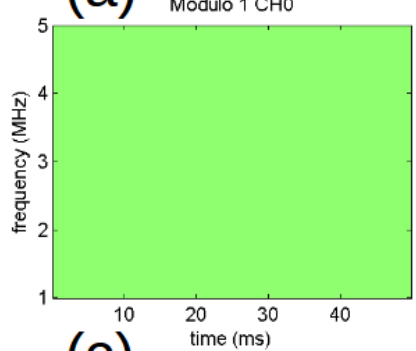

(c)

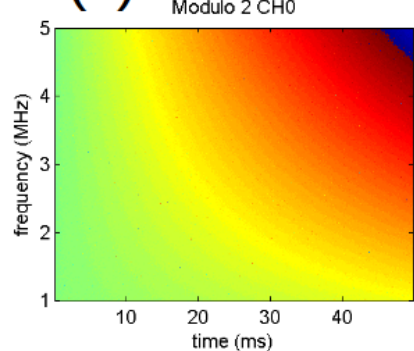

(b) Modul 1 CH1

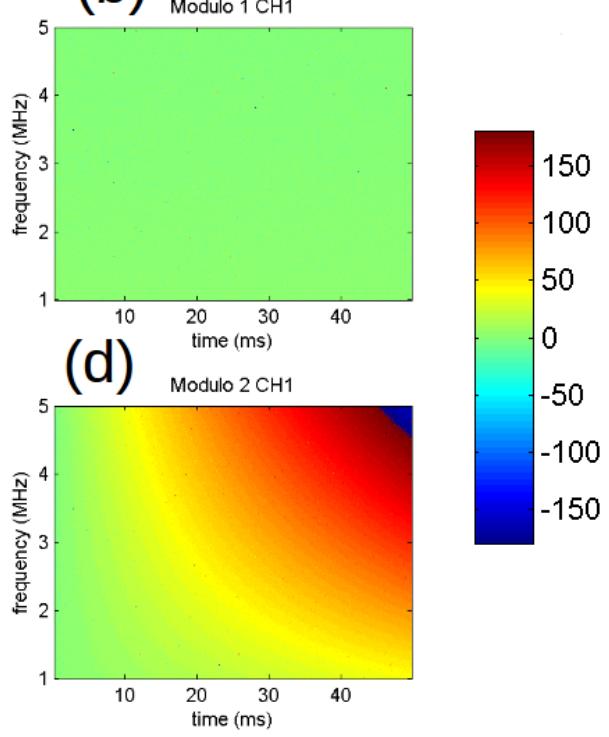

Figura 2.11: Diferença de fase entre os sinais de ruído adquiridos simultaneamente nos dois módulos NI-USB 5133. O sinal do Modulo 1 CHO (a) foi usado como referência. Vemos que a fase em relação ao sinal adquirido com o mesmo módulo (b) é zero para todos os tempos e frequências. Já a fase em comparação com o sinal do outro módulo, (c) e (d), varia com o tempo e com a frequência. Por variar no tempo indica que temos uma pequena diferença na taxa de aquisição entre os dois módulos.

Na figura 2.11 vemos a diferença de fase entre os canais para um mesmo sinal, o sinal 
é ruído gerado pelo AGILENT 33220A. Como a aquisição é simultânea, não deveria haver diferença de fase entre os sinais. Mas ela existe e, além de ter um comportamento diferente para cada frequência, evolui no tempo. Isso indica que temos uma pequena diferença na taxa de aquisição entre os dois módulos NI-USB 5133. Temos dificuldades se quisermos comparar a fase de diferentes sinais, e, para limitar esse efeito, temos que comparar a fase de sinais somente se eles estiverem no mesmo módulo.

\subsection{Interferômetro}

De acordo com a equação do contínuo de Alfvén (eq.1.16), a frequência das ressonâncias de Alfvén depende diretamente da densidade do plasma, e mais que isso, para se calcular o contínuo de Alfvén é preciso saber o perfil da densidade $n(r)$ e da corrente do plasma (perfil do fator de segurança $q$ ), além do campo magnético e do raio maior $R$. Determinar em detalhe esses dois perfis no TCABR não é possível devido a falta de diagnósticos, porém é possível fazer estimativas. Realmente, para a identificação da onda Global de Alfvén, que se propaga perto do mínimo do contínuo de Alfvén, precisamos saber o máximo da densidade e o mínimo do fator de segurança. Com o uso de, pelo menos, dois canais do interferômetro, podemos estimar o perfil e o máximo da densidade. Nesta seção apresentamos como é feita essa estimativa do perfil de densidade, e na próxima, mostramos como podemos estimar o perfil de corrente.

Para estimar o perfil de densidade usamos um interferômetro multicanal [53]. O esquema do interferômetro do TCABR é apresentado na figura 2.12. Seu princípio de funcionamento é a injeção de uma onda, na faixa de microondas, que atravesse o plasma, ou seja, com frequência acima da frequência de plasma. A presença do plasma muda a velocidade de propagação da onda, a deixando mais lenta. Comparando a onda detectada após atravessar o plasma com um sinal de referência, e com o sinal no vácuo, antes da formação do plasmas, observamos uma defasagem entre os sinais. Como a velocidade de propagação da onda depende da densidade do plasma, a defasagem 
medida é proporcional a densidade do plasma.

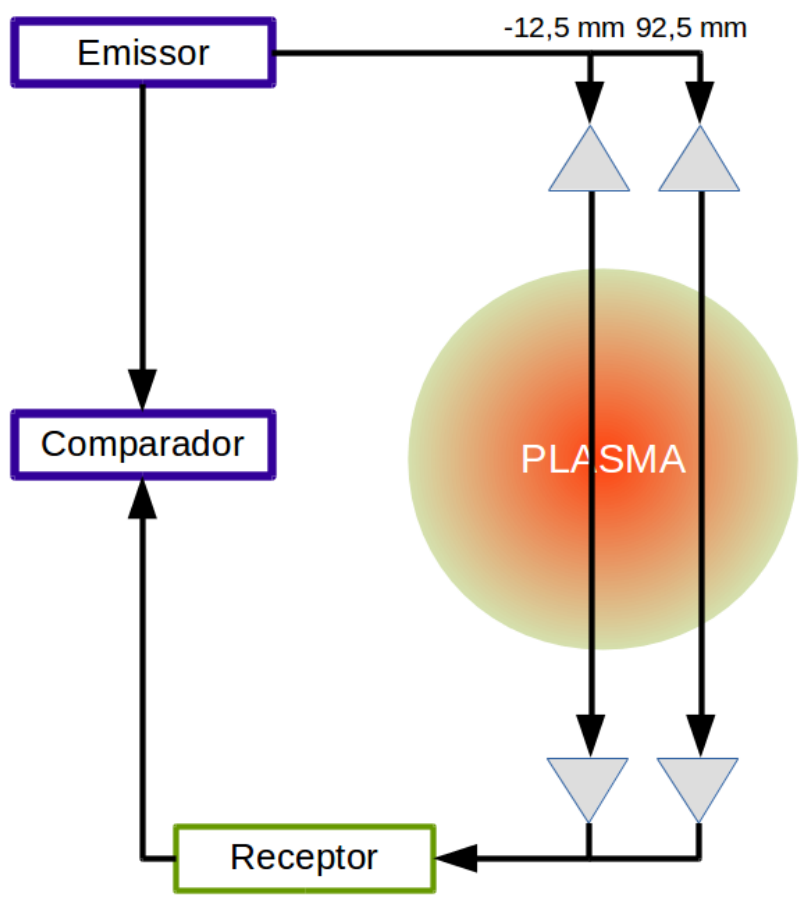

Figura 2.12: Esquema do interferômetro do TCABR, mostrando os dois canais utilizados nos experimentos.

No TCABR, para se medir a densidade com o interferômetro, se tem uma antena emissora acima do plasma e outra abaixo, cruzando o plasma em um raio específico no seu horizonte. Uma particularidade do valor de densidade obtido com o interferômetro é que ele representa a densidade integrada do plasma, ou seja, temos uma medida da defasagem do sinal que passa pelo plasma, que é proporcional a densidade média do plasma, realmente, proporcional a densidade integrada na linha que forma o caminho de propagação da onda. Com o uso de vários canais de interferometria, é possível uma medida da densidade integrada na linha em diferentes cordas do plasma e, assim, obter informação sobre o perfil de densidade do plasma.

No TCABR, temos disponíveis apenas dois canais de interferometria. Colocamos um deles perto do centro do plasma $(-12,5 \mathrm{~mm})$ e o outro no meio do raio $(92,5 \mathrm{~mm})$. A posição do plasma pode mudar ao longo do disparo, mas a posição do centro da coluna de plasma é medida com diagnóstico magnético, e podemos corrigir a posição 
dos canais do interferômetro em relação ao centro do plasma. Porém, como ambos os canais estão em uma região mais central do plasma, uma pequena variação na posição não muda muito o valor do sinal obtido.

A frequência de ressonância das ondas de Alfvén mostram uma dependência maior com a densidade no centro do plasma que com a densidade integrada na linha. Principalmente, para casos onde há injeção de gás para fazer uma rampa na densidade, que altera o perfil de densidade.

Para calcular a densidade do plasma no centro da coluna e a potência $\alpha$, partimos do modelo para o perfil radial de densidade:

$$
n(r)=n_{0}\left(1-\frac{r^{2}}{a^{2}}\right)^{\alpha}
$$

onde $a$ é o raio do plasma e $n_{0}$ a densidade no centro do plasma.

Com a suposição de um perfil de densidade parabólica elevado a uma potência para a densidade do plasma, é possível, com o uso dos dois canais, determinar a densidade no centro do plasma e a potência $(\alpha)$. Esse perfil deve ser válido para a região mais interna do plasma, a região onde medem os canais do interferômetro. O valor de densidade integrada na linha, obtido com o interferômetro, é calculado como

$$
n_{l}\left(r_{l}\right)=\frac{n_{0}}{\sqrt{a^{2}-|r l|^{2}}} \int_{0}^{\sqrt{a^{2}-|r l|^{2}}}\left(1-\frac{\left(y-r_{l}\right)^{2}}{a^{2}}\right)^{\alpha} d y
$$

com $r_{l}$ sendo o raio da corda onde é obtido o valor da densidade de linha. É possível resolver a equação acima de forma analítica

$$
n_{l}\left(r_{l}\right)=\frac{n_{0}}{2} \frac{\left(-r_{l}^{2} / a^{2}+1\right)^{\alpha} \Gamma(\alpha+1) \sqrt{\pi}}{\Gamma(\alpha+3 / 2)}
$$

Como temos este resultado analítico e o valor da densidade integrada na linha em dois raios diferentes, é possível resolver um sistema de equações para $n_{0}$ e $\alpha$. A solução deste sistema é 


$$
\begin{gathered}
\alpha=-\frac{\log \left(\frac{n_{l}\left(r_{l 1}\right)}{n_{l}\left(r_{l 2}\right)}\right)}{-\log \left(-\left(r_{l 1} / a\right)^{2}+1\right)+\log \left(-\left(r_{l 2} / a\right)^{2}+1\right)} \\
n_{0}=1.1284 \frac{n_{l}\left(r_{l 1}\right) \Gamma(\alpha+1.5)}{\left(-\left(r_{l 1} / a\right)^{2}+1\right)^{\alpha} \Gamma(\alpha+1)}
\end{gathered}
$$

Com estas duas equações obtemos informação sobre o perfil de densidade, que será importante para a análise das ondas de Alfvén e determinação da massa efetiva do plasma.

Um exemplo do resultado obtido com este método está apresentado na figura 2.13. Nesse disparo houve injeção de gás no plasma, criando um aumento de densidade. Como podemos observar, o aumento de densidade cria uma mudança no perfil de densidade.

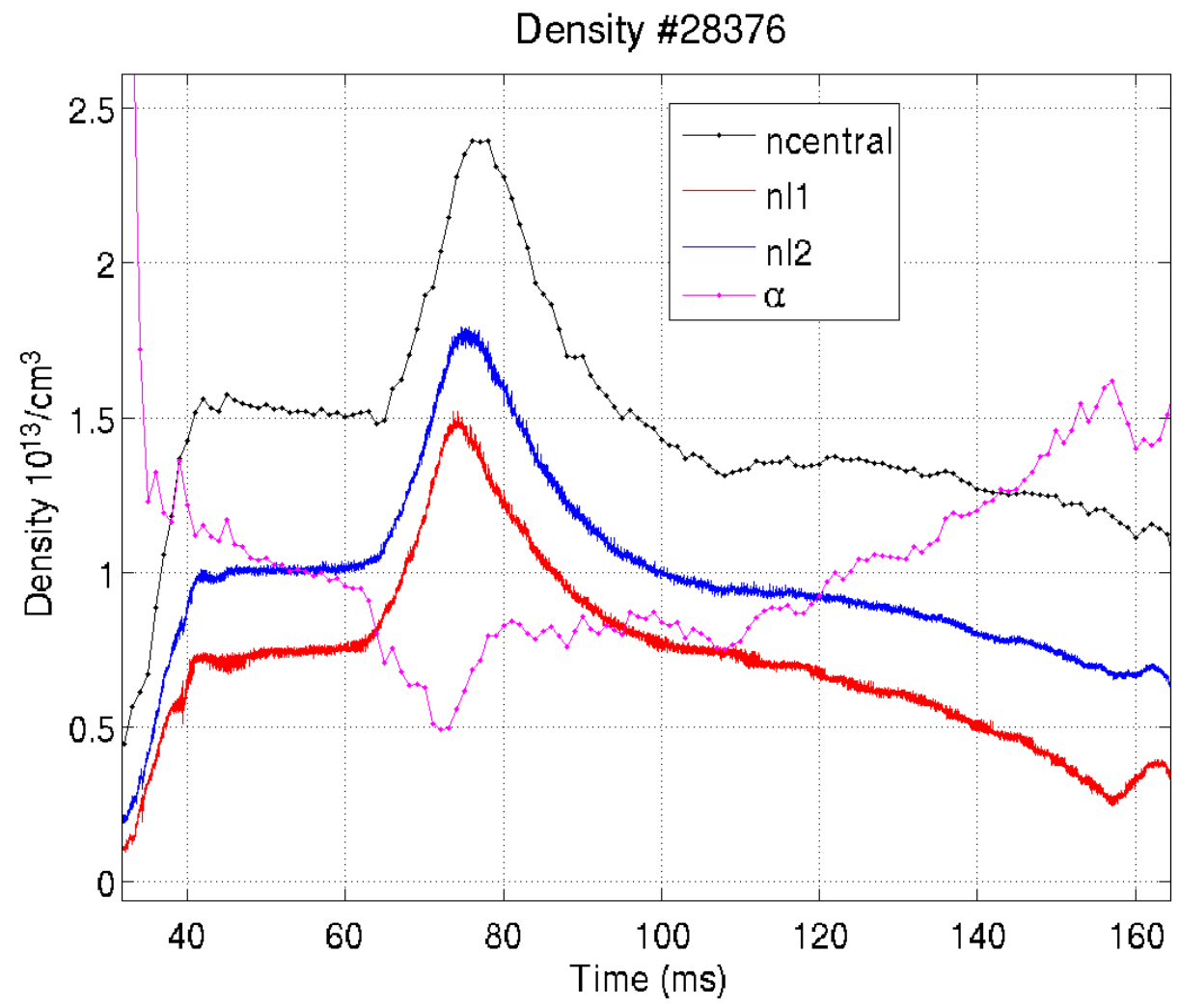

Figura 2.13: Cálculo da densidade no centro do plasma e do parâmetro a com o método apresentado, a análise foi feita para o disparo \# 28376. Podemos ver claramente a mudança do perfil quando há injeção de gás, e consequente aumento da densidade, a partir de $t \approx 65 \mathrm{~ms}$. 


\subsection{Raio-X mole e identificação do fator de segu- rança por oscilações dentes de serra}

Agora que já determinamos o perfil de densidade, vamos explicar como podemos estimar o perfil do fator de segurança, do qual depende o contínuo de Alfvén, (eq. 1.16), com a detecção de instabilidades dente de serra. O fator de segurança possui, para as descargas ôhmicas, seu mínimo no centro do plasma. Quando o mínimo se encontra inferior ao valor $q=1$, acontece um regime de oscilações de relaxação, chamadas de oscilações ou instabilidades dente de serra.

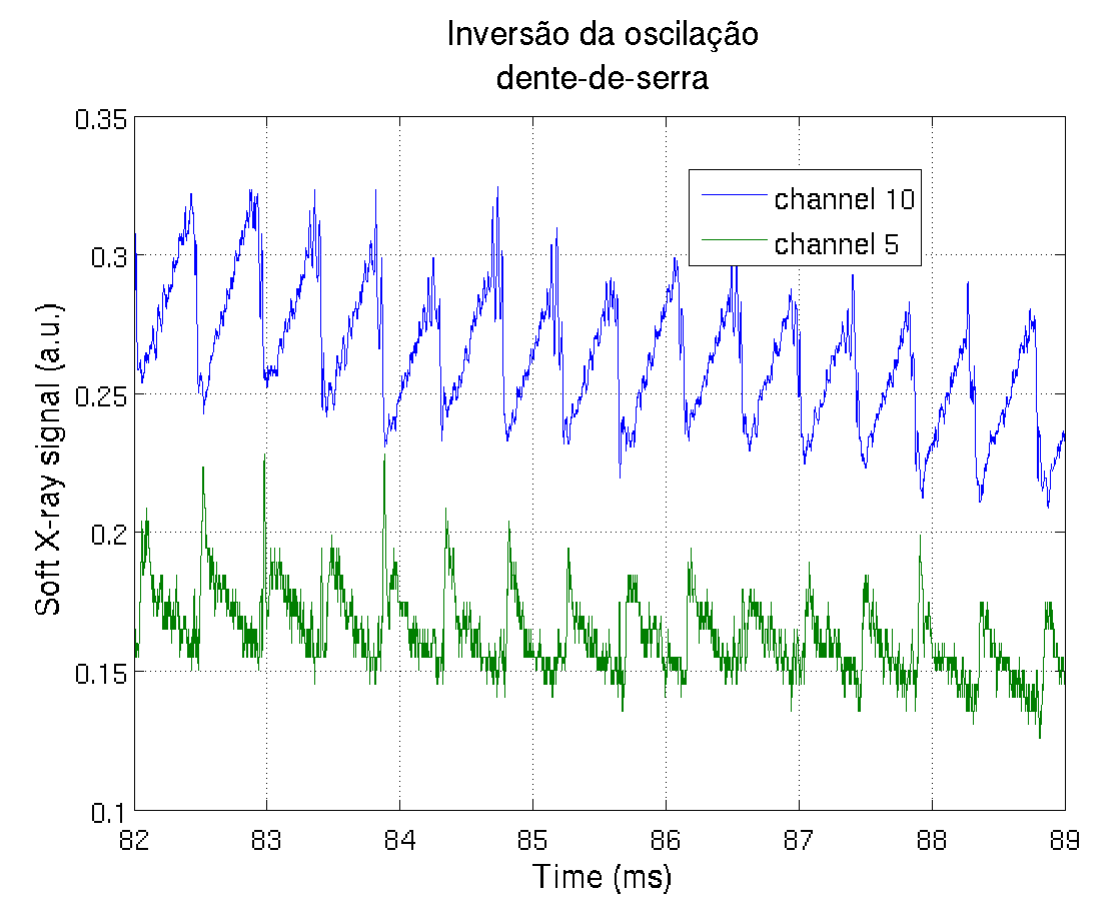

Figura 2.14: Sinal do raio-X mole para o disparo \# 28376. Podemos ver claramente a mudança de fase da instabilidade dente de serra entre o centro do plasma (canal 10 $r=-7.0 \mathrm{~mm}$ ) e um canal mais afastado (canal $5 \mathrm{r}=-79.6 \mathrm{~mm}$ ).

As oscilações dente de serra são uma instabilidade MHD, chamada de kink [11]. Essa instabilidade causa uma relaxação no centro da coluna de plasma. A relaxação é composta de duas fases, primeiro há uma subida lenta da temperatura dos elétrons, e depois temos uma rápida queda, chamada de crash. Durante o crash a temperatura e densidade caem no centro do plasma, mas aumentam em uma região mais afastada do centro. O raio em que há a inversão entre a diminuição e o aumento durante o 
crash é a superfície com o fator de segurança $q=1[11,52]$. O sinal do dente de serra obtido com o detector de raio-X mole do TCABR pode ser visto na figura 2.14 , onde apresentamos o sinal de uma corda central $(r=-7.0 \mathrm{~mm})$ e uma corda mais afastada $(r=-79.6 \mathrm{~mm})$. Vemos claramente o crash e a inversão de fase do sinal quando fora da superfície $q=1$.

O valor de $q$ na borda no plasma depende apenas da corrente total do plasma

$$
q_{a}=q(a)=\frac{a^{2}}{R} \frac{B_{T}}{0.2 I_{P}}
$$

com $a$ o raio menor do plasma, $R$ o raio maior, $B_{T}$ o campo toroidal e $I_{P}$ a corrente de plasma. Podemos determinar também a posição da superfície $q=1$, o raio de inversão da oscilação dente de serra. Assim temos dois pontos para estimar o perfil de $q$. Novamente, como para o perfil de densidade, vamos supor que temos um perfil parabólico elevado a uma potência. Para a densidade de corrente temos:

$$
j(r)=j_{0}\left(1-\frac{r^{2}}{a^{2}}\right)^{\gamma}
$$

Onde $j_{0}$ é a densidade de corrente no centro do plasma, $a$ o tamanho do raio menor do plasma $(18 \mathrm{~cm}), r$ o raio e $\gamma$ um parâmetro a ser ajustado de modo que a superfície $q=1$ seja no mesmo raio que em que medimos a inversão de fase da oscilação dente de serra. O valor de $j_{0}$ é definido pelo valor de $q$ na borda.

O método para encontrar o raio onde a superfície $q=1$ se encontra, foi desenvolvida em [52]. Para este método se usa o sinal de raio-X mole. No TCABR este diagnóstico é um array de fotodiodo com um filtro de berílio, deixando passar apenas a radiação de maior energia. Apesar do nome de raio-X mole, realmente, medimos radiação na banda ultravioleta. O diagnóstico faz a medida na região horizontal do plasma.

Para encontrar a superfície $q=1$, usamos dados de todo o array e interpolamos a fase entre os canais. O resultado da análise pode ser visto na figura 2.15. Onde apresentamos o perfil de emissão multiplicado pela fase em relação ao canal central, 
quando há uma mudança de sinal, significa que houve uma mudança de fase. No local da mudança de fase temos a superfície $q=1$.

Devido ao deslocamento do plasma do centro geométrico da câmara de vácuo do TCABR, a posição da superfície $q=1$ é diferente na parte superior e inferior. Para obtermos apenas um valor de posição, fazemos uma média entre os dois valores obtidos.

Finalmente, podemos obter um valor para o parâmetro $\gamma$ da (eq. 2.7). Assim podemos estimar o contínuo de Alfvén e as frequências de ressonância do GAW.

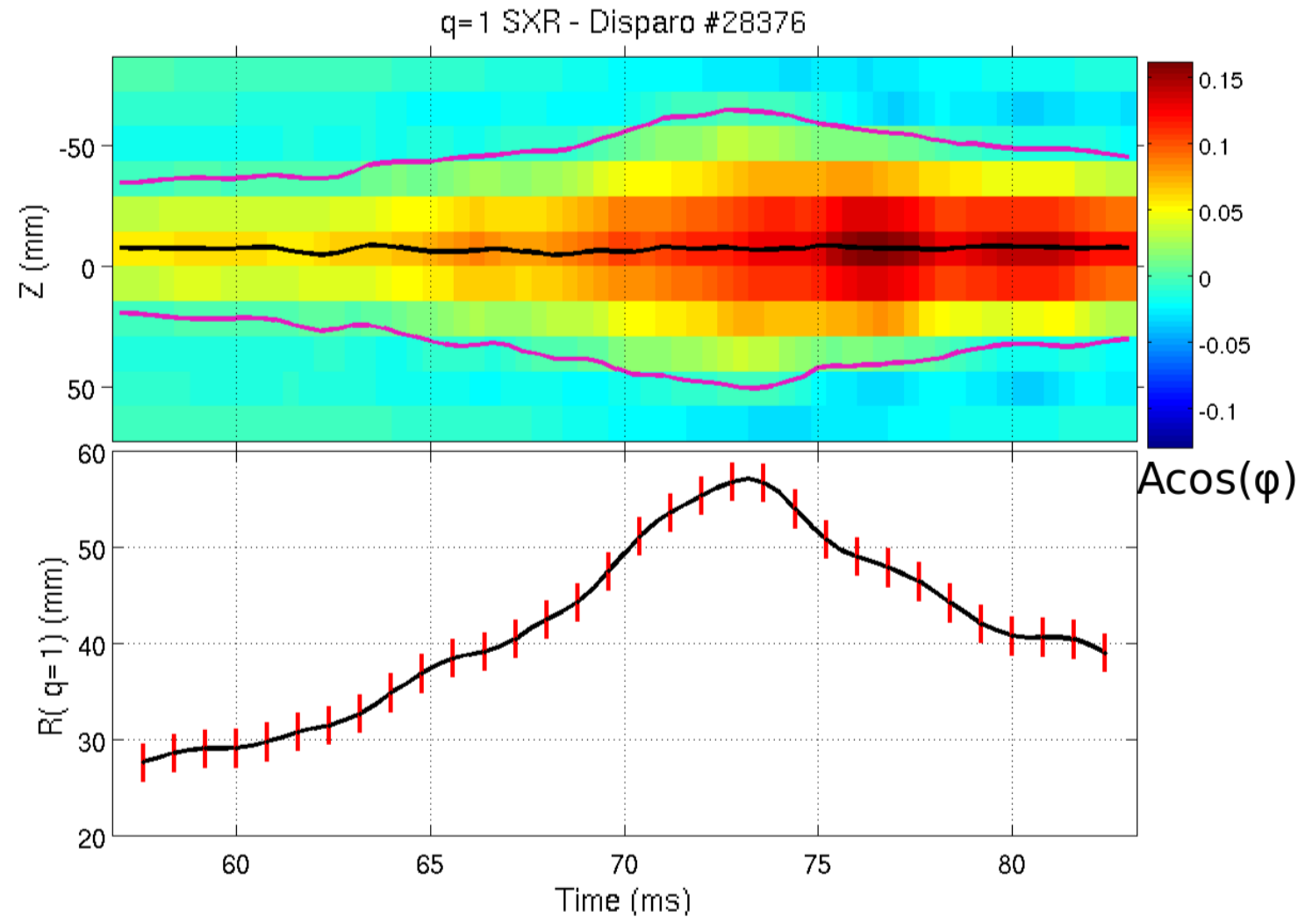

Figura 2.15: Análise da localização da superfície $q=1$ com o uso do sinal do raio$X$ mole, para o disparo \#28376. A escala de cores representa a amplitude do sinal multiplicado pelo cosseno da diferença de fase em relação ao canal central.

\subsection{Reflectometro}

Para fazer medidas auxiliares, durante os experimentos, do perfil de densidade eletrônica do plasma, temos disponível no TCABR um reflectômetro $[54,55]$. O princípio de funcionamento do reflectômetro é o mesmo de um radar. Uma onda eletromag- 
nética, na faixa de micro-ondas, é emitida pelo corneto de uma antena e refletida no plasma na superfície em que a frequência da onda é igual a frequência de plasma $\left(f_{p e}(r)=\sqrt{\frac{e^{2} n_{e}(r)}{\pi m_{e}}}\right)$, esquematicamente mostrado na figura 2.16. A onda refletida é captada por uma segunda antena e, com o uso de um comparador, podemos determinar a diferença de fase entre a onda transmitida e refletida. A distância do ponto de emissão até o ponto de reflexão pode ser determinada pela defasagem entre o sinal enviado com o sinal refletido. Com varredura da frequência de sondagem, é possível usar um reflectômetro para medir o perfil de densidade dos elétrons no plasma.

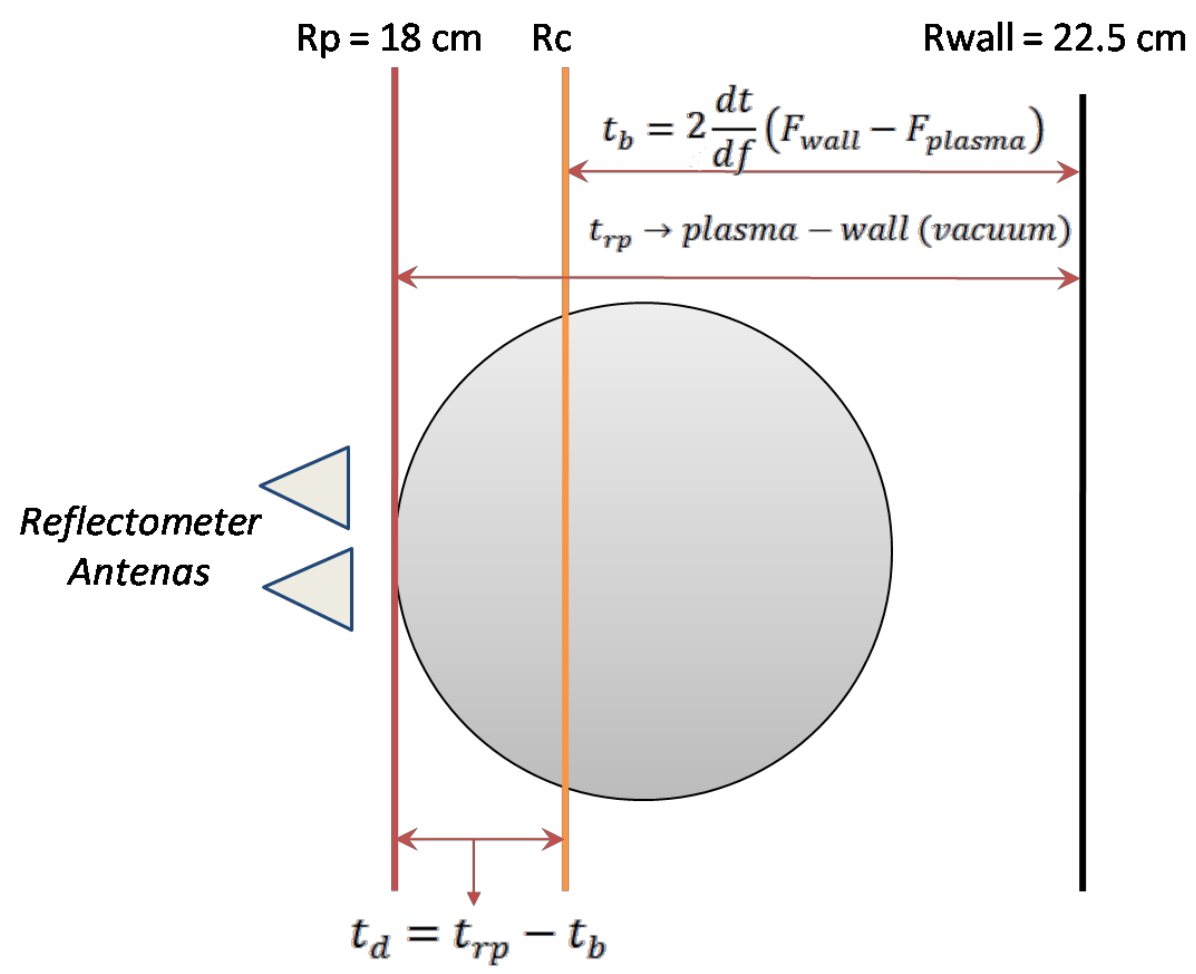

Figura 2.16: Esquema de funcionamento do reflectômetro do TCABR para determinação do tempo de voo da onda no plasma.

Para um reflectômetro do tipo $O$-mode existe reflexão quando a frequência da onda lançada é igual a frequência do plasma [54], pois o campo elétrico da onda é paralelo ao campo magnético do plasma. Há também reflectômetros de $X$-mode, que usa os campos elétricos perpendiculares a linha de campo magnética. Neste caso há uma mudança na frequência de reflexão, que depende também do campo magnético, e é possível realizar medidas na região de campo magnético mais alto ( $h i g h$ field side), $B=\frac{B_{0} R_{0}}{R_{0}+r \cos \theta}$. 
Temos disponível um reflectômetro com uma alta taxa de amostragem, de 200MS/s. A proposta deste equipamento são medidas tanto o perfil de densidade quanto das oscilações da densidade ao mesmo tempo [40], teoricamente possível devido a sua alta taxa de amostragem.

O reflectômetro opera na banda de frequência de $f=16.4-40.2 G H z$, fazendo a varredura em um tempo de no mínimo $8 \mu s$, com intervalo de $7 \mu s$ entre varreduras. Há duas bandas de funcionamento do reflectômetro, uma de $16.4-26.8 G H z$, que é de baixa frequência e chamada de banda $K$, e mede apenas a região mais externa da coluna de plasma. A outra banda vai de 24.6 - 40.2GHz, chamada de banda $K a$, e tem a possibilidade de medir a região mais interna da coluna de plasma, com densidade máxima de $n_{0} \approx 2 \times 10^{19} / \mathrm{m}^{3}$. Realmente, não trabalhamos com as frequências no limite das bandas, pois encontramos distorções, assim ignoramos aproximadamente $2 G H z$ das bordas das bandas.

O reflectômetro trabalha de modo homodino, ou seja, detectamos a amplitude da onda refletida multiplicada pelo cosseno da diferença de fase entre as ondas emitidas e refletidas. Se fosse um sistema heteródino (por quadratura), onde detectamos sinal refletido com o sinal emitido e o sinal emitido defasado de $90^{\circ}$, teríamos acesso a fase e amplitude da onda refletida diretamente. Quando fazemos uma varredura de frequência ocorre uma mudança de fase entre a onda refletida e a de referência, criando uma frequência de batimento $\left(f_{b}\right)$ na diferença de fase. Essa frequência de batimento é proporcional a velocidade de varredura e a posição da reflexão da onda, sendo dada por

$$
f_{b}=\frac{d f}{d t} \tau_{v o o}
$$

onde $f$ a frequência de sondagem do reflectômetro e $\tau_{v o o}$ o tempo de voo da onda sair e voltar para a antena. Considerando que a variação da frequência de sondagem no tempo é constante, permite que escrevamos 


$$
\frac{d f}{d t}=\frac{\Delta f}{\Delta t} \rightarrow \tau_{\text {voo }}=\frac{\Delta t}{\Delta f} f_{b}
$$

Tornando simples a relação da frequência de batimento com o tempo de voo. Essa aproximação de linearidade na variação da frequência, apesar de satisfatória, não deve representar o caso real. Possíveis erros na determinação do tempo de voo podem ser atribuídos a essa aproximação.

No esquema presente na figura 2.16 é mostrado como se determina o tempo de voo no TCABR. Para a determinação do tempo de voo é preciso definir um ponto de referência. No nosso caso, usamos a parede do TCABR, já que a distância entre a antena do reflectômetro e a parede do vaso é conhecida.

Acompanhando a figura 2.16, vemos que, uma vez que já tenha sido determinada a frequência de batimento na parede do vaso $\left(F_{\text {wall }}\right)$ e no plasma $\left(F_{\text {plasma }}\right)$, com a diferença entre as frequências podemos obter o tempo de voo entre a parede e a superfície de reflexão no plasma $\left(t_{b}\right)$. Porém o valor desse tempo de voo não é de interesse. O interesse é obter o tempo de voo da borda do plasma até a superfície de reflexão. Supondo que o raio do plasma é de $18 \mathrm{~cm}$ e com os dados sobre a geometria da câmara de vácuo, podemos transferir a origem da parede para a borda do plasma. Desse modo, obtemos o tempo de atraso $t_{d}$ (time delay), que é de interesse para a análise dos dados do reflectômetro.

Para obtermos a frequência de batimento fazemos um espectrograma dos dados obtidos pelo reflectômetro. Encontramos a amplitude máxima do espectrograma, que corresponde a frequência de batimento, como pode ser visto, para a reflexão na parede do vaso no vácuo, na figura 2.17. Para construir a figura 2.17 foi feita uma média de 100 varreduras. Nessa figura apresentamos a frequência de batimento para as bandas $K$ e $K a$. Podemos ver que, mesmo no vácuo, o sinal é muito ruidoso e apresenta bandas referentes a reflexões secundárias e batimento entre as ondas. Porém, na maioria dos casos podemos determinar a frequência de batimento sem problema.

Na figura 2.17, vemos que a frequência de batimento das duas bandas distintas é 


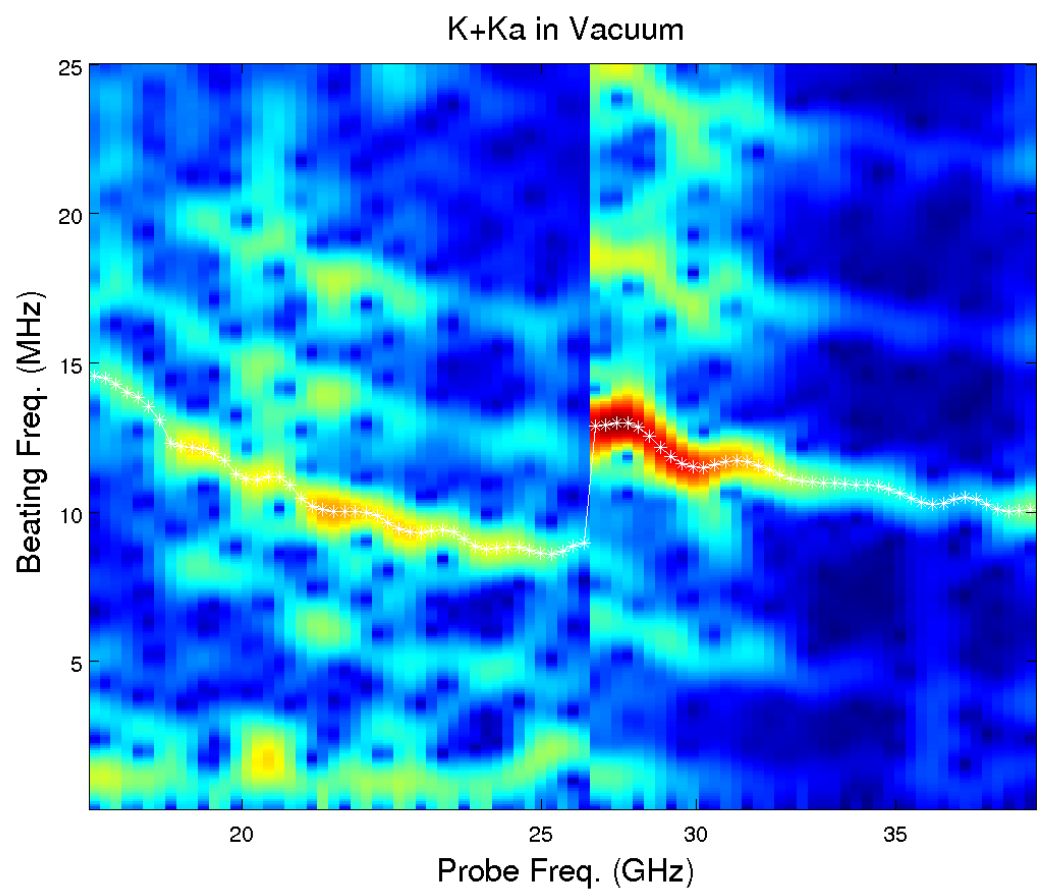

Figura 2.17: Espectrograma das bandas $K$ e $K a$ quando refletidas na parede do vaso do TCABR, para o disparo \#30407.

diferente. Isso se deve a diferença entre a taxa de variação da frequência, como vemos na (eq. 2.9). A diferença da frequência mínima para a máxima é de $8.4 G H z$ para a banda $\mathrm{K}$ e de $12.6 \mathrm{GHz}$ para a banda Ka. Porém, como o tempo de varredura é o mesmo para as duas bandas, temos uma diferença no tempo de voo.

Observamos também, que a frequência de batimento muda com a frequência. Essa característica, a primeira vista, é estranha, pois estamos medindo a frequência de batimento em um ponto fixo no vácuo, temos o mesmo tempo de voo. A mudança na frequência de batimento é explicada por dispersões nos guias de onda do reflectômetro. A velocidade de grupo de uma onda eletromagnética de frequência $f$ se propagando dentro de um guia de onda retangular é da forma [56]

$$
v_{g}=c \sqrt{1-\frac{f_{c u t}^{2}}{f^{2}}}
$$

Com $f_{\text {cut }}$ a frequência de corte inferior, dada pela geometria do guia de onda. $\mathrm{O}$ tempo de atraso na linha, para uma onde de frequência $f$ e um guia de comprimento 
$L$

$$
t_{g}=\frac{L}{v_{g}}
$$

Supondo $f \gg f_{c u t}$, ou seja, estamos trabalhando longe da frequência de corte inferior, tomando $a=f / f_{\text {cut }}$ e expandindo em série de Taylor até segunda ordem, com $a \rightarrow \infty$, obtemos

$$
\frac{1}{\sqrt{1-\frac{1}{a^{2}}}}=C_{0}+C_{1} \frac{1}{a^{2}}+C_{2} \frac{1}{a^{4}}
$$

Pela (eq. 2.8) a frequência de batimento pode ser dada da forma

$$
f_{b_{W a l l}}=A_{0}+\frac{A_{1}}{f^{2}}+\frac{A_{1}}{f^{4}}
$$

Com os coeficientes $A_{i}$ determinados com um ajuste aos dados obtidos.
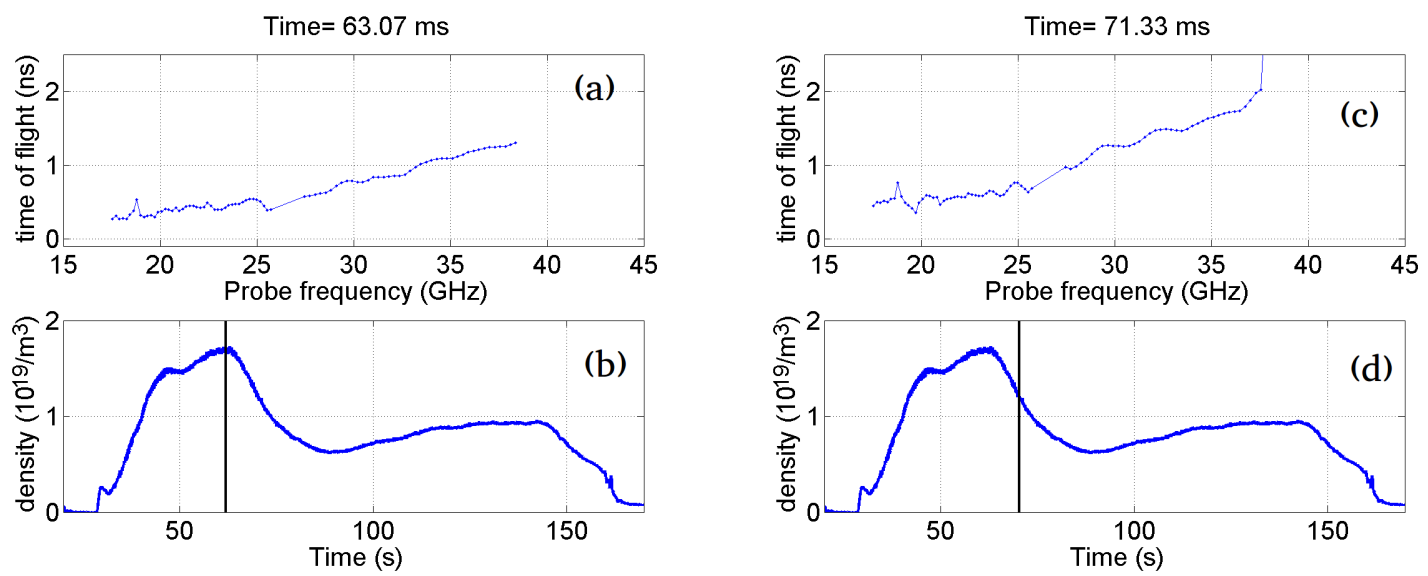

Figura 2.18: Medida do tempo de vôo $\left(t_{d}\right)$ entre a antena e o plasma, para os momentos $T=63.07 \mathrm{~ms}$ (a) e $T=71.33 \mathrm{~ms}$ (c) para o disparo \# 3040\%. Comparado com a densidade do plasma (b) e (d).

Para fazer a subtração da frequência de batimento entre a parede e o plasma usamos os dados brutos, e não a (eq. 2.13). A subtração é feita dessa forma para levar em conta possíveis mudanças na taxa de variação da frequência e irregularidades no reflectômetro.

O tempo de voo da onda no plasma é apresentado na figura 2.18 (a) e (c) para o disparo \#30407. Esse disparo é interessante pois há uma alta taxa de variação na 
densidade e podemos ver mudanças no tempo de voo com a variação da frequência de sondagem. Quanto maior a densidade, menor deve ser o tempo de voo, pois a onda é refletida mais perto da antena.

Após obtermos o tempo de voo, temos que descrever a mudança de fase dentro do plasma, para podermos relacionar o tempo de voo com a densidade dos elétrons. Para o reflectômetro do TCABR, que opera em modo $O$, a defasagem de uma onda com a frequência de sondagem $f$ é

$$
\phi(t)=\frac{4 \pi f(t)}{c} \int_{r_{c}}^{a} \sqrt{1-\frac{f_{p e}^{2}(r)}{f^{2}}} d r-\pi
$$

sendo $f_{p e}(r)=\sqrt{\frac{e^{2} n_{e}(r)}{\pi m_{e}}}$ a frequência de plasma dos elétrons no raio $r, r_{c}$ é o raio em que a frequência do plasma é igual a frequência de sondagem $\left(f=f_{p e}\left(r_{c}\right)\right)$, onde ocorre a reflexão da onda e $a$ o raio do plasma.

O tempo de atraso de grupo $\left(\tau_{d}\right)$, o tempo de voo, pode ser obtido por

$$
\tau_{d}(f)=\frac{d \phi}{d \omega}=\frac{2 f}{c} \int_{r_{c}}^{a} \frac{1}{\sqrt{f^{2}-f_{p e}^{2}(r)}} d r
$$

Como na reflectometria temos interesse na reconstrução do perfil de densidade do plasma, aplicamos uma inversão de Abel na (eq. 2.15). Obtemos a posição de reflexão em relação a frequência de sondagem, que é equivalente a densidade do plasma

$$
a-r_{c}\left(f_{c}\right)=\frac{c}{\pi} \int_{0}^{f_{c}} \frac{\tau(f)}{\sqrt{f_{c}^{2}-f^{2}}} d f
$$

onde $f_{c}$ é a frequência de corte, ou a frequência em que houve reflexão no plasma.

Com a (eq. 2.16) é possível reconstruir, a partir dos dados obtidos com o reflectômetro, o perfil de densidade do plasma. Porém, este método é complicado e foi preferível uma análise com um perfil de densidade simplificado, usando só o tempo de atraso (eq. 2.15). Por exemplo, podemos supor um perfil de densidade como na (eq. 2.1) e ajustar os parâmetros $\alpha$ e $n_{0}$ de modo que melhor representem o tempo de voo obtido 
Capítulo 2. Os equipamentos usados para o sistema de diagnóstico de 54

Alfvén

experimentalmente. Essa análise mostrou resultados mais robustos e são importantes para a discussão dos resultados obtidos com a excitação de ondas da Alfvén. 


\section{Capítulo 3}

\section{Experimentos de excitação de ondas globais de Alfvén}

Neste capítulo apresentamos os resultados experimentais sobre a excitação de ondas Globais de Alfvén (GAE). Primeiro, apresentaremos os resultados que foram obtidos com o uso de um único strap da antena. Depois apresentaremos os resultados obtidos com um par de straps, um de cada módulo de antena, localizados em posições toroidalmente opostas, para a identificação da paridade dos modos excitados. Para estudar as GAE no TCABR foram realizados dois tipos diferentes de disparos. Um deles com densidade de plasma variável e a frequência da corrente de RF constante; o outro com densidade razoavelmente constante e a corrente de RF com frequência variável, formando rampas de frequência. As ressonâncias identificadas com ambos os métodos apresentam concordância e os mesmos comportamentos.

Inicialmente apresentamos a comparação de dois tipos diferentes de disparos. Depois mostramos um gráfico classificando todas as ressonâncias obtidas em relação a densidade. Identificamos diferentes ressonâncias, correspondendo a diferentes números de onda $N$ (toroidal) e/ou $M$ (poloidal) dos automodos de Alfvén.

A corrente de RF permanece na antena por $\approx 20 \mathrm{~ms}$, e somente ativamos o sistema de excitação de ondas de Alfvén no plateau de densidade do plasma. A duração de um disparo é de $\approx 120-160 m s$ e comumente trabalhamos no intervalo de tempo de $60-90 m s$. 


\subsection{Método de análise dos sinais}

Para começar descrevemos a metodologia de análise dos sinais da sonda magnética e da corrente de RF. As características gerais da análise dos sinais do sistema de RF estão apresentadas na figura 3.1. Nesta figura, mostramos a análise do sinal da corrente de RF na antena para o disparo \#30010.

\section{Método de análise dos sinais}
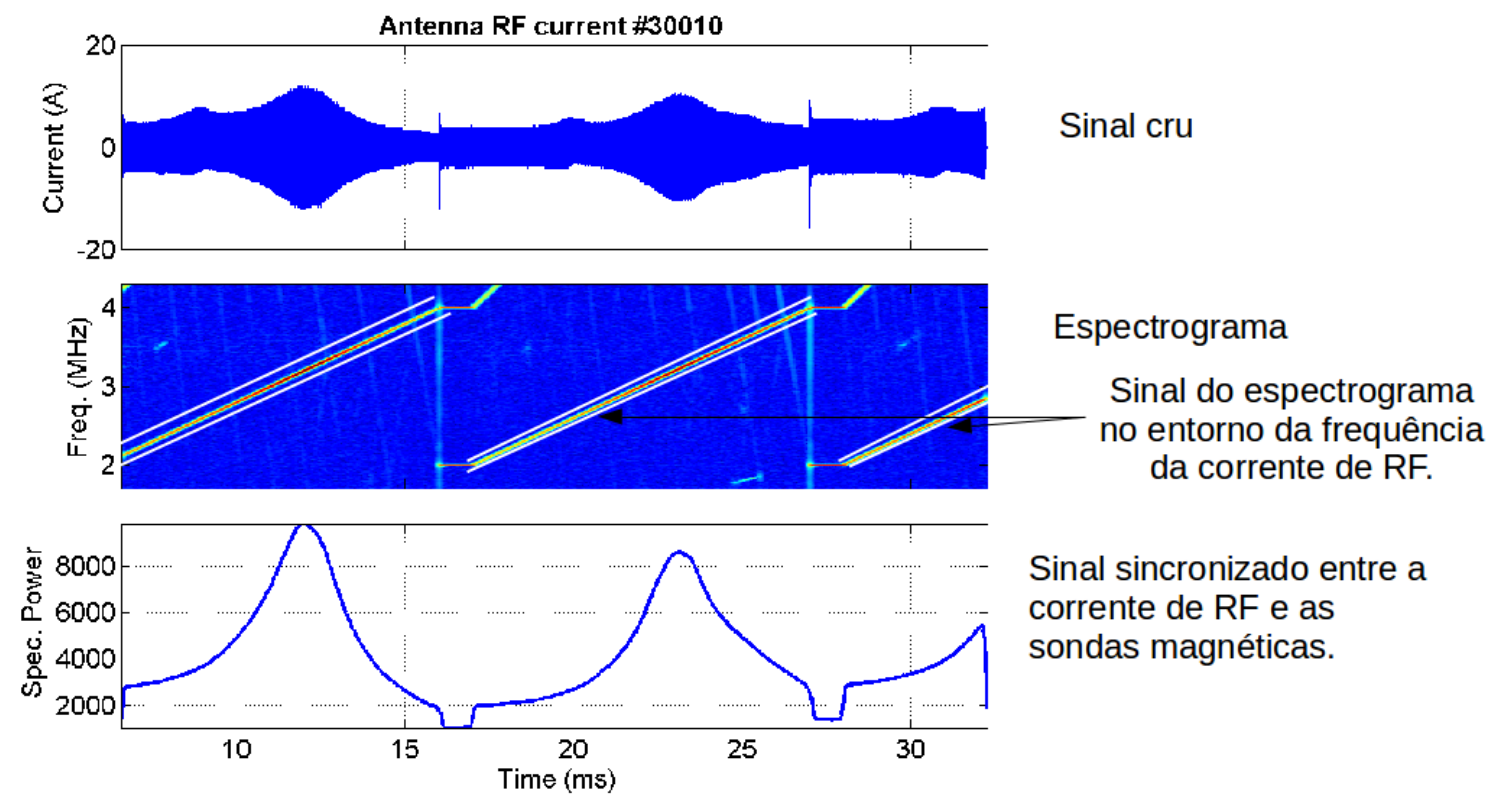

Figura 3.1: Exemplo do método de análise dos sinais de RF. Temos no caso a corrente de RF para o disparo \#30010.

Primeiramente, fazemos um espectrograma de cada um dos sinais. Dado o espectrograma, para cada instante de tempo identificamos a frequência com maior amplitude espectral no sinal da corrente de RF. Essa frequência corresponde a frequência da corrente de RF em cada instante.

Uma vez identificada a frequência, coletamos a potência espectral para cada instante de tempo, tanto no espectrograma da sonda magnética como no da corrente de RF. Para coletar esses valores, fazemos uma janela em frequência de $\approx 10 \mathrm{KHz}$ e somamos o espectro de potência para cada frequência dentro dessa janela.

Por fim, dividimos a potência espectral da sonda magnética pela da corrente de RF, 
já que a dependência com a corrente é linear devido a pequena amplitude de oscilação

do plasma. Na apresentação do sinal da sonda magnética nas próximas seções normalizamos o seu sinal pelo seu valor máximo, isso é feito puramente por conveniência, e temos uma valor que varia de $0-1$.

\subsection{Ressonância da onda de Alfvén induzida por campo RF com varredura de frequência}

Neste método de detecção das ressonâncias tentamos manter a densidade do plasma com pequenas variações no tempo, e no mesmo momento fazemos uma varredura na frequência do campo de RF. Quando dizemos que a densidade tem pouca variação, significa que é uma variação menor que a variação da frequência da corrente de $R F$ $\frac{1}{n} \frac{d n}{d t} \ll \frac{1}{f} \frac{d f}{d t}$.

Com este método, podemos excitar múltiplas ressonâncias em um mesmo disparo devido as possibilidades do amplificador de RF. Como cada pulso de RF dura aproximadamente $25 \mathrm{~ms}$ e podemos fazer uma varredura na faixa de frequência de $1.5-4.5 \mathrm{MHz}$ em um tempo menor que $10 \mathrm{~ms}$, podemos realizar mais de uma varredura na frequência durante um único disparo de RF. A maioria das ressonâncias apresentadas na figura 3.9 foram identificadas com esse método. O valores da duração de cada varredura e a faixa de frequência são ajustáveis e dependem exclusivamente do gerador de sinais.

\subsubsection{Análise do sinal das sondas magnéticas em um disparo com densidade estável}

Para ilustrar a identificação de ressonâncias com esse método, usamos o disparo \#29589. Os parâmetros do plasma deste disparo, densidade de linha, emissão de raio$\mathrm{X}$ mole, bolômetro e raio-X duro, corrente de plasma, voltagem de loop, posição vertical e horizontal e oscilações magnéticas estão apresentados na figura 3.2. A densidade de elétrons, a corrente de plasma, a voltagem de loop e a posição variam pouco para esse disparo, quando comparada com a taxa de variação da frequência da corrente de RF na antena. 
Os sinas da análise dos dados das sondas magnéticas são apresentados na figura 3.3, onde podemos ver que há mais de uma varredura de frequência, cada varredura com duração de $10 m s$ e de $2-4 M H z$. Foram identificadas sete ressonâncias. Cada ressonância identificada está em destaque com círculos no sinal da sonda magnética. Os picos que tratam da ressonância estão marcados com diferentes linhas. As diferentes ressonâncias, identificadas em uma mesma varredura, se referem a diferentes números de onda dos GAEs excitados.

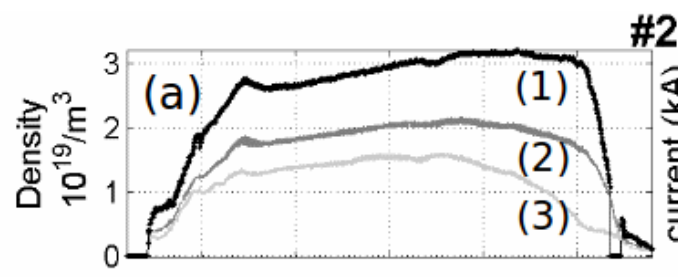

\#29589
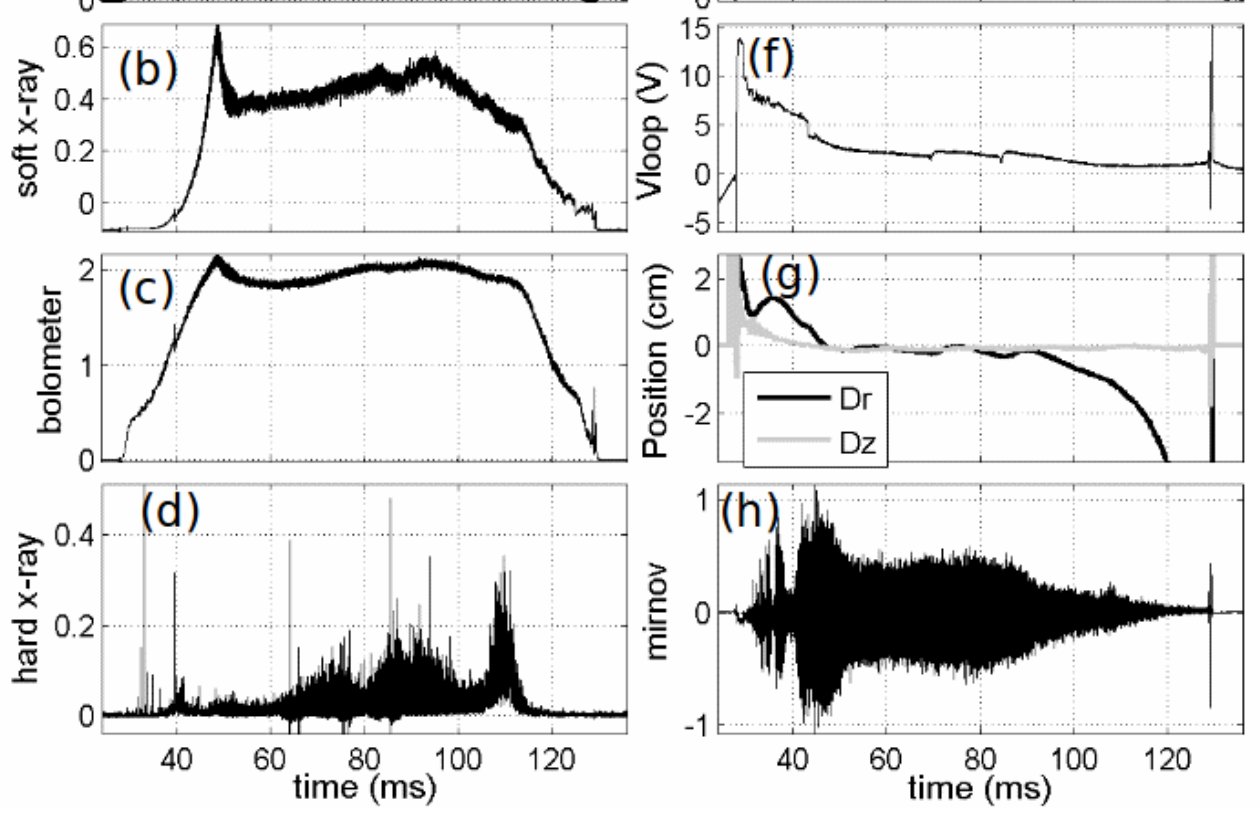

Figura 3.2: Evolução temporal dos principais parâmetros do plasma para o disparo \#29589. Os sinais apresentados são densidade de linha (a), onde a curva mais alta é a densidade calculado no centro (a1), densidade de linha do interferômetro nos raios $-1.25 \mathrm{~cm}$ (a2) e $9.25 \mathrm{~cm}$ (a3), emissão de raio-X mole do centro (b), sinal do bolômetro do centro (c), sinal de raio-X duro (d), corrente de plasma (e), voltagem de loop ( $f$ ), posição vertical e horizontal ( $g$ ), e oscilações magnéticas (h).

A identificação das ressonâncias nos sinais se dá, tanto pelos picos na figura 3.3, como por mudanças de fase abruptas entre a corrente de RF e o sinal da sonda magnética, ou entre os sinais das duas sondas magnéticas. No disparo \#29589 os picos já 


\subsection{Ressonância da onda de Alfvén induzida por campo RF com varredura}

de frequência

são suficientes para identificar as ressonâncias. Como foi mencionado na seção 2.2, não conseguimos identificar o modo toroidal com a defasagem entre o sinal das duas sondas magnéticas. Na figura 3.3 mostramos apenas o sinal de uma das sondas, já que o sinal da outra sonda não apresenta informação extra.

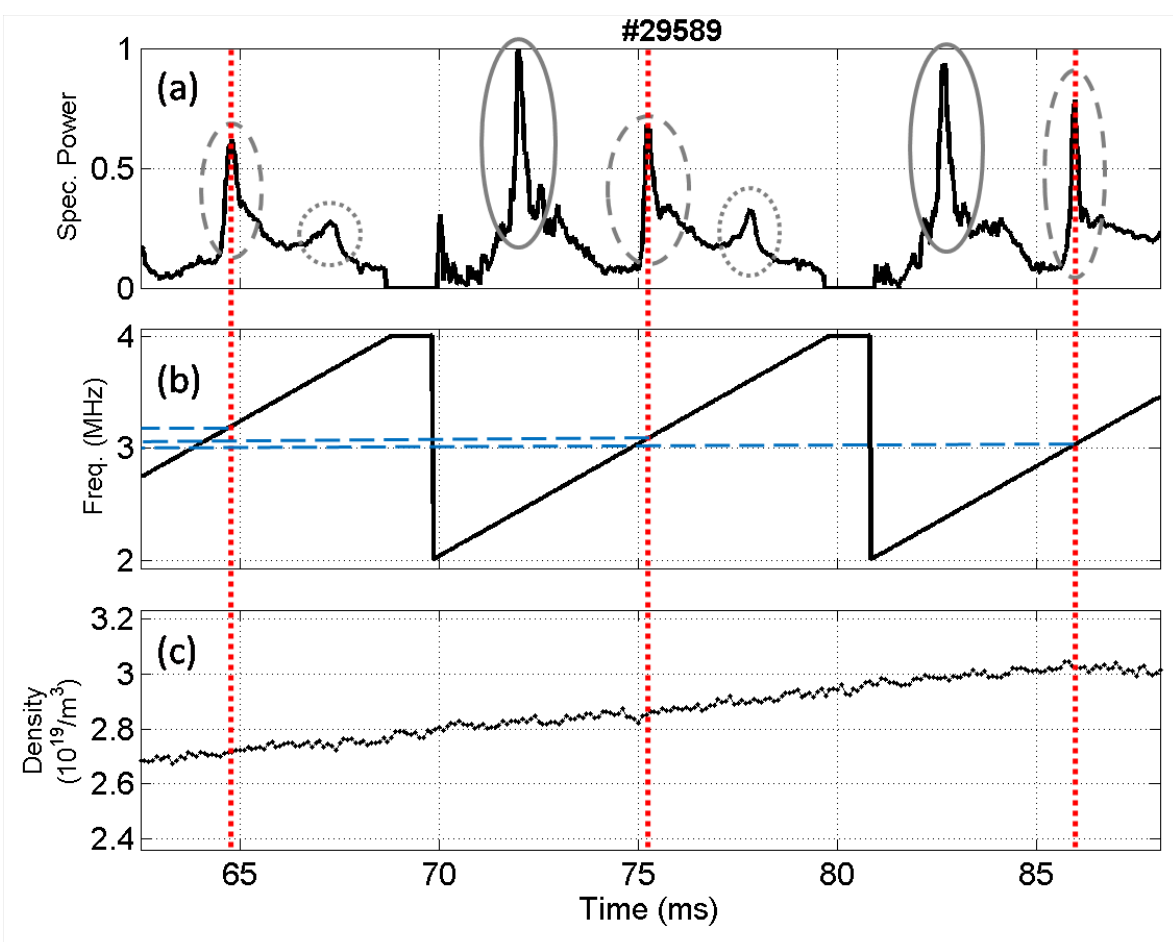

Figura 3.3: Evolução temporal da potência espectral (a) do sinal da sonda magnética, normalizado pela amplitude da corrente de $R F$, em comparação com as varreduras de frequência (b) da corrente de RF e a densidade de elétrons no centro do plasma (c), para o disparo \#29589.

Ainda na figura 3.3, podemos observar a dependência da frequência de ressonância com a densidade do plasma, indicado pelas linhas tracejadas vermelhas e azuis. Porém, como há uma pequena variação na densidade, a variação na frequência também é pequena. Como podemos ver, conforme há o aumento da densidade, ocorre uma diminuição na frequência de ressonância, como esperado pela (eq. 1.16) do contínuo de Alfvén. A seguir apresentamos um disparo onde há uma variação maior na densidade e, consequentemente, uma maior variação na frequência de ressonância. 


\subsubsection{Análise do sinal das sondas magnéticas em um disparo com forte variação da densidade}

Um estudo sobre disrupções estava em curso no TCABR quando foi realizado o disparo \#30044, cujos parâmetros do plasma estão apresentados na figura 3.4. Podemos ver que há uma grande variação na densidade do plasma, essa grande variação leva a disrupção do plasma, que foi omitida na figura 3.4 .
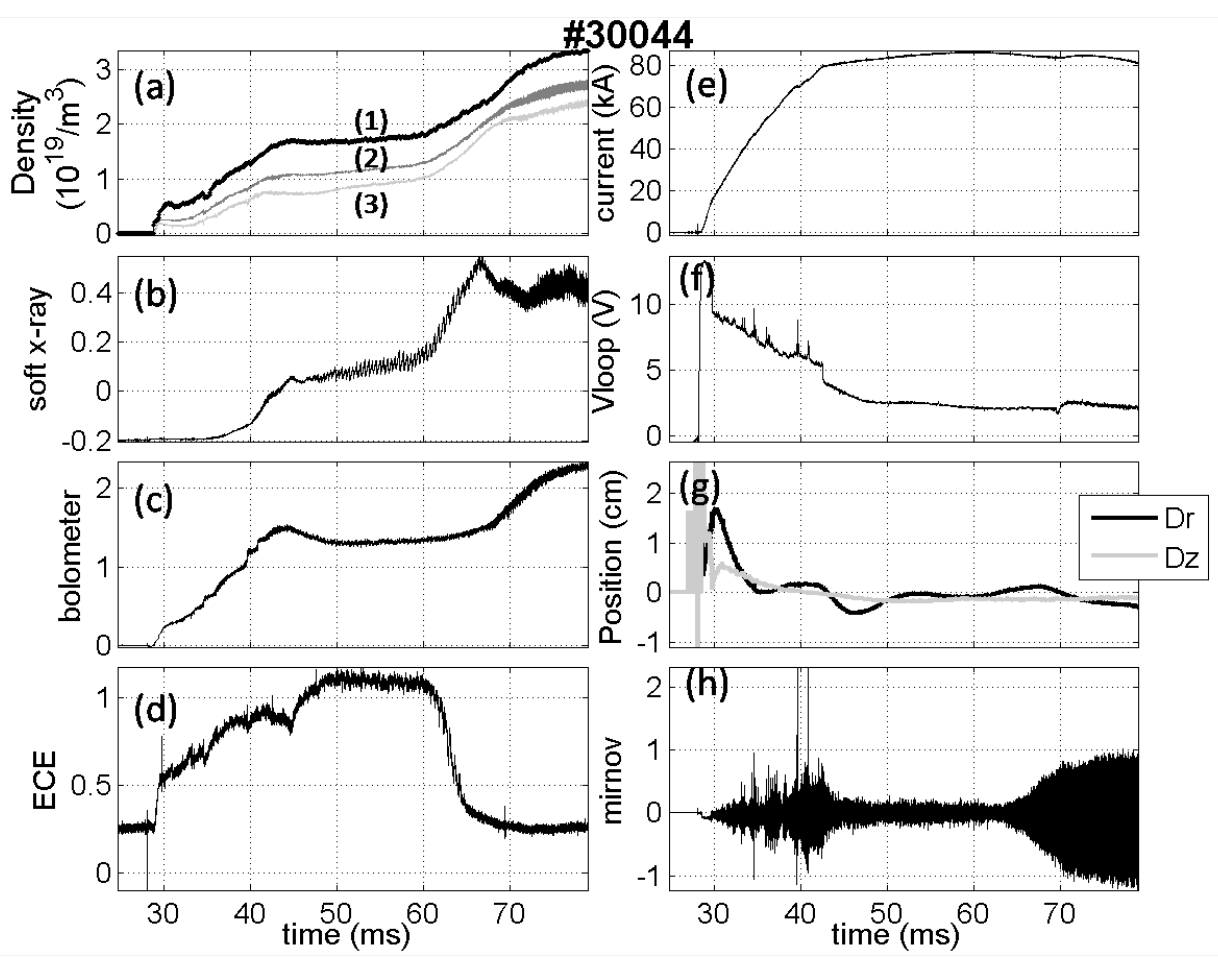

Figura 3.4: Evolução temporal dos principais parâmetros do plasma para o disparo \#30044. Os sinais apresentados são densidade de linha (a), onde a curva mais alta é a densidade calculado no centro (a1), densidade de linha do interferômetro nos raios $-1.25 \mathrm{~cm}$ (a2) e $9.25 \mathrm{~cm}$ (a3), emissão de raio-X mole do centro (b), sinal do bolômetro do centro (c), emissão do ECE (d), corrente de plasma (e), voltagem de loop (f), posição vertical e horizontal (g), e oscilações magnéticas (h). O sinal do ECE diminui, pois a densidade está acima do corte.

O sistema de excitação de ondas de Alfvén foi ligado neste disparo entre 60 - $80 \mathrm{~ms}$. Como utiliza uma baixa potência, não causa perturbação no plasma e pode ser usado em qualquer disparo.

Como podemos observar, antes da disrupção o plasma tem comportamento normal. Devido a grande variação de densidade, podemos detectar a mudança da frequência 
de ressonância. Este comportamento faz deste disparo um bom exemplo do comportamento dos GAE no TCABR. Podemos notar também, que a amplitude do sinal ressonante aumenta com densidade do plasma.

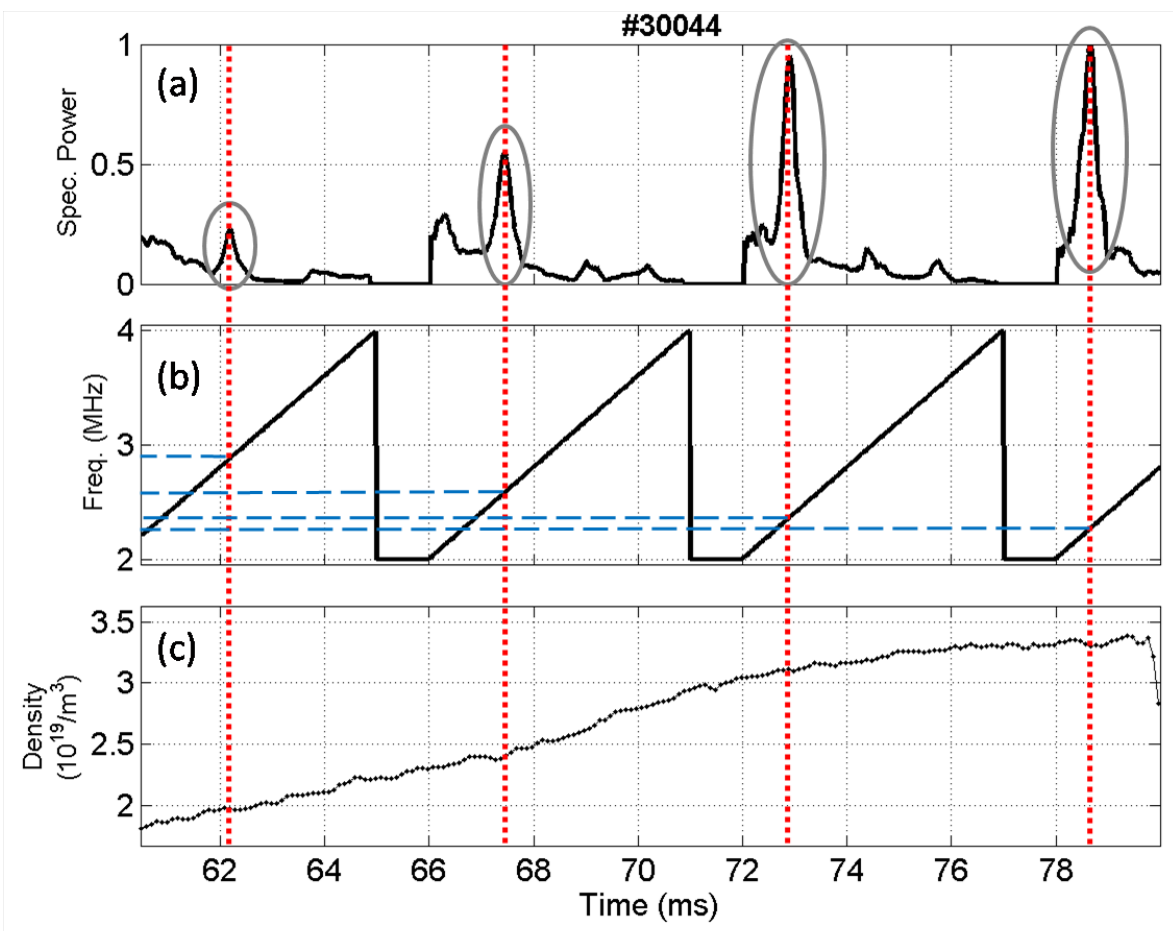

Figura 3.5: Evolução temporal da potência espectral (a) do sinal da sonda magnética, normalizado pela amplitude da corrente de $R F$, em comparação com as varreduras de frequência (b) da corrente de RF e a densidade de elétrons no centro do plasma (c), para o disparo \#30044.

Os sinais relevantes para a análise da excitação de ondas de Alfvén são apresentados na figura 3.5. O método de análise dos sinais é o mesmo da seção anterior. Vemos que, neste disparo, o sinal da sonda magnética apresenta um forte pico na frequência de ressonância, que estão realçados com círculos cinzas.

Como na figura 3.3, marcamos com linhas tracejadas vermelhas e azuis a densidade e frequência em que ocorrem as ressonâncias, respectivamente, para facilitar a comparação. Acompanhando as marcações vemos a dependência da densidade com a frequência de maneira mais clara e pronunciada que na figura 3.3. Havendo uma mudança considerável no valor da frequência de ressonância.

A mudança da frequência de ressonância é inversamente proporcional ao aumento 
da densidade, ou seja, a frequência diminui conforme temos um aumento da densidade, como mostra a (eq. 1.16) do contínuo de Alfvén. Esse comportamento é o mesmo que o observado no disparo \#29589.

\subsection{Ressonância do ondas de Alfvén com frequên- cia de RF fixa em um plasma com rampa de densidade}

Nos experimentos de excitação de ondas de Alfvén com a corrente de RF em frequência fixa, variamos a densidade para encontrar a condição ressonante. Sendo assim, fazemos disparos com uma rampa de densidade.

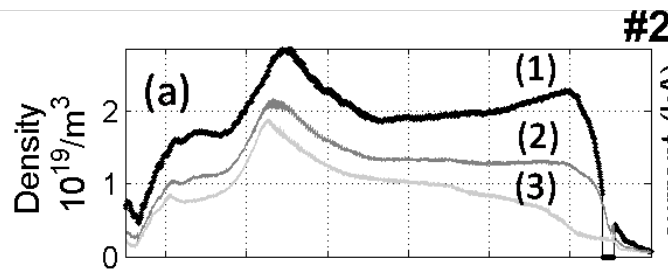

\#29565
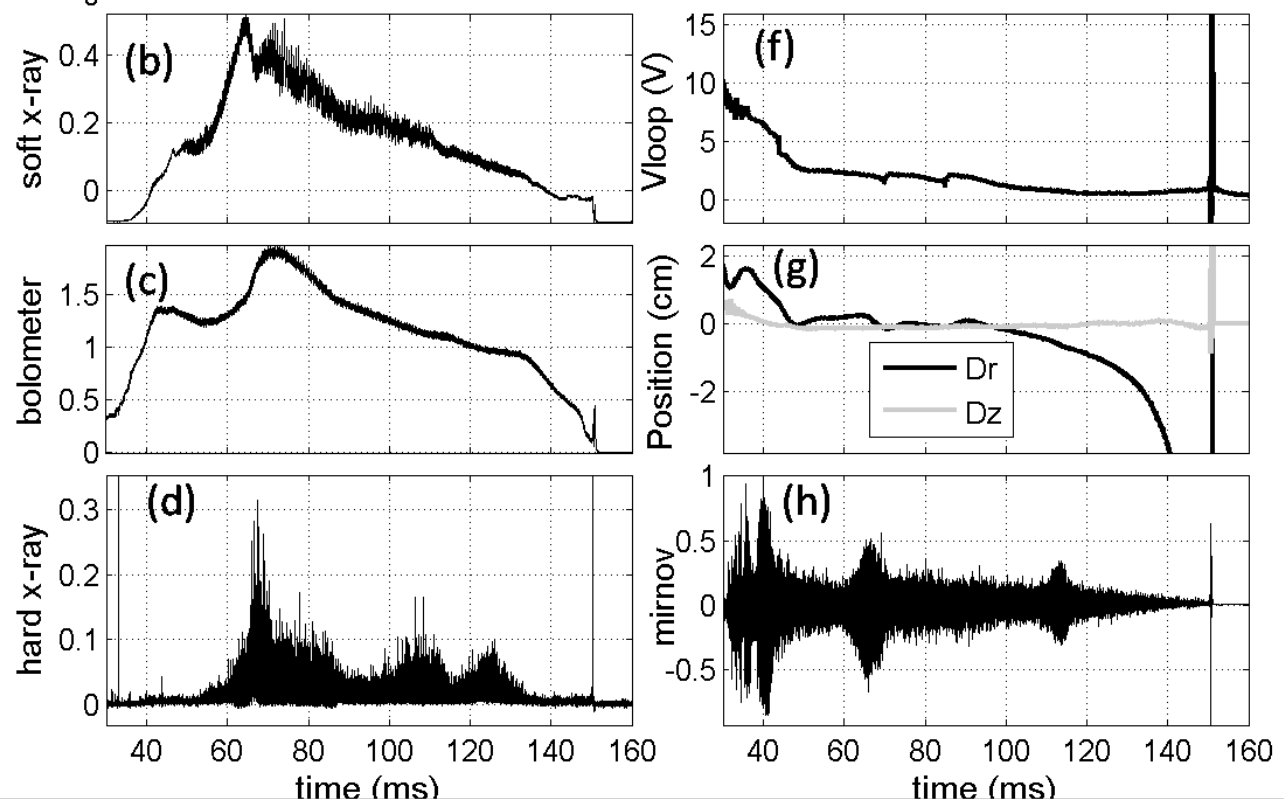

Figura 3.6: Evolução temporal dos principais parâmetros do plasma para o disparo \#29565. Os sinais apresentados são densidade de linha (a), onde a curva mais alta é a densidade calculada no centro (a1), densidade de linha do interferômetro nos raios $-1.25 \mathrm{~cm}$ (a2) e $9.25 \mathrm{~cm}$ (a3), emissão de raio-X mole do centro (b), sinal do bolômetro do centro (c), sinal de raio-X duro (d), corrente de plasma (e), voltagem de loop (f), posição vertical e horizontal (g), e oscilações magnéticas (h). A rampa na densidade é devida a injeção de gás no plasma $t=50-60 \mathrm{~ms}$. 


\subsection{Ressonância do ondas de Alfvén com frequência de RF fixa em um}

plasma com rampa de densidade

Para criar a rampa de densidade executamos uma injeção de gás, adicional, durante o plateau do plasma. O gás injetado causa um aumento na densidade do plasma. Usaremos como exemplo o disparo \#29565. Nesse disparo a injeção de gás ocorre em $\sim 55 \mathrm{~ms}$ e observamos o consequente aumento na densidade, como pode ser visto na figura 3.6. Na mesma figura vemos os outros parâmetros do plasma. A mudança na densidade estimada no centro não acompanha exatamente a densidade de linha, há uma mudança no perfil de densidade, como apresentado na figura 2.13.

A vantajem do método com frequência de RF fixa, é que podemos fazer uma análise espectral mais detalhada. Como a frequência é fixa, podemos usar janelas de tamanho maior para a transformada de Fourier, do que as usadas em disparo com varredura na frequência. Fora isso, podemos observar detalhes da excitação das GAEs, já que o plasma permanece mais tempo na condição ressonante.

\subsubsection{O efeito da oscilação dente de serra nas ressonâncias de Alfvén}

O efeito das oscilações dente de serra com a ressonância de Alfvén é mostrado no disparo \#29565, como exemplo. Neste disparo o sistema de Alfvén foi ligado entre 60 -90ms. Os resultados da análise do sinal, das sondas magnéticas para este disparo, podem ser vistos na figura 3.7. Podemos observar que existem duas ressonâncias, uma na subida da rampa de densidade e outra na descida. Ambas as ressonâncias ocorrem na mesma densidade.

Uma observação interessante é que ocorre um forte efeito de oscilação na amplitude do sinal da sonda magnética, em fase com as oscilações dente de serra. O dente de serra é uma instabilidade kink, que ocorrem em disparos Ôhmicos quando o fator de segurança é menor que um no centro do plasma $\left(q_{0}<1\right)$. A oscilação de amplitude ocorre durante a ressonância de Alfvén, na densidade. As oscilações dente-de-serra são visíveis no sinal do raio-X mole e podemos comparar esse sinal com o comportamento do sinal da sondas magnética. A mudança de amplitude no sinal da sonda magnética é apresentado em mais detalhe na parte em zoom da figura 3.7, destacando a coincidência de fase entre os 
sinais com linhas verticais. A inversão de fase entre os sinais apresentados é destacada por uma linha vertical contínua.

A oscilação de amplitude, observada no sinal da sonda magnética, é atribuída a mudanças na concentração de impurezas e densidade na parte central do plasma. Durante a rampa de subida da oscilação dente de serra [57] ocorre um aumento na concentração de impurezas e densidade. Já no crash do dente-de-serra essas quantidades tem seus valores diminuídos. O sinal da sonda magnética detecta uma mudança de amplitude conforme a variação dos parâmetros do plasma o aproxima ou o afasta da condição de ressonância do GAE. A inversão de fase, entre o sinal da sonda magnética e as oscilações dente-de-serra, indica a exata condição para a ressonância do GAE.

Neste disparo específico, a superfície $q=1$ está no raio de $4 \mathrm{~cm}$ durante o momento da ressonância. Dada a inversão na fase entre os sinais, podemos dizer que a ressonância se encontra dentro do raio $q=1$. Acompanhando a figura 3.7 vemos que os sinais começam com a fase oposta durante a rampa de descida da densidade. Como estamos com a densidade diminuindo, temos a condição ressonante, inicialmente, em uma densidade menor. Conforme há um aumento da densidade ou impurezas no centro, durante a subida do dente-de-serra, temos um distanciamento da condição ressonante e o sinal da sonda magnética diminui de amplitude. Quando ocorre o crash, nos aproximamos da condição ressonante, ocorre uma diminuição da densidade ou impurezas, e o sinal da sonda magnética aumenta. Quando passamos pela ressonância o comportamento se inverte, fazendo os sinais ficarem em fase, como indicado pelas setas. Podemos concluir que o ponto exato da ressonância se dá onde há a inversão na fase da oscilação da amplitude do sinal da sonda magnética, com o sinal das oscilações dentes de serra, medidas pelo detector de raio-X mole.

Essa informação será útil para a identificação do número de onda dos modos. Como sabemos que a ressonância está localizada na parte central do plasma, isso limita nossas possibilidades de números de onda. No caso, temos dúvida se estamos lidando com o modo $M, N=(2,1) ;(1,2) ;(0,3)$, desses o modo $M, N=2,1$ se localiza fora da parte 


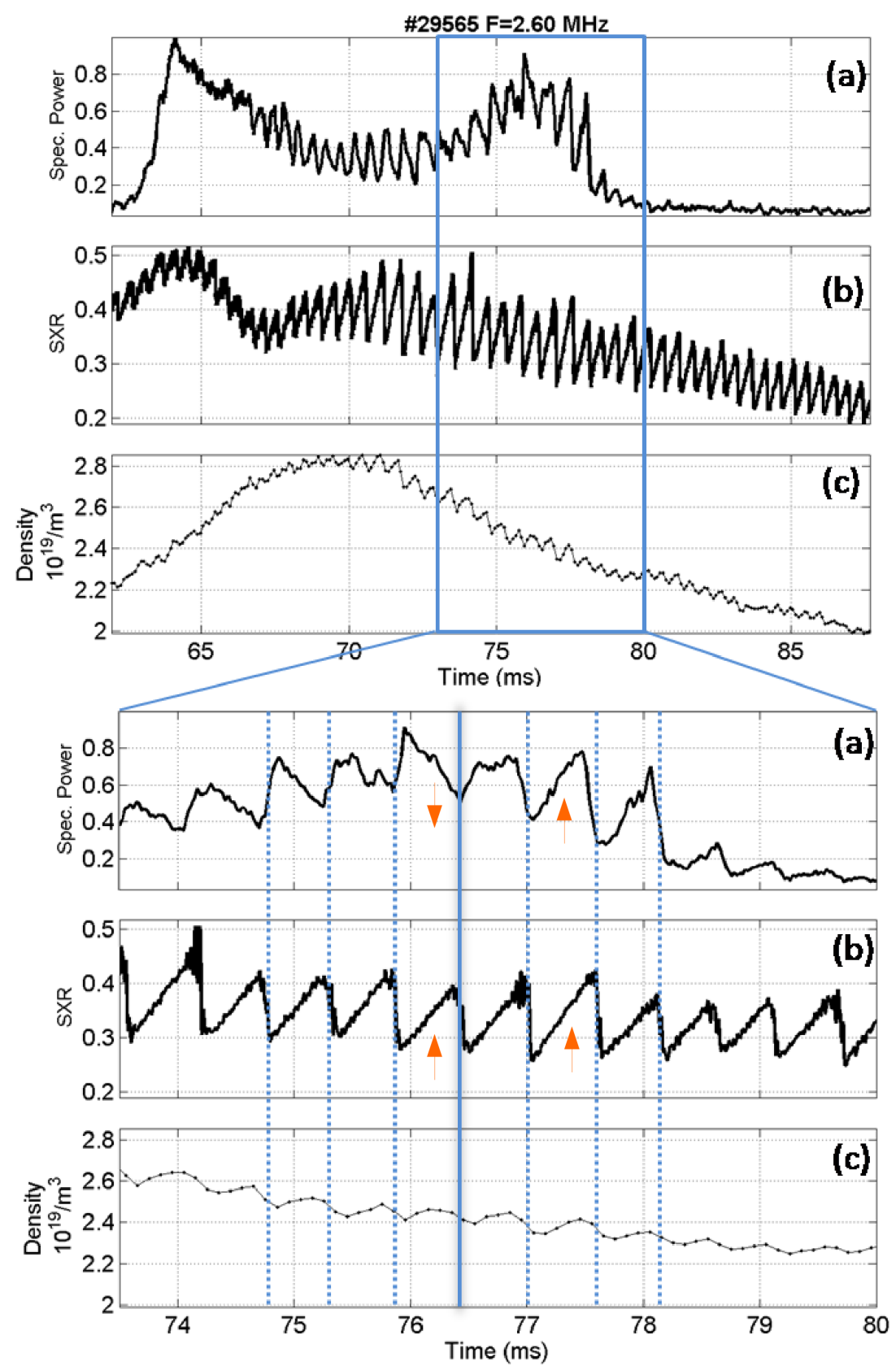

Figura 3.7: Evolução temporal da potência espectral do sinal da sonda magnética, normalizado pela amplitude da corrente de RF, com frequência fixa de $2.6 \mathrm{MHz}$ (a), comparado com o sinal da emissão de raio- $X$ mole (b) e a densidade de elétrons calculada no centro (c), para o disparo \#29565. A área em destaque é ampliada para observarmos detalhes da fase entre os sinais. As linhas sólidas e pontilhadas indicam a correlação entre a potencia espectral e o crash do dente de serra, as setas indicam a mudança de fase. 
central do plasma, e portanto pode ser descartado. Restando como candidatos os modos com os números de onda $M, N=(1,2) ;(0,3)$.
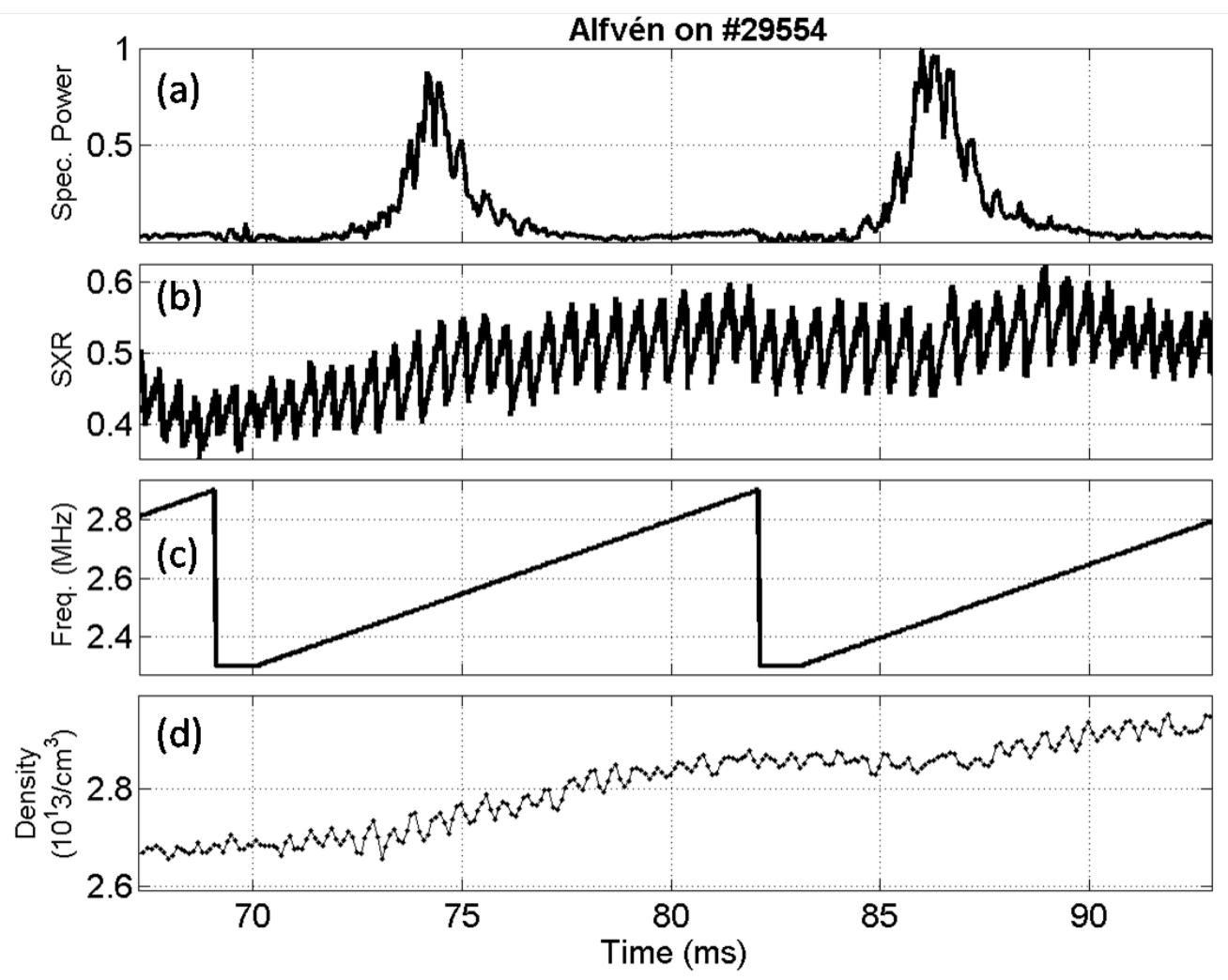

Figura 3.8: Evolução temporal da potência espectral do sinal da sonda magnética, normalizado pela amplitude da corrente de RF (a), comparado com o sinal da emissão de raio-X mole medido por um canal central (b), a frequência da corrente de $R F$ (c) e a densidade calculada no centro (d), para o disparo \#29554.

A oscilação de amplitude do sinal da sonda magnética, em conjunto com as oscilações dente-de-serra, são também observados em disparos com rampa de frequência, como o disparo \#29554, que pode ser visto na figura 3.8. Para isso precisamos fazer uma varredura de frequência lenta. Neste caso, as oscilações observadas não são tão detalhadas e não conseguimos identificar a inversão de fase. Mas, de qualquer forma, o efeito de coincidência da oscilação de amplitude entre os sinais é presente.

A falta de detalhe se deve a poucas oscilações durante a ressonância, e a rápida mudança na frequência da corrente de RF. Como a frequência das ondas de Alfvén depende do inverso da raiz da densidade, qualquer pequena mudança na frequência causa uma grande mudança no valor da densidade ressonante. Na figura 3.8 temos uma 
varredura de $600 \mathrm{kHz} / 15 \mathrm{~ms}=40 \mathrm{kHz} / \mathrm{ms}$, quando normalmente fazemos varreduras de $200 \mathrm{kHz} / \mathrm{ms}$. Apesar dessa diminuição, fica difícil analisar em detalhe a oscilação de amplitude da sonda magnética com o sinal do dente de serra e observar a inversão de fase.

\subsection{Comportamento geral das ressonâncias}

Na figura 3.9, apresentamos os dados obtidos com diversos disparos $(\approx 50)$ e os diferentes modos que foram observados no TCABR. Para caracterizar as ressonâncias fizemos um gráfico da frequência pela densidade, comparando o comportamento dos dados com a (eq. 1.16) $f \propto\left(n_{e}\right)^{-\frac{1}{2}}$.

Vemos que há quatro ramos bem distintos nessa figura. Como já foi mencionado, cada ramo corresponde a um número de onda diferente. Com a informação atual, podemos afirmar apenas o valor da soma de $|M|+|N|$ para os ramos identificados, indo de dois, para o azul, até cinco, para o rosa. Conseguimos identificar o primeiro, azul, como o modo $(\mathrm{N}=-1, \mathrm{M}=-1)$, que é o modo mais baixo que pode ser excitado. O segundo modo, verde, foi determinado com o uso de uma segunda antena, e será apresentado em detalhe no próximo capítulo. Podemos adiantar que foi identificado como o modo $(\mathrm{N}=-2, \mathrm{M}=-1)$. Os outros dois ramos são, provavelmente, ligados aos $\operatorname{modos} N / M=-3 /-1 \mathrm{e}-4 /-1$. Mas temos outras possibilidades de combinações para estes ramos, de números de onda maior, e eles não foram identificados.

Para os pontos em verde, temos dúvidas do número de onda do modo excitado, podemos ter $(\mathrm{N}=-1, \mathrm{M}=-2)$ ou $(\mathrm{N}=-2, \mathrm{M}=-1)$. Como a frequência de ressonância destes modos é diferente, isso implicaria uma estimativa da massa efetiva do plasma diferente. Por isso é importante determinar com mais exatidão o número de onda dos GAEs excitados.

Os dados obtidos com rampa de densidade são compatíveis com o ramo verde da figura 3.9, cujos dados foram obtidos em disparos com frequência de RF variável. Isso nos leva a crer que essas ressonâncias correspondem ao mesmo número de onda. 


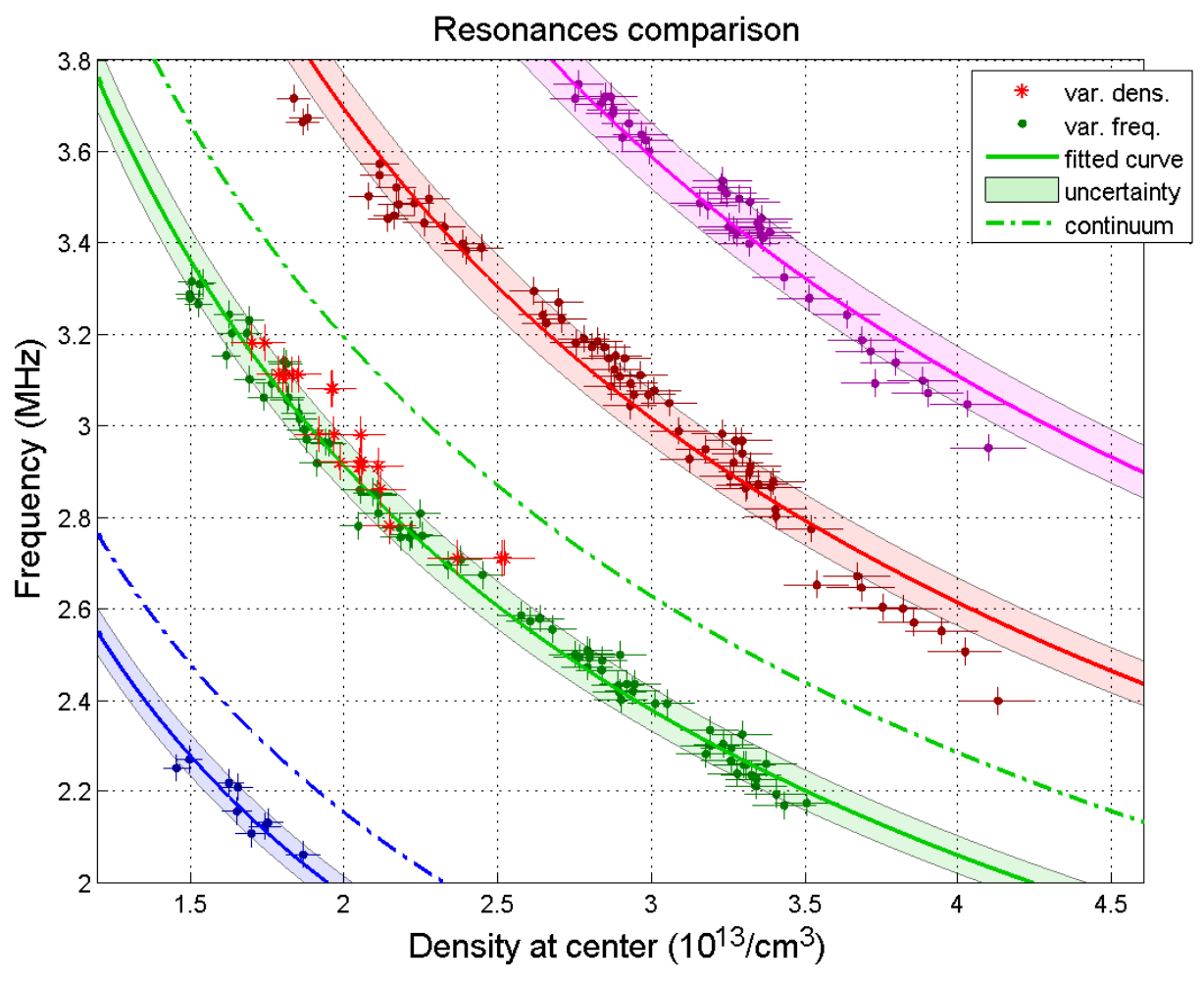

Figura 3.9: Dependência da frequência das ressonâncias identificadas com a densidade calculado para o centro do plasma. Para os modos $|N|+|M|=2$ (azul), 3 (verde), 4 (vermelho) e 5 (rosa). As linhas pontilhadas correspondem ao cálculo do contínuo de Alfvén para os modos $\frac{M}{N}=\frac{-1}{-1}, \frac{-2}{-1}$ para os parâmetros do TCABR e massa efetiva 1,45 .

Estes dados foram ajustados pelo método dos mínimos quadrados, com uma função como $F_{\text {res }}=\frac{A}{\sqrt{n_{0}}}$, para ser análoga ao contínuo de Alfvén. Estimamos uma incerteza para a densidade central de $5 \%$ e uma incerteza de $40 \mathrm{KHz}$ na frequência de ressonância, para o ajuste.

Além do ajuste, calculamos o contínuo de Alfvén para os modos $\frac{M}{N}=\frac{-1}{-1}, \frac{-2}{-1}$ usando os parâmetros do TCABR, tabela 1.1. Para a massa efetiva usamos o valor de 1.5 massas de hidrogênio. Vemos na figura 3.9 que as ressonâncias são identificadas em uma frequência menor que a calculada para o contínuo, isso é esperado para o comportamento do modo global.

Como ainda há dúvidas em relação ao número de onda dos modo excitados, montamos um amplificador de RF para ser ligado no módulo de antenas na região oposta do 
tokamak. Como explicado no capítulo 2, sobre os equipamentos do sistema de Alfvén. Com o segundo módulo de antenas podemos induzir um campo de RF com modos toroidais pares ( $\mathrm{N}=2$ ou 4) ou ímpares ( $\mathrm{N}=1$ ou 3 ). Assim, conseguimos determinar a paridade dos dois modos de frequência mais baixa. Os modos que correspondem a números de onda mais altos não foram determinados, devido a limitações no funcionamento dos amplificadores e a não definição completa de seu número de onda apenas pela paridade toroidal. Os resultados obtidos são apresentados na seção seguinte.

\subsection{Identificação da paridade toroidal dos modos $G A W$}

Devido a dificuldades nas medidas da defasagem entre as sondas magnéticas do sinal da ressonância da onda de Alfvén excitada não conseguimos identificar os modos toroidais e poloidais da $G A W$. Podemos inferir, para o modo de menor frequência da figura 3.9 (azul), que temos o modo $M / N= \pm 1 / 1$, pois é o de menor valor que pode ser excitado no modelo cilíndrico, mais detalhes sobre a determinação desse modo serão apresentados. Já para os modos de frequência mais alta temos dúvidas devido a múltipla combinação de números toroidais e poloidais. Nesta seção identificamos o modo representado pela cor verde, que temos dúvidas se tem é o modo $N / M=1 / 2$, $2 / 1$ ou $0 / 3$.

A identificação do número de onda é importante para uma melhor estimativa da massa efetiva e localização espacial da GAW (na região central do plasma ou afastado). Mesmo com a identificação das oscilações de dentes de serra no sinal das sondas, não temos uma medida direta que o número de onda toroidal é par ou ímpar. Para sanar estas questões, foi proposto o uso de duas antenas para excitar os GAWs, como apresentado na figura 2.1. Com as duas antenas dispostas toroidalmente em $180^{\circ}$ pode-se fazer o controle da paridade do modo toroidal, usando a diferença de fase entre ambas as correntes de RF, determinando se o modo excitado tem o número de onda toroidal $N$ par ou ímpar. 


\subsubsection{Escolha de paridade com duas antenas}

Para excitar modos toroidais com a paridade definida fazemos uso de duas antenas, que estão dispostas em lados toroidais opostos do tokamak. A paridade do modo excitado pode ser escolhida com a diferença de fase entre as correntes que passam nas antenas, cujos valores podem ser $[0,0]$ ou $[0, \pi]$.

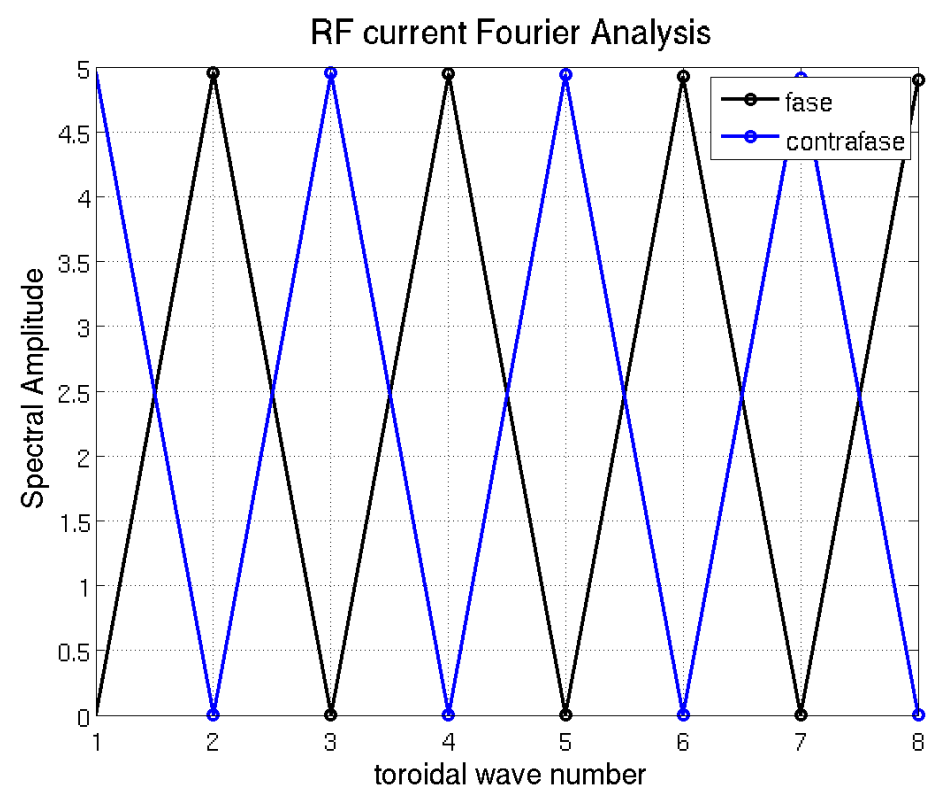

Figura 3.10: Cálculo da amplitude espectral para duas antenas dispostas toroidalmente em lados opostos do tokamak. Somamos em $M$ de -2 à 2 . Foram calculados os casos para as correntes com diferença de fase de $0^{\circ}$ (fase ou par) ou $180^{\circ}$ (contrafase ou impar).

Vamos supor que temos correntes com amplitudes e frequências idênticas passando em cada uma das antenas, e que podemos escolher a fase entre as correntes facilmente. Sendo assim, podemos calcular a transformada de Fourier para este sistema. Para facilitar os cálculos usamos uma geometria cilíndrica, que é próxima a geometria de um tokamak e possui condições de contorno periódicas. O resultado da transformada de Fourier deste sistema é apresentado na figura 3.10, para correntes em ambas as antenas e com diferença de fase de $0^{\circ}$ (em fase) ou $180^{\circ}$ (em contrafase). Observamos que quando as correntes estão em fase, excitamos modos pares, e quando estão em contrafase, excitamos modos ímpares. Sendo assim, podemos determinar a paridade toroidal do modo excitado com a fase entre as correntes nas antenas. 
Quando realizamos a experiência, porém, não temos as correntes exatamente em fase ou defasadas em $180^{\circ}$, e nem com a mesma amplitude. As antenas não são idênticas, uma é de cobre e tem proteção de nitreto de boro, a outra é de aço e é envolta por uma gaiola de Faraday. Isso faz com que harmônicos vizinhos sejam excitados também, mesmo que com intensidade bem menor. Para ilustrar isso temos a figura 3.11, onde consideramos um caso com a diferença de amplitude de $20 \%$ e outro com uma diferença de fase de $30^{\circ}$, ambos desviados do modo par. Ressaltamos que como temos uma geometria toroidal, modos vizinhos já são excitados.

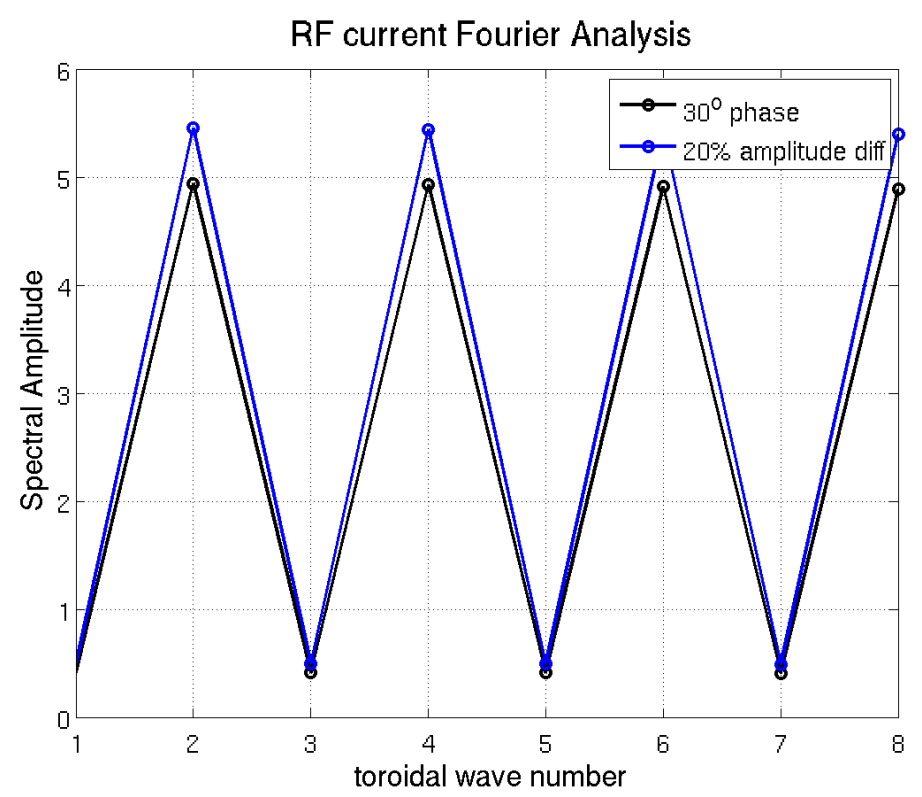

Figura 3.11: Cálculo da amplitude espectral para duas antenas dispostas toroidalmente em lados opostos do tokamak. Somamos em $M$ de -2 à 2. Foram calculados com amplitude e diferença de fase entre as correntes simulando condições experimentais.

Na figura 3.12 apresentamos a diferença de fase entre as correntes dos dois amplificadores de RF. A análise foi feita para uma única varredura. O valor obtido para diferença de fase pode variar para varreduras diferentes, principalmente se há uma mudança na amplitude de corrente. A figura serve como uma ilustração da diferença das dificuldades práticas, e mostra que temos uma região limitada de operação para o estudo da paridade dos modos GAE. 


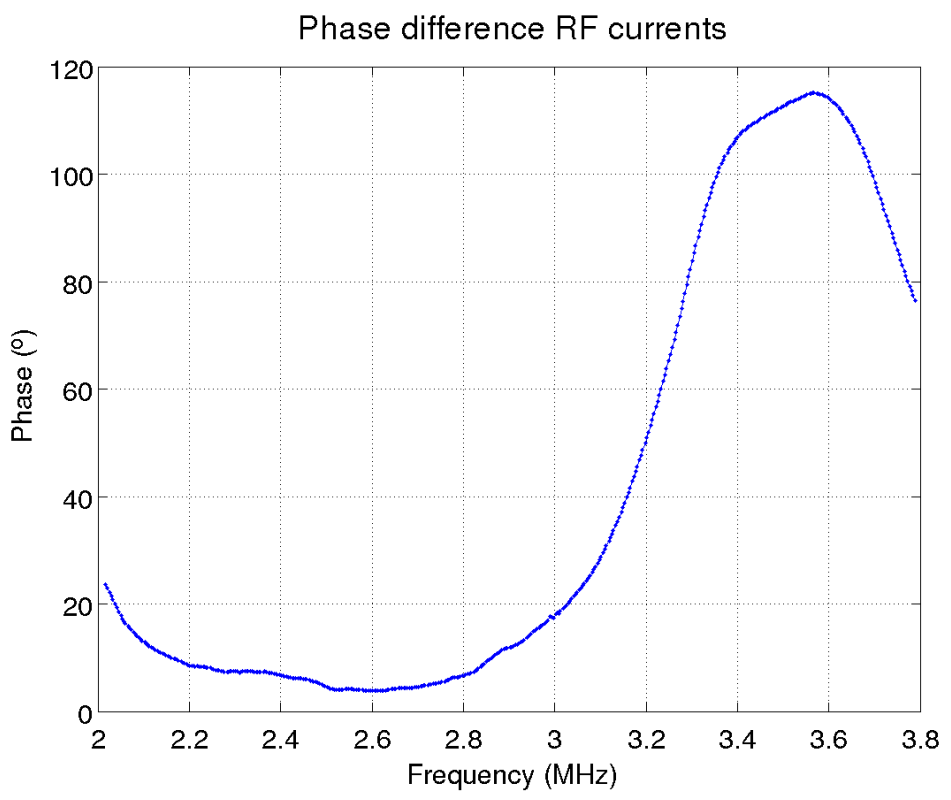

Figura 3.12: Diferença de fase entre as correntes de RF nas duas antenas.

\subsubsection{Excitação de corrente de RF nas duas antenas}

Para fazer a ligação das duas antenas foram usados duas fontes de corrente DC e dois amplificadores baseados em MOSFETS. Porém o chaveamento dos MOSFETs era determinado pelo sinal de um único gerador de funções (AGILENT 33220A 20 MHz - Arbitrary Waveform Generator), comum para ambos os amplificadores. Isso foi preferível pois, assim, temos a mesma frequência na corrente que passa pelas duas antenas, sem defasagem adicional. O esquema da ligação está apresentado na figura 2.1. Dado o modo com é feita a ligação, podemos alterar a amplitude de corrente em ambas as antenas independentemente, já que usamos duas fontes DC separadas. Mas não podemos corrigir a fase, pois usamos apenas um gerador de sinais para os dois amplificadores.

Como ressalva para a ligação, é preciso cuidado para não se criar um loop de terra no sistema. Para evitar o loop de terra temos que fazer a ligação ao terra em apenas um ponto. No caso o ponto de aterramento foi a antena que não estava protegida pela gaiola de Faraday. Outro ponto de cuidado é o gerador de funções, que ficou com o terra na tomada flutuando. Assim evitamos qualquer loop de terra. 


\subsubsection{Excitação preferencial do modo $N=1$}

Por causa de periodicidade toroidal e poloidal do tokamak, o menor modo que pode ser excitado corresponde ao modo $M / N=-1 /-1$. Como já foi mencionado, o modo azul na figura 3.9, já é identificado e é o modo $M / N=-1 /-1$. Assim, podemos usar essa ressonância para testar o método de identificação da paridade das ondas e julgar se o resultado obtido é satisfatório.

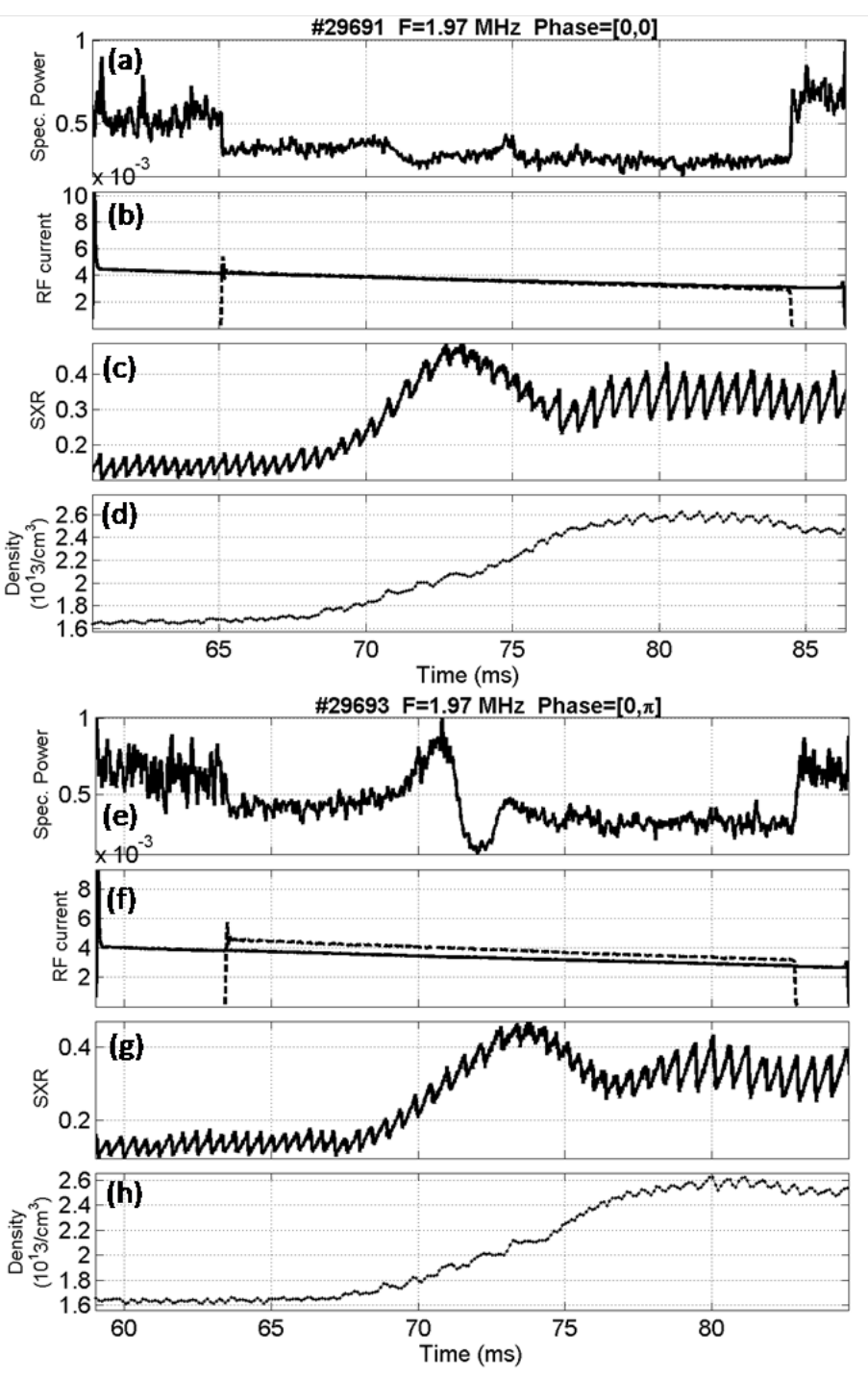

Figura 3.13: Evolução temporal da potência espectral do sinal da sonda magnética normalizado pela amplitude da corrente de RF, (a) e (e), amplitude espectral da corrente de $R F$ em ambas as antenas, (b) e (f), sinal do raio- $X$ mole, (c) e (g) e a densidade calculada no centro do plasma, (d) e (h), para os disparos \#29691 (a)-(d) e \#29693 (e)-(h). A linha pontilhada em (b) e (f) é a corrente na segunda antena. 
Para fazer este experimento usamos os dois métodos desenvolvidos, com rampa na densidade de plasma e frequência fixa na corrente de $\mathrm{RF}$ e, o outro método, com rampa na frequência da corrente de RF e a densidade com pouca variação.

Primeiro fazemos o experimento com frequência fixa e rampa na densidade. Podemos comparar o sinal obtido pela sonda magnética para os casos de ligação par e ímpar. Os resultados obtidos são apresentados na figura 3.13.
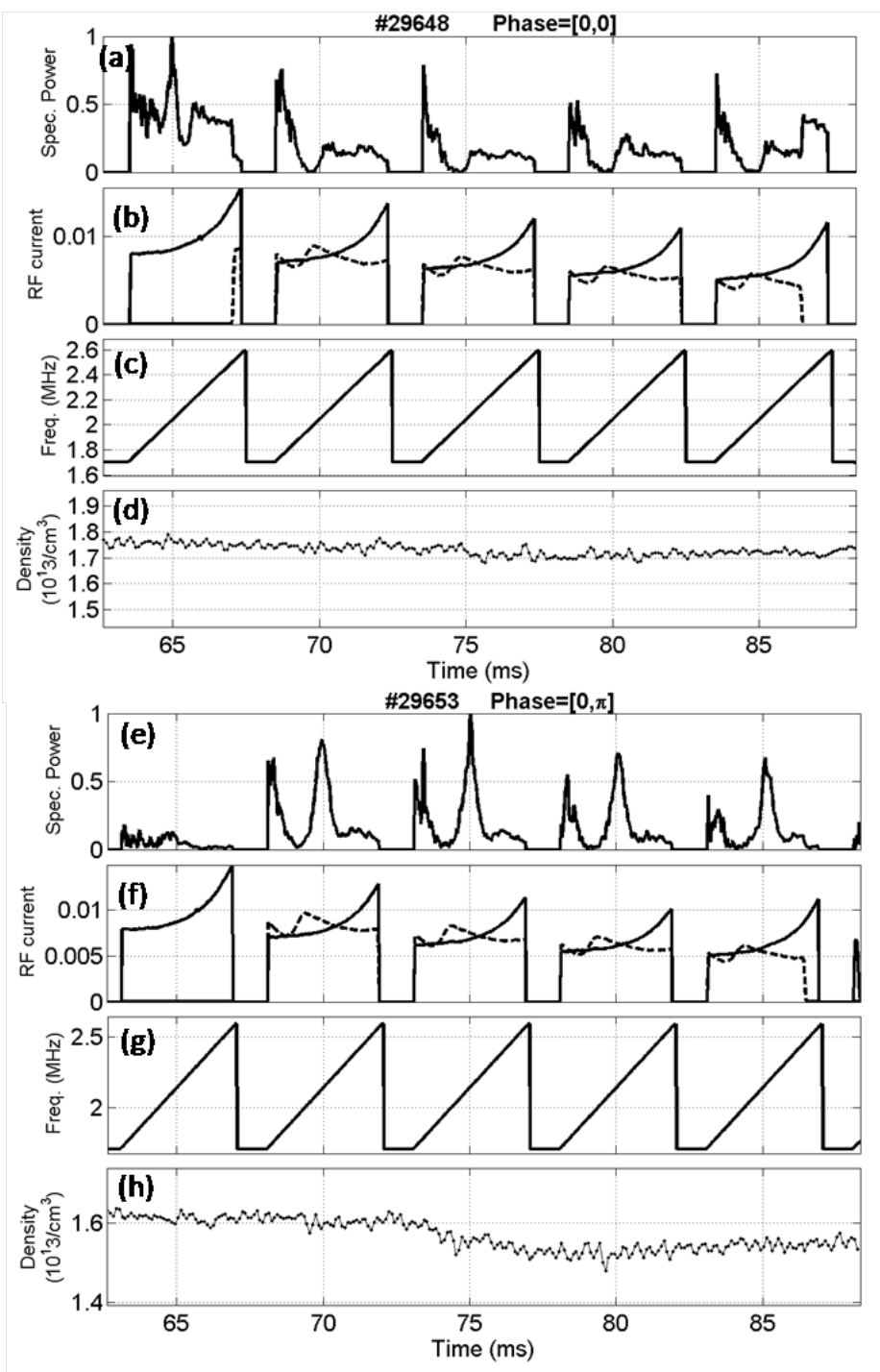

Figura 3.14: Evolução temporal da potência espectral do sinal da sonda magnética normalizado pela amplitude da corrente de RF, (a) e (e), amplitude espectral da corrente de RF em ambas as antenas, (b) e (f), a frequência da corrente de $R F$, (c) e (g) e a densidade calculada no centro do plasma, (d) e (h), para os disparos \#29648 (a)-(d) e \#29653 (e)-(h). A linha pontilhada em (b) e (f) é a corrente na segunda antena.

Vemos que quando temos a excitação dos modos $N$ pares o sinal de resposta das 
sondas é muito pequeno, e quando temos a excitação do modo $N$ ímpar a resposta da sonda é muito mais intensa. Vale salientar que, apesar das amplitudes da corrente de RF serem praticamente idênticas nas duas antenas, a fase entre elas não é exatamente $[0,0]$ ou $[0, \pi]$. Mas o desvio de fase, no entanto, não é superior a $20^{\circ}$. Mesmo assim, isso implica que estamos favorecendo a paridade escolhida, mas que ainda há sinal referente a paridade que desejamos eliminar. Podemos concluir que o modo toroidal $N$ excitado é ímpar.

Repetimos a experiência para rampa de frequência. Como nos experimentos anteriores aplicamos a corrente de $\mathrm{RF}$ para as antenas, tanto para o modo $N$ par, quanto ímpar. Vemos na figura 3.14 que a excitação é muito mais acentuada para o modo ímpar. Podemos concluir novamente que excitamos o modo $N$ ímpar, e que o método proposto é válido.

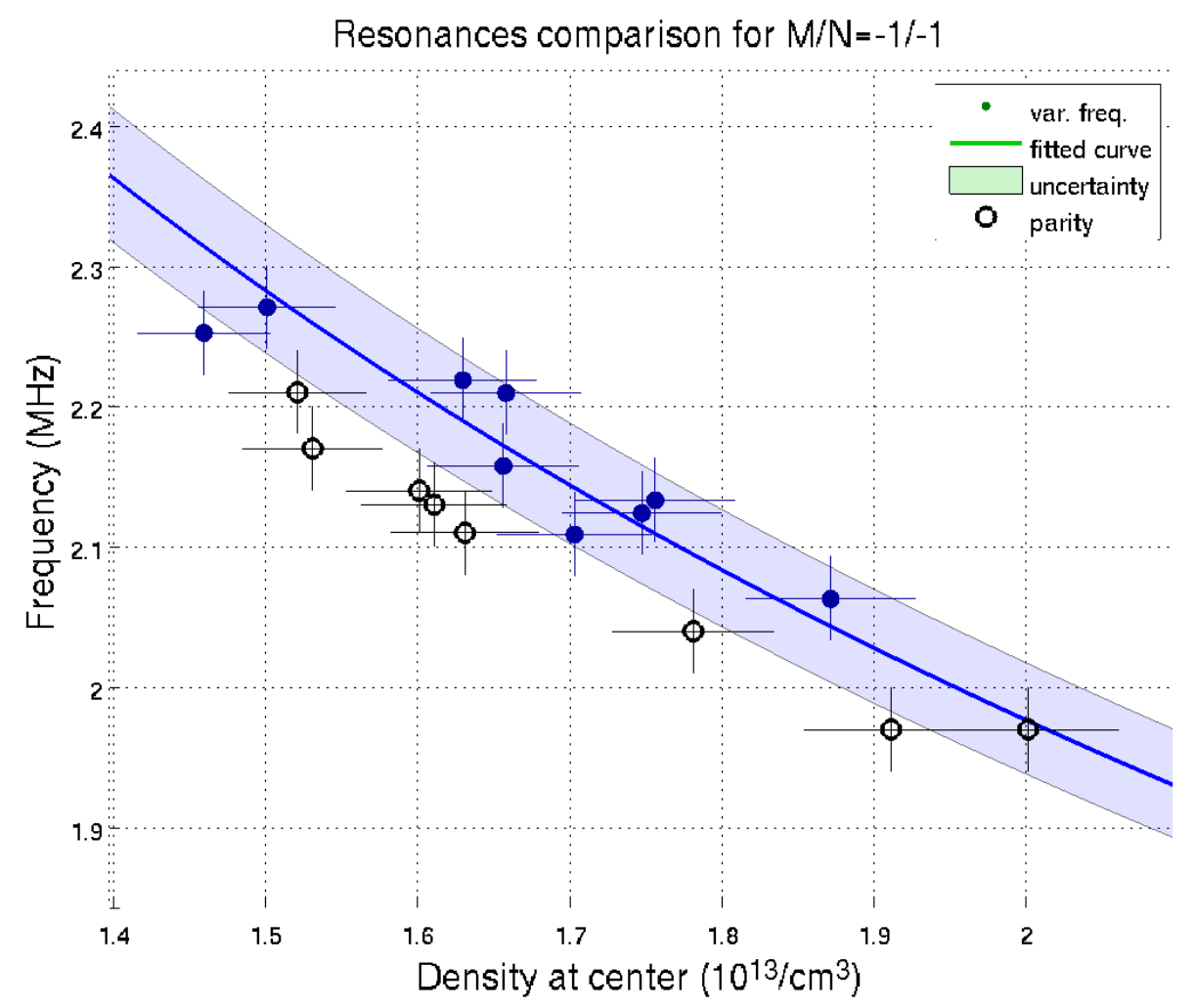

Figura 3.15: Resumo da condição de ressonância $M / N=-1 /-1$ encontrada em comparação com resultados antigos para uma série de disparos, em destaque, com círculos pretos, os dados apresentados nessa seção para a excitação com duas antenas e com paridade definida. 
Podemos comparar as ressonâncias obtidas por experimentos com as duas antenas com experimentos a série de disparos presente na figura 3.9. A comparação está apresentada na figura 3.15, que apresenta outras ressonâncias obtidas com duas antenas. Vemos que, claramente, as ressonâncias obtidas com as duas antenas se encontram próximas da curva que identificamos como $M / N=-1 /-1$. Isso é como o esperado e confirma que a excitação com duas antenas funciona e é satisfatória.

Observando com cuidado a figura 3.15, vemos que a frequência das ressonâncias encontradas é sistematicamente menor que a presente em disparos anteriores. Isso provavelmente se deve ao acúmulo de impurezas. Nesta seção tratamos de disparos realizados após o TCABR estar por quase 6 meses com baixa utilização.

\subsubsection{Excitação preferencial do modo $N=2$}

O mesmo método apresentado na seção anterior foi feito para excitar outro modo, que temos dúvidas se é $M / N=-2 /-1$ ou $-1 /-2$. Para isso, repetimos a mesma experiência realizada na seção anterior para uma faixa de densidades e frequências diferentes. Nos experimentos realizados nestas condições, com apenas uma antena, não pudemos afirmar qual era a paridade toroidal dos modos excitados. Agora, usando a defasagem entre a corrente nas antenas de $[0,0]$ e $[0, \pi]$ mostramos que temos a excitação do modo $M / N=1 / 2$, como foi apresentado em trabalhos anteriores [30]. A discussão sobre a paridade do modo se dará em mais detalhe no próximo capítulo.

Os resultados obtidos com os disparos com rampa na densidade e frequência fixa estão apresentados na figura 3.16. Vemos que a ressonância se apresenta de forma mais clara no caso de $N$ par, indicando que o modo excitado é o $M / N=-1 /-2$.

Como o sinal das sondas é normalizado pelo máximo do próprio, para melhor visualização, não fica muito clara a diferença no sinal das sondas. Na figura 3.17 apresentamos sinais da sonda para os dois disparos na mesma escala. Assim, fica mais claro que o modo excitado é o modo toroidal par.

Repetimos o mesmo experimento com densidade fixa e varredura de frequência da 

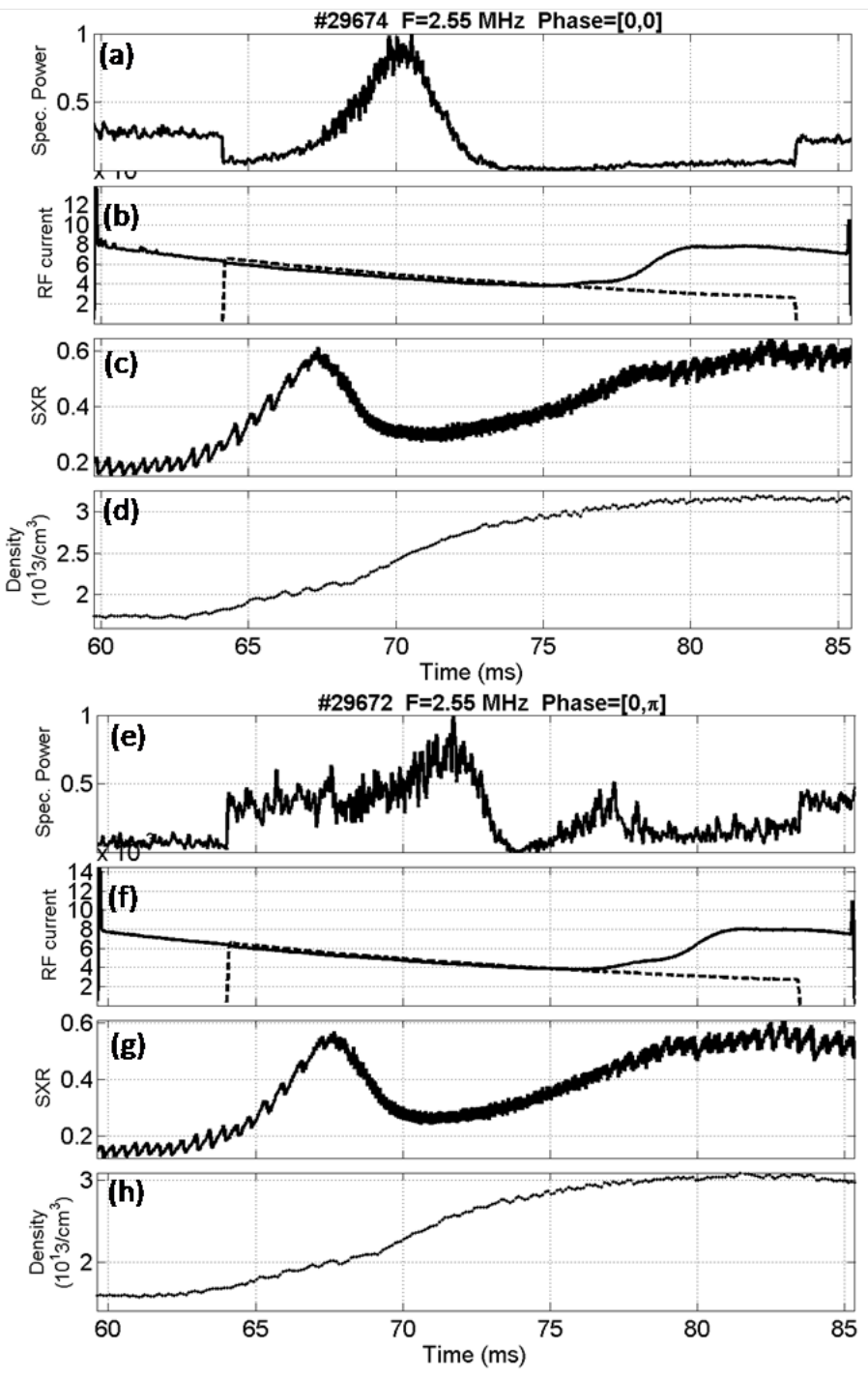

Figura 3.16: Evolução temporal da potência espectral do sinal da sonda magnética normalizado pela amplitude da corrente de RF, (a) e (e), amplitude espectral da corrente de $R F$ em ambas as antenas, (b) e (f), sinal do raio-X mole, (c) e (g) e a densidade calculada no centro do plasma, (d) e (h), para os disparos \#29674 (a)-(d) e \#29672 (e)-(h). A linha pontilhada em (b) e (f) é a corrente na segunda antena.

corrente de RF. Vemos os resultados na figura 3.18. Podemos ver um pico, que indica a ressonância, muito mais proeminente com a ligação das antenas em modo par. Isso confirma o resultado apresentado na figura 3.16. Temos um modo toroidal de paridade par. 


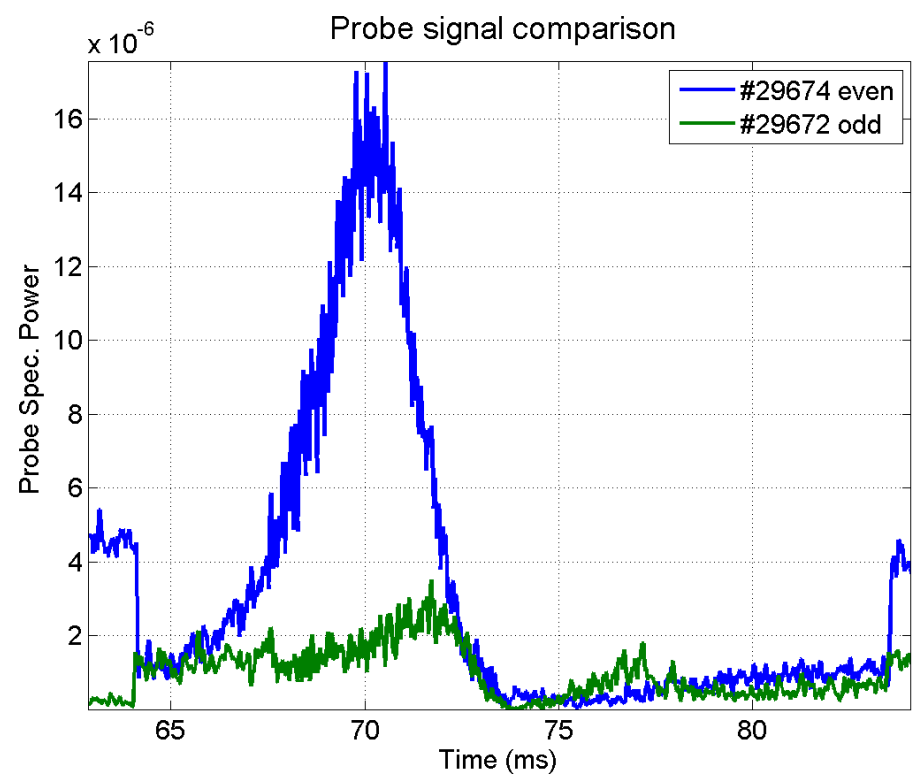

Figura 3.17: Comparação da amplitude do sinal de RF das sondas magnéticas, mesmos disparos que na figura 3.16.

Na figura 3.18, temos um fato interessante, pois conseguimos ver que há uma ressonância presente quanto temos corrente em apenas uma antena. Vemos que essa ressonância continua com a passagem da corrente na segunda antena, quando ligada no modo par, e é suprimida com a ligação no modo ímpar. Sendo assim, fica muito clara a excitação de um modo toroidal $N$ par.

Comparamos os experimentos realizados com duas antenas com os dados da figura 3.9. Na figura 3.19 este modo é representado pela curva verde. O modo excitado nesse caso poderia ser o modo $N / M=1 / 2$, mas isso indicaria uma paridade toroidal ímpar. Sendo assim temos a excitação do modo $N / M=2 / 1$.

Essa identificação é condizente com a observação da oscilação da amplitude do sinal da sonda magnética com as oscilações dente de serra. Como foi mencionado, a condição ressonante se encontra na parte central da coluna de plasma, fato indicado pela inversão de fase da amplitude do sinal da sonda magnética com as oscilações dente de serra. $\mathrm{O}$ GAE para o número de onda $N / M=2 / 1$ tem sua condição ressonante justamente na parte mais central da coluna de plasma, corroborando nossa identificação do número de onda. 

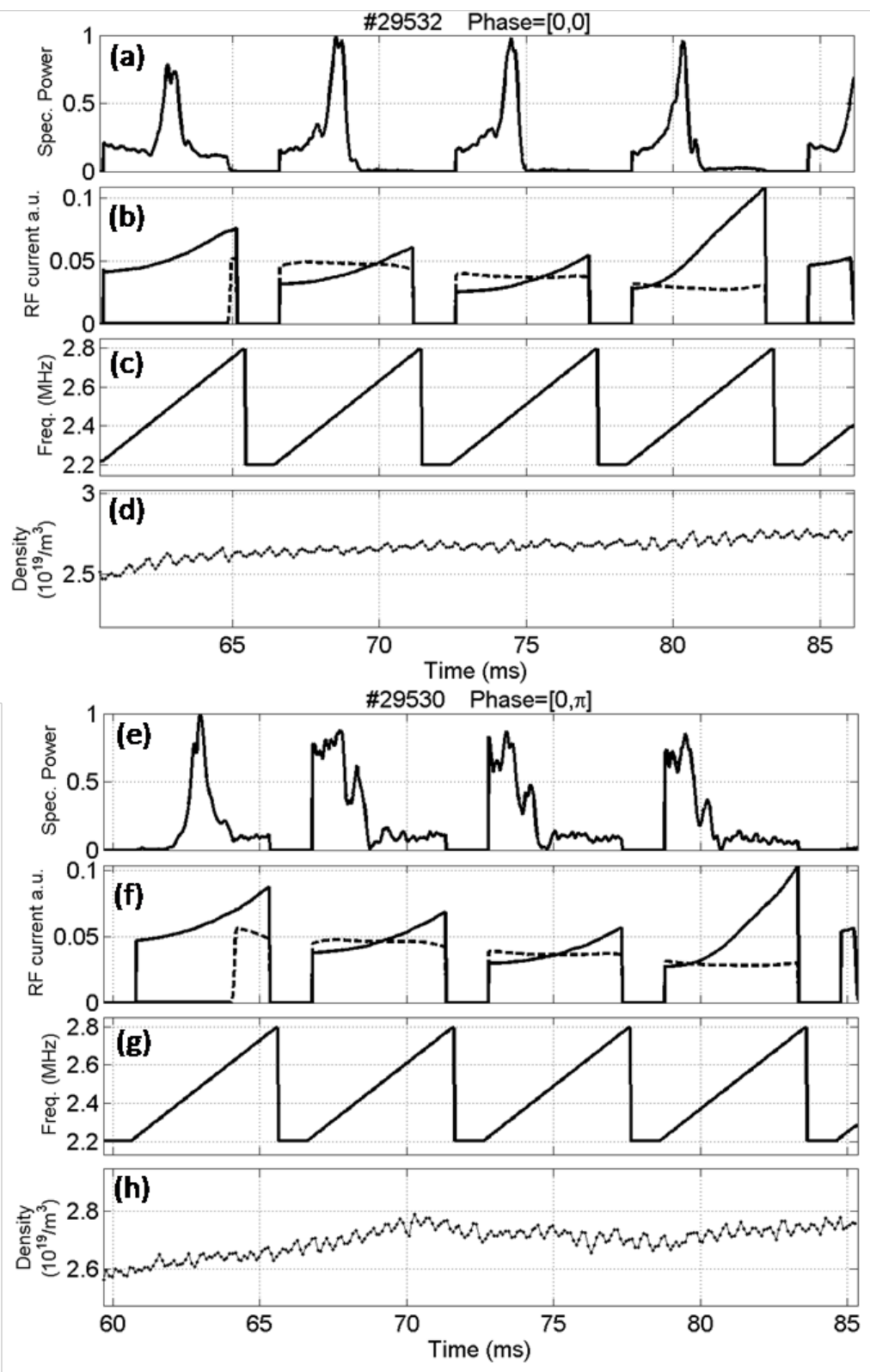

Figura 3.18: Evolução temporal da potência espectral do sinal da sonda magnética normalizado pela amplitude da corrente de RF, (a) e (e), amplitude espectral da corrente de RF em ambas as antenas, (b) e (f), a frequência da corrente de $R F$, (c) e (g) e a densidade calculada no centro do plasma, (d) e (h), para os disparos \#29532 (a)-(d) $e$ \#29530 (e)-(h). A linha pontilhada em (b) e (f) é a corrente na segunda antena. 


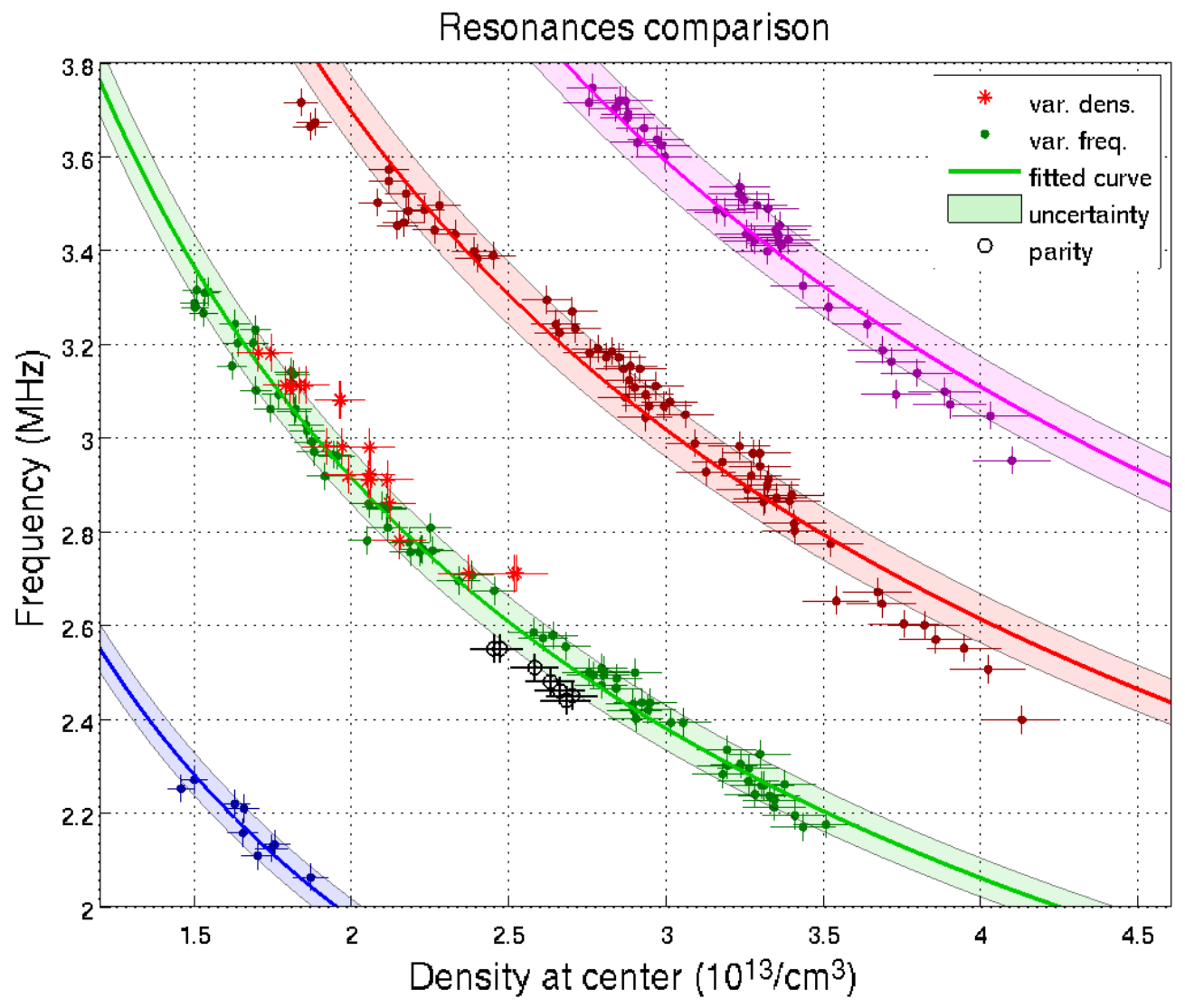

Figura 3.19: Resumo da dependência da frequência da ressonância do GAW condição de ressonância encontrada para uma série de disparos, estão em preto os dados apresentados nessa seção para a excitação com o uso de duas antenas, para o modo $M / N=-1 /-2$.

Na figura 3.19 vemos que o valor da ressonância encontrada é menor que os dos disparos mais antigos. Tal fato também ocorre na figura 3.15, o ocorrido foi atribuído à um grande intervalo de baixa utilização do TCABR, que favoreceu o acumulo de impurezas.

\subsubsection{Conclusão}

Finalmente, concluímos que foi possível determinar experimentalmente a paridade toroidal dos dois primeiros modos excitados da figura 3.9 , sendo $N / M=1 / 1$ o ramo azul e $N / M=2 / 1$ o ramo verde. O resultado obtido para o modo $N / M=2 / 1$ confirma as nossas suspeitas sobre o número de onda deste modo, devido a presença da oscilação da amplitude do sinal da sonda magnética, durante a ressonância de Alfvén, 
e a inversão de fase com as oscilações dente de serra, suspeitávamos que este modo se encontrava na parte central do plasma. 


\section{Capítulo 4}

\section{Discussão dos resultados}

Neste capítulo apresentamos a discussão detalhada dos resultados obtidos com o sistema de excitação e deteç̧ão de ondas de Alfvén no TCABR. Principalmente, buscamos identificar o número de onda dos modos excitados e, assim, determinar a localização dos modos. Fazemos a estimativa do valor da massa efetiva no centro do plasma e comparamos com o valor da carga efetiva para o TCABR. Dado os resultados obtidos, foram feitos disparos com plasma de hélio para calibrar o sistema excitação de ondas de Alfvén. Comparamos todos os resultados com cálculos de um código sobre ondas de Alfvén [27].

Fora isso, estudamos em mais detalhe o efeito de dentes de serra sobre a amplitude do sinal da sonda magnética, que ocorrem durante a ressonância de Alfvén. Analisamos qual a mudança na concentração de impurezas no centro durante a oscilação. Supomos uma mudança no perfil dada pela diferença no transporte entre as partículas diferentes para entender como ocorre esse aumento de impurezas.

Descobrimos que o valor da massa efetiva obtida para o plasma de hidrogênio se mostrou muito elevado, quando comparado com o valor da carga efetiva, (eq. 1.25). Atribuímos esse valor a algum erro na estimativa da densidade central, obtida com os dois canais do interferômetro. O método de cálculo da densidade central deve apresentar algum erro sistemático. Para calibrar o sistema de determinação da massa efetiva usamos plasma de hélio, que tem a mesma razão carga massa que a maioria das impurezas. Uma vez calibrado, conseguimos obter um valor menor para a massa efetiva do 
plasma de hidrogênio, que corresponde a carga efetiva estimada para o TCABR.

\subsection{Número de onda dos modos excitados}

Como foi apresentado no capítulo anterior, com o uso de duas antenas foi determinada a paridade dos dois primeiros modos excitados, que estão representados pelos pontos azuis e verdes na figura 3.9. Com a identificação do número de onda desse modos, podemos inferir o valor da massa efetiva. A identificação do número de onda é importante pois, considerando a mesma densidade de elétrons mas quantidades de impureza diferentes, obtemos valores distintos da frequência de ressonância para os GAE.
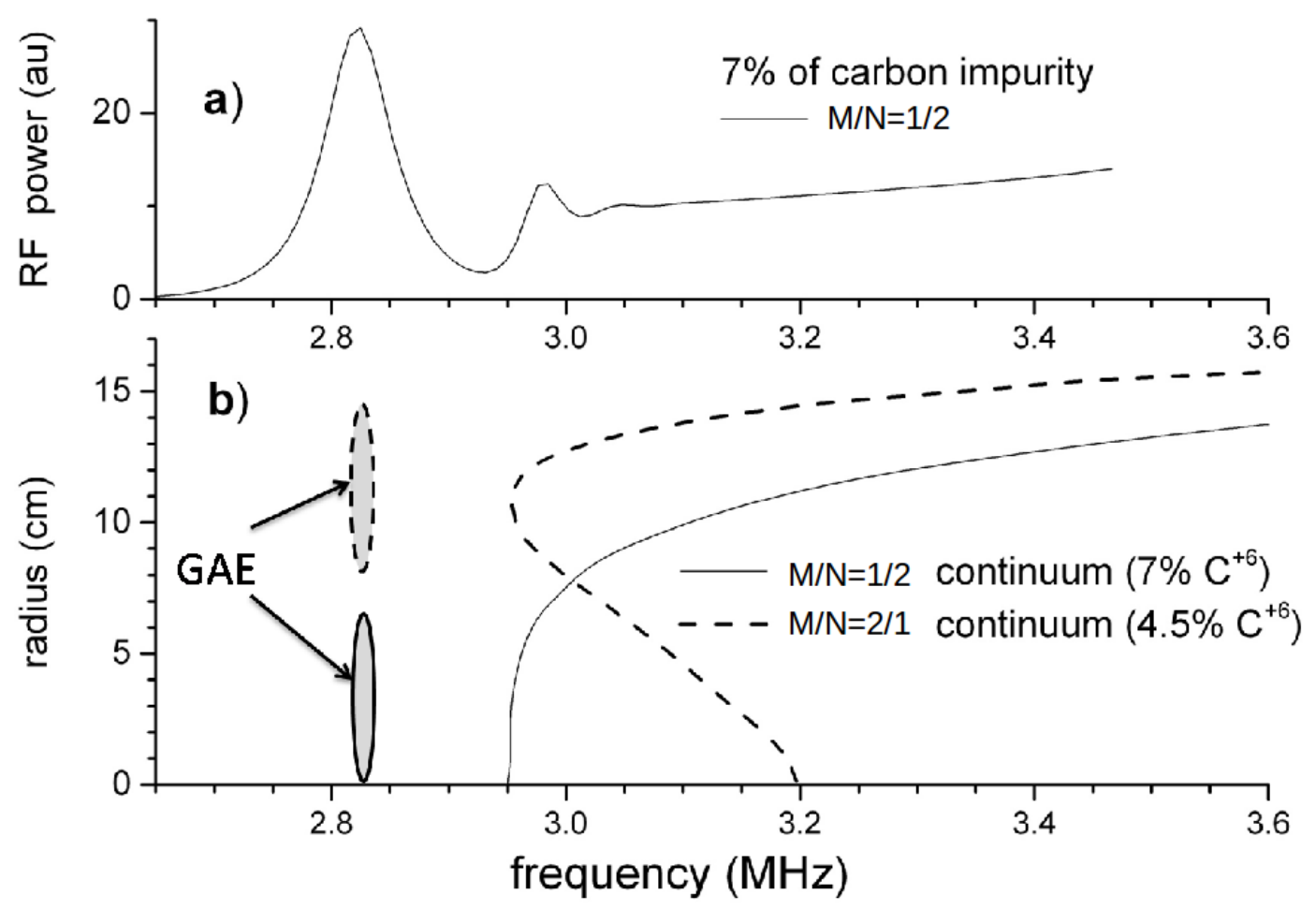

Figura 4.1: Gráfico de cálculos com código cinético da potência dissipada pelo GAE (a) para o modo $M / N=1 / 2$ para $7 \%$ de concentração de impurezas de carbono e curvas do contínuo de Alfvén para os modos $M / N=1 / 2$ e $M / N=2 / 1$ para a concentração de carbono de $7 \%$ e $4.5 \%$ (b), respectivamente. A região em destaque é a largura radial do GAE. 
Como pode ser visto na figura 4.1, encontramos valores de massa efetiva diferentes para dois modos com a mesma densidade de elétrons no plasma e a mesma frequência de ressonância, mas número de onda diferentes. Na figura 4.1 (a), temos a curva de impedância da antena calculada com código disponível no laboratório [27] para o modo $M / N=-1 /-2$. Para os cálculos foi considerada apenas impureza de carbono no plasma. Os valores do nível de impureza de carbono $n_{C} / n_{e}$ considerados foram de respectivamente $7 \%$ para o modo $M / N=-1 /-2$ e $4,5 \%$ para o modo $M / N=-2 /-1$. A massa efetiva corresponde a $A_{\text {eff }} \approx 1,42$ e $A_{\text {eff }} \approx 1,27$ respectivamente. Na figura 4.1 (b) temos a a curva do contínuo para dois modos diferentes, o modo de linha contínua tem sua ressonância no centro do plasma e $N=2$, o modo de linha tracejada tem $N=1$ e sua ressonância mais afastada do centro.

Nos cálculos do contínuo e da curva de impedância da antena usamos valores típicos do TCABR, com o perfil parabólico da densidade elevado à potência $\alpha=0.8$, com densidade central de elétrons de $n_{0}=2.4 \times 10^{19} m-3$ e o perfil de corrente parabólica elevada a potência $\alpha_{\text {curr }}=2.55$.

Dada a diferença no valor da concentração de carbono, fica clara a importância da paridade do modo toroidal $(N=1 \mathrm{ou} N=2)$ na determinação da massa efetiva $A_{\text {eff }}$. Para esclarecer o número de onda toroidal foi necessário fazer experiência com duas antenas em lados toroidais opostos com corrente defasadas em $[0,0]$ e $[0, \pi]$.

Tendo a paridade toroidal do modo bem determinada, finalmente podemos discutir o nível de impurezas no plasma do TCABR. Os dois primeiros modos identificados se localizam na região central do tokamak, onde $q \lesssim 1$. Tal fato é indicado pela oscilação da amplitude do sinal da sonda magnética com as oscilações dente de serra e pela paridade toroidal. Assim foi possível identificar os dois primeiros modos como $\mathrm{M} / \mathrm{N}=$ $-1 /-1$ e $-1 /-2$. Os sinais negativos do número de onda dos automodos são definidos pelo termo de efeito Hall [28].

Um dado que foi de muito auxílio para a classificação das ressonâncias, foi a estimativa da densidade central do plasma com dois canais do interferômetro. Principalmente 
para os disparos com rampa de densidade, onde há maior deformação no perfil de densidade do plasma durante o disparo. O valor da massa efetiva é totalmente dependente da estimativa da densidade central de elétrons no plasma.

\subsubsection{Determinação do valor da massa efetiva}

Tendo em vista a discussão apresentada, a identificação dos modos perto do centro da coluna de plasma e sua paridade, podemos determinar a massa efetiva dos íons $A_{e f f}$ do plasma. Para tanto usaremos apenas as duas primeiras ressonâncias da figura 3.9, que já se mostraram suficiente para esse objetivo [33].

Para estimar a massa efetiva para este disparo usamos a equação para o contínuo de Alfvén. Sabemos, por cálculos com código [27], que a frequência do modo global é aproximadamente $5-6 \%$ menor que a do contínuo de Alfvén para o TCABR.

$$
\frac{\omega_{A}-\omega_{G A E}}{\omega_{A}} \approx 5-6 \%
$$

Sendo assim, podemos calcular o contínuo de Alfvén para o TCABR e comparar com a curva ajustada pelos dados, na figura 3.9. Na figura temos os pontos ajustados para a função $F$

$$
\frac{\omega_{A}}{\sqrt{1-\frac{\omega_{A}^{2}}{\omega_{c o}^{2}}}}=\frac{F}{\sqrt{n}} \quad ; \quad F \equiv k_{\|} \frac{B}{\sqrt{4 \pi A_{e f f}}}
$$

O valor de $F$ é ajustado para os pontos experimentais, mas também pode ser calculado para os parâmetro do TCABR. Temos que considerar um valor para a massa efetiva e o fator de segurança para efetuar esse cálculo. No caso, consideramos a massa efetiva $A_{e f f}=1$, plasma de hidrogênio puro, e o fator de segurança no centro $q_{0}=0.95$. O contínuo de Alfvén é calculado para o centro da coluna de plasma. Com ambos os valores de $F$, o experimental e o calculado, facilmente encontramos a massa efetiva para o plasma do TCABR 


$$
A_{\text {eff }}=\left(\frac{F_{\text {calc }}}{F_{\text {exp }}}\right)^{2}
$$

Usamos a curva verde, modo $(\mathrm{N}=2, \mathrm{M}=1)$, da figura 3.9 , onde a densidade no centro é calculada usando o perfil de densidade da (eq.2.1). Obtemos o valor para a massa efetiva $A_{\text {eff }}=1.75 \pm 0.07$. Podemos estimar a composição das impurezas, levando em conta o grau de ionização dos átomos no centro do TCABR. Como a temperatura dos elétrons no TCABR é maior que $400 \mathrm{eV}$, podemos considerar o carbono completamente ionizado; mais detalhes sobre a ionização de átomos em um reservatório térmico estão na referência [58].

O valor da massa efetiva encontrado é mais alto que o que esperávamos. Considerando que a única impureza no TCABR é carbono, obtemos uma concentração de impureza de carbono completamente ionizado de $n_{C} \approx 12.5 \%$. Alternativamente podemos considerar uma pequena concentração de íons metálicos, que nos daria $n_{C} \approx 11.8 \%$ de carbono e $n_{F e} \approx 0.1 \%$ de ferro ionizado 19 vezes [38].

Dado um valor para a concentração das impurezas, podemos calcular qual o valor da carga efetiva $Z_{\text {eff }}$. No caso de $12.5 \%$ de carbono temos uma carga efetiva de $Z_{\text {eff }}=4.75$. Já para um pouco de impureza metálica, obtemos $Z_{\text {eff }}=4$.88. Esses valores para a carga efetiva são maiores do que o estimado para o caso do TCABR.

Pretendemos melhorar o método de análise levando em consideração a fórmula mais exata para o contínuo com as impurezas, levando em consideração o termo de efeito íon-cíclotron. No caso, temos para o contínuo.

$$
\sum_{i} \frac{\omega_{p i}^{2}}{\omega_{c i}^{2}} \frac{\omega_{A}^{2}}{\left(1-\frac{\omega_{A}^{2}}{\omega_{c i}^{2}}\right)}=k_{\|}^{2} c^{2}
$$

Apesar de o termo de efeito íon-cíclotron $\frac{\omega_{A}^{2}}{\omega_{c i}^{2}}$ poder ser desconsiderado para o hidrogênio, ele não o é para as outras espécies de íons. Assim podemos obter um valor menor para as impurezas. Supondo um plasma com somente impurezas de carbono, obtemos uma concentração de $n_{C} \approx 9.5 \%$. Valor menor que o estimado pelo contínuo 
sem considerar o termo de correção de íon-cíclotron.

Consideramos também uma mudança no valor de $q_{0}$ com a densidade, variando de $0.90-0.99 \mathrm{com}$ a densidade variando de $n_{0}=1.4-4 \times 10^{19} / \mathrm{m}^{3}$. Isso corresponde a uma variação do parâmetro do perfil da corrente de $\gamma=2.4-2.9$, junto com uma diminuição da corrente com a densidade, figura 4.2. Para a análise, fizemos uma variação linear do valor de $q_{0}$. O expoente do perfil da densidade foi mantido fixo como $\alpha=0.8$. A frequência do modo global foi determinada como 5.5\% abaixo do mínimo do contínuo. Isso ajuda com a fidelidade da comparação.

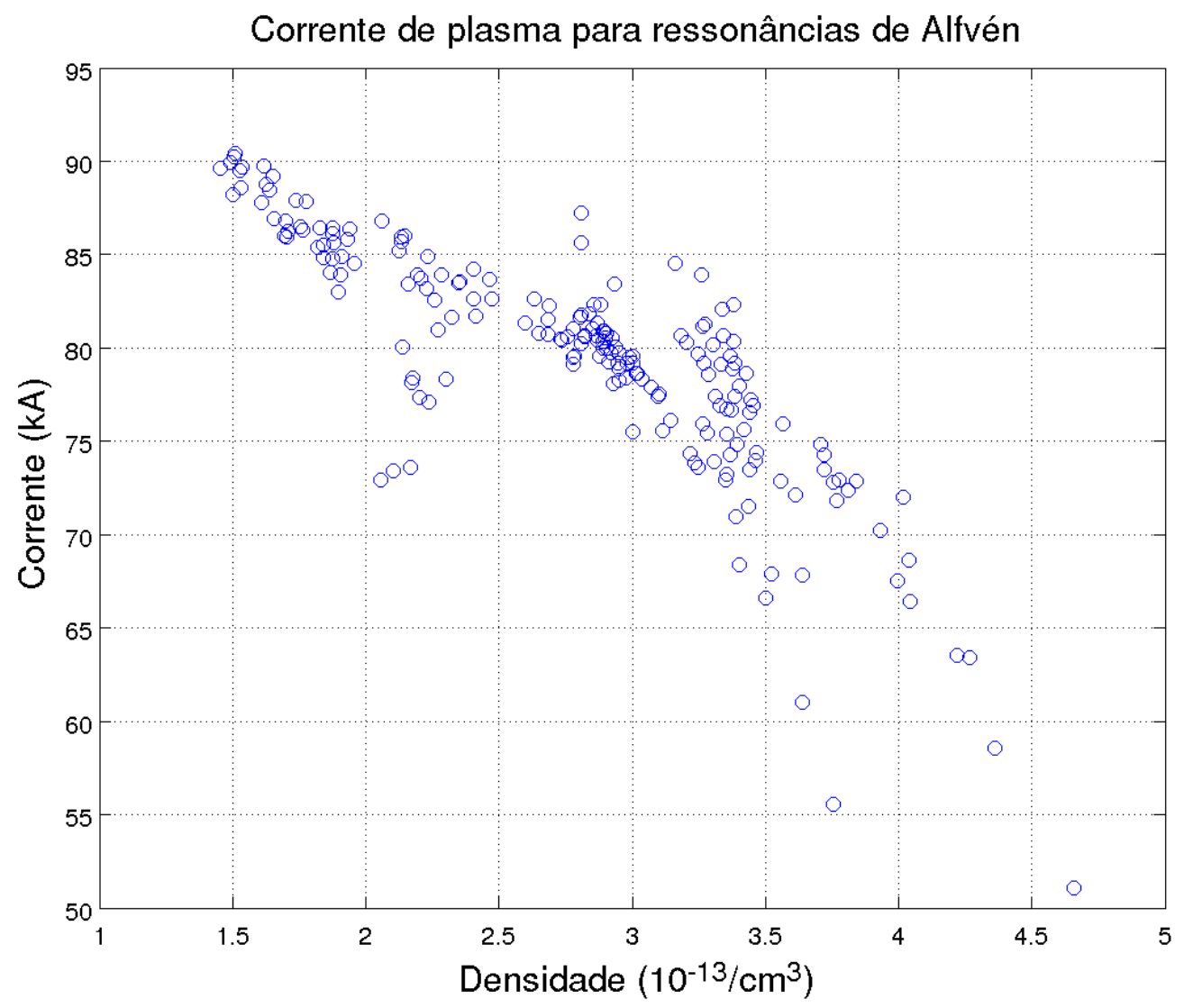

Figura 4.2: Gráfico da corrente de plasma pela densidade dos disparos com ressonâncias detectadas.

Podemos ver o ajuste com esses parâmetros na figura 4.3. Consideramos a concentração de carbono em 9.5\%, que corresponde à superfície $q=1$ em $r \approx 3 \mathrm{~cm}$, obtido pela inversão dos dentes de serra.

Como o modo $N=2, M=1$ está no centro do plasma, pode ser comparado 
diretamente com o valor da densidade no centro. No caso do modo $N=1, M=1$, a localização do modo é mais afastada, e se localiza num valor de frequência menor que o no centro do plasma. Neste caso, calculando o contínuo para todo o raio da coluna de plasma, obtemos um valor para o mínimo do contínuo aproximadamente $70 \mathrm{kHz}$ menor que o valor obtido no centro do plasma. Essa correção foi utilizada para a composição da figura 4.3.

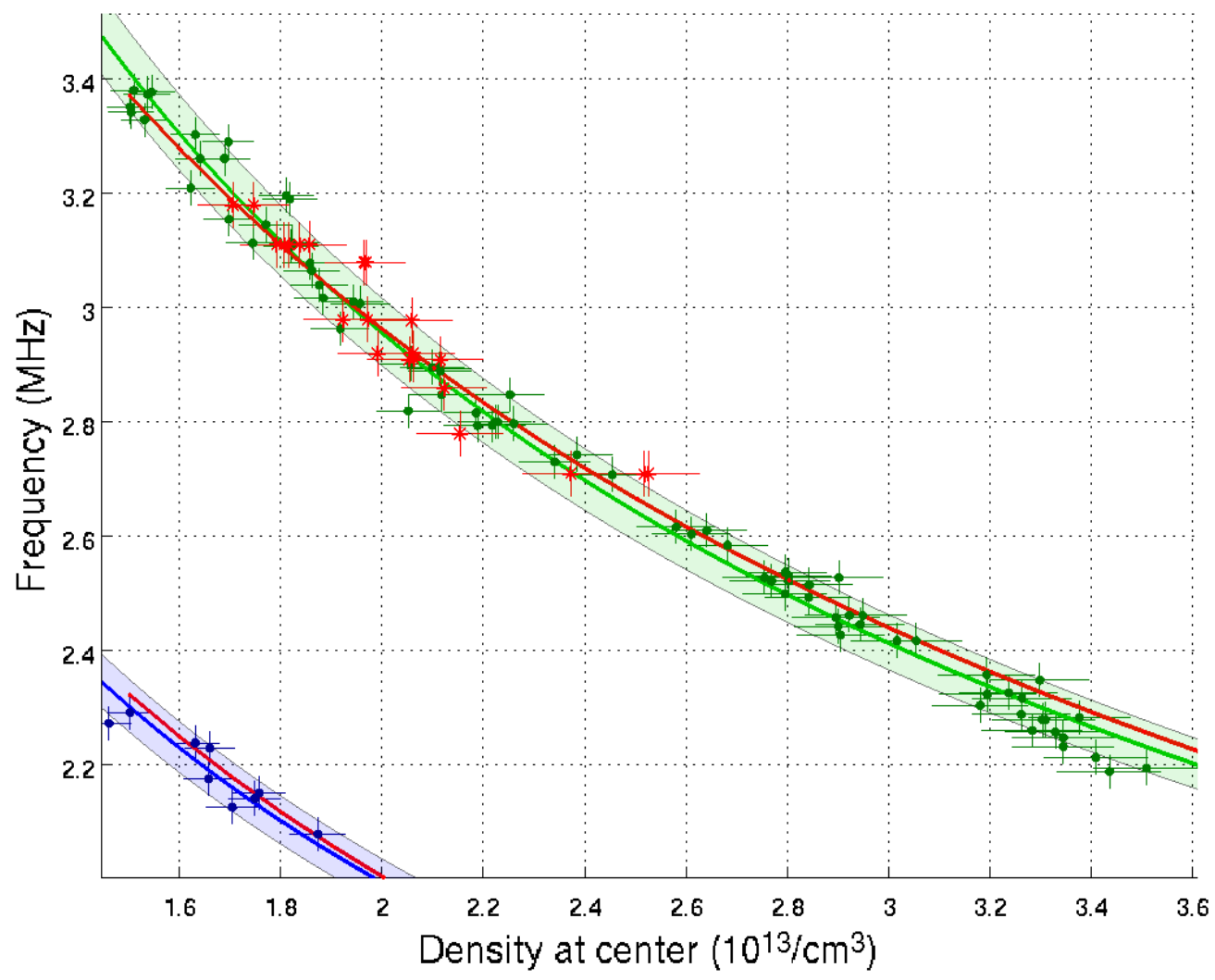

Figura 4.3: Comparação dos dados obtidos, apresentados na figura 3.9, com cálculos do contínuo de Alfvén para os modos $N / M=2 / 1$ e $1 / 1$ com consideração de impurezas e termo de efeito Hall (linha vermelha).

Como podemos observar, há uma boa concordância entre os cálculos de contínuo com impurezas e o valor da densidade. Com o valor de $9.5 \%$ de carbono obtemos $A_{e f f}=1.57 \pm 0.06$ e $Z_{e f f}=3.85$. Valor inferior ao obtido com o contínuo de Alfvén em sua forma aproximada. Alternativamente podemos ter $n_{C} \approx 9 \%$ de carbono e $n_{F e} \approx$ $0.1 \%$ de ferro ionizado 19 vezes, que corresponde a $A_{\text {eff }}=1.57 \pm 0.06$ e $Z_{\text {eff }}=4.01$. 


\subsubsection{Comparação com estimativa da carga efetiva}

Para avaliar a qualidade do resultado que obtivemos para a massa efetiva, vamos utilizar o valor da carga efetiva $Z_{\text {eff }}$. Usando o valor de $12.7 \%$ de carbono, obtido com o ajuste para os dados experimentais das frequências de ressonâncias, podemos obter o valor do $Z_{\text {eff }}=4.81$.

Tomemos o disparo \#30044 como exemplo para comparação, calculando $Z_{\text {eff }}$ usando uma aproximação já validada para o TCA de Lausanne [38],

$$
Z_{\text {eff }}(0)=1.84 V_{\text {loop }} T_{e}^{1.5} / B_{0}-0.755
$$

Usando os dados apresentados na figura 3.4, referente ao disparo \#30044, e a temperatura dos elétrons de $450 \mathrm{eV}$, obtida por espalhamento Thomson, obtemos o valor da carga efetiva como $Z_{\text {eff }} \approx 3.1$. Esse valor é bem menor do que o calculado para a porcentagem de carbono que estimamos. Isso indica que o valor da massa efetiva apresentada é acima do que realmente existe no TCABR. Dificilmente achamos condições no TCABR em que $Z_{\text {eff }}>4$, [38].

Concluímos que, o valor obtido para a massa efetiva pode estar influenciado por algum erro sistemático, que acreditamos estar ligado a medida da densidade no centro da coluna. Com o intuito de diminuir os erros sistemáticos vamos considerar o deslocamento de Shafranov para a determinação da densidade central. Fora isso, realizamos disparos com gás hélio para calibrar o sistema de Alfvén; os resultados são apresentados na próxima seção.

\subsubsection{Deslocamento de Shafranov e medida de densidade com interferômetro}

\section{Deslocamento de Shafranov}

Dada as diferenças obtidas na estimativa da massa efetiva com a comparação com o valor empírico para a carga efetiva validado para o TCA, suspeitamos ter um erro sistemático na determinação da densidade do centro do plasma. Como um erro na 
medida da densidade influência diretamente a estimativa da massa efetiva vamos fazer uma discussão sobre possíveis fontes de erro na estimativa da densidade central.

Um fator que pode ser responsável pelo erro na estimativa da densidade no centro do plasma é o deslocamento de Shafranov, que é o deslocamento do eixo magnético em relação ao eixo geométrico do plasma. Primeiramente, vamos tentar repetir a análise, usando agora o reflectômetro, levando em conta o tempo de atraso. Ajustamos os dados de tempo de atraso obtidos ao que seria esperado para um plasma com o perfil de densidade parabólico elevado a uma potência. Os resultados do ajuste, para um momento específico $(110 \mathrm{~ms})$ do disparo \#28267, estão apresentados na figura 4.4.

\section{Reflectômetro \#28267}

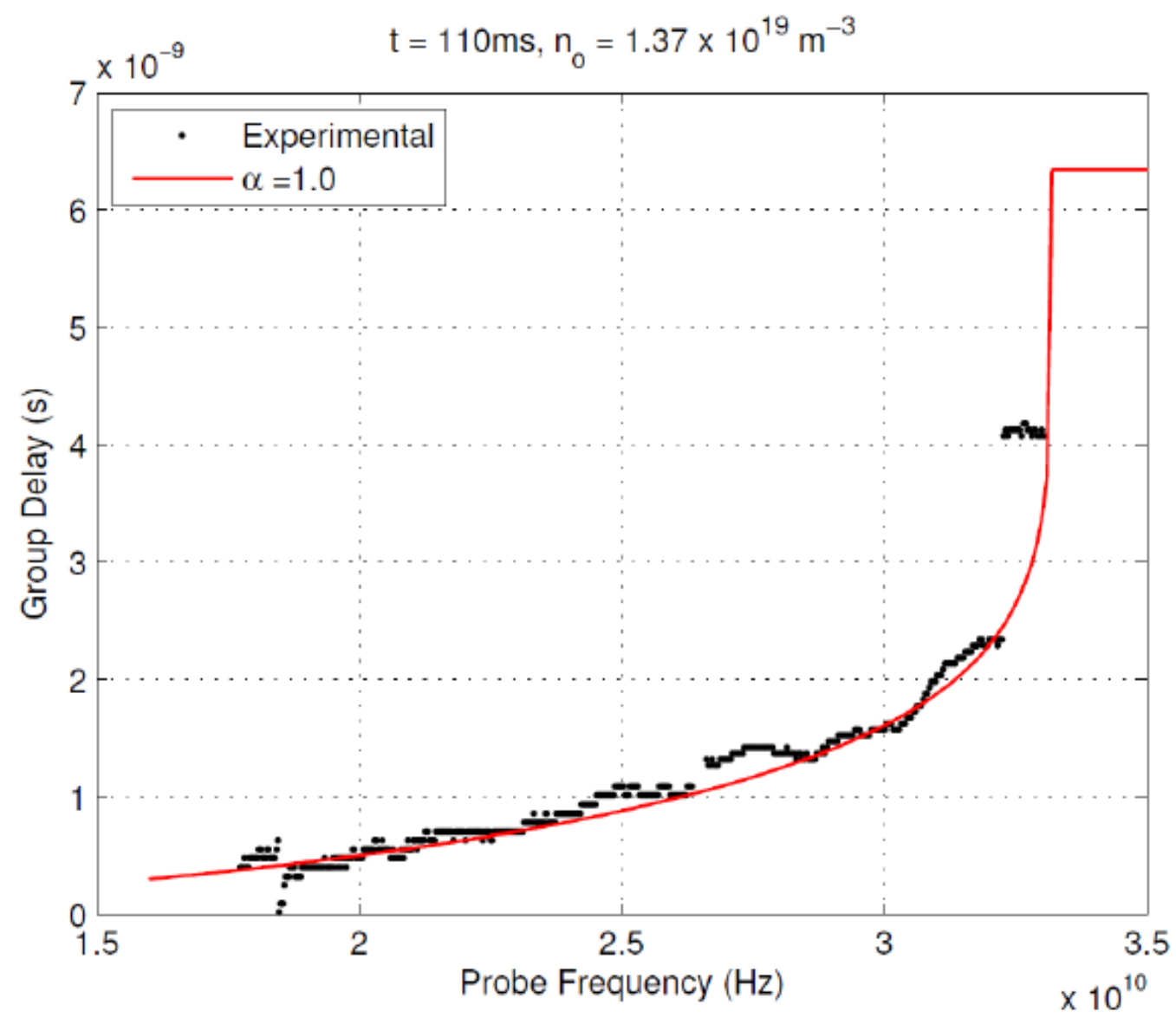

Figura 4.4: Tempo de atraso medido pelo interferômetro e ajuste dos dados pelo tempo de atraso considerando um perfil parabólico, para o instante $110 \mathrm{~ms}$ do disparo \#28267. Obtemos o valor de $n_{0}=1.37 \times 10^{19}$ e $\alpha=1.0$. 
Como podemos observar, o valor ajustado para o parâmetro $\alpha$ é 1.0. O valor obtido é maior que o estimado pelos dois canais do interferômetro, que indica $\alpha=0.7$.

Como temos um dos canais do interferômetro na posição $r=-1.25 \mathrm{~cm}$ e o outro na posição $r=9.25 \mathrm{~cm}$, e como o deslocamento de Shafranov se dá na direção positiva, temos um efeito de alisamento no perfil da densidade. Esse efeito faz que os valores de densidade obtidos pelos dois canais tenham um valor mais próximo, entre si, do que teriam se não houvesse deslocamento de Shafranov.

Para entender o quanto isso afeta nossa estimativa sobre a densidade central do plasma, vamos supor um perfil de densidade que considere o deslocamento de Shafranov [21].

$$
n(r)=n_{0}\left(1-y^{2}-\left[x-\delta\left(1-x^{2}\right)\right]^{2}\right)
$$

Onde temos $\delta$ o deslocamento de Shafranov normalizado, dado por $\delta=\frac{a}{2 R}\left(\bar{\beta}_{p}+\frac{1}{4}\right)$. Para calcular o $\bar{\beta}_{p}$ médio usamos a fórmula [59]

$$
\bar{\beta}_{p}=4.03 \times 10^{-11} \bar{n}\left(\mathrm{~cm}^{-3}\right) \bar{T}(\mathrm{eV}) \bar{B}_{p}^{-2}(G)
$$

para os valores médios do TCABR. No caso podemos considerar uma temperatura de $T_{e} \approx 300 \mathrm{eV}$, uma densidade de $1-2 \times 10^{13} / \mathrm{cm}^{3}$ e $B_{p} \approx 800-1000 G$, correspondendo a uma corrente de $70-90 k A$. Assim, obtemos $\beta_{p} \approx 0.15-0.50$ e o deslocamento de Shafranov é estimado entre 1 e $2 \mathrm{~cm}$.

Podemos recalcular os valores da densidade no centro e do expoente $\alpha$ para o disparo \#28267, considerando o perfil de densidade com deslocamento de Shafranov. Os valores de densidade e $\alpha$ obtidos serão comparados com os valores do perfil sem deslocamento. Para os cálculos vamos usar o valor de $1.5 \mathrm{~cm}$ para o deslocamento de Shafranov, $\delta=$ 0.08. Os resultados são apresentados na figura 4.5.

Como pode ser observado, há uma mudança considerável no valor da densidade do centro do plasma, calculado com dados do interferômetro, quando consideramos 
o deslocamento de Shafranov. O valor do parâmetro $\alpha$ muda de 0.7 para próximo de 1.0, apresentando maior concordância com a medida feita pelo reflectômetro. A densidade no centro aumenta em torno de 15\%. Essa diferença no valor da densidade já é suficiente para explicar o erro na medida da massa efetiva.

\section{\#28267 - Interferômetro}

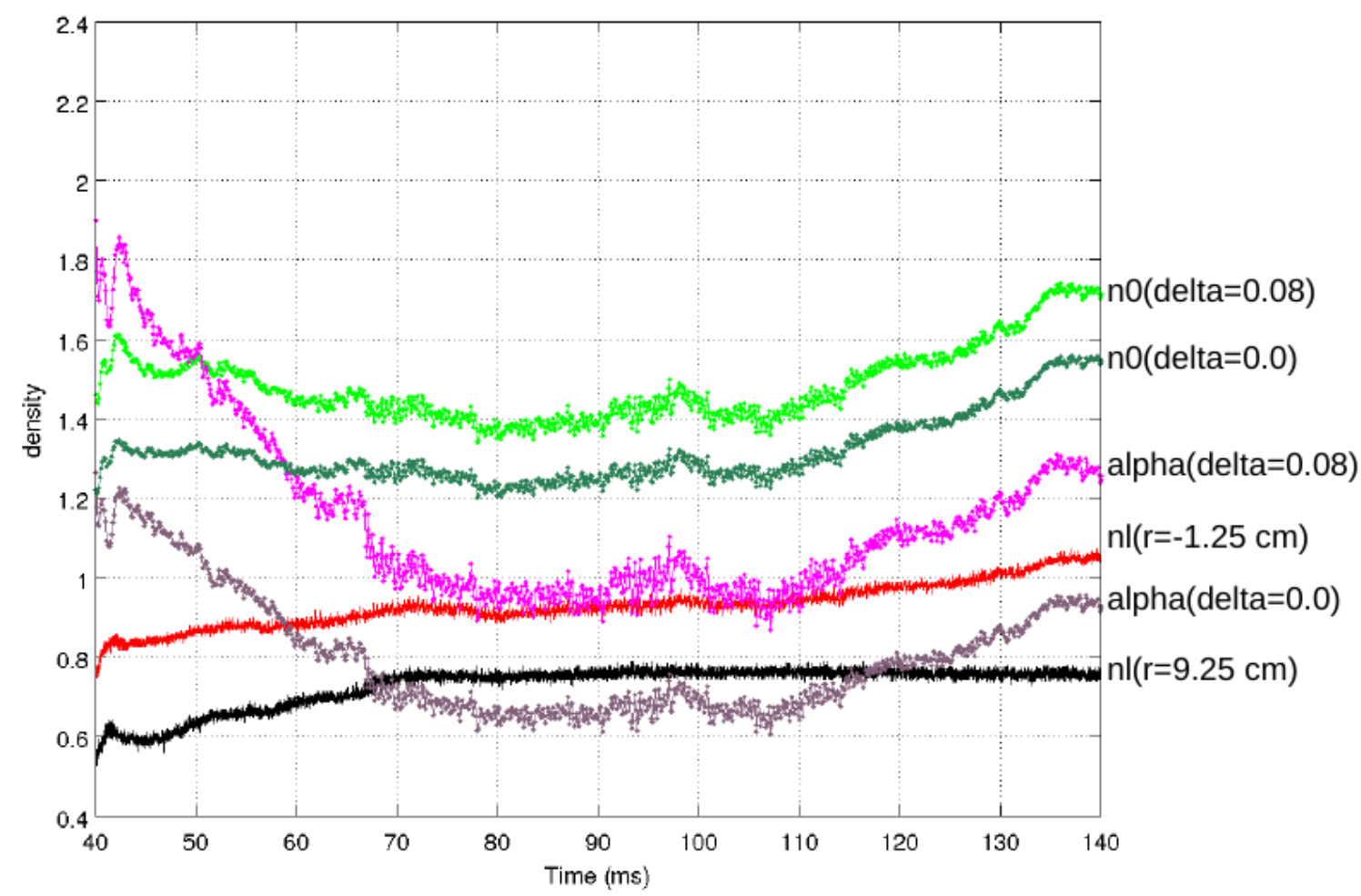

Figura 4.5: Comparação do cálculo da densidade no centro do plasma e do valor do parâmetro $\alpha$, com deslocamento $(\delta=0.08)$ e sem deslocamento $(\delta=0.00)$ o perfil com deslocamento de Shafranov.

Apesar da consideração do deslocamento de Shafranov apresentar uma boa concordância com o valor estimado para a massa efetiva, o valor exato do deslocamento não é bem conhecido e não temos um diagnóstico específico para o medir.

\section{Interferência do campo magnético nas medidas com o interferômetro}

Outra fonte de erro sistemático é a interferência do campo magnético, devido às correntes nas bobinas que geram o plasma e fazem seu controle. Os dados do interferômetro no vácuo apresentam um valor diferente de zero, como podemos ver na figura 4.6 
para o disparo \#28385, em que não houve plasma. No caso, vemos que é apresentado um valor positivo para a densidade em grande parte do disparo, e há uma pequena diferença entre ambos os canais. Sendo assim, a interferência nos faz obter um valor de densidade maior que o real.

TCABR \#28385

(a) nne03(x1e18)

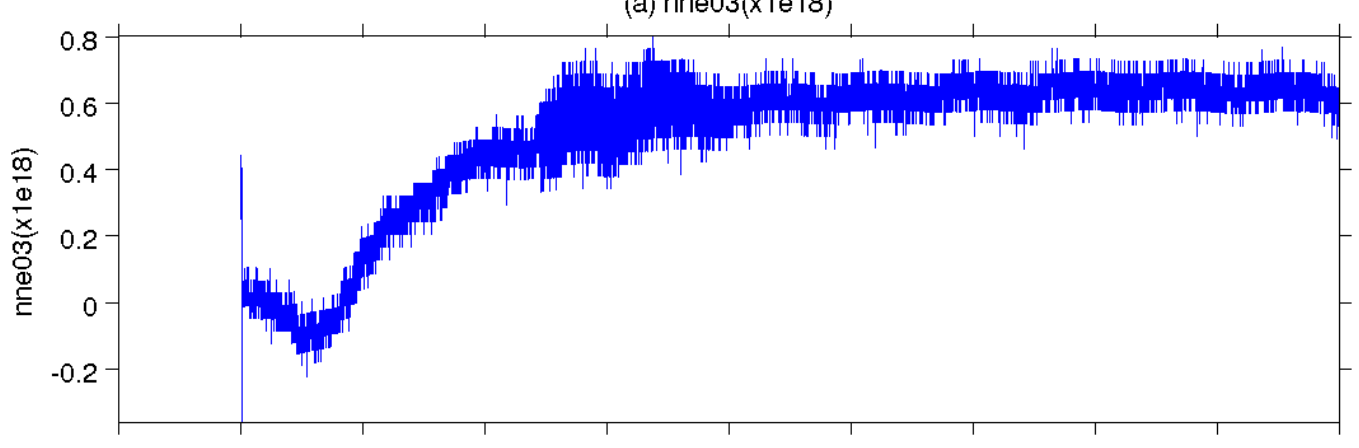

(b) nne02(x1e18)

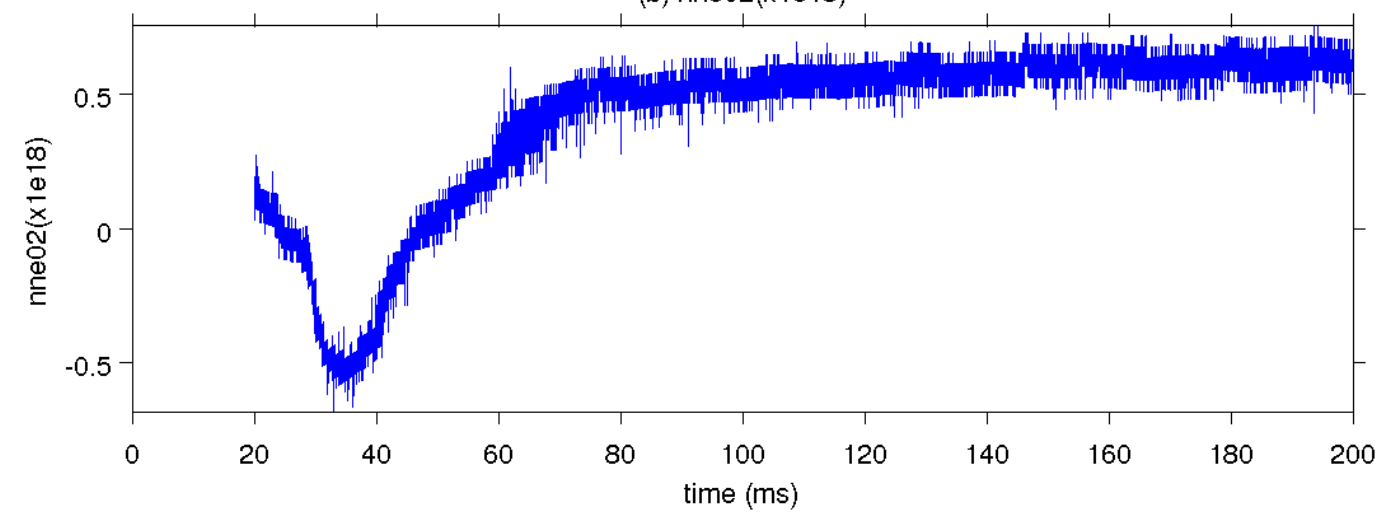

Figura 4.6: Sinal nos canais do interferômetro em um disparo sem plasma, \#28385.

Fazendo a correção da densidade estimada no centro obtemos uma diminuição de até 3\% no valor da densidade central do plasma. Acreditamos que uma combinação entre esse efeito e o deslocamento de Shafranov possa explicar o valor da massa efetiva maior.

\subsubsection{Estimativa da massa efetiva com densidade corrigida pelo deslocamento de Shafranov}

Podemos reconstruir a figura 3.9 usando a densidade central corrigida pelo deslocamento de Shafranov e considerando a perturbação nas medidas do interferômetro 
devida ao campo magnético do ôhmico. Usaremos o valor de $\delta=0.08$. O resultado é apresentado na figura 4.7. O valor do deslocamento de Shafranov foi considerado como o mesmo para todos os pontos experimentais. Essa suposição não deve corresponder ao caso real do TCABR, mas é uma aproximação boa. Se considerarmos $\delta=\beta_{p} \sim \frac{\bar{n} \bar{T}}{\bar{B}_{p}}$, podemos supor que as variações das três grandezas se compensam na média, ou seja, com uma maior densidade temos uma temperatura e um campo menores. Apesar de ser uma aproximação, ela se mostra suficiente para a nossa análise.

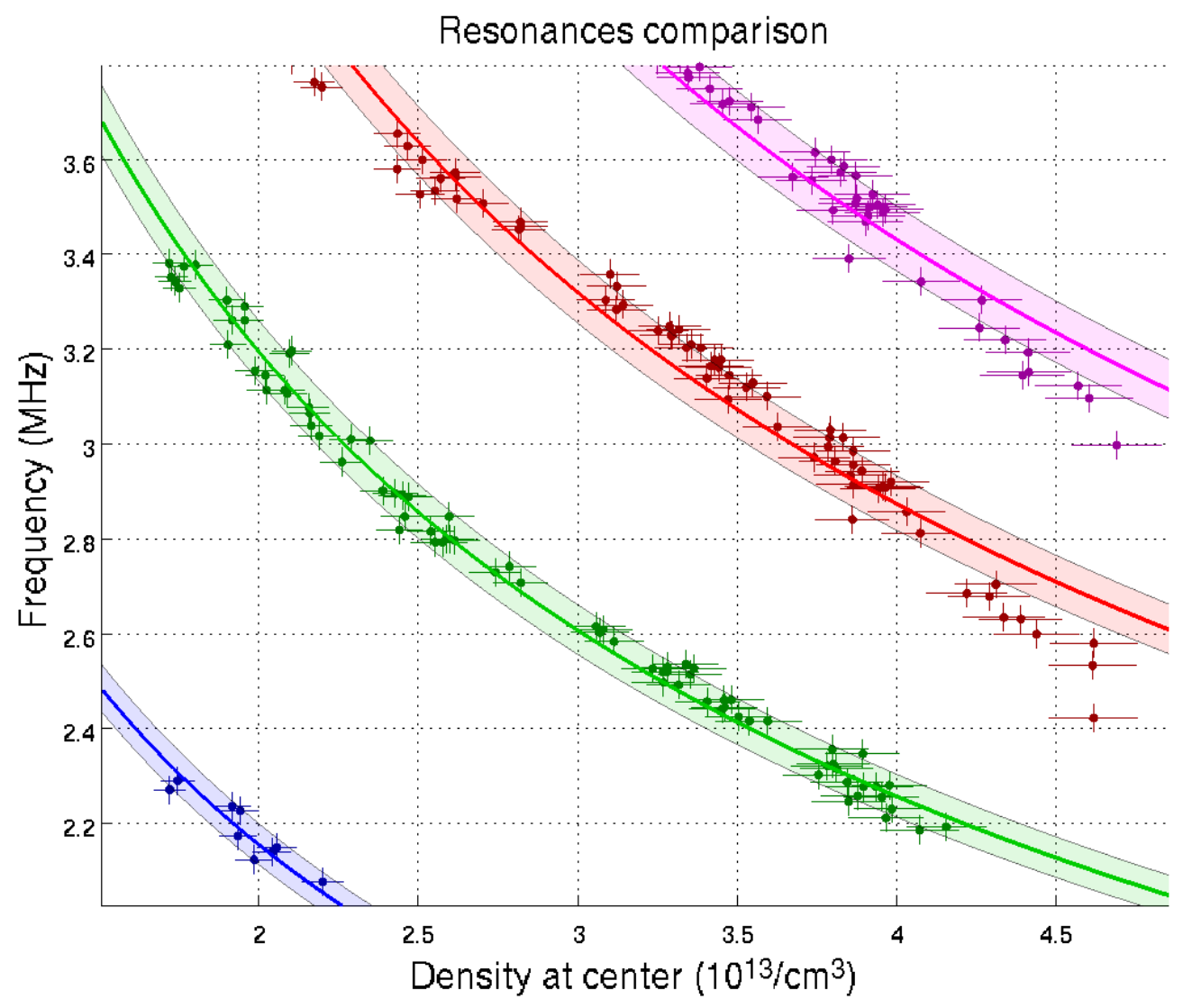

Figura 4.7: Ressonância de GAW da figura 3.9, com o valor da densidade central dos elétrons corrigida pelo deslocamento de Shafranov.

Para os dois primeiros modos excitados, que são os modos $N / M=1 / 1$ e $2 / 1$, calculamos o valor da frequência de ressonância do modo global, considerando a densidade no centro do plasma. Calculamos o contínuo analogamente ao apresentado na figura 4.3. O resultado é apresentado na figura 4.8. Para o cálculo do contínuo de Alfvén, usamos uma concentração de carbono de $n_{C} \approx 6.5 \%$ e uma variação do fator de segu- 
rança no centro com a densidade linear $q_{0}=0.92-0.99$ para $n_{0}=1.3-4.0 \times 10^{19} / \mathrm{m}^{3}$, como uma aproximação. Como o perfil de densidade é mais agudo, a diferença entre o centro e o mínimo do contínuo muda drasticamente, de $70 \mathrm{KHz}$ para $10 \mathrm{~K} \mathrm{~Hz}$, aproximadamente, para o modo $N=1, M=1$. Consideramos o expoente do perfil de densidade $\alpha=1.1$, escolhemos este valor, devido ao perfil de densidade agudo que é obtido com a correção pelo deslocamento de Shafranov.

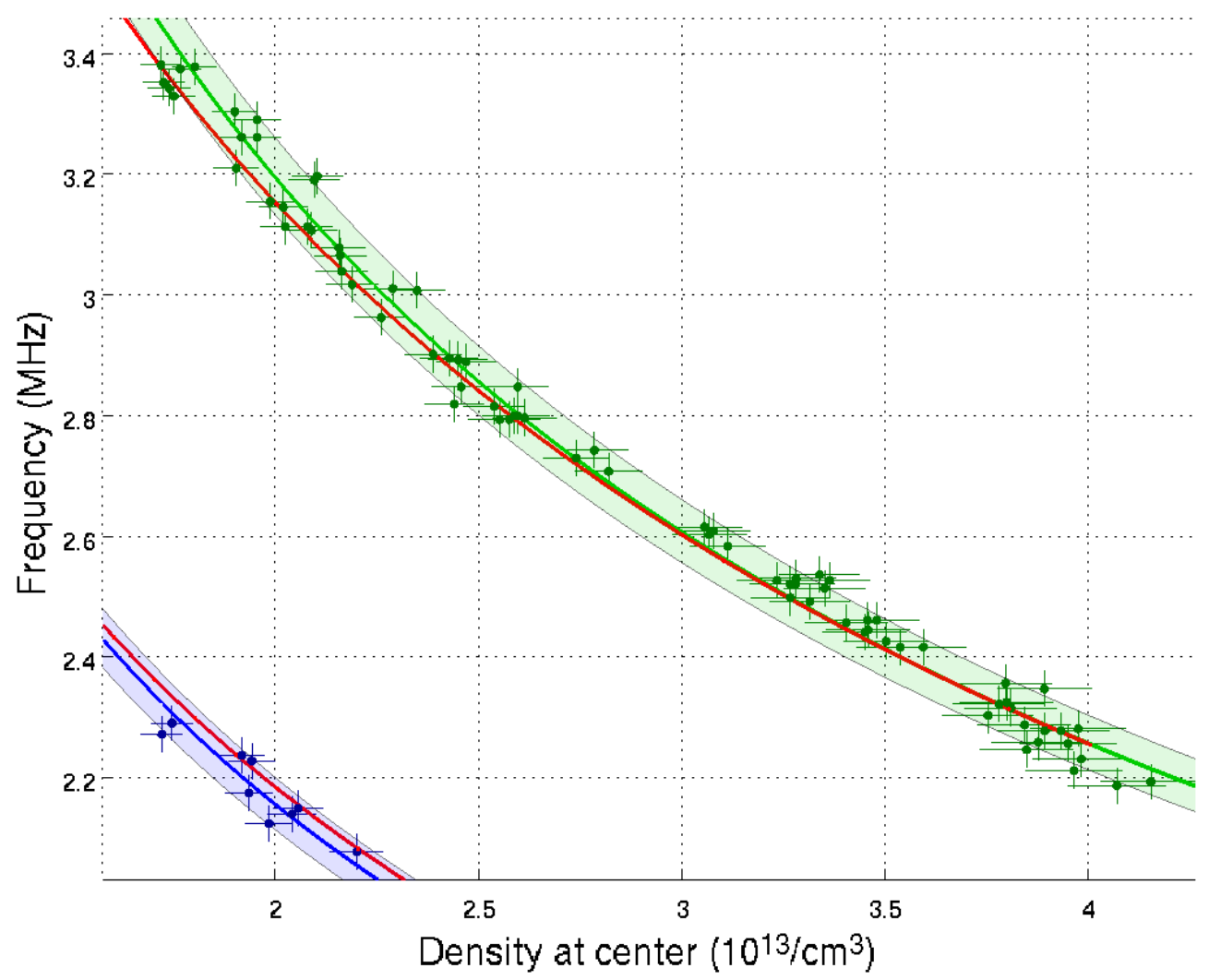

Figura 4.8: Correção da densidade central pelo deslocamento de Shafranov, para identificação das ressonâncias para os modos $N / M=2 / 1$ e 1/1, com cálculo do contínuo com impurezas (vermelho).

Com a concentração de carbono estimada, obtemos a massa efetiva $A_{\text {eff }}=1.40 \pm$ 0.06 e um valor compatível com a nossa estimativa da carga efetiva $Z_{\text {eff }} \approx 3.0$. Este resultado confirma nossas suspeitas sobre uma menor concentração de impurezas no TCABR.

Alternativamente, podemos considerar uma mistura de íons leves, $A_{l}=14$ e $Z_{l}=7$, 
uma mistura de carbono, oxigênio e nitrogênio, com íons pesados, sendo ferro ionizado $19\left(\mathrm{Fe}^{+19}\right)$ vezes $\left(A_{h}=56\right.$ e $\left.Z_{h}=19\right)$. Esses valores são estimados experimentos conduzidos no TCA em Lausanne [38]. Obtemos a concentração de 4.5\% de íons leves e $0.15 \%$ de íons pesados, aproximadamente. Consideramos nitrogênio pois temos proteção de nitreto de boro para as antenas.

\subsection{Excitação de $G A W$ com plasma de Hélio}

Para tentar eliminar erros sistemáticos na estimativa da massa efetiva, efetuamos uma calibração do sistema de Alfvén com descargas ôhmicas com gás hélio. O objetivo da realização desses experimentos foi calibrar o sistema, identificando a massa efetiva com outro gás e assim ter uma melhor medida da massa efetiva pelo método proposto.

A importância de usar um gás como o hélio nos experimentos é que sua razão carga massa é igual a das impurezas mais relevantes para o TCABR, como o nitrogênio, oxigênio e o carbono.

Para entendermos a importância da razão carga massa, vamos calcular o contínuo de Alfvén quando se considera mais de uma espécie de íons com a mesma razão carga massa. Temos a equação do contínuo de Alfvén

$$
\sum_{i} \frac{\omega_{p i}^{2} \omega_{A}^{2}}{\left(\omega_{c i}^{2}-\omega_{A}^{2}\right)}=k_{\|}^{2} c^{2}
$$

Supomos que a razão carga massa é a mesma para todas as espécies do plasma e que as impurezas estão completamente ionizadas, hipóteses razoáveis para a temperatura dos elétrons no centro do TCABR $T_{e} \approx 500 e V[60]$. Com essas suposições fica simples calcular a massa efetiva. Lembrando que $\omega_{c i}=\frac{Z_{i} e B}{m_{i} c}$ e $\omega_{p i}=\sqrt{\frac{4 \pi n_{i} Z_{i}^{2} e^{2}}{m_{i}}}$, obtemos

$$
\sum_{i} \frac{4 \pi n_{i} Z_{i}^{2} e^{2}}{m_{i}} \frac{m_{i}^{2} c^{2}}{Z_{i}^{2} e^{2} B^{2}} \frac{\omega_{A}^{2}}{\left(1-\frac{\omega_{A}^{2}}{\omega_{c i}^{2}}\right)}=k_{\|}^{2} c^{2}
$$

Como sabemos que a razão carga massa é a mesma para todas as espécies $i$, podemos escrever $R=m_{i} / Z_{i}$ (neste caso temos $R=2$ ) 


$$
\sum_{i} \frac{4 \pi n_{i} m_{i}}{B^{2}} \frac{\omega_{A}^{2}}{\left(1-\frac{R^{2} \omega_{A}^{2}}{e^{2} B^{2}}\right)}=\frac{4 \pi}{B^{2}} \frac{\omega_{A}^{2}}{\left(1-\frac{R^{2} \omega_{A}^{2}}{e^{2} B^{2}}\right)} \sum_{i} n_{i} m_{i}=k_{\|}^{2}
$$

Agora vamos escrever a densidade das espécies de íons em função da densidade dos elétrons, como $n_{i}=\frac{n_{e_{i}}}{Z_{i}}$

$$
\frac{4 \pi}{B^{2}} \frac{\omega_{A}^{2}}{\left(1-\frac{R^{2} \omega_{A}^{2}}{e^{2} B^{2}}\right)} \sum_{i} R n_{e_{i}}=k_{\|}^{2}
$$

Como a somatória da densidade de elétrons de cada espécia nos da a densidade de elétrons total $\sum_{i} n_{e_{i}}=n_{e}$, obtemos finalmente

$$
\omega_{A}=\frac{B k_{\|}}{\sqrt{4 \pi R n_{e}}} \sqrt{1-\frac{R^{2} \omega_{A}^{2}}{e^{2} B^{2}}}
$$

pode ser escrito, isolando $\omega_{A}$, como

$$
\omega_{A}=\frac{B k_{\|}}{\sqrt{4 \pi R n_{e}}} \frac{1}{\sqrt{1+\frac{R k_{\|}^{2}}{4 \pi e^{2}}}}=\frac{k_{\|} v_{A}}{\sqrt{1+\frac{k_{\|}^{2} v_{A}^{2}}{\omega_{c i}^{2}}}},
$$

que é a equação para o contínuo de Alfvén. Denominamos de correção íon-cíclotron o termo extra na expressão do contínuo de Alfvén. Para o caso do hidrogênio, esse termo pode ser desprezado, mas para átomos mais pesados, como o hélio, sua influência é maior.

Vemos que a massa efetiva é o valor de $A_{e f f}=R$. O mesmo resultado pode ser obtido diretamente da definição de massa efetiva

$$
A_{e f f}=\frac{\sum_{i} m_{i} n_{i}}{m_{H} n_{e}}
$$

Podemos dizer que a massa efetiva de um plasma de hélio totalmente ionizado é $A_{e f f}=2$. Com certeza há um pequeno desvio desse valor, devido a impurezas metálicas, mas como a concentração dessas impurezas é muito baixa $(<0,5 \%)$, a mudança no valor da massa efetiva é menor que $1 \%$. 


\subsubsection{Correção pelo termo íon-cíclotron}

No caso do plasma de hélio temos mais influência do termo íon-cíclotron $\left(\omega_{A} / \omega_{c}\right)$ do que em um plasma de hidrogênio. Sendo assim, vamos levar esse fator em conta na análise dos dados. Dada a (eq. 4.12), obtemos para o contínuo de Alfvén

$$
\omega_{A}=k_{\|} v_{A} \frac{1}{\sqrt{1+\frac{k_{\|}^{2} v_{A}^{2}}{\omega_{c i}^{2}}}}
$$

Essa correção também pode ser aplicada para plasmas de hidrogênio, mas seu efeito é bem menor. Para um próton, a frequência de ciclotron é a metade do valor da mesma para uma partícula alfa, mas como temos o termo ao quadrado obtemos um valor para a razão 4 vezes menor. No caso do hidrogênio teríamos uma correção menor que $1 \%$. Para estimar a correção em um plasma de hélio, tomamos a frequência da ressonância do GAE em 2.4MHz.

$$
\begin{gathered}
\frac{k_{\|}^{2} v_{A}^{2}}{\omega_{c i}^{2}} \approx\left(\frac{2.4 M H z}{8.2 M H z}\right)^{2} \approx 0.09 \\
\omega_{A} \approx 0.96 \times k_{\|} v_{A}
\end{gathered}
$$

Há uma mudança na frequência de cerca de 4\%. Essa correção é importante para comparar melhor a massa efetiva do plasma de hélio com a de hidrogênio. Para comparar a massa efetiva, lembramos que a frequência de Alfvén depende do inverso da raiz da massa, sendo assim temos uma correção de cerca de $8 \%$ no valor da massa efetiva.

Efetivamente, faremos o ajuste das frequências de ressonância detectadas com o plasma de hélio usando a (eq. 4.15), para compararmos com os ajustes da figura 3.9. Mas é útil estimar seu valor e justificar a diferença no ajuste das ressonância em relação ao plasma de hidrogênio. 


\subsubsection{Ressonâncias detectadas}

Neste seção iremos tratar os experimentos de excitação de ondas de Alfvén em plasma de hélio. Os experimentos foram realizados de maneira análoga aos experimentos com plasma de hidrogênio, apresentado no capítulo anterior.

Houve uma dificuldade inicial em obter o plasma de hélio no TCABR. Infelizmente a válvula rápida, que controla a injeção de gás, não responde muito rapidamente ao hélio. Porém, com injeção de gás contínua e com um controle auxiliar com a válvula rápida, conseguimos disparos com plasma de qualidade. Outra alteração realizada para conseguirmos disparos bons foi aumentar a energia depositada no plasma, pelo sistema ôhmico, no começo da descarga. Isso garante que ionizamos completamente o hélio, que precisa de mais energia que o hidrogênio. Outra dificuldade foi na determinação da densidade do centro, pois, infelizmente o segundo canal do interferômetro não estava operante. Com isso não foi possível determinar com qualidade a densidade no centro do plasma com o mesmo método usado para o hidrogênio.

O valor da densidade central estimada para o hélio é afetado pelo deslocamento de Shafranov e pela interferência no sinal do interferômetro. Porém, como não estavam disponíveis os dois canais do interferômetro quando foram feitos disparos com hélio, a discussão fica mais limitada. Como foi necessário supor um perfil para o hélio sem muita informação, podemos dizer que a diferença pela interferência está incluída na incerteza dos dados. Já para o perfil, supomos que é parecido com o do plasma de hidrogênio sem a correção pelo deslocamento de Shafranov, pois esses dados foram obtidos com menos suposições.

Os dados básicos de um disparo típico, como o \#31658, se encontram na figura 4.9. Apesar de apresentar um alto nível no sinal de raio-X duro, este nível permaneceu baixo durante a aplicação da corrente de RF, para excitação de ondas. Os parâmetros do plasma não apresentam diferença dos parâmetros de um plasma de hidrogênio, e a temperatura dos elétrons se apresentou um pouco mais alta $\left(\Delta T_{e} \approx 50 \mathrm{eV}\right)$.

Na figura 4.10 são apresentados os dados relevantes para a detecção das ondas de 

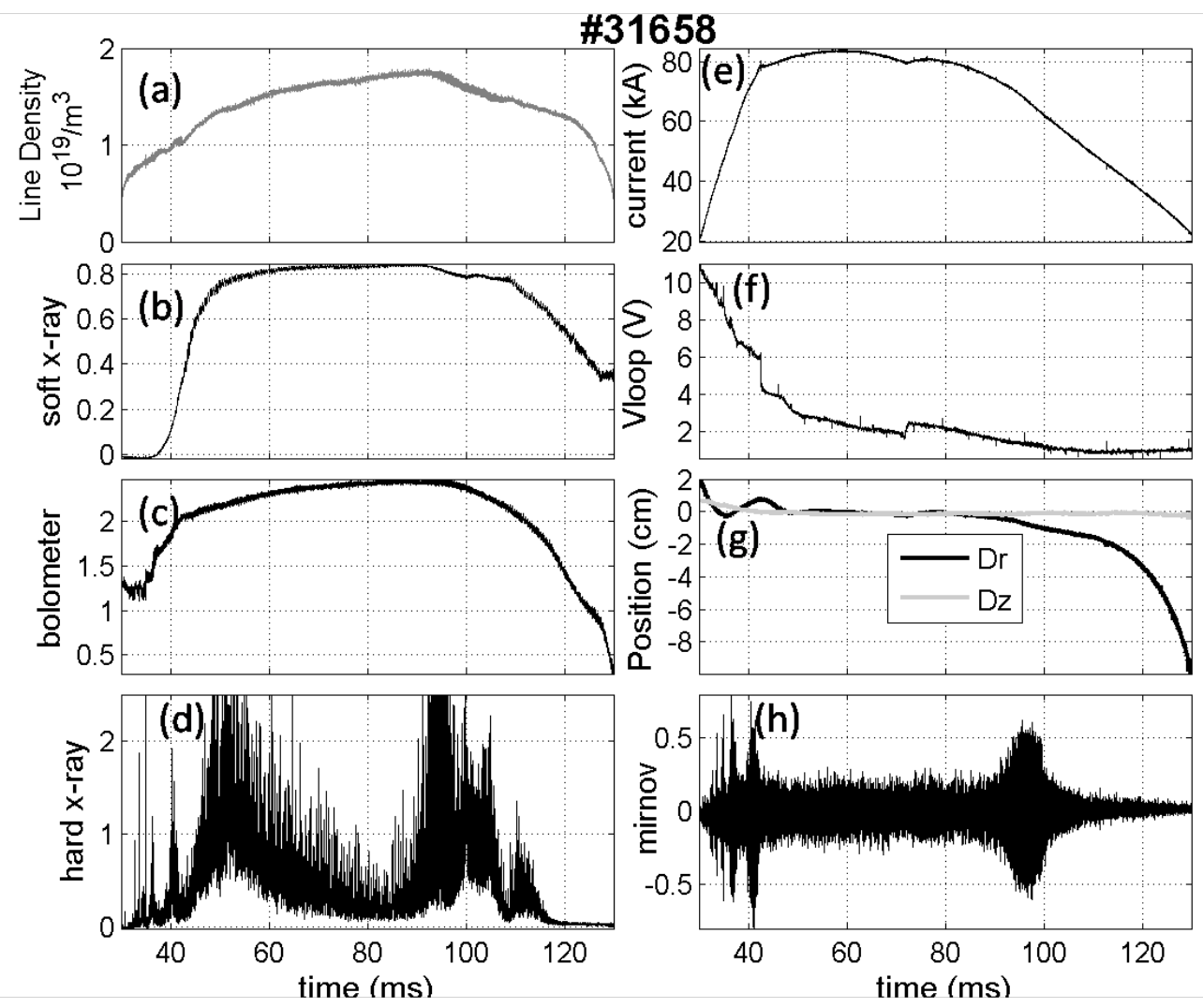

Figura 4.9: Evolução temporal dos principais parâmetros do plasma para o disparo \#31658. Os sinais apresentados são densidade de linha no raio $-1.25 \mathrm{~cm}$ (a), emissão de raio- $X$ mole do centro (b), sinal do bolômetro do centro (c), sinal do raio- $X$ duro $(d)$, corrente de plasma (e), voltagem de loop (f), posição vertical e horizontal (g), e oscilações magnéticas ( $h$ ).

Alfvén. É possível observar claramente os picos no sinal da sonda magnética identificados como as ressonâncias dos GAEs. As ressonâncias estão destacadas no gráfico, há também uma terceira ressonância que não está visível nesta escala. Vemos claramente a presença de oscilações dente de serra, que auxiliam na determinação do valor do fator de segurança.

Assim como com o plasma de hidrogênio, foram realizados diversos disparos para o plasma de hélio. O conjunto das ressonâncias identificadas está apresentado na figura 4.11. Obtivemos ressonâncias de três modos distintos. Para a ressonância mais baixa, que é a azul na figura 3.9, não obtemos dados pois o plasma precisaria de uma densidade muito baixa e com essas densidades não conseguimos produzir disparos estáveis.

Um cuidado para se fazer esta figura foi em relação a medida da densidade, devido 

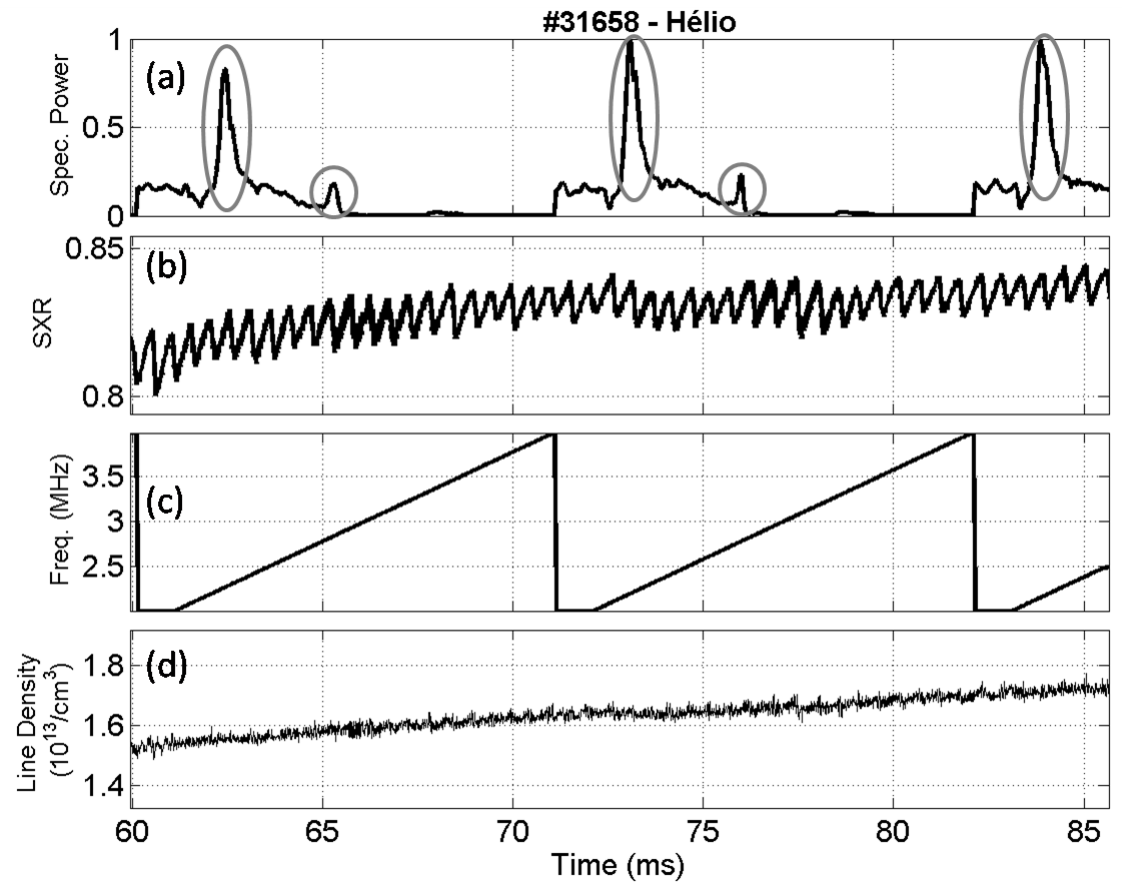

Figura 4.10: Evolução temporal da potência espectral do sinal da sonda magnética, normalizado pela amplitude da corrente de RF (a), comparado com o sinal da emissão de raio-X mole (b), a frequência da corrente de $R F$ (c) e a densidade de linha no raio $-1.25 \mathrm{~cm}$ (d), para o disparo \#31658.

a falta do segundo canal do interferômetro. Assim, nosso método de determinar a densidade no centro, com o uso de dois canais, não pode ser utilizado. Para contornar esse problema, supomos um perfil semelhante ao do hidrogênio para o hélio, com o expoente $\alpha=0.9$, na (eq. 2.1).

Fora isso, descartamos pontos de ressonância onde o deslocamento radial era maior que $0.2 \mathrm{~cm}$. Isso nos garantiu uma relação melhor entre a densidade e a frequência de ressonância. Mesmo que o expoente $\alpha$ seja um pouco diferente para o hélio, não fará muita diferença $(<10 \%)$ na estimativa da densidade do centro do plasma, se comparada as medidas com o plasma de hidrogênio.

Para fazer o ajuste da frequência das ressonâncias em relação a densidade, no caso do plasma de hélio, usamos uma função que leva em conta a correção pelo termo Hall.

$$
\frac{\omega_{G A E}}{\sqrt{1-\frac{\omega_{G A E}^{2}}{\omega_{c_{H e}}^{2}}}}=k_{\|} v_{A}=\frac{F}{\sqrt{n}}
$$


O termo $F$ é definido como na (eq. 4.2). Vamos usar essa função para o ajuste da frequência de ressonância pela densidade e comparar para plasmas com diferentes massa dos íons.

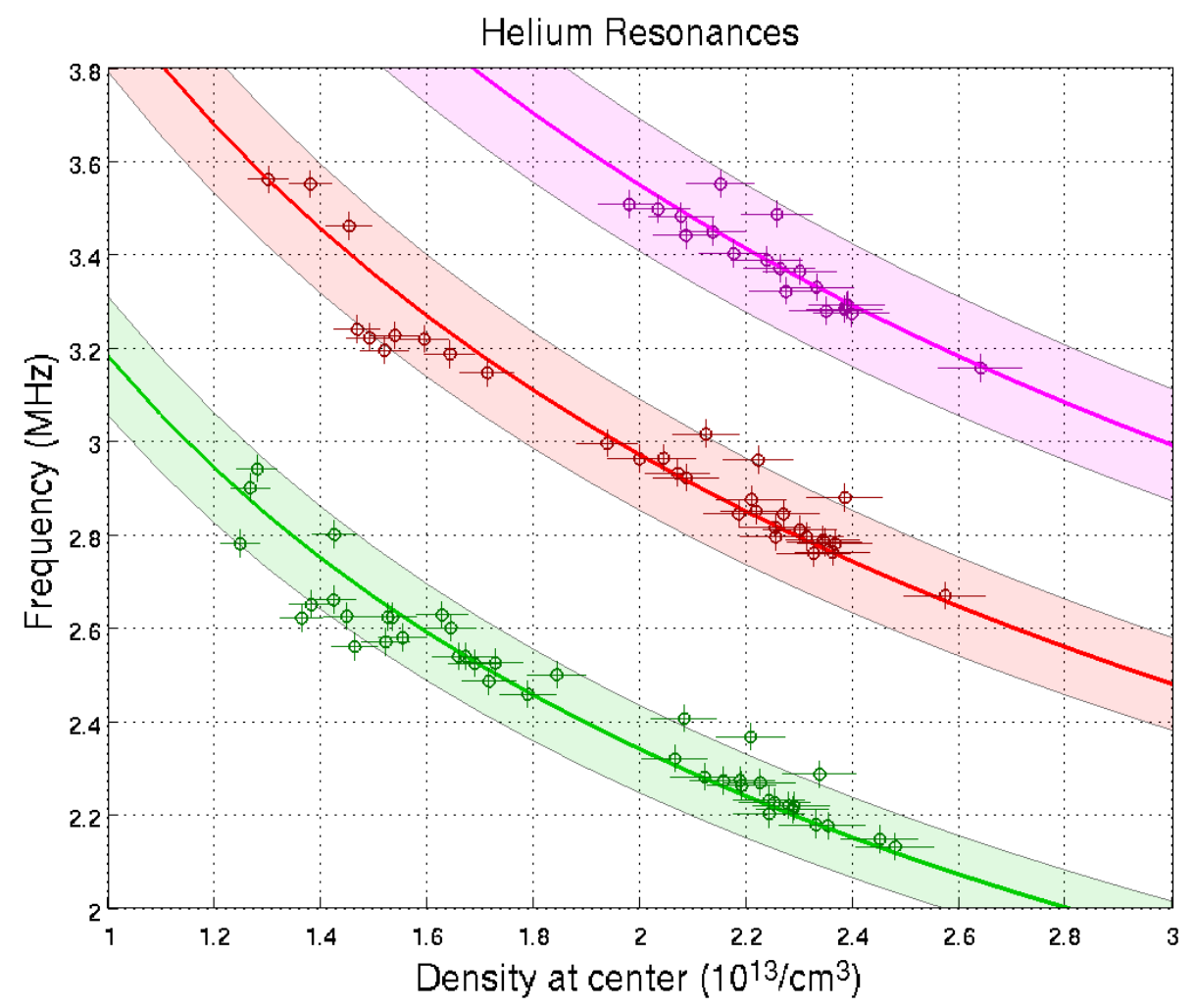

Figura 4.11: Dependência da frequência das ressonâncias identificadas com a densidade calculado para o centro do plasma. Para os modos $|N|+|M|=3$ (verde), 4 (vermelho) e 5 (rosa).

Comparando a figura 4.11 com a figura 3.9, vemos que as ressonâncias têm o mesmo comportamento, mas se encontram com frequências diferentes para a mesma densidade. Isso é esperado pela diferente massa efetiva dos íons.

\subsubsection{Comparação com plasma de hidrogênio}

Como sabemos o valor da massa efetiva do plasma de hélio, podemos recalcular a massa efetiva do plasma de hidrogênio. Para isso são usados os ajustes mostrados nas figuras 3.9 e 4.11 .

O fator $F$ é o mesmo para ambos os ajustes, representando o parâmetros do 
TCABR. A razão entre os calores de $F$ obtidos para o hidrogênio e o hélio indica a massa efetiva dos íons do plasma. Como sabemos que a massa efetiva do plasma de Hélio é $A_{e f f_{H e}}=2$, temos a massa efetiva do hidrogênio como

$$
A_{e f f_{H}}=2\left(\frac{F_{H e}}{F_{H}}\right)^{2}
$$

No caso nós detectamos três ramos de ressonância. Sendo assim, podemos fazer a média ponderada pela incerteza entre os três. O valor obtido, nesse caso, para a massa efetiva no plasma de hidrogênio é $A_{e f f_{H}}=1.40 \pm 0.07$. Se considerarmos apenas o modo $(\mathrm{N}=2, \mathrm{M}=1)$, ramo verde, obtemos $A_{e f f_{H}}=1.37 \pm 0.04$, sendo, portanto, valores compatíveis.

Apesar de ambos os valores serem compatíveis, os valores ajustados para os modos de número de onda mais alto apresentam uma massa efetiva maior, mas com uma incerteza também mais alta. Sendo assim, acabam por influenciar pouco o valor da massa efetiva. Fora isso, o mínimo do contínuo não está, necessariamente, ligado ao valor da densidade no centro do plasma para os outros modos. Eles podem estar um pouco deslocados do centro, e assim é difícil afirmar o valor que obtivemos. O valor da densidade do centro para o hélio não é bem conhecido também, um erro em sua estimativa pode influenciar diretamente o valor estimado para a massa efetiva.

Nessa aproximação, uma massa efetiva de $A_{e f f_{H}}=1.40$ significa que temos uma concentração aproximada de carbono de $6.5 \%$ ou, equivalentemente, $6 \%$ de carbono e $0.15 \%$ de ferro ionizado 19 vezes, típico para $T_{e} \approx 500 \mathrm{eV}$. A carga efetiva estimada nesses casos é $Z_{\text {eff }} \approx 3.0 \pm 0.2$; esse valor é compatível com o valor calculado para as condições de plasma no TCABR.

Com o valor obtido para a massa efetiva, podemos ter uma mistura de cerca de $4.5 \%$ de íons leves e $0.15 \%$ de íons pesados. Para a mistura dos íons leves, com $A_{l}=14$ e $Z_{l}=7$, é uma mistura de carbono, oxigênio e nitrogênio, para os íons pesados consideramos ferro ionizado $19\left(\mathrm{Fe}^{+19}\right)$ vezes $\left(A_{h}=56\right.$ e $\left.Z_{h}=19\right)$.

Concluímos que, com a calibração do sistema de Alfvén com plasma de hélio, con- 
seguimos uma boa estimativa da massa efetiva da parte central do plasma no TCABR $A_{e f f}=1.40 \pm 0.07$. Este resultado confirma valores menores de concentração de impurezas do que obtidos na subseção 4.1.1, fornecendo um valor compatível com o obtido quando consideramos os erros sistemáticos na determinação da densidade central (deslocamento de Shafranov). Isso nos permite concluir que precisamos considerar o deslocamento de Shafranov para estimar a densidade no centro do plasma, para assim estimar corretamente a massa efetiva.

\subsection{Excitação de modos de Alfvén com números de onda elevados}

Com o valor de massa efetiva estimado, podemos calcular o contínuo de Alfvén para o TCABR para qualquer número de onda. Desta forma, vamos fazer algumas considerações quanto ao número de onda não determinado dos outros dois modos, os ramos vermelho e rosa apresentados na figura 4.7 .

Escolhemos a densidade $n_{0}=3.3 \times 10^{19} / \mathrm{m}^{3}$, na figura 4.7 . Vemos que nessa densidade conseguimos detectar 3 modos distintos. O modo $N / M=2 / 1$, já discutido, e outros dois com frequências mais elevadas. Inicialmente ajustamos o nível de impureza para o modo $N / M=2 / 1$, depois calculamos a frequência do modo global para os outros modos e vemos qual mais se aproxima aos dados experimentais. Usamos os sequintes parâmetros para o plasma: potência do perfil de corrente $\gamma=2.85$, corrente de plasma de $75 k A$, com o raio $q=1$ em $r \approx 1.5 \mathrm{~cm}$ e $q_{0}=0.99$, potência do perfil de densidade $\alpha=1.1$. Usando a ressonância $N / M=2 / 1$, estimamos a concentração de impurezas como $n_{C}=5.5 \%$ de carbono completamente ionizado e $n_{F e}=0.1 \%$ de ferro ionizado 19 vezes. Consideramos, baseado nos cálculos com código de [27], a frequência do GAE como 5.5\% abaixo do mínimo do contínuo.

Os valores das ressonâncias obtidos pela função de ajuste dos pontos experimentais são de $2.49 M H z, 3.17 M H z$ e $3.80 M H z$.

Acreditamos que cada ressonância corresponde a modos toroidais diferentes. Pelas 
estimativas usando o contínuo de Alfvén, figura 4.12, vemos que as frequências de ressonância são equivalentes às obtidas nos experimentos. Porém, como estamos lidando com um perfil de densidade agudo $(\alpha>1.1)$, o mínimo do contínuo é sempre próximo do centro. Isso implica que a localização do GAE é no centro e a frequência de ressonância depende quase que somente da densidade no centro do plasma.

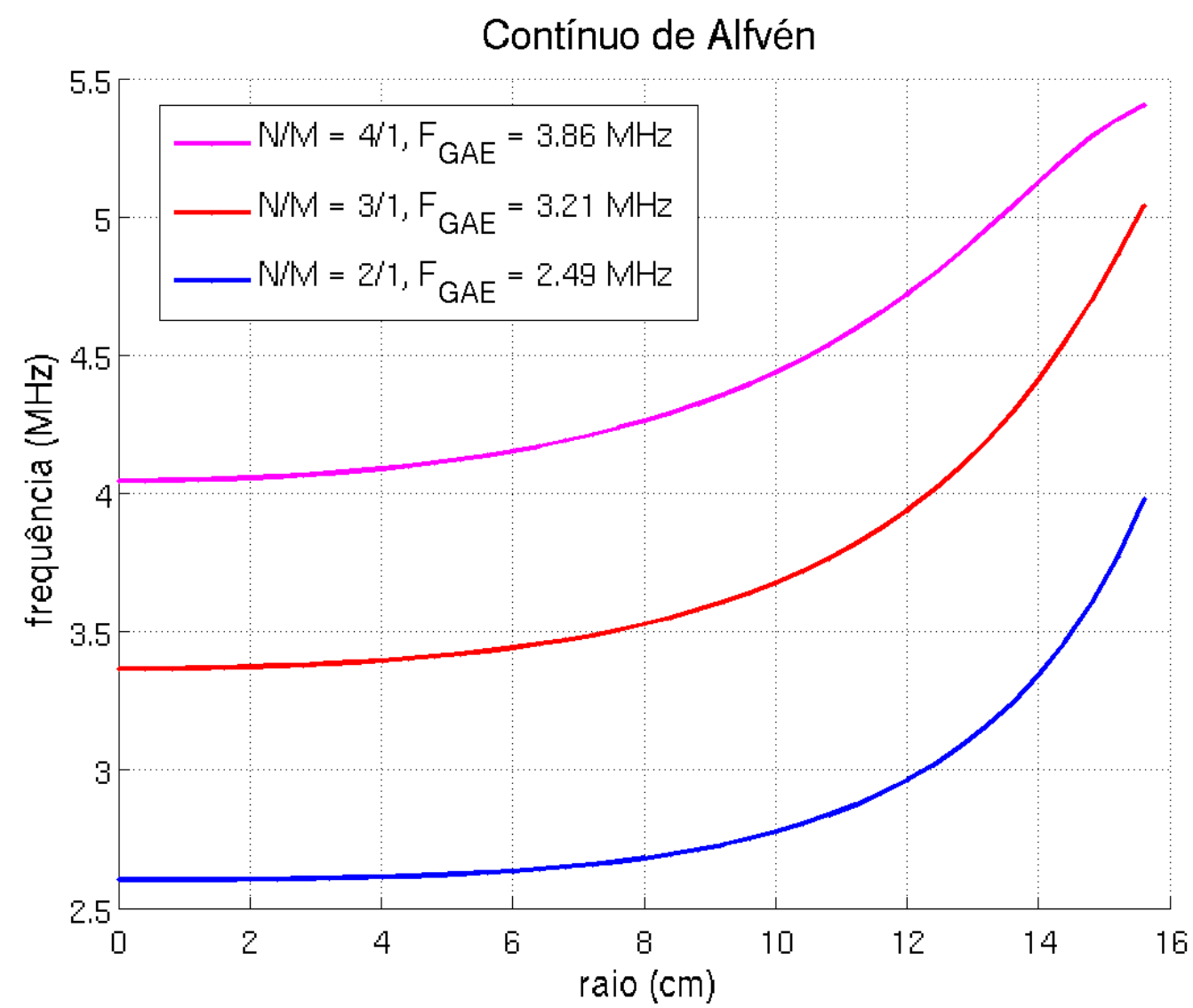

Figura 4.12: O contínuo de Alfvén para o plasma do TCABR para os modos $N / M=$ 2/1,3, 1 e 4/1, consideramos a densidade de $n_{0}=3.3 \times 10^{13} / \mathrm{cm}^{3}$ e a frequência do modo global como $\approx 5 \%$ menor que o mínimo do contínuo.

Como podemos observar, os valores das frequências dos três modos calculados são equivalentes aos das frequências obtidas experimentalmente. Porém, considerando um perfil de densidade agudo, o valor da frequência do GAE de modos com a mesma soma $N+M$ é muito próxima. Isso não permite que determinemos, apesar de termos um dos modos identificado, o número de onda dos modos usando somente a frequência de ressonância. 

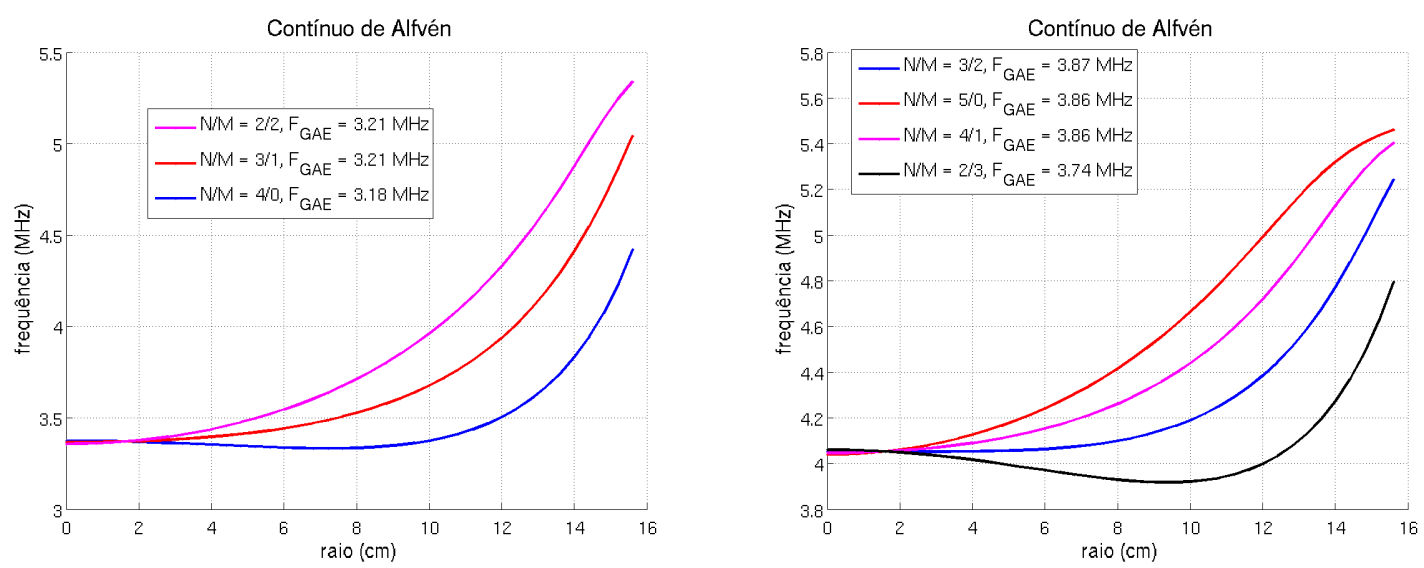

Figura 4.13: O contínuo de Alfvén para o plasma do TCABR para os modos diferentes modos $N / M$, mostrando a incerteza na determinação do número de onda dos modos para a soma $N+M=4$ (esquerda) e 5 (direita).

Na figura 4.13 apresentamos as frequências de alguns dos outros modos possíveis. Vemos que todos apresentam valores muito próximos da frequência do GAE.

No caso de considerarmos um perfil de densidade menos agudo, apenas os modos que se localizam mais no centro, ou tem o mínimo do contínuo próximo do valor do centro, são compatíveis com os dados experimentais.

\subsection{Oscilação da massa efetiva por dentes de serra}

Analisaremos em mais detalhe o disparo \#29565, em que podemos observar oscilações dente de serra. Os dados referentes a este disparo estão disponíveis nas figuras 3.6 e 3.7 .

Podemos observar a oscilação da amplitude do sinal de RF da sonda magnética, no momento da ressonância de Alfvén, com a oscilação dente de serra. Essa oscilação indica que ocorre um aumento no nível de impurezas no centro do plasma durante um ciclo do dente de serra. Podemos estimar quanto deve variar a massa efetiva baseado na amplitude da oscilação na sonda magnética, no sinal do raio-X mole e no sinal do ECE.

Primeiramente, precisamos considerar que a corda central do detector de raio-X mole detecta emissão de Bremsstrahlung, que pode ser escrita como 


$$
P_{B r}=S X R=\frac{\sum\left(Z_{i}^{2} n_{i}\right) n_{e} T_{e}^{1 / 2}}{\left(7.69 \times 10^{18} / m^{3}\right)^{2}} \propto n_{e}^{2} Z_{e f f} T_{e}^{1 / 2}
$$

Podemos estimar a radiação da emissão induzida pela oscilação dente de serra como:

$$
\frac{\Delta S X R_{S T}}{S X R_{S T}}=2 \frac{\Delta n_{e}}{n_{e}}+\frac{\Delta T_{e}}{2 T_{e}}+\frac{\Delta Z_{\text {eff }}}{Z_{\text {eff }}} \approx 25-30 \%
$$

onde temos $2 \frac{\Delta n_{e}}{n_{e}} \approx 2-3 \%$, obtido pelo sinal do interferômetro, $\frac{\Delta T_{e}}{T_{e}} \approx 5-6 \%$, dado pelo sinal do ECE no centro, que nos dá uma variação de $\frac{\Delta Z_{\text {eff }}}{Z_{\text {eff }}} \approx 18-22 \%$. O valor obtido para a variação da densidade leva em conta que as oscilações dente de serra aumentam a concentração de impurezas no centro e causam uma diminuição até aproximadamente o raio $q=2$.

Dado que $\frac{A_{e f f}}{Z_{e f f}} \approx \frac{1}{Z_{i}-1}$ para um plasma de hidrogênio, e considerando principalmente uma variação na concentração de íons leves $\left(Z_{i}=7\right)$, obtemos uma variação da carga efetiva corresponde a uma variação na massa efetiva de $\frac{\Delta A_{e f f}}{A_{e f f}} \approx 3-4 \%$, que coincide com o valor de massa efetiva $A_{\text {eff }}=1.40$.

A meia largura na ressonância é estimada em 6\%, pelo variação do valor da densidade durante a rampa de queda da densidade. Temos um valor que é comparável com a variação da densidade e da massa $\left(n_{e} A_{e f f}\right)^{-1 / 2}$, que é dada pela frequência do GAE durante o ciclo do dente de serra.

Podemos concluir que a oscilação de amplitude observada no sinal da sonda magnética, pode ser explicada pela acumulação de impurezas e mudança de densidade causada por um ciclo da oscilação dente de serra.

\subsection{O perfil de densidade com impurezas}

Baseado no valor obtido para a massa efetiva $A_{\text {eff }}=1.40$, sendo considerada uma concentração de cerca de $4.5 \%$ de íons leves e $0.15 \%$ de íons pesados $\left(\mathrm{Fe}^{+19}\right)$, obtemos valores compatíveis com a estimativa do $Z_{\text {eff }}$ para o TCABR, $Z_{e f f}=3$. Com essas 
informações podemos fazer uma discussão sobre a distribuição das impurezas levando em conta os parâmetros do TCABR.

Primeiramente vamos tratar os dados do plasma em mais detalhe. Vamos supor um valor de densidade no centro de $n_{0}=2 \times 10^{19} / \mathrm{m}^{3}$, típico para os disparos apresentados, e o parâmetro $\alpha=0,8$ para o perfil de densidade. O valor da corrente de plasma de $I_{p}=85 k A$ e para a voltagem de loop $V_{l o o p}=2 \mathrm{~V}$. A temperatura de elétrons no centro é estimada em $450 \mathrm{eV}-500 \mathrm{eV}$ [60] para essa densidade.

Para o TCABR temos a temperatura dos íons estimada em $150 \mathrm{eV}-180 \mathrm{eV}$ [61, 62], pela fórmula de Artsimovich. Com esses valores podemos calcular o tempo de confinamento de energia. Para isso partimos do balanceamento de energia $I_{p} V_{\text {loop }}=$ $\frac{\int \frac{3}{2} n\left(T_{e}+T_{i}\right) d^{3} x}{\tau_{e}}$, obtemos $\tau_{e} \approx 2 m s$, que é compatível com a lei de escala de medidas realizadas no TCA em Lausanne [38].

No caso do TCABR podemos calcular os coeficientes de difusão do plasma para diferentes limites, no limite Pfirsch-Schlüter, que é o a difusão resultante do mecanismo de transporte clássico (colisional) considerando uma geometria toroidal (tokamak), e no limite plateau.

$$
D_{P-S}=\left(1+q^{2}\right) \nu \rho^{2} \quad ; \quad D_{\text {plateau }}=\frac{q v_{T i}}{R} \rho^{2}
$$

Onde $q$ é o fator de segurança; $\rho=v_{t} / \omega_{c}$ o raio de Larmor; $\nu$ a taxa de colisão entre duas espécies, no caso podemos considerar íon-elétron; e $v_{T i}$ a velocidade térmica de íons.

Fazendo a comparação do coeficiente de difusão nesses limites para os íons do TCABR chegamos a condição que, para $Z_{\text {eff }}=3$ temos $D_{P-S}$ da mesma ordem de $D_{\text {plateau. }}$ Nesse caso, podemos considerar que temos um regime Pfirsch-Schlüter e, de acordo com [63], nesse regime o perfil de densidade das impurezas é da forma

$$
n_{z}=n_{z}(0)\left(\frac{n_{i}}{n_{i 0}}\right)^{Z}\left(\frac{T_{i}}{T_{0}}\right)^{-\frac{Z-1}{2}}
$$


onde $Z$ é a carga das impurezas, podemos perceber que o perfil de densidade das impurezas é mais agudo que o perfil de densidade do íon principal do plasma. A acumulação de impurezas está ligada ao transporte de íons sobre transporte de elétrons no caso do transporte clássico ou neoclássico. As impurezas interagem com o íon principal do plasma trocando de posição. No caso do plasma de hidrogênio, uma impureza de carga $e_{i m p}=Z_{i m p} e_{p}$ troca de posição com Z prótons. Isso ocorre graças a quase neutralidade do plasma e a ambipolaridade do transporte.

Podemos também considerar o caso em que temos uma mistura de transportes, com difusão Pfirsch-Schlüter para os íons e impurezas, junto com um regime de difusão anômalo (ou turbulento) para os elétrons. A difusão anômala é maior que a PfirschSchlüter. A concentração das impurezas, dada essa mistura de transportes, se dá como [63]

$$
n_{z}=n_{z}(0)\left[\frac{\left(\frac{n_{i}}{n_{0}}\right)^{Z}}{\left(\frac{T_{i}}{T_{0}}\right)^{\frac{Z-1}{2}}}\right]^{\frac{\beta}{1+\beta}} \exp \left[\frac{-\alpha r^{2}}{2 a^{2}(1+\beta)}\right]
$$

onde $\beta=\frac{D_{P S}}{D_{a} \text { nom }}$. Devido a essa relação, o perfil da densidade dos elétrons fica da forma

$$
n_{e}=n_{0 H}\left(1-\frac{r^{2}}{a^{2}}\right)^{\alpha}+n_{0 Z} \exp \left[-\frac{r^{2}}{(0,4 a)^{2}}\right]
$$

que corresponde a formação de um calombo no centro do plasma, em cima do perfil parabólico. Esse calombo é observado em descargas ôhmicas de tokamaks grandes [57] e até no TCA, quando instalado em Lausanne [38].

Ambos os perfis propostos indicam que há uma maior concentração de impurezas no centro do plasma. Como os modos que foram excitados estão localizados na parte mais central do plasma, e dependem muito da densidade central, há a possibilidade de o valor encontrado para a concentração de impurezas ser maior que a quantidade média de impurezas ao longo do raio do TCABR. 


\section{Capítulo 5}

\section{Conclusão}

Neste trabalho apresentamos os resultados das campanhas experimentais sobre a excitação de ondas de Alfvén no TCABR para a determinação da massa efetiva. Para fazer isso, detectamos modos globais de Alfvén (GAE) excitados por antenas externas alimentadas com baixa potência de $\mathrm{RF}(<1 \mathrm{~kW})$. A massa efetiva de $A_{\text {eff }}=1.40 \pm 0.04$ foi estimada, e corresponde ao valor estimado do $Z_{\text {eff }}$ para o TCABR. Também foi estimada sua variação devida a oscilações do tipo dente-de-serra.

A massa efetiva estimada para a região central do TCABR corresponde a uma concentração de aproximadamente $6.5 \%$ ou, equivalentemente, $6 \%$ de carbono e $0.15 \%$ de ferro ionizado 19 vezes, valores típicos para $T_{e} \approx 500 \mathrm{eV}$. A carga efetiva estimada nesses casos é $Z_{\text {eff }} \approx 3.0 \pm 0.2$ e esse valor é compatível com o calculado a partir de expressão empírica, para as condições do plasma no TCABR. Com o valor da massa efetiva obtido, podemos ter uma mistura de cerca de $4.5 \%$ de íons leves com $A_{l}=14$ e $Z_{l}=7$ e $0.15 \%$ de íons pesados, sendo ferro ionizado $19\left(\mathrm{Fe}^{+19}\right)$ vezes $\left(A_{h}=56 \mathrm{e}\right.$ $\left.Z_{h}=19\right)$. A mistura de íons leves é correspondente a uma mistura de carbono, oxigênio e nitrogênio.

Os GAEs foram detectados para uma ampla gama de densidades e correntes do TCABR, e a variação da frequência de ressonância com a densidade corresponde ao esperado para ondas de Alfvén. A densidade central do plasma calculada com o uso 
de dois canais do interferômetro se mostrou melhor do que a densidade de linha para a caracterização dos GAEs. Porém, acreditamos haver um erro sistemático na estimativa da densidade devido ao deslocamento de Shafranov. Aplicando esta correção aos dados, foi possível obter valores da massa efetiva do plasma correspondentes a estimativas do $Z_{\text {eff }}$ pela condutividade de Spitzer para o TCABR.

Para confirmar os valores de massa efetiva encontrados usamos descargas em plasma de hélio. Como o hélio possui a mesma massa efetiva que a maior parte das impurezas do TCABR, consideramos que a massa efetiva deste plasma já é predeterminada. Assim, usamos o hélio para calibração do sistema e obtivemos a mesma massa efetiva que a estimada com a correção pelo deslocamento de Shafranov na densidade central.

Comparando o trabalho apresentado com trabalhos anteriores [33], trabalhos em que foi usada apenas uma antena para identificação da massa efetiva, os novos resultados obtidos tem identificação do número de onda do modo excitado com o uso de um par de antenas. Isto nos permitiu uma melhor determinação da massa efetiva. Além disso, permitiu também uma melhor identificação da ressonância considerando o batimento provocado pelos dentes-de-serra.

A estimativa do nível de impurezas é condizente com o esperado para as condições do plasma do TCABR. O método apresentado pode ser aplicado em outros tokamaks ou outros tipos de plasmas confinados magneticamente. Também pode ser usado com outros tipos de automodos das ondas de Alfvén (TAE, BAE ou modos geodésicos) no lugar do GAE. O método apresentado é simples e de baixo custo permitindo adquirir informação sobre o nível de impureza do perfil do fator de segurança. As medidas podem ser realizadas com uma sonda magnética e geradores de baixa potência de RF são disponíveis comercialmente. 


\subsection{Propostas para trabalhos futuros}

Como trabalhos futuros proponho melhorias no sistema e investigação de outras ondas.

-Uma melhoria possível no sistema é construir um diagnóstico de detecção síncrona com field-programmable gate array (FPGA). O equipamento já está disponível no laboratório de física de plasmas do IFUSP. Com a FPGA poderíamos fazer detecção dos modos excitados pelo sinal da sonda magnética em tempo real e controlar o valor da frequência da corrente de RF, fazendo detecção dos modos.

-No trabalho apresentado fizemos medidas com poucas sondas magnéticas. Para melhorar a análise dos modos, podemos usar uma maior quantidade de sondas magnéticas dispostas toroidalmente no tokamak, estando as sondas equidistantes ou não.

-A paridade dos outros dois modos com número de onda maiores não foi determinada. Isso pode ser realizado com pequenas modificações no filtro de saída dos amplificadores ou com mudanças de fase entre os MOSFETs, que pode ser conseguida com o uso de uma FPGA.

-Investigação de outros automodos das ondas de Alfvén. Podemos tentar excitar outros automodos das ondas de Alfvén com o sistema de RF. Propomos a excitação de modos toroidais de Alfvén (TAE). Eles possuem frequência abaixo do GAE, sendo estimada em trono de $200-900 \mathrm{kHz}$. O amplificador de RF usado pode trabalhar nesta faixa com pequenas modificações. Principalmente no indutor no dreno do MOSFET e no filtro de saída.

-Outro tópico de possível interesse é um estudo sobre o amortecimento do GAE no TCABR. O amortecimento pode ser determinado pela largura do pico das ressonâncias. Pode ser feito um estudo sobre como o amortecimento depende dos parâmetros do plasma.

- Verificar se há mudança na frequência de ressonância com a presença de oscilações de Mirnov. Presença de Mirnov no começo do disparo pode causar uma maior concentração de impurezas. 


\section{Apêndice A}

\section{Detalhes do sistema de diagnóstico por ondas de Alfvén}

Nesta seção apresentamos fotos com mais detalhes sobre o sistema de excitação de ondas de Alfvén, facilitando a operação futura do equipamento.

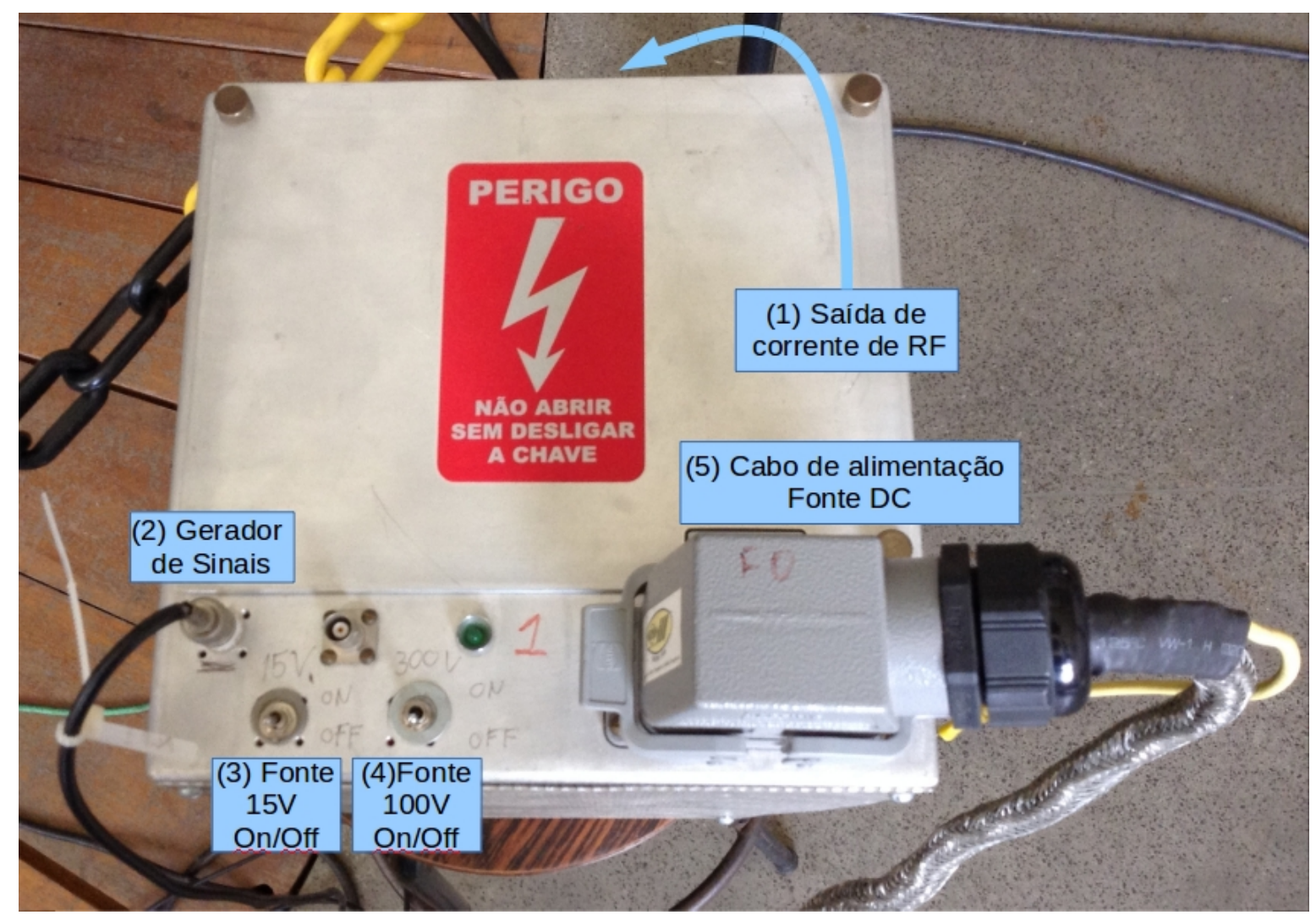

Figura A.1: Amplificador de RF, onde estão os MOSFETs. Foto comentada.

Começamos pelo amplificador de RF, onde estão os MOSFETs, cuja foto comentada está apresentada na figura A.1. Destacado na figura temos: 
- (1) A saída do gerador de RF, que vai para a antena, está na parte de cima e não aparece na foto.

- (2) Entrada do sinal proveniente do gerador de sinais. São injetadas ondas quadradas de $-500 m V$ à $4 V$, na frequência escolhida para a corrente de $\mathrm{RF}$ ou rampas de frequência.

- (3) Chave para permitir a passagem de corrente da fonte DC de $15 \mathrm{~V}$, que alimenta os drivers do MOSFET.

- (4) Chave para permitir a passagem de corrente da fonte DC de 0-100V, que alimenta os drivers do MOSFET.

- (5) Cabo da fonte DC, entrada dos sinais de potência e alimentação.

Para ligar potência no amplificador de RF, figura A.1, evitando problemas, seguimos uma ordem. Primeiro injetamos o sinal do gerador de sinais com as chaves das fontes DC desligadas. Ligamos a chave da fonte DV de $15 \mathrm{~V}$ e vemos se há corrente sendo consumida, que deve ser menos de $1 \mathrm{~A}$. Se tudo está normal, com a fonte DC de $0-100 \mathrm{~V}$ colocada com 0V, ligamos a chave dessa fonte e aumentamos a voltagem até próximo de 100V (com $80 \mathrm{~V}$ já conseguimos obter a corrente máxima). Seguindo esse procedimento conseguimos evitar danos aos MOSFETs.

Uma das duas fontes DC esta apresentada na figura A.2, com mais detalhes na figura A.3. Para manuseio da fonte há o manual disponível no laboratório. Realmente, há mais de uma fonte DC no módulo. Temos uma fonte de $15 \mathrm{~V}$ para alimentar os drivers dos MOSFETs e outra de $100 \mathrm{~V}$ para os MOSFETs. A fonte de $100 \mathrm{~V}$ libera corrente apenas quando recebe um trigger por contato seco (curto). A corrente é liberada por aproximadamente $30 \mathrm{~ms}$, que é o tempo em que é aplicada potência de RF no plasma.

Para controlar o tempo de aplicação da corrente e o nível de tensão usamos os dials mostrados na figura A.2(3). Fora isso, tem uma chave que permite corrente contínua ou o modo disparo para a fonte de $100 \mathrm{~V}$, é importante sempre checar se está em modo disparo, no modo contínuo queimaria os MOSFETs. 


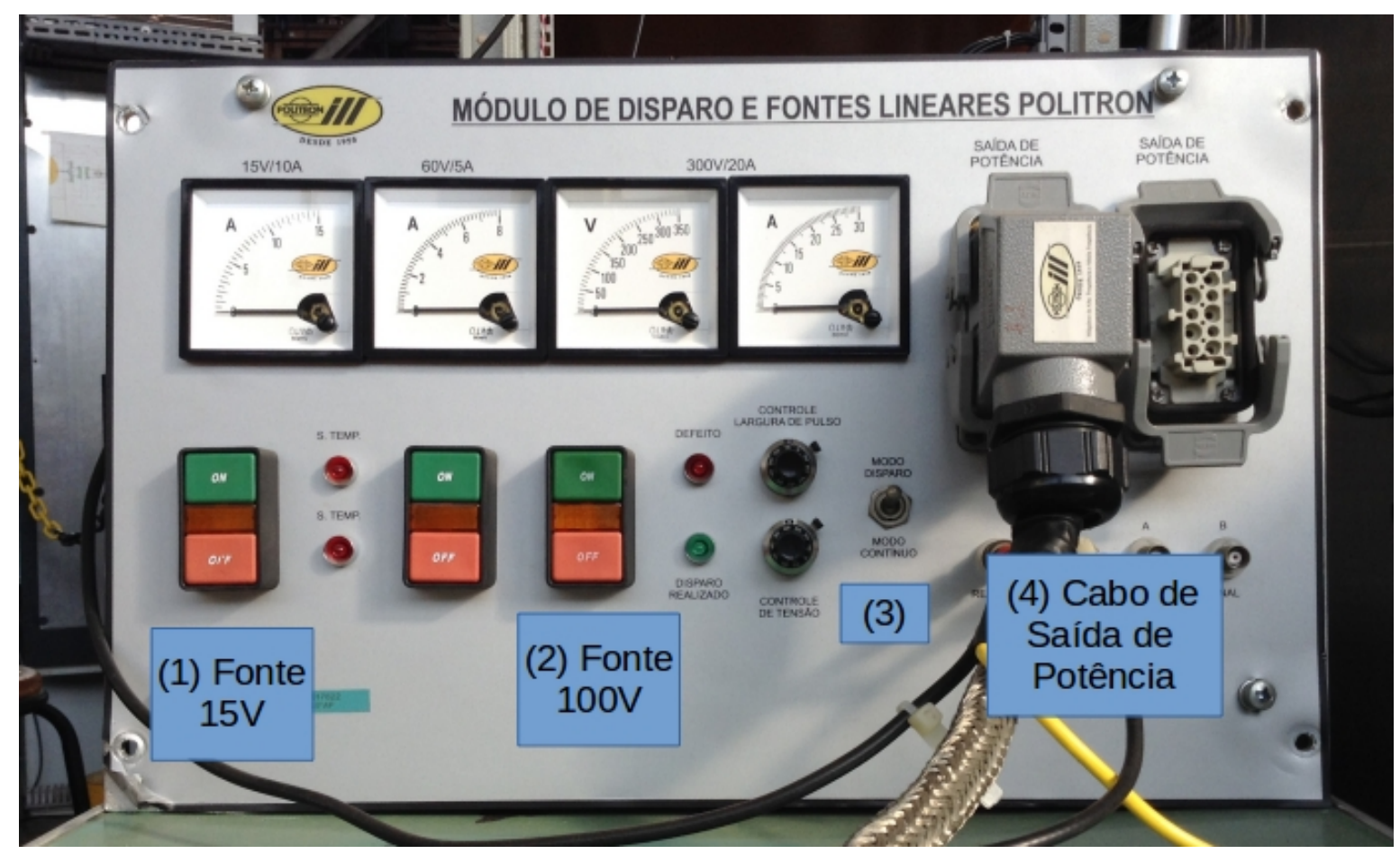

Figura A.2: Foto de uma das fontes DC usadas nos experimentos de excitação de ondas de Alfvén, com comentários.

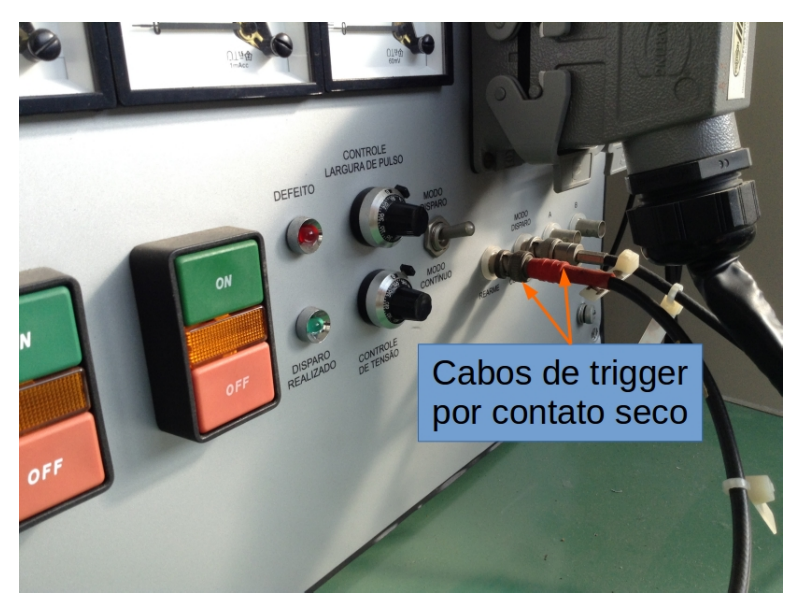

Figura A.3: Foto da fonte DC com detalhe nos cabos responsáveis por "triggerar"a parte de potência da fonte. O trigger é feito por contato seco (curto), um é o cabo para disparar e o outro para rearmar a fonte.

Na figura A.4 temos o circuito de trigger, ele é alimentado pela fonte de $15 \mathrm{~V}$ da fonte DC. Esse trigger recebe o sinal ótico do VME para disparar a fonte DC por contato seco e também disparar o sistema de aquisição da NI. O cabo que sai de (4) na figura A.4 serve para disparar o sistema de aquisição da NI e também é enviado para o VME, informando o começo do tempo de aquisição, assim podemos sincronizar os diferentes 
118 Apêndice A. Detalhes do sistema de diagnóstico por ondas de Alfvén
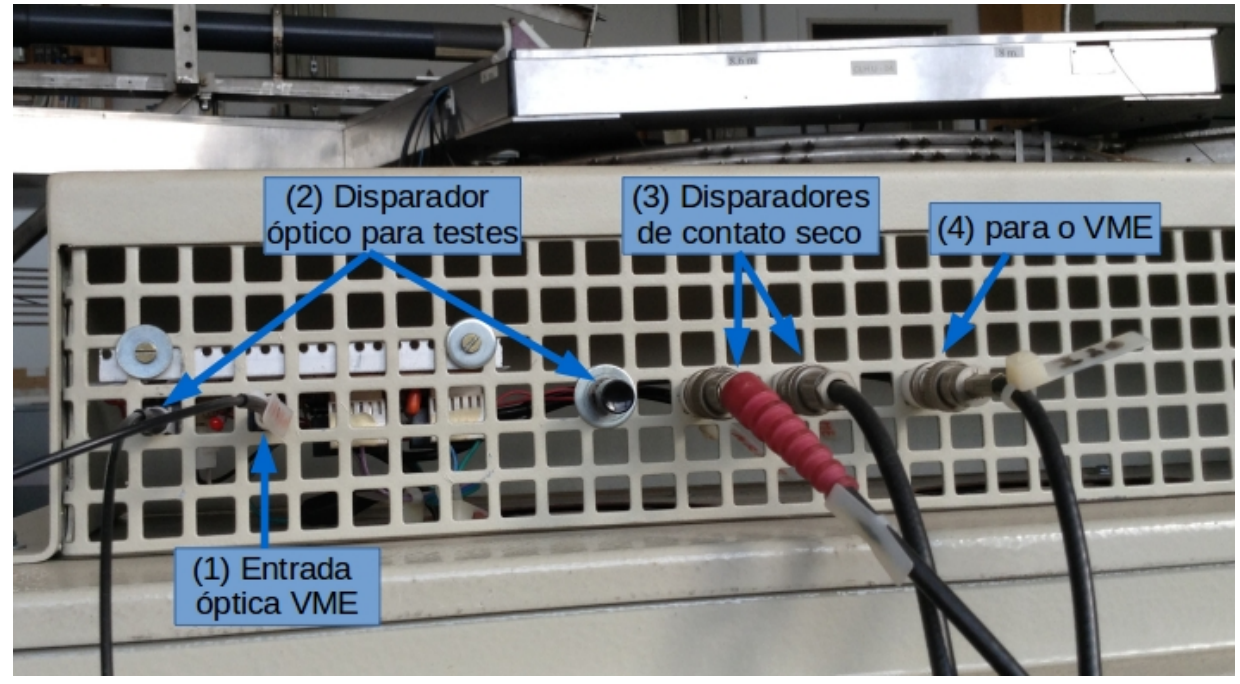

Figura A.4: Localização do trigger para a fonte DC e o sistema de aquisição.

diagnósticos. Para ser enviado ao VME o sinal passa por um isolador óptico, afim de evitar loops de terra.
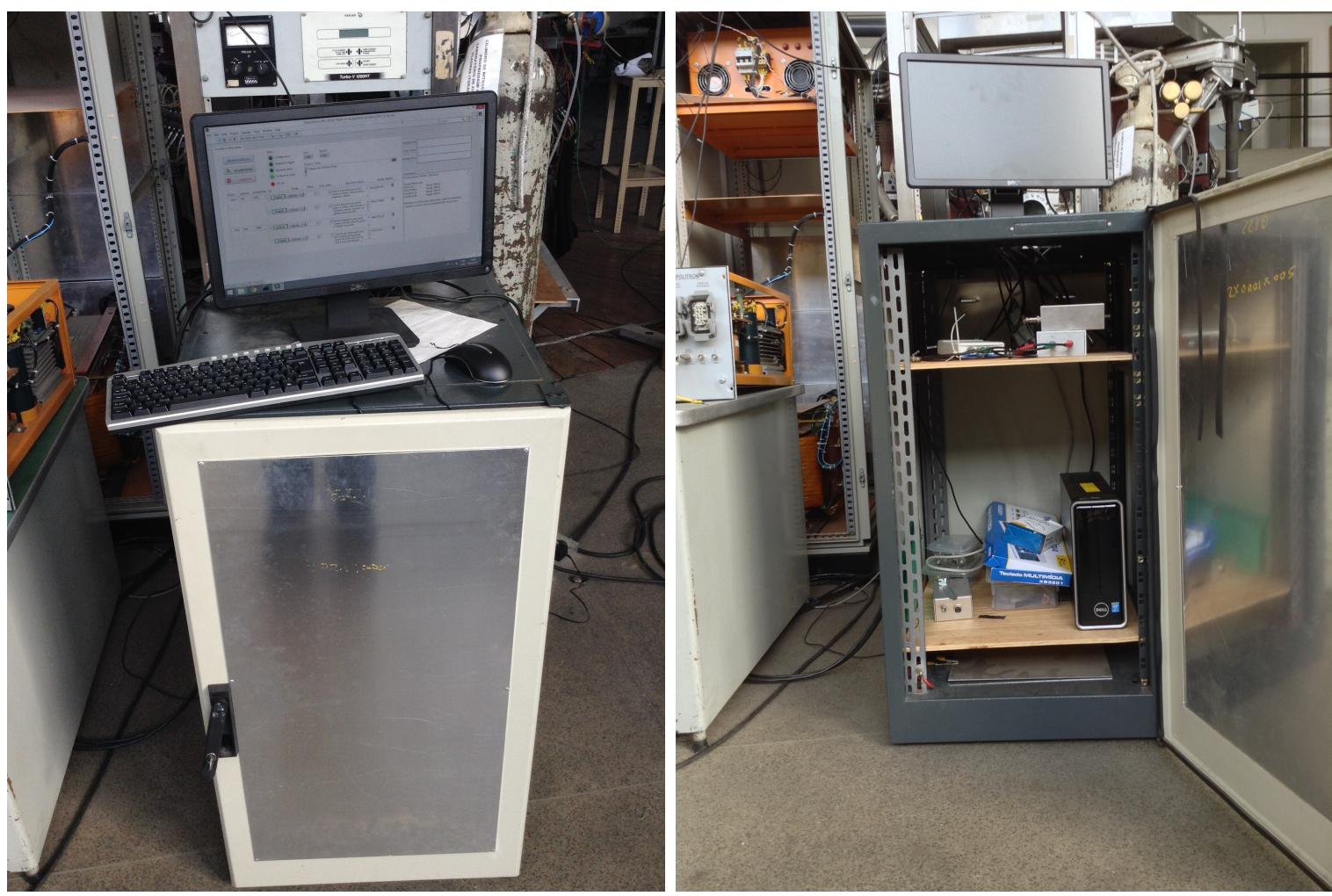

Figura A.5: Gabinete onde se encontra o PC de aquisição de dados. Os sinais das sondas magnéticas e das bobinas de Rogowski são enviados a este gabinete com cabos $B N C$ e $B N O$.

Ainda na figura A.4, temos duas fibras ópticas duas fibras ópticas, em (1) é a 
entrada de uma fibra óptica que vem do VME e dispara o sistema no tempo definido no sistema de controle do TCABR. Já a outra (2) é uma saída óptica e é usada para testes, quando queremos disparar o sistema para fazer algum teste no vácuo, ligamos a saída (2) em (1), com uma fibra óptica, e podemos disparar com o botão realçado em $(2)$.

Na figura A.5 apresentamos uma foto do gabinete de aquisição onde fica o PC de aquisição de dados. Como já mencionamos, o acesso ao PC é feito de forma remota. Na parte de baixo do gabinete fica o PC, na parte superior temos os BALUNS e NI-USB 5133. Na parte inferior, também estão guardados conectores e documentos relevantes para o diagnóstico.

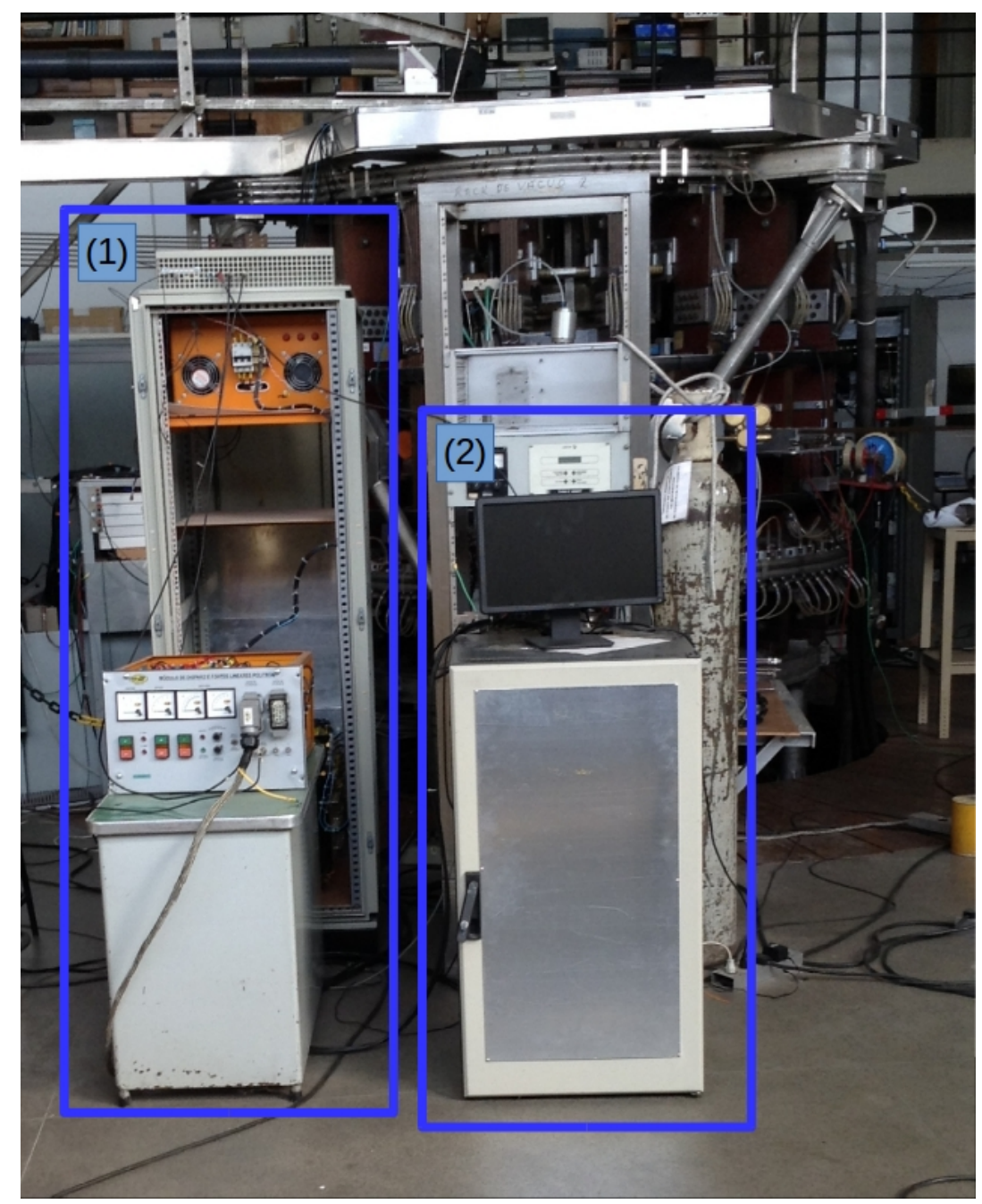

Figura A.6: Vista conjunta do gabinete das fontes $D C$ (1) e do gabinete do $P C$ de aquisição (2). 


\section{Apêndice A. Detalhes do sistema de diagnóstico por ondas de Alfvén}

Na figura A.6 temos uma visão conjunta do gabinete da fonte DC e do gabinete do PC de aquisição. O trigger apresentado na figura A.4 ficá em cima do gabinete das fontes DC, e usa a fonte de $15 \mathrm{~V}$ da fonte DC que está colocada no gabinete. A outra fonte DC está em cima de uma mesa para manutenção.

As figuras A.7 e A.8 mostram uma foto de um BALUN, usado para a aquisição dos dados das sondas magnéticas, e a localização dos conectores das sondas magnéticas no TCABR, respectivamente.

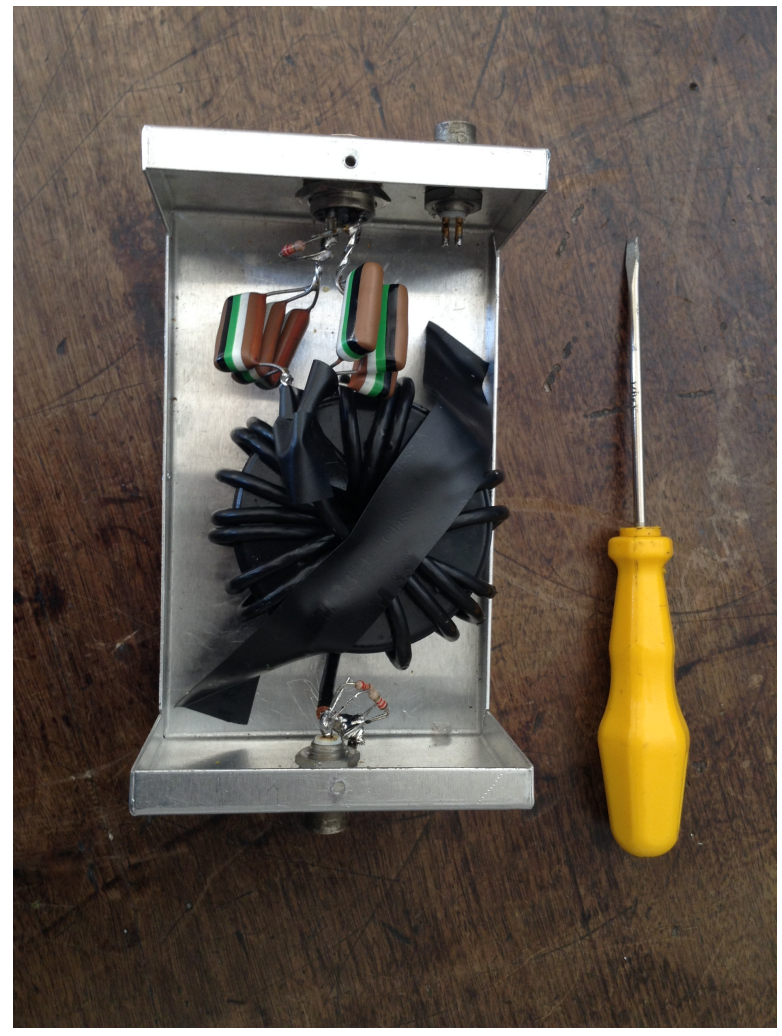

Figura A.7: Foto do BALUN usado para aquisição dos dados das sondas magnéticas, chave de fenda para escala. 

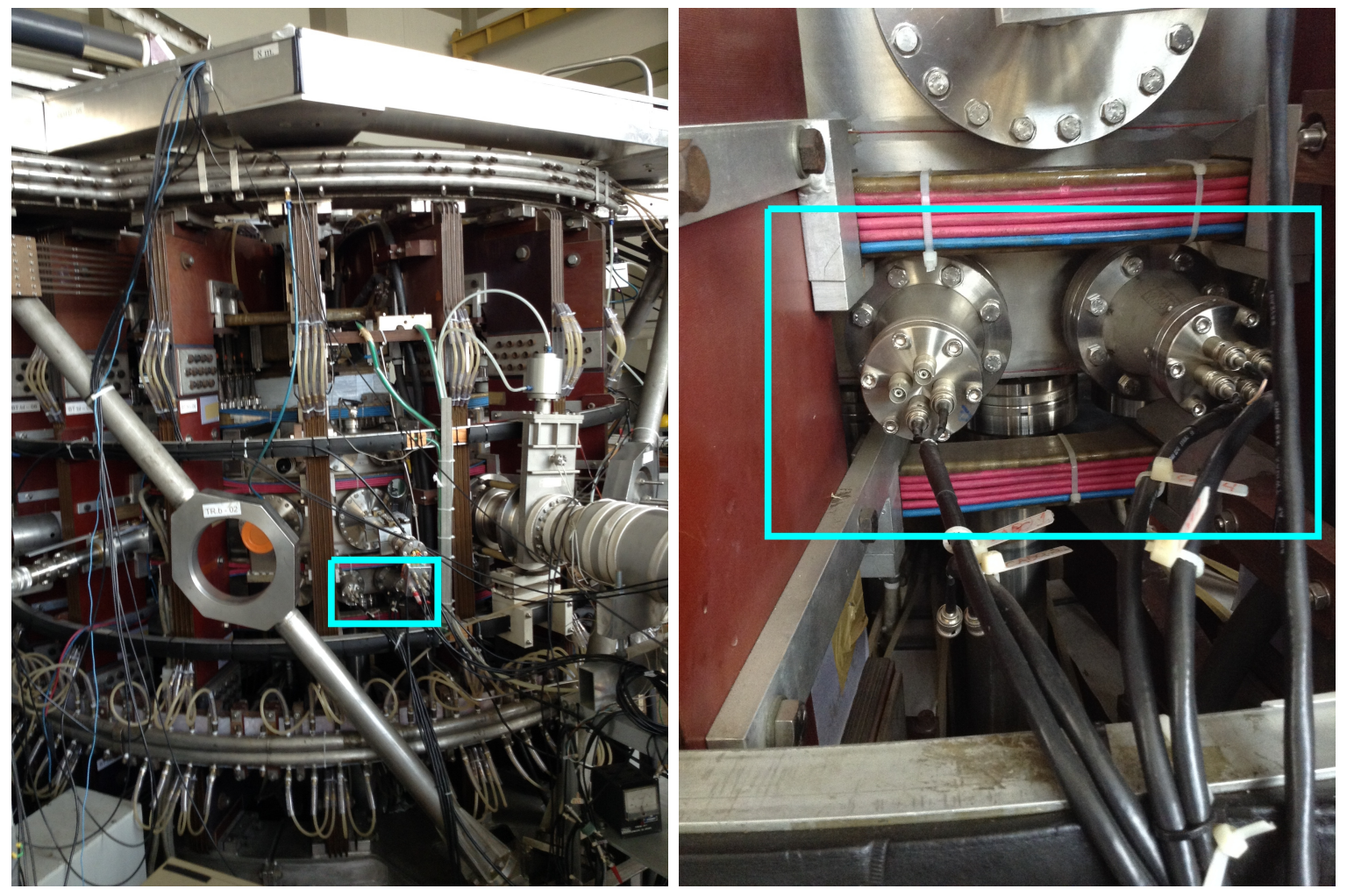

Figura A.8: Localização das sondas magnéticas no tokamak, em destaque. 
122 Apêndice A. Detalhes do sistema de diagnóstico por ondas de Alfvén 


\section{Apêndice B}

\section{Código em LabVIEW para aquisição de dados}

Para a aquisição de dados foi usado um digitalizador da National Instruments, o NIUSB 5133. A aquisição de dados com esse instrumento foi programada em LabVIEW. Fora as rotinas de aquisição de dados, também foram desenvolvidas rotinas de comunicação com o servidor, para receber informações sobre o disparo; rotinas para salvar os dados na na formatação MDSPlus e rotinas para enviar os dados para o banco de dados do TCABR. O padrão MDSPlus é muito usado em tokamaks, sendo de simples acesso para visitantes e pessoas da área, que normalmente já tem familiaridade com o protocolo.

Neste apêndice vamos apresentar resumidamente o código em LabVIEW e como ele opera. O código está disponível no PC de aquisição de dados, para acessá-lo é preciso entrar na pasta $F: \backslash$ Acquisition.

A versão mais recente do projeto é o arquivo Acquisition_v4.lvproj, quando aberto o projeto o arquivo de aquisição é Acquisition_v4.vi. Neste apêndice vamos tratar deste último. O acesso ao PC de aquisição é feita de forma remota, para isso é necessário autorização do responsável pelo sistema de aquisição do TCABR.

O painel frontal do programa de aquisição de dados está presente na figura B.1. Vemos que o painel é carregado de informações necessárias para o funcionamento adequado do sistema de aquisição e facilitando o acesso futuro à base de dados. Podemos ver o painel frontal dividido em cinco partes: 


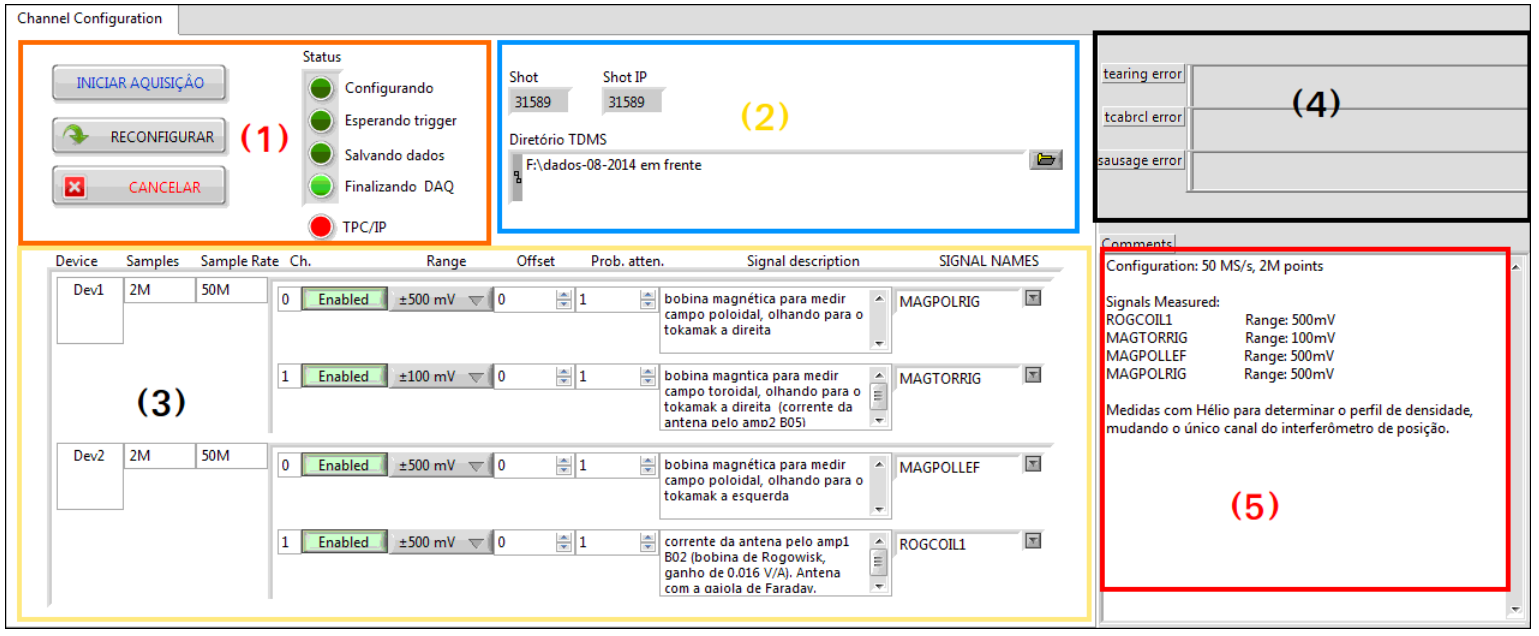

Figura B.1: Painel frontal do programa de aquisição de dados. Foi dividido em 5 partes para facilitar a descrição, cada parte correspondendo a uma função diferente.

- (1) Há 3 botões para ativação e manuseamento do programa de aquisição, um botão para iniciar a aquisição e esperar o trigger, outro para reconfigurar o sistema, baseado em alguma mudança em (3), e outro para cancelar e parar o programa. Fora isso, estão presentes alarmes de status do sistema de aquisição, indicando o estado em que o programa se encontra e se tem comunicação pela internet com o servidor do TCABR.

- (2) Indica o número do disparo, tanto pela leitura no site da base de dados (logbook) quanto pelo número disponível pelo servidor. Os dados, além de serem salvos na base de dados do MDSplus, também são salvos no formato .tdms, que é um tipo de arquivo binário do LabVIEW, no próprio PC de aquisição de dados. O diretório onde esses arquivos são salvos pode ser escolhido no campo de texto.

- (3) Parâmetros de configuração dos canais de aquisição. Podemos escolher os parâmetros de aquisição e que canais usar. Há uma descrição do sinal, que pode ser acessada posteriormente pela base de dados e o nome do sinal. Há uma lista de nomes de sinais que correspondem aos diferentes diagnósticos usados na análise de dados. Os nomes possíveis estão nessa lista, qualquer nome adicional tem que ser colocado na árvore do MDSplus. 
- (4) Indicador da comunicação com os servidores da base de dados do TCABR. Mostra se foi realizada a cópia da base de dados.

- (5) Comentários referentes a configuração e o experimento sendo realizado, devem seguir o padrão do exemplo.

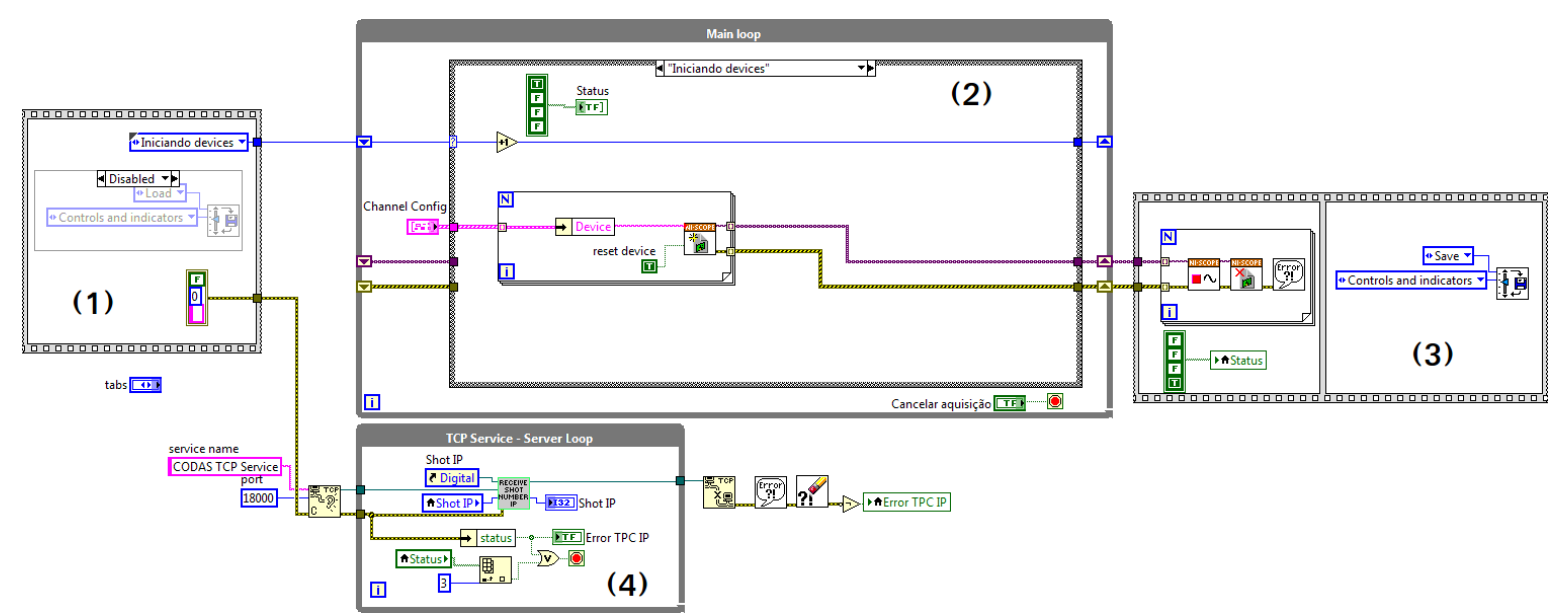

Figura B.2: Diagrama de blocos geral do programa de aquisição de dados dividido em 4 partes: (1) carregar configurações (não utilizado), (2) aquisição de dados, (3) encerramento do programa e (4) comunicação por internet.

Na figura B.2 temos o diagrama de blocos do sistema. Pode ser dividido em 4 partes, como apresentado. Vamos nos focar na parte (2), de aquisição de dados e configuração do sistema. Nessa parte temos um while loop com uma case structure, que representa uma máquina de estados. Essa máquina de estados tem uma ordem de tarefas a seguir para configurar a aquisição e salvar os dados. As informações de configuração de devices (módulos, canais de aquisição etc) são passadas por um cluster.

Para entender o funcionamento da máquina de estados apresentamos as figuras comentadas B.3, B.4, B.5, B.6, B.7 e B.8. Essas figuras seguem a ordem de operação do sistema. 


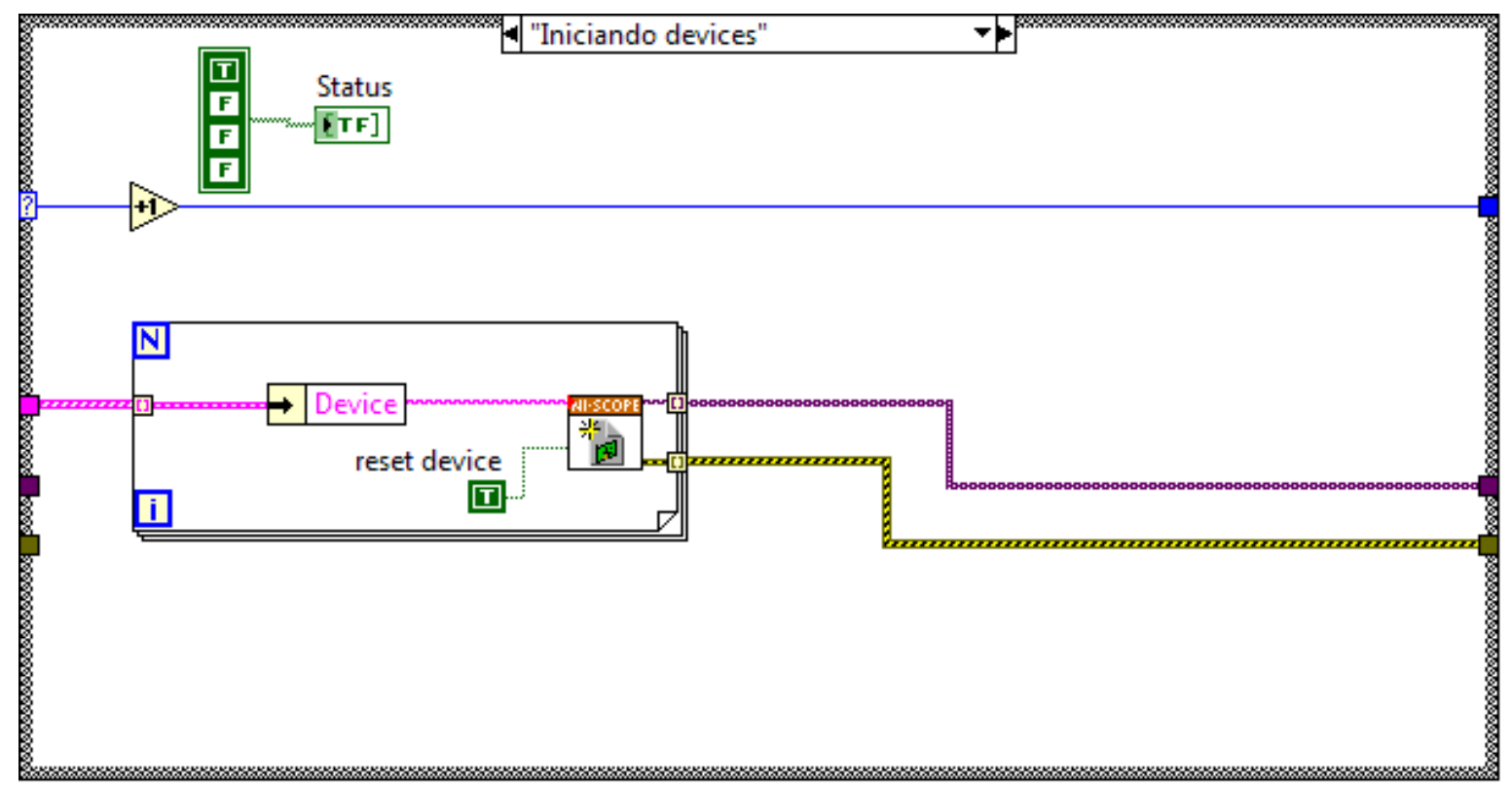

Figura B.3: Inicia os Devices. Inicia qualquer um dos módulos NI-USB para serem usados para aquisição de dados. Configura o display de estado do sistema para mostrar "Configurando".

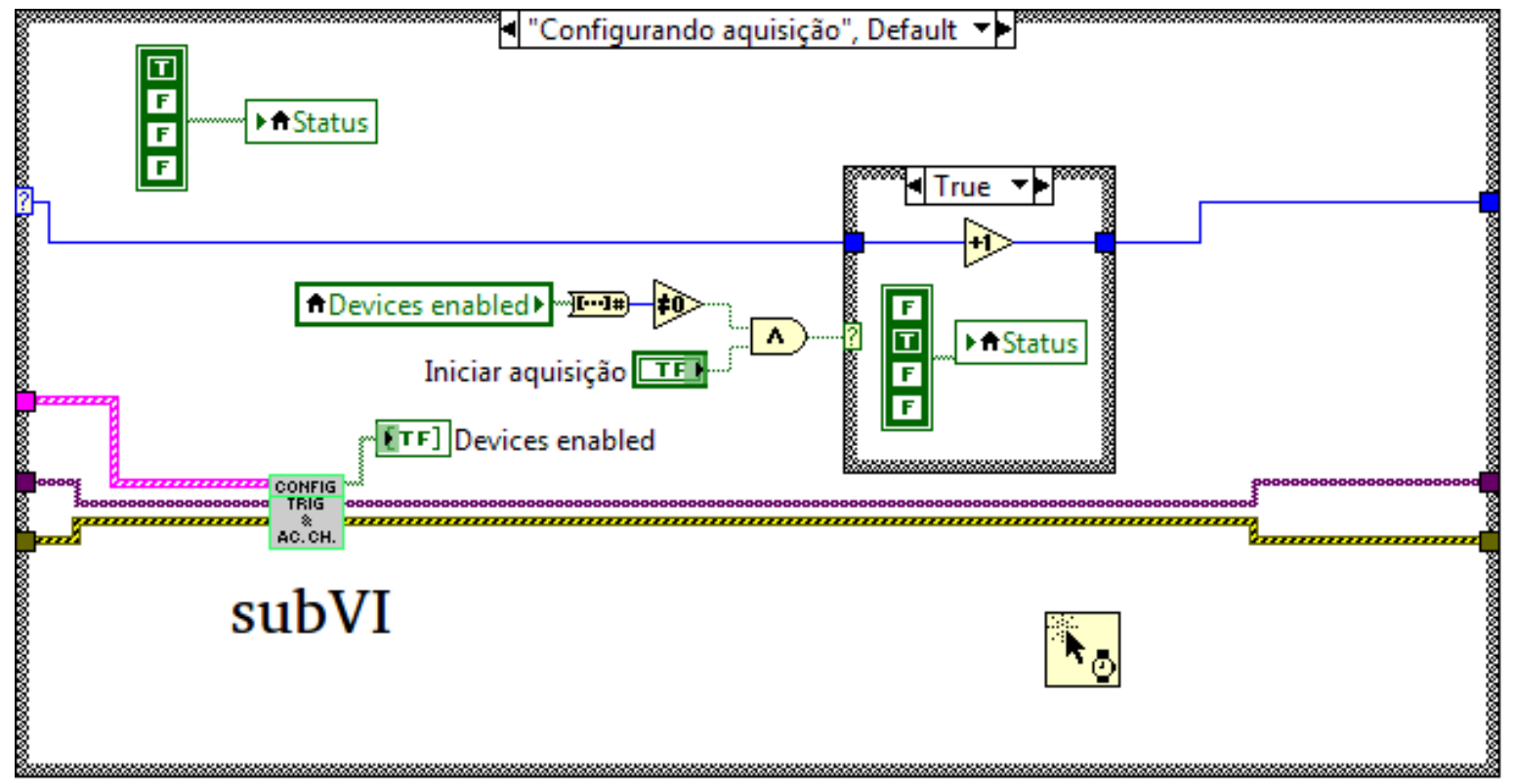

Figura B.4: Configura parâmetros da aquisição com os parâmetros colocados no campo (3) do painel frontal, figura B.1. A rotina de configuração está na subVI apontada. Uma vez configurados os canais de aquisição, espera o usuário apertar o botão "Iniciar Aquisição"no painel frontal. Uma vez feito isso, muda o estado do display para "Esperando Trigger". 


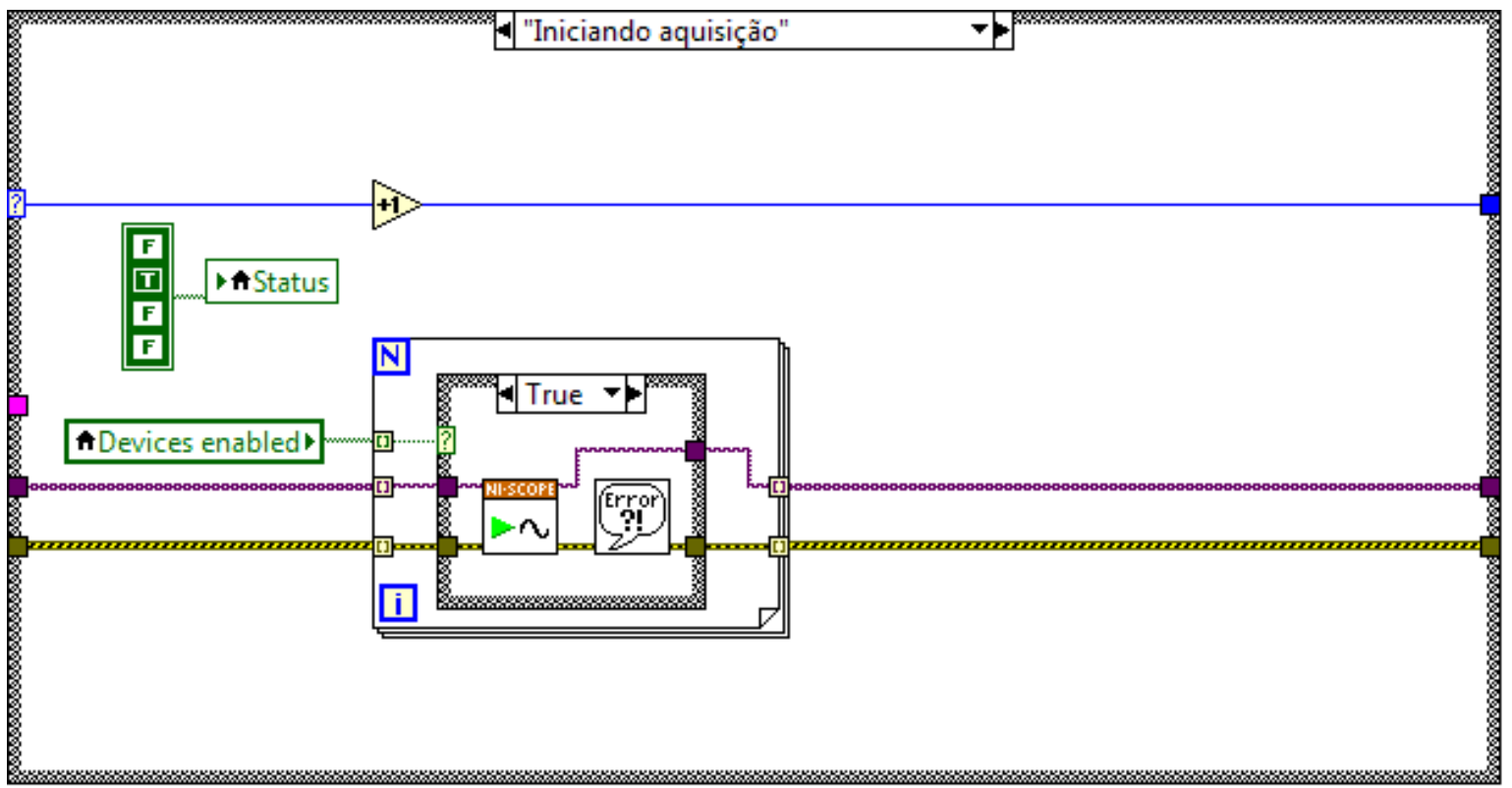

Figura B.5: Habilita os módulos NI-USB 5133 a adquiriram dados. Uma vez que os módulos NI-USB 5133 foram configurados e habilitados, eles esperam o trigger para adquirir os dados. O trigger é dado pelo VME e está atrelado ao disparo da corrente de $R F$ nas antenas.

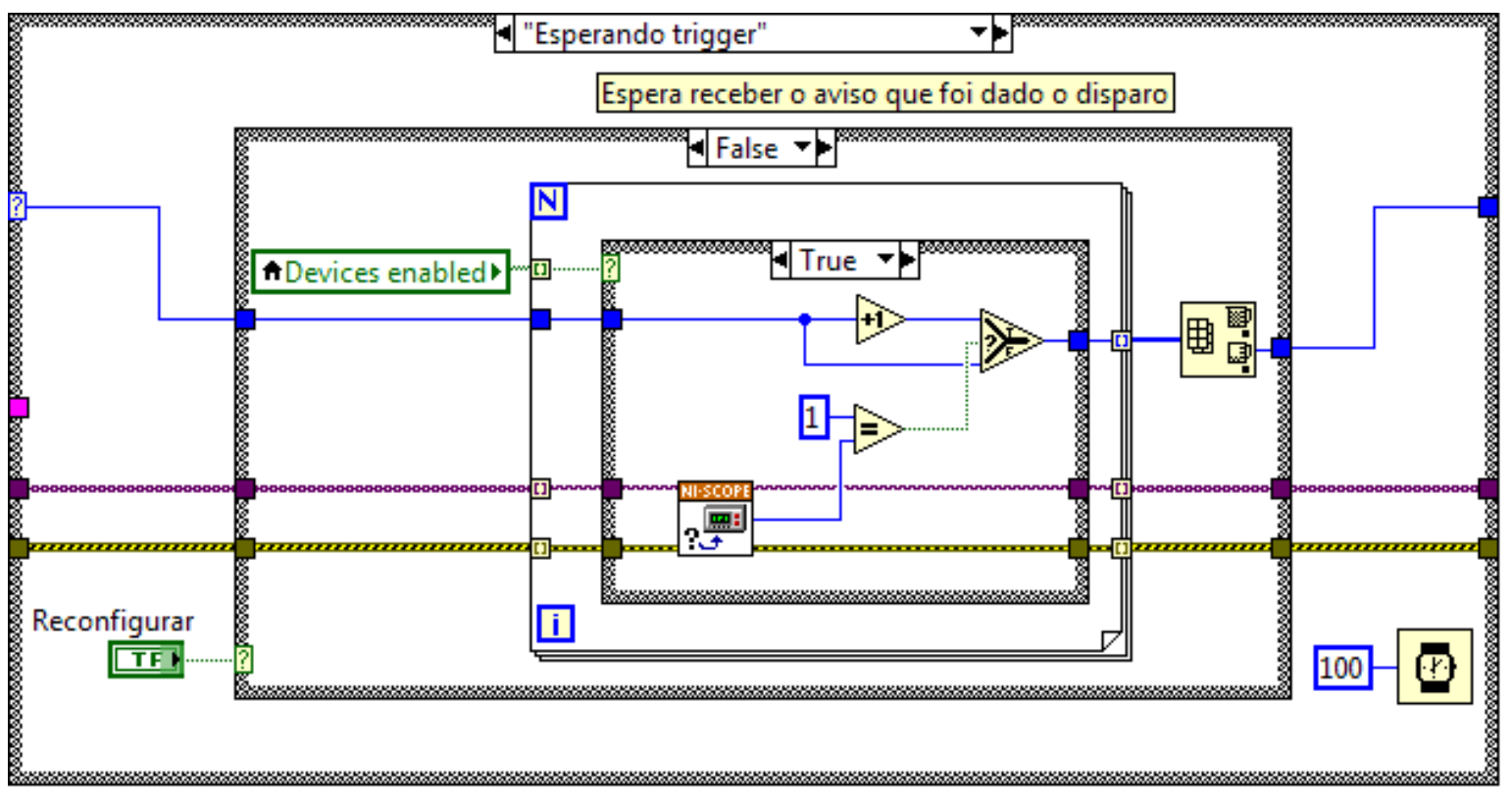

Figura B.6: Esse estado recebe a informação se o trigger já foi recebido e os dados já foram adquiridos. Uma vez que isso acontece, segue-se para o próximo estado. Esse estado é onde o sistema fica na maior parte do tempo, já que está sempre esperando o próximo disparo e raramente são feitas modificações entre um disparo e outro. Nesse estado também temos o botão de reconfigurar, do painel fronta, figura B.1. Uma vez pressionado, voltamos ao estado apresentado na figura B.4 e os canais são reconfigurados de acordo com as modificações realizadas no painel frontal. 


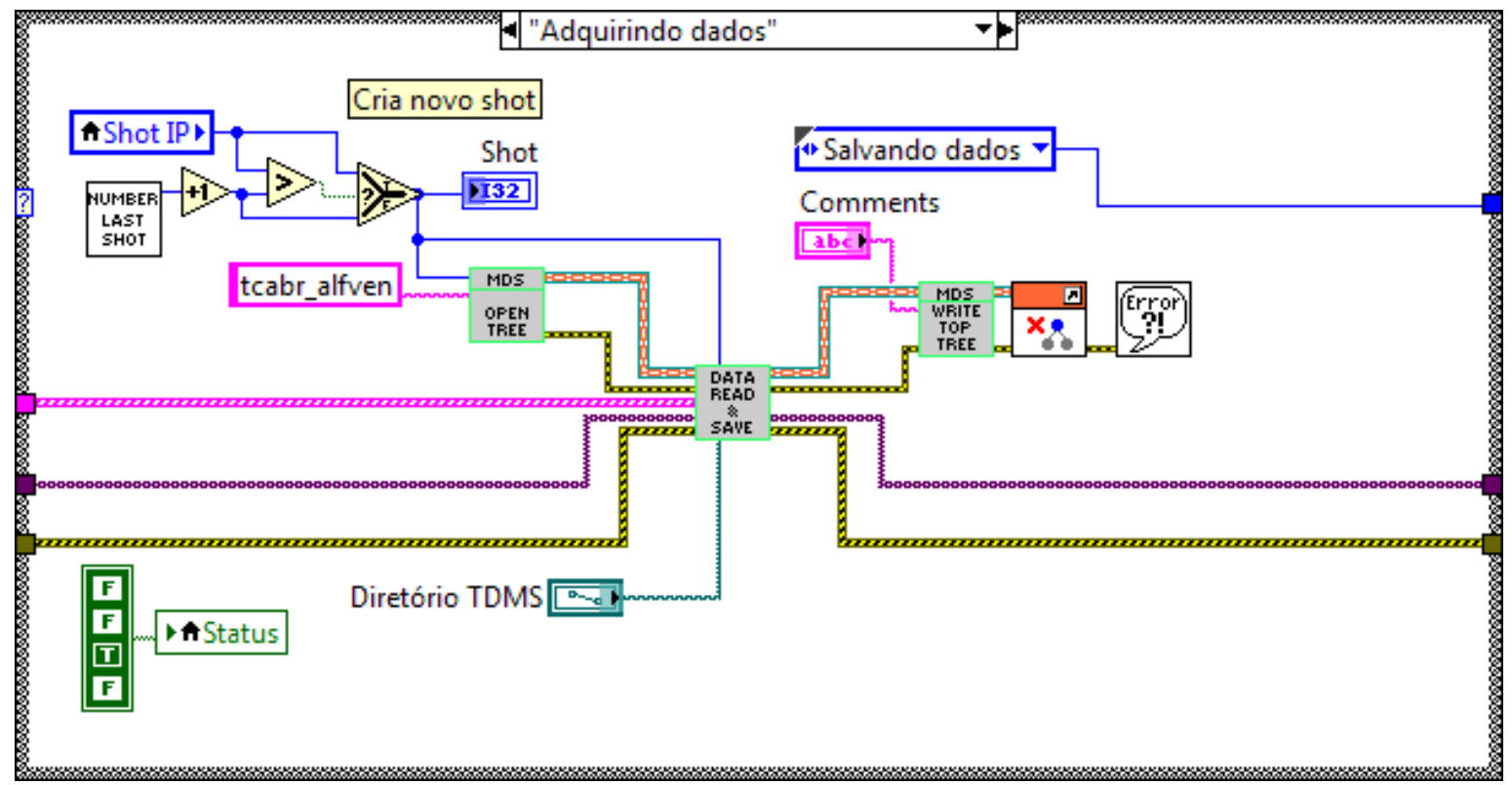

Figura B.7: Neste estado salvamos os dados em arquivos. Como mencionado, os arquivos são salvos tanto no formato .tdms em uma pasta local no computador, quanto na árvore MDSplus. A árvore MDSplus é criada e salva no próprio $P C$ de aquisição.

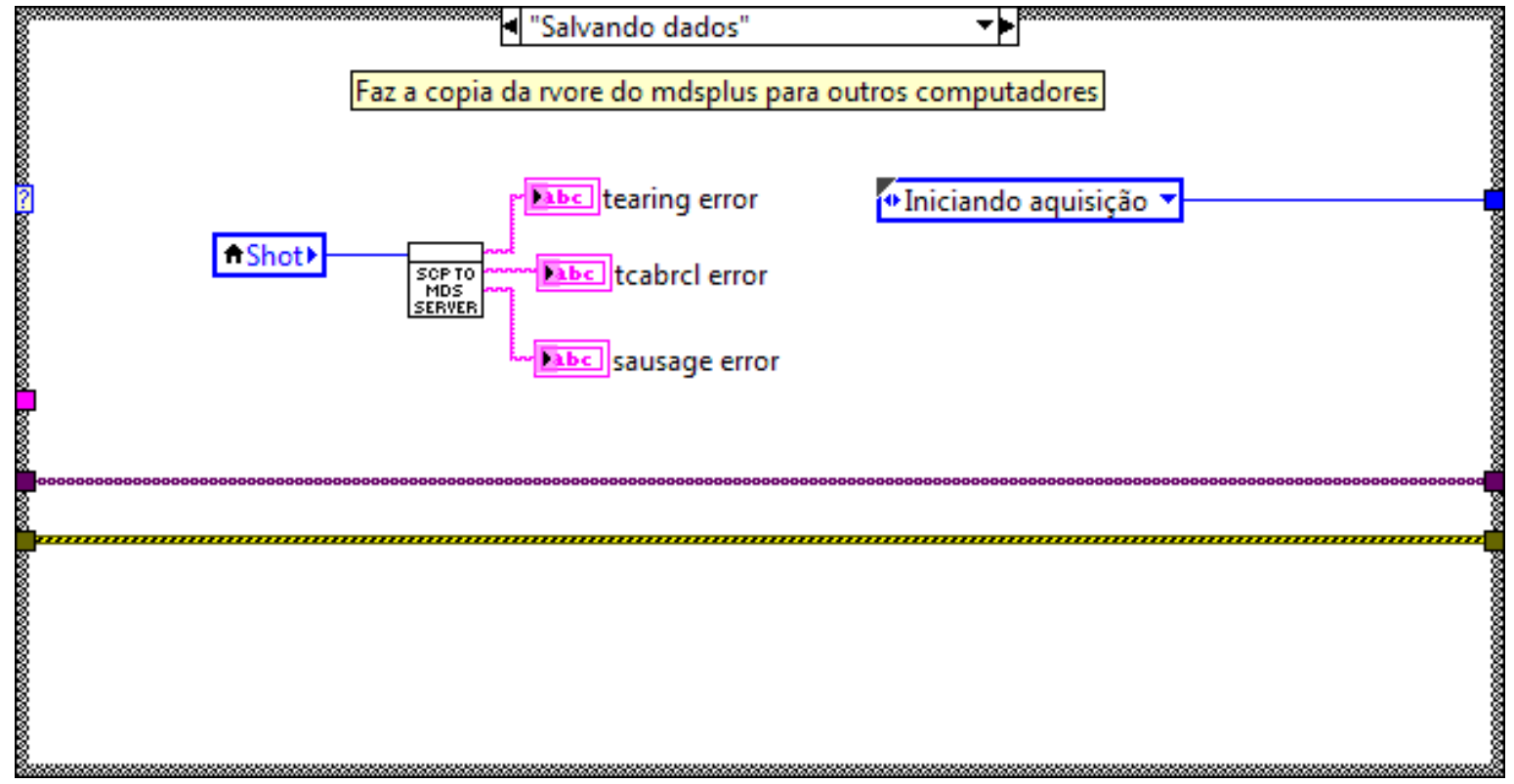

Figura B.8: Envia os dados da a árvore do MDSplus para os três computadores que fazem o backup do banco de dados. Uma vez a árvore do MDSplus criada no PC de aquisição, ela é enviada por protocolo SSH para três servidores do TCABR. Uma vez nessas máquinas, podem ser acessadas remotamente por protocolo MDSplus. 


\section{Apêndice $\mathrm{C}$}

\section{Códigos em Matlab usados para a análise de dados}

As funções de análise dos dados obtidos com o PC de aquisição estão no servidor tcabrcl, na pasta/home/ppuglia/matlab functions/alfven/. Temos os arquivos de Matlab:

- analise.m - Programa que faz a análise entre dois canais de aquisição. No caso, sempre usamos a corrente que passa pela antena como referência e o sinal de uma sonda magnética.

- maxspec.m - Encontra a frequência de amplitude máxima de um espectrograma e a amplitude na mesma frequência em outro espectrograma. Faz a detecção síncrona entre os sinais.

- read_alfven.m - Lê os sinais na base de dados.

- spectrogram_pg.m - Calcula o espectrograma dos sinais.

- acq_begin.m - Informa o tempo em que começou a aquisição de dados do PC de aquisição.

Estas são as funções básicas para a análise de dados realizada neste trabalho. A sequir apresentamos o código comentado dessas funções. 


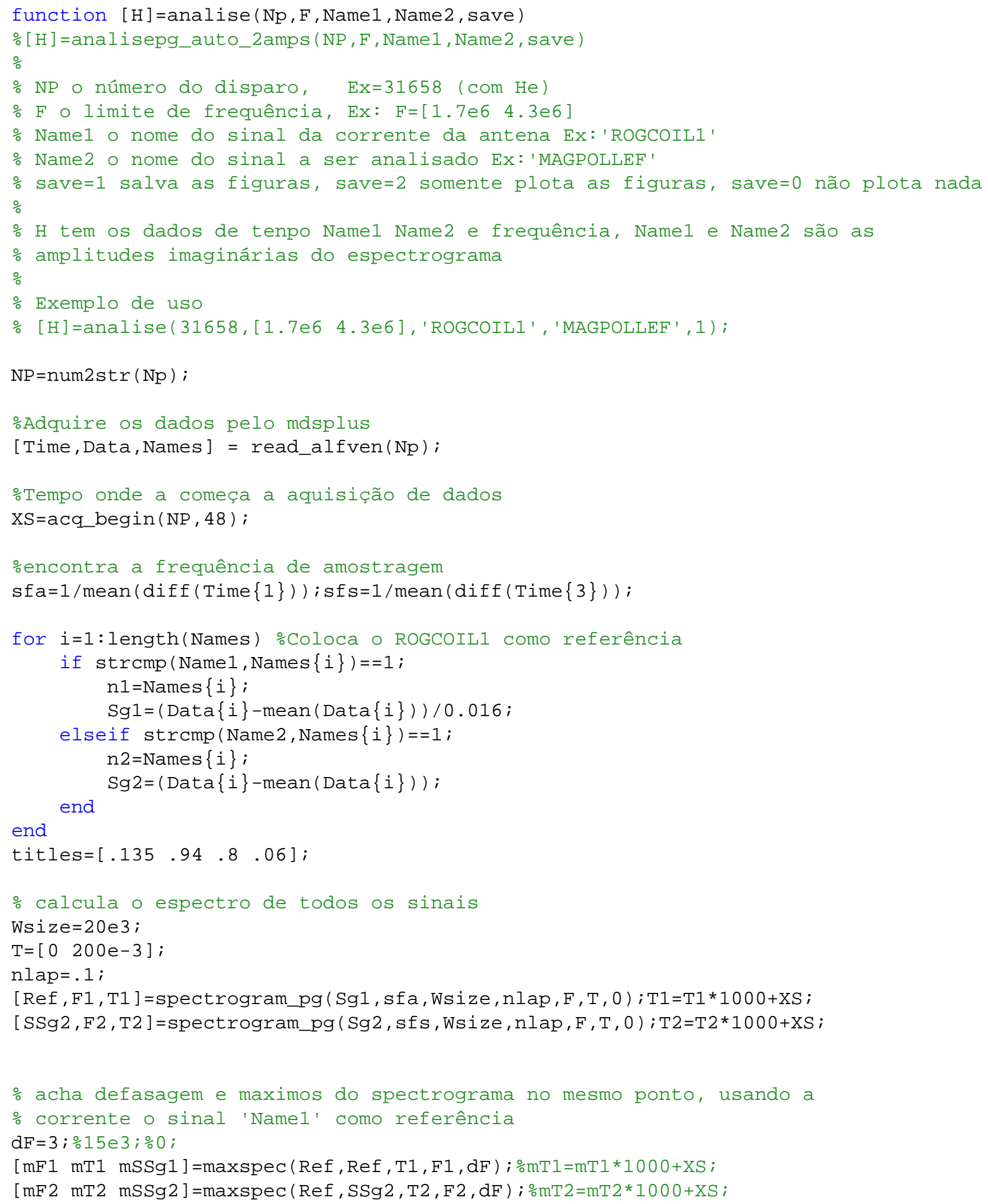




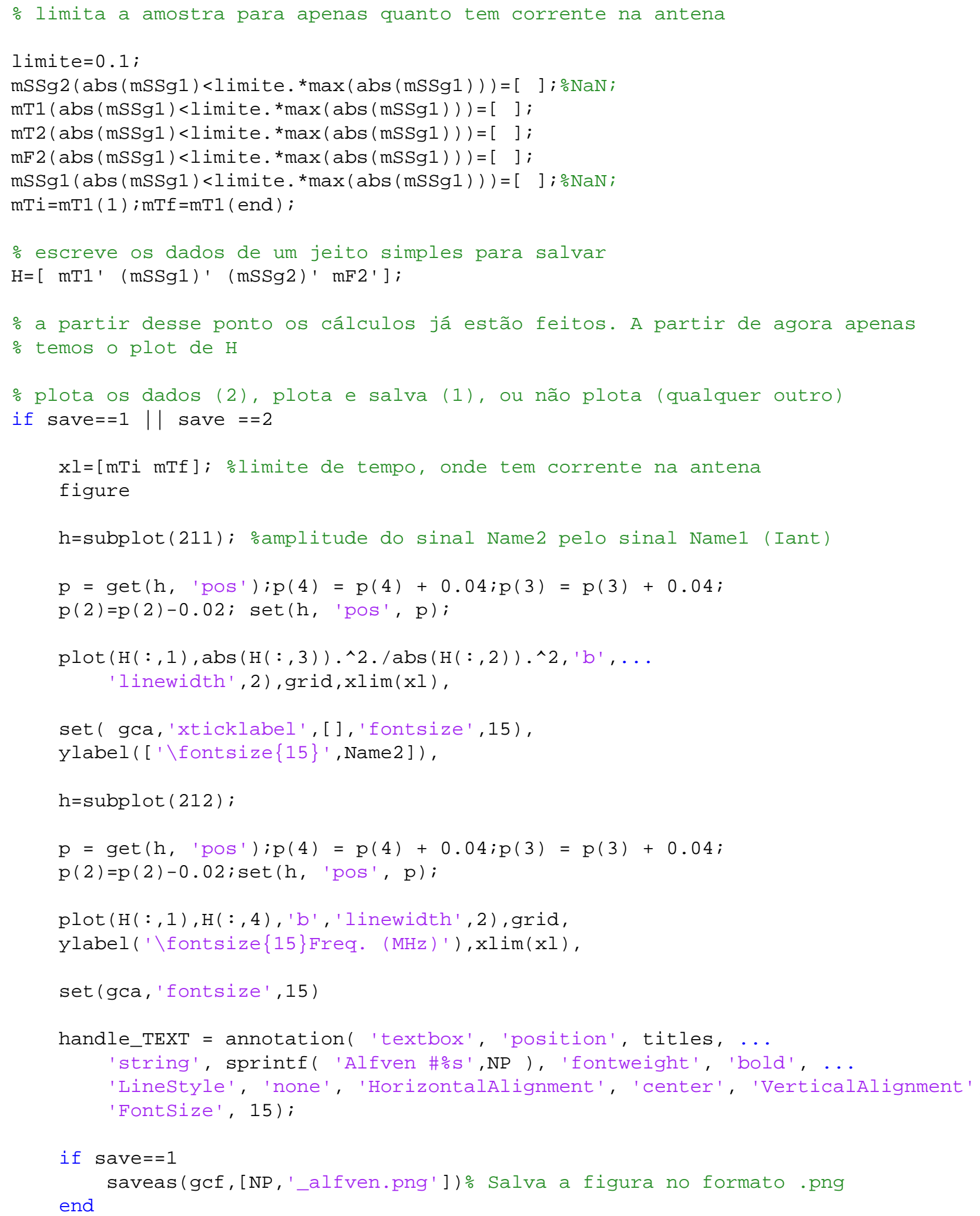



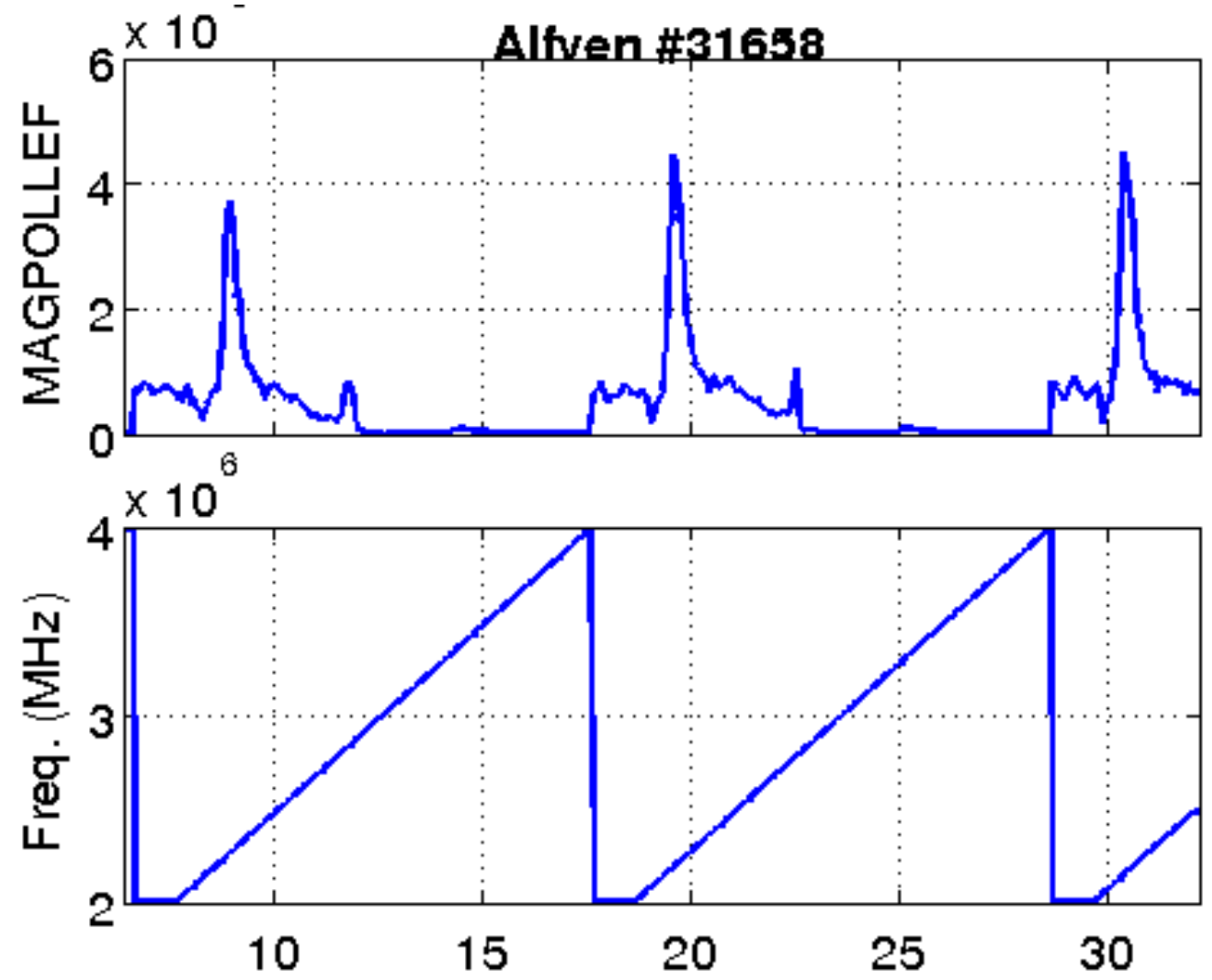

Published with MATLAB® R2013a 


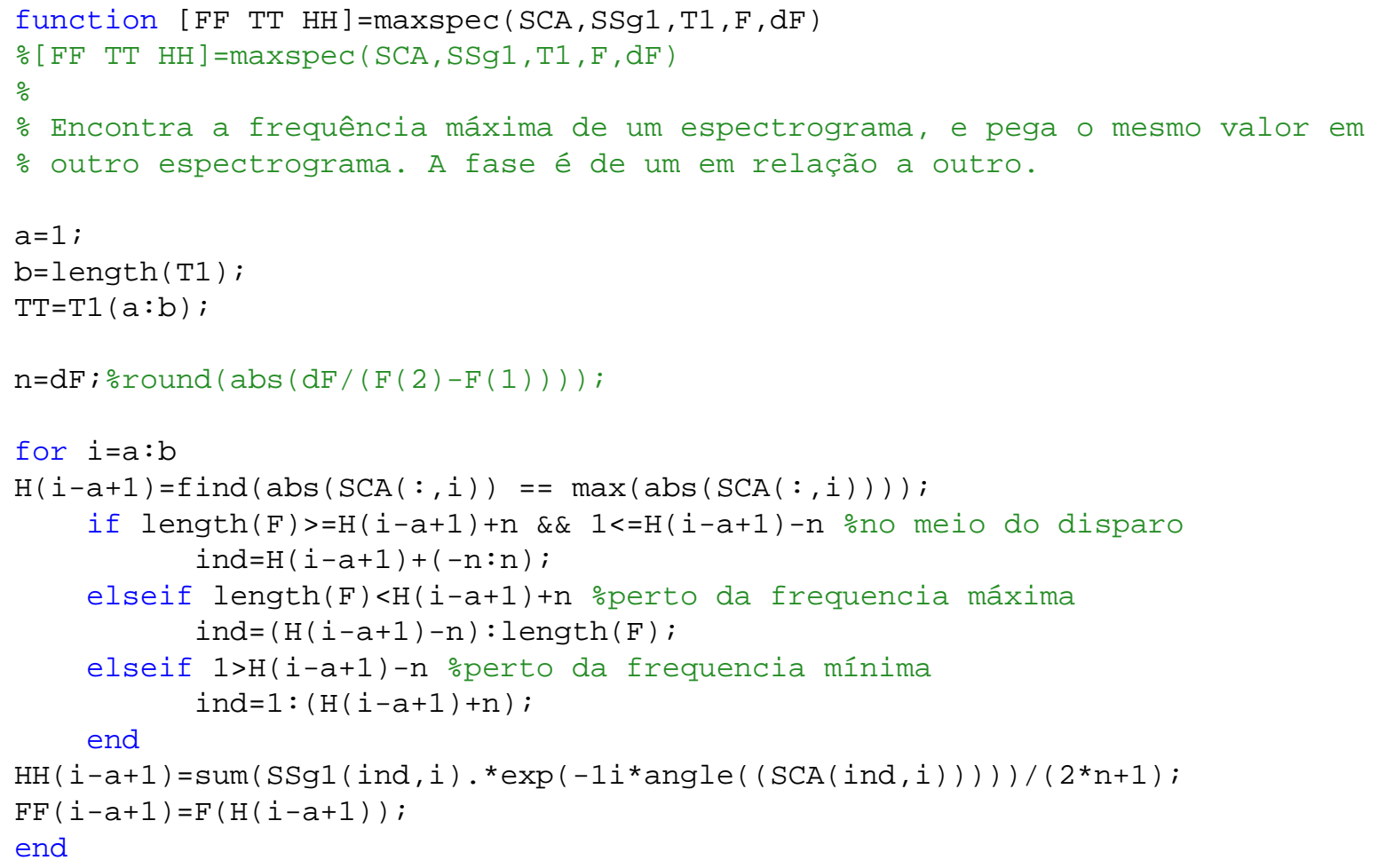

Published with MATLAB® R2013a 


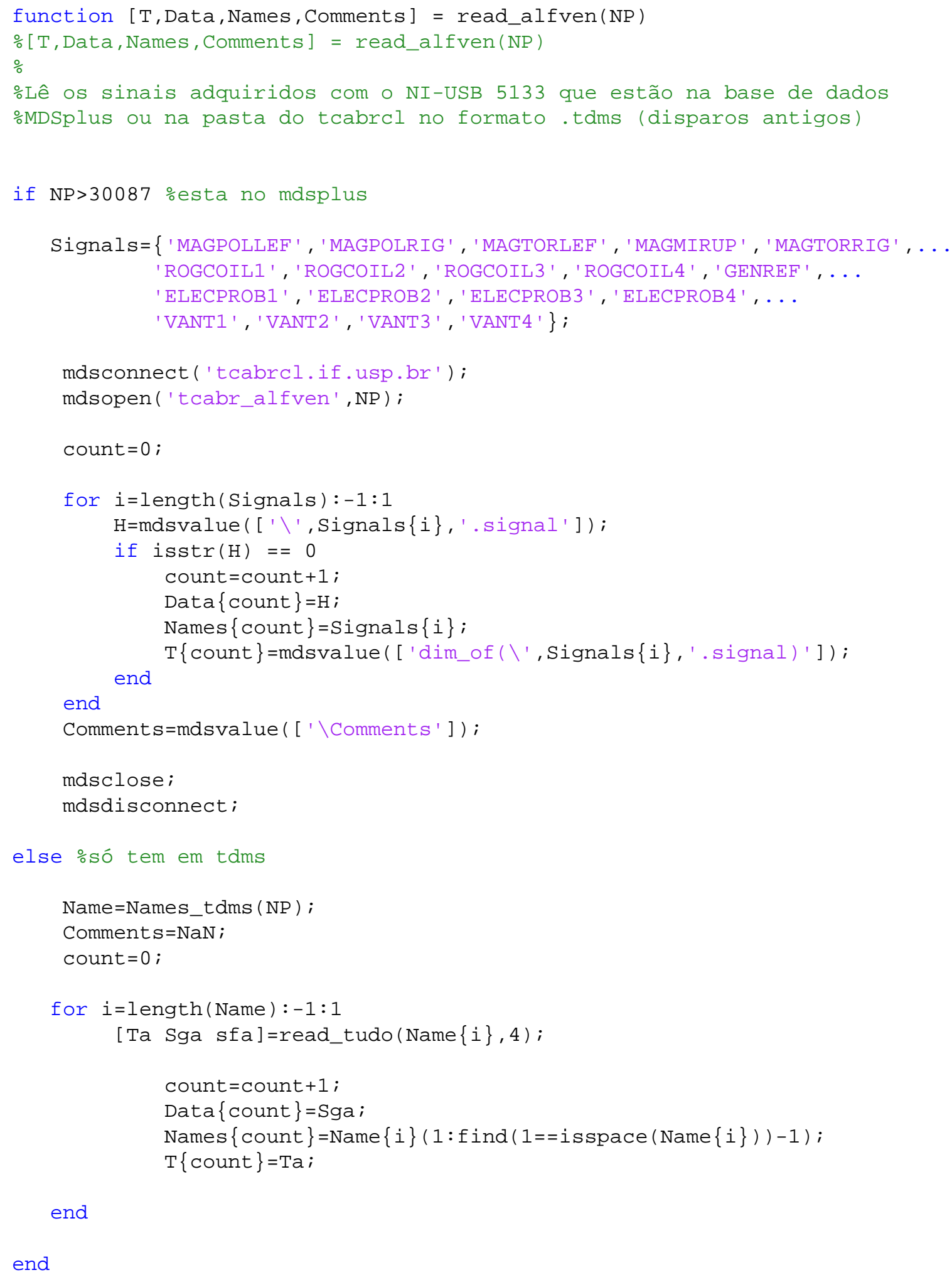




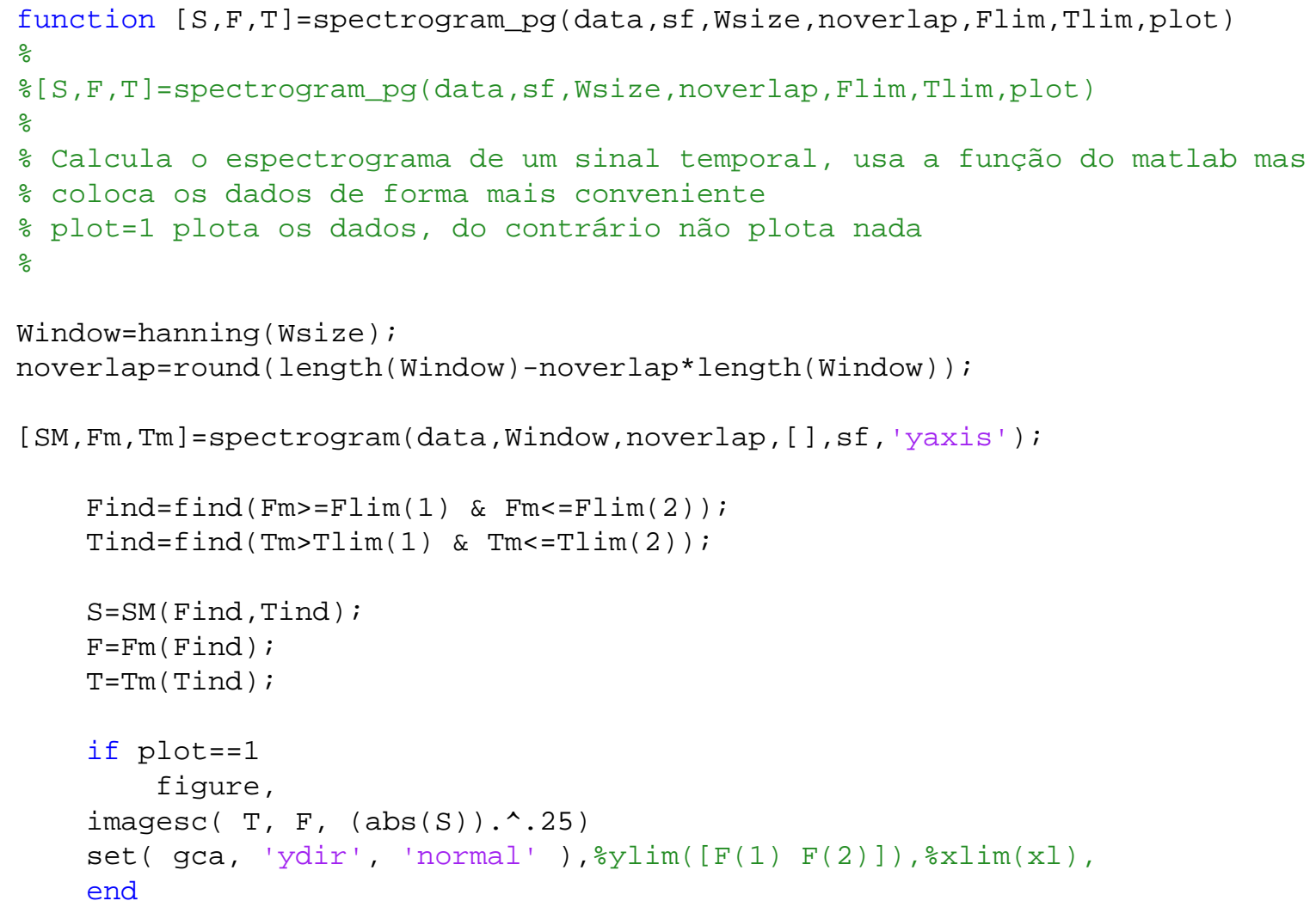

Published with MATLAB® R2013a 


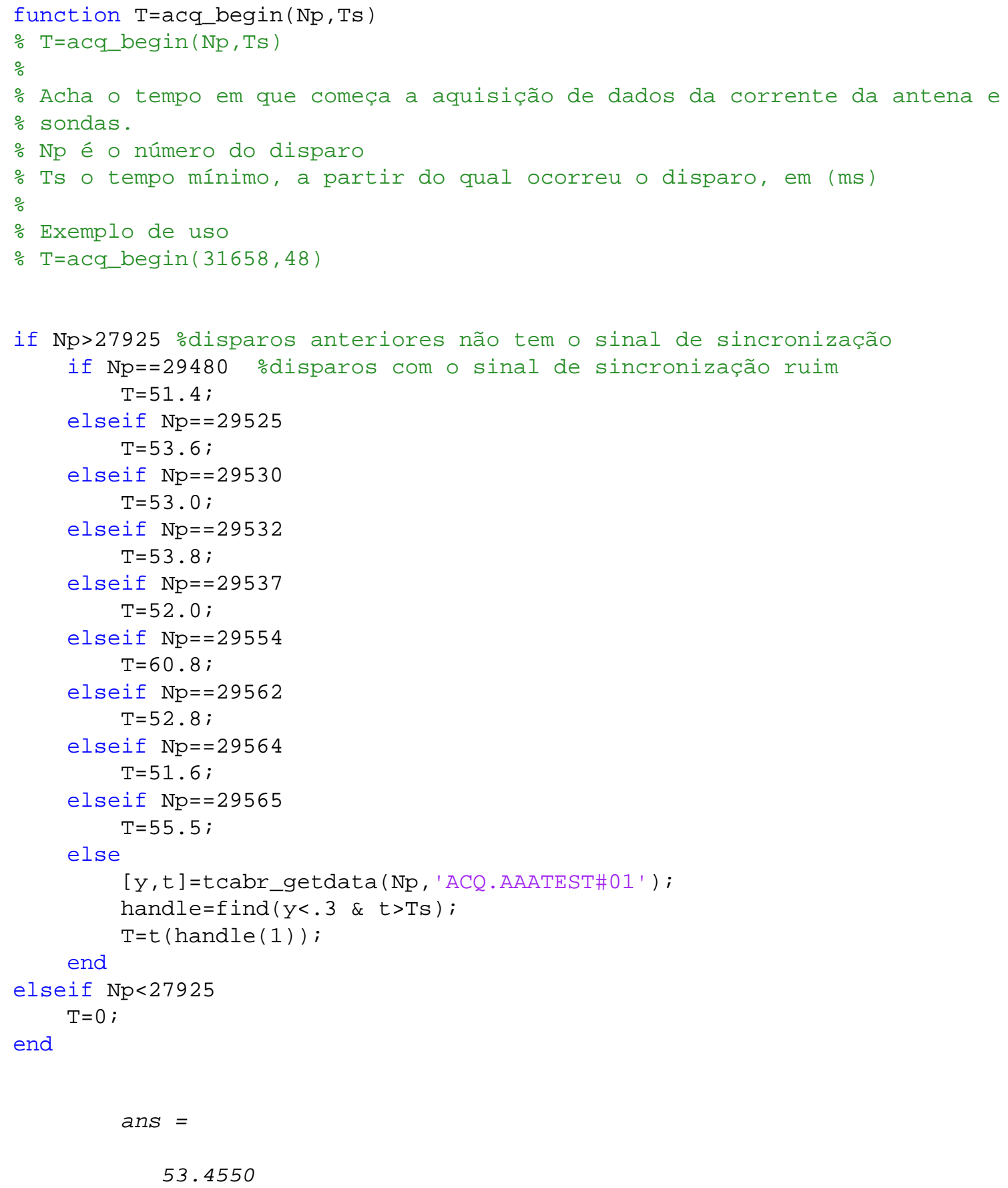

Published with MATLAB® R2013a 


\section{Lista de Figuras}

1.1 Esquema representativo de um tokamak [9]. . . . . . . . . . . . . . . 11

1.2 Perturbação de campo magnético por onda de Alfvén. . . . . . . . . . . 15

1.3 Diferentes tipos de ressonância que podem ocorrer em um plasma de

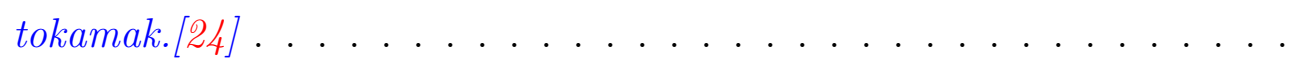

1.4 (a) Dependência da impedância de uma antena externa ao plasma pela frequência da corrente de RF. Calculado para o modo $N / M=2 / 1$ e parâmetros do plasma típicos para o TCABR e diferentes concentrações de carbono. Com densidade de elétrons no centro de $n_{0}=2.5 \times 10^{13} / \mathrm{cm}^{3}$ e concentração de $10.0 \% 10.6 \%$ de carbono relativa a concentração de hidrogênio. (b) Cálculo do contínuo de Alfvén pelo raio do plasma para os mesmos parâmetros, a região em destaque é a largura radial do GAE.

1.5 Gráfico do perfil radial dos campos elétricos poloidal e radial para o

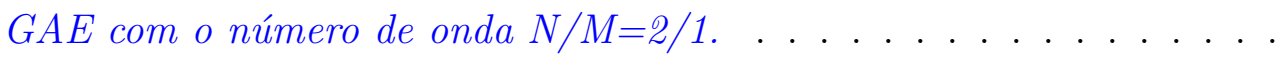

2.1 Representação esquemática do sistema de detecção e excitação de ondas de Alfvén do TCABR. Sentido de propagação do modo global de Alfvén na direção toroidal (a favor da corrente e contrário ao campo magnético) devido a efeito Hall $\left(\sim \omega / \omega_{c i}\right)$ é indicado pela flecha. . . . . . . . . . .

2.2 Detalhe de um strap da antena de aço inox. . . . . . . . . . . . . . 30

2.3 Foto da antena dentro do vaso, com a proteção de nitreto de boro. . . . 31

2.4 Esquema da gaiola de Faraday para proteção da antena. . . . . . . . . . 32 
2.5 Comparação do sinal de dois disparos diferentes, um sem a blindagem do feedthrough (\# 26536, vermelho) e outro com a blindagem do feedthrough (\# 26556, azul). São apresentados sinais do soft $x$-ray (a) e do bolometro (b). . . . . . . . . . . . . . . . . .

2.6 Esquema das bobinas ortogonais da sonda magnética usada para fazer as medidas do campo magnético [31] . . . . . . . . . . . . . .

2.7 Esquema de ligação do PC à sonda magnética via BALUN. Usamos uma indutância de $1 m H$ para o BALUN. . . . . . . . . . . . . .

2.8 Detecção das oscilações da ilha magnética do TCABR com as sondas magnéticas de Alfvén, para o disparo\# 28605. Temos o espectrograma com o máximo destacado em branco e, a defasagem entre o sinal duas sondas, referente a frequência que segue a linha branca. A defasagem é $d e \approx 27^{\circ} \ldots \ldots \ldots \ldots \ldots \ldots$

2.9 Esquema de blocos do gerador de potência com varredura de frequência.

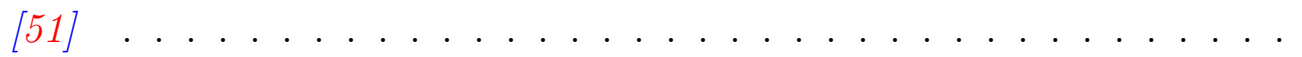

2.10 Performance do amplificador de RF, com a corrente em modo de frequência fixa (\#28376) e em modo de varredura de frequência (\#28605). Podemos ver, para os dois disparos diferentes, o sinal da corrente de RF que passa pela antena obtido com uma bobina de Rogowski (a), o espectrograma desse sinal (b) e a potencia espectral na frequência da corrente de $R F(c) \ldots \ldots \ldots \ldots \ldots \ldots \ldots$

2.11 Diferença de fase entre os sinais de ruído adquiridos simultaneamente nos dois módulos NI-USB 5133. O sinal do Modulo 1 CHO (a) foi usado como referência. Vemos que a fase em relação ao sinal adquirido com o mesmo módulo (b) é zero para todos os tempos e frequências. Já a fase em comparação com o sinal do outro módulo, (c) e (d), varia com o tempo e com a frequência. Por variar no tempo indica que temos uma pequena diferença na taxa de aquisição entre os dois módulos. . . . . . 
2.12 Esquema do interferômetro do TCABR, mostrando os dois canais utilizados nos experimentos. . . . . . . . . . . . . . . . .

2.13 Cálculo da densidade no centro do plasma e do parâmetro $\alpha$ com o método apresentado, a análise foi feita para o disparo \# 28376. Podemos ver claramente a mudança do perfil quando há injeção de gás, e consequente aumento da densidade, a partir de $t \approx 65 \mathrm{~ms} . \ldots . . . .$.

2.14 Sinal do raio-X mole para o disparo \# 28376. Podemos ver claramente a mudança de fase da instabilidade dente de serra entre o centro do plasma (canal $10 r=-7.0 \mathrm{~mm}$ ) e um canal mais afastado (canal $5 \mathrm{r}=-79.6 \mathrm{~mm}) .45$

2.15 Análise da localização da superfície $q=1$ com o uso do sinal do raio-X mole, para o disparo \#28376. A escala de cores representa a amplitude do sinal multiplicado pelo cosseno da diferença de fase em relação ao

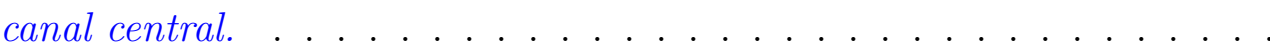

2.16 Esquema de funcionamento do reflectômetro do TCABR para determinação do tempo de voo da onda no plasma. . . . . . . . . . . . . . .

2.17 Espectrograma das bandas $K$ e Ka quando refletidas na parede do vaso do TCABR, para o disparo \#30407. . . . . . . . . . . . . .

2.18 Medida do tempo de vôo $\left(t_{d}\right)$ entre a antena e o plasma, para os momentos $T=63.07 \mathrm{~ms}$ (a) e $T=71.33 \mathrm{~ms}$ (c) para o disparo \# $3040 \%$. Comparado com a densidade do plasma (b) e (d). . . . . . . . . . . .

3.1 Exemplo do método de análise dos sinais de RF. Temos no caso a corrente de RF para o disparo \#30010. . . . . . . . . . . . . . 
3.2 Evolução temporal dos principais parâmetros do plasma para o disparo \#29589. Os sinais apresentados são densidade de linha (a), onde a curva mais alta é a densidade calculado no centro (a1), densidade de linha do interferômetro nos raios $-1.25 \mathrm{~cm}$ (a2) e $9.25 \mathrm{~cm}$ (a3), emissão de raio-X mole do centro (b), sinal do bolômetro do centro (c), sinal de raio-X duro (d), corrente de plasma (e), voltagem de loop (f), posição vertical e horizontal (g), e oscilações magnéticas (h). . . . . . . . . . 58

3.3 Evolução temporal da potência espectral (a) do sinal da sonda magnética, normalizado pela amplitude da corrente de RF, em comparação com as varreduras de frequência (b) da corrente de $R F$ e a densidade de elétrons no centro do plasma (c), para o disparo \#29589. . . . . . . . . .

3.4 Evolução temporal dos principais parâmetros do plasma para o disparo \#30044. Os sinais apresentados são densidade de linha (a), onde a curva mais alta é a densidade calculado no centro (a1), densidade de linha do interferômetro nos raios $-1.25 \mathrm{~cm}$ (a2) e $9.25 \mathrm{~cm}$ (a3), emissão de raio-X mole do centro (b), sinal do bolômetro do centro (c), emissão do ECE (d), corrente de plasma (e), voltagem de loop (f), posição vertical e horizontal (g), e oscilações magnéticas (h). O sinal do ECE diminui, pois a densidade está acima do corte. . . . . . . . . . . . .

3.5 Evolução temporal da potência espectral (a) do sinal da sonda magnética, normalizado pela amplitude da corrente de RF, em comparação com as varreduras de frequência (b) da corrente de $R F$ e a densidade de elétrons no centro do plasma (c), para o disparo \#30044. . . . . . . . . . 
3.6 Evolução temporal dos principais parâmetros do plasma para o disparo \#29565. Os sinais apresentados são densidade de linha (a), onde a curva mais alta é a densidade calculada no centro (a1), densidade de linha do interferômetro nos raios $-1.25 \mathrm{~cm}$ (a2) e $9.25 \mathrm{~cm}$ (a3), emissão de raio-X mole do centro (b), sinal do bolômetro do centro (c), sinal de raio-X duro (d), corrente de plasma (e), voltagem de loop (f), posição vertical e horizontal (g), e oscilações magnéticas (h). A rampa na densidade é devida a injeção de gás no plasma $t=50-60 \mathrm{~ms}$. . . . . .

3.7 Evolução temporal da potência espectral do sinal da sonda magnética, normalizado pela amplitude da corrente de RF, com frequência fixa de $2.6 \mathrm{MHz}$ (a), comparado com o sinal da emissão de raio-X mole (b) e a densidade de elétrons calculada no centro (c), para o disparo \#29565. A área em destaque é ampliada para observarmos detalhes da fase entre os sinais. As linhas sólidas e pontilhadas indicam a correlação entre a potencia espectral e o crash do dente de serra, as setas indicam a mudança de fase. . . . . . . . . . . . . . . . .

3.8 Evolução temporal da potência espectral do sinal da sonda magnética, normalizado pela amplitude da corrente de RF (a), comparado com o sinal da emissão de raio-X mole medido por um canal central (b), a frequência da corrente de RF (c) e a densidade calculada no centro (d), para o disparo \#29554. . . . . . . . . . . . . . . . .

3.9 Dependência da frequência das ressonâncias identificadas com a densidade calculado para o centro do plasma. Para os modos $|N|+|M|=2$ (azul), 3 (verde), 4 (vermelho) e 5 (rosa). As linhas pontilhadas correspondem ao cálculo do contínuo de Alfvén para os modos $\frac{M}{N}=\frac{-1}{-1}, \frac{-2}{-1}$ para os parâmetros do TCABR e massa efetiva 1,45 . . . . . . . . . 
3.10 Cálculo da amplitude espectral para duas antenas dispostas toroidalmente em lados opostos do tokamak. Somamos em $M$ de -2 à 2 . Foram calculados os casos para as correntes com diferença de fase de $0^{\circ}$ (fase ou par) ou $180^{\circ}$ (contrafase ou impar). . . . . . . . . . . . . . .

3.11 Cálculo da amplitude espectral para duas antenas dispostas toroidalmente em lados opostos do tokamak. Somamos em $M$ de -2 à 2. Foram calculados com amplitude e diferença de fase entre as correntes simulando condições experimentais. . . . . . . . . . . . . . . . .

3.12 Diferença de fase entre as correntes de RF nas duas antenas. . . . . . .

3.13 Evolução temporal da potência espectral do sinal da sonda magnética normalizado pela amplitude da corrente de RF, (a) e (e), amplitude espectral da corrente de RF em ambas as antenas, (b) $e(f)$, sinal do raio-X mole, (c) e (g) e a densidade calculada no centro do plasma, (d) e (h), para os disparos \#29691 (a)-(d) e \#29693 (e)-(h). A linha pontilhada em (b) e (f) é a corrente na segunda antena. . . . . . . . .

3.14 Evolução temporal da potência espectral do sinal da sonda magnética normalizado pela amplitude da corrente de $R F$, (a) e (e), amplitude espectral da corrente de RF em ambas as antenas, (b) e (f), a frequência da corrente de RF, (c) e (g) e a densidade calculada no centro do plasma, (d) e (h), para os disparos \#29648 (a)-(d) e \#29653 (e)-(h). A linha pontilhada em (b) e (f) é a corrente na segunda antena. . . . . . . . . .

3.15 Resumo da condição de ressonância $M / N=-1 /-1$ encontrada em comparação com resultados antigos para uma série de disparos, em destaque, com círculos pretos, os dados apresentados nessa seção para a excitação com duas antenas e com paridade definida. . . . . . . . . . 
3.16 Evolução temporal da potência espectral do sinal da sonda magnética normalizado pela amplitude da corrente de RF, (a) e (e), amplitude espectral da corrente de RF em ambas as antenas, (b) e (f), sinal do raio-X mole, (c) e (g) e a densidade calculada no centro do plasma, (d) e (h), para os disparos \#29674 (a)-(d) e \#29672 (e)-(h). A linha pontilhada em (b) e (f) é a corrente na segunda antena. . . . . . . . . .

3.17 Comparação da amplitude do sinal de RF das sondas magnéticas, mesmos disparos que na figura 3.16. . . . . . . . . . . . . .

3.18 Evolução temporal da potência espectral do sinal da sonda magnética normalizado pela amplitude da corrente de RF, (a) e (e), amplitude espectral da corrente de RF em ambas as antenas, (b) e (f), a frequência da corrente de RF, (c) e (g) e a densidade calculada no centro do plasma, (d) e (h), para os disparos \#29532 (a)-(d) e \#29530 (e)-(h). A linha pontilhada em (b) e (f) é a corrente na segunda antena. . . . . . . . . .

3.19 Resumo da dependência da frequência da ressonância do GAW condição de ressonância encontrada para uma série de disparos, estão em preto os dados apresentados nessa seção para a excitação com o uso de duas antenas, para o modo $M / N=-1 /-2 \ldots \ldots \ldots$

4.1 Gráfico de cálculos com código cinético da potência dissipada pelo GAE (a) para o modo $M / N=1 / 2$ para $7 \%$ de concentração de impurezas de carbono e curvas do contínuo de Alfvén para os modos $M / N=1 / 2$ e $M / N=2 / 1$ para a concentração de carbono de $7 \%$ e $4.5 \%$ (b), respectivamente. A região em destaque é a largura radial do GAE. . . . . . .

4.2 Gráfico da corrente de plasma pela densidade dos disparos com ressonâncias detectadas. . . . . . . . . . . . . . . . .

4.3 Comparação dos dados obtidos, apresentados na figura 3.9, com cálculos do contínuo de Alfvén para os modos $N / M=2 / 1$ e $1 / 1$ com consideração de impurezas e termo de efeito Hall (linha vermelha). . . . . . . . . . . 
4.4 Tempo de atraso medido pelo interferômetro e ajuste dos dados pelo tempo de atraso considerando um perfil parabólico, para o instante $110 \mathrm{~ms}$ do disparo $\# 28267$. Obtemos o valor de $n_{0}=1.37 \times 10^{19}$ e $\alpha=1.0$. .

4.5 Comparação do cálculo da densidade no centro do plasma e do valor do parâmetro $\alpha$, com deslocamento $(\delta=0.08)$ e sem deslocamento $(\delta=$ 0.00) o perfil com deslocamento de Shafranov. . . . . . . . . . . . .

4.6 Sinal nos canais do interferômetro em um disparo sem plasma, \#28385.

4.7 Ressonância de GAW da figura 3.9, com o valor da densidade central dos elétrons corrigida pelo deslocamento de Shafranov. . . . . . . . . .

4.8 Correção da densidade central pelo deslocamento de Shafranov, para identificação das ressonâncias para os modos $N / M=2 / 1$ e 1/1, com cálculo do contínuo com impurezas (vermelho). . . . . . . . . . . . . .

4.9 Evolução temporal dos principais parâmetros do plasma para o disparo \#31658. Os sinais apresentados são densidade de linha no raio $-1.25 \mathrm{~cm}($ a), emissão de raio-X mole do centro (b), sinal do bolômetro do centro (c), sinal do raio-X duro (d), corrente de plasma (e), voltagem de loop (f), posição vertical e horizontal (g), e oscilações magnéticas (h). . . . . . . 101

4.10 Evolução temporal da potência espectral do sinal da sonda magnética, normalizado pela amplitude da corrente de RF (a), comparado com o sinal da emissão de raio-X mole (b), a frequência da corrente de RF (c) e a densidade de linha no raio $-1.25 \mathrm{~cm}$ (d), para o disparo \#31658. . . 102

4.11 Dependência da frequência das ressonâncias identificadas com a densidade calculado para o centro do plasma. Para os modos $|N|+|M|=3$ (verde), 4 (vermelho) e 5 (rosa). . . . . . . . . . . .

4.12 O contínuo de Alfvén para o plasma do TCABR para os modos $N / M=$ 2/1,3, 1 e 4/1, consideramos a densidade de $n_{0}=3.3 \times 10^{13} / \mathrm{cm}^{3}$ e a frequência do modo global como $\approx 5 \%$ menor que o mínimo do contínuo. 106 
4.13 O contínuo de Alfvén para o plasma do TCABR para os modos diferentes modos $N / M$, mostrando a incerteza na determinação do número de onda dos modos para a soma $N+M=4$ (esquerda) e 5 (direita). . . . . . 107

A.1 Amplificador de RF, onde estão os MOSFETs. Foto comentada. . . . . 115

A.2 Foto de uma das fontes DC usadas nos experimentos de excitação de ondas de Alfvén, com comentários. . . . . . . . . . . . . . 117

A.3 Foto da fonte DC com detalhe nos cabos responsáveis por "triggerar"a parte de potência da fonte. O trigger é feito por contato seco (curto), um é o cabo para disparar e o outro para rearmar a fonte. . . . . . . . . 117

A.4 Localização do trigger para a fonte DC e o sistema de aquisição. . . . . 118

A.5 Gabinete onde se encontra o PC de aquisição de dados. Os sinais das sondas magnéticas e das bobinas de Rogowski são enviados a este gabinete com cabos BNC e BNO. . . . . . . . . . . . . . . . . . . 118

A.6 Vista conjunta do gabinete das fontes DC (1) e do gabinete do PC de aquisição (2) . . . . . . . . . . . . . . . . . . . . 119

A.7 Foto do BALUN usado para aquisição dos dados das sondas magnéticas, chave de fenda para escala. . . . . . . . . . . . . . . . . 120

A.8 Localização das sondas magnéticas no tokamak, em destaque. . . . . . . 121

B.1 Painel frontal do programa de aquisição de dados. Foi dividido em 5 partes para facilitar a descrição, cada parte correspondendo a uma função

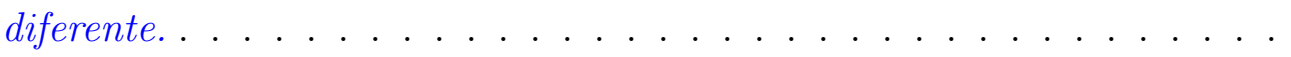

B.2 Diagrama de blocos geral do programa de aquisição de dados dividido em 4 partes: (1) carregar configurações (não utilizado), (2) aquisição de dados, (3) encerramento do programa e (4) comunicação por internet. .

B.3 Inicia os Devices. Inicia qualquer um dos módulos NI-USB para serem usados para aquisição de dados. Configura o display de estado do sistema para mostrar "Configurando". 
B.4 Configura parâmetros da aquisição com os parâmetros colocados no campo (3) do painel frontal, figura B.1. A rotina de configuração está na subVI apontada. Uma vez configurados os canais de aquisição, espera o usuário apertar o botão "Iniciar Aquisição"no painel frontal. Uma vez feito isso, muda o estado do display para "Esperando Trigger". . . . . . . . .

B.5 Habilita os módulos NI-USB 5133 a adquiriram dados. Uma vez que os módulos NI-USB 5133 foram configurados e habilitados, eles esperam o trigger para adquirir os dados. O trigger é dado pelo VME e está atrelado ao disparo da corrente de RF nas antenas. . . . . . . . . . .

B.6 Esse estado recebe a informação se o trigger já foi recebido e os dados já foram adquiridos. Uma vez que isso acontece, segue-se para o próximo estado. Esse estado é onde o sistema fica na maior parte do tempo, já que está sempre esperando o próximo disparo e raramente são feitas modificações entre um disparo e outro. Nesse estado também temos o botão de reconfigurar, do painel fronta, figura B.1. Uma vez pressionado, voltamos ao estado apresentado na figura $B .4$ e os canais são reconfigurados de acordo com as modificações realizadas no painel frontal. . . . . . . .

B.7 Neste estado salvamos os dados em arquivos. Como mencionado, os arquivos são salvos tanto no formato .tdms em uma pasta local no computador, quanto na árvore MDSplus. A árvore MDSplus é criada e salva no próprio $P C$ de aquisição. . . . . . . . . . . . . . . . .

B.8 Envia os dados da a árvore do MDSplus para os três computadores que fazem o backup do banco de dados. Uma vez a árvore do MDSplus criada no PC de aquisição, ela é enviada por protocolo SSH para três servidores do TCABR. Uma vez nessas máquinas, podem ser acessadas remotamente por protocolo MDSplus. . . . . . . . . . . . . . . 


\section{Referências Bibliográficas}

[1] J. Ongena and G. Van Oost. Energy for Future Centuries: Will fusion be an inexhaustible, safe and clean energy source? 2008. http://www.fusie-energie. nl/artikelen/ongena.pdf, Janeiro 2011.

[2] I. E. Tamm. Theory of magnetic thermonuclear reactor (Part 1). Plasma Physics and the Problem of Controlled Thermonuclear Reactions, v. 1, p. 1, 1961.

[3] A. D. Sakharov. Theory of magnetic thermonuclear reactor (Part 2). Plasma Physics and the Problem of Controlled Thermonuclear Reactions, v. 1, p. 21, 1961.

[4] I. E. Tamm. Theory of magnetic thermonuclear reactor (Part 3). Plasma Physics and the Problem of Controlled Thermonuclear Reactions, v. 1, p. 35, 1961.

[5] S. D. Drell and S. P. Kaptiza. Sakharov Remembered: A tribute by Friends and Coleagues. American Institute of Physics.

[6] J. D. Lawson. Some Criteria for a Useful Thermonuclear Reactor. Atomic Energy Research Estabilishment, GP/R 180\%, 1955.

[7] http://www.iter.org, Agosto 2015.

[8] http://fusionforenergy . europa.eu/understandingfusion/demo.aspx, Agosto 2015.

[9] http://www.jet.efda.org/, Julho 2010.

[10] F. F. Chen. Introduction to plasma physics and controlled fusion. Springer, 1984. 
[11] J. Wesson. Tokamaks. Claredon Press, Oxford, 2004.

[12] I. N. Golovin and V. D. Shafranov. Sakharov Remembered: A tribute by Friends and Coleagues. 1991.

[13] W. Grossman and G. Tataronis. Z. Phys 217(261m), 1973.

[14] S.D.Piazza G.G.Borg, J.B.Lister and Y.Martin. Nuclear Fusion, v. 33, p. 841, 1993.

[15] L.F.Ruchko et al. Advanced antenna system for Alfvén wave plasma heating and current drive in TCABR tokamak. Fusion Engineering and Design, v. 43, p. 15, 1998.

[16] E.M.Ozono. Desenvolvimento do sistema de excitação de ondas de Alfvén no TCABR. PhD thesis, IFUSP, 2000.

[17] H.Goedbloed and S.Poedts. Principles of Magnetohydrodynamics. Cambridge University Press, 2004.

[18] H. Alfvén. Nature, v. 150, p. 450.

[19] A.I.Akhiezer. Plasma Electrodynamics vol 1. New York: Pergamon, 1976.

[20] A. A. Rukhadze A. F. Alexandrov, L. S. Bogdankevich. Principles of Plasma Electrodynamics. Springer, 1984.

[21] Kenro Miyamoto. Controlled Fusion and Plasma Physics. Taylor \& Francis, 2007.

[22] G.L. Chen D.W. Ross and S.M. Mahajan. Kinetic description of alfvén wave heating. Phys. Fluids, v. 25, p. 652, 1982.

[23] A. Hasegawa and C. Uberoi. The Alfvén Wave. U. S. DOE, Oak Ridge.

[24] W. W. Heidbrink. Basic physics of Alfvén instabilities driven by energetic particles in toroidally confined plasmas. Physics of Plasmas, v. 15, 055501,, 2008. 
[25] K Appert, R Gruber, F Troyuon and J VaclavikT. Excitation of global eigenmodes of the Alfven wave in Tokamaks. Plasma Phys. 24 1147, 1982.

[26] Paulo Giovane P. P. Puglia. Excitação de Ondas de Helicon e de Alfvén no Tokamak TCABR. Master's thesis, IFUSP, 2011.

[27] G. Amarante Segundo. Análise numérica do aquecimento de plasmas, geração de corrente e fluxo de onda de Alfvén no Tokamak TCABR. PhD thesis, IFUSP, 1999.

[28] J. Vaclavik K. Appert and L. Villard. Introduction to the Theory of Alfvén wave heating. CRPP Report, LRP 238/84, 1984.

[29] G. Vlad, F. Zonca and S. Briguglio. Dynamics of Alfvén waves in tokamaks. Rivista del Nuovo Cimento vol. 22, n. 7, 1999.

[30] G. A. Collins, F. Hofmann, B. Joye, R. Keller, A. Lietti et al. The Alfvén wave spectrum as measured on a tokamak. Phys. Fluids 29, 2260; doi: 10.1063/1.865563, 1986.

[31] E. A. LERCHE. Desenvolvimento e Caracterização dos Sistemas de Alimentação e Diagnóstico para Excitação de Ondas de Alfvén do Tokamak TCABR. Master's thesis, IFUSP, 1998.

[32] E. A. LERCHE. Aquecimento do plasma por ondas de Alfvén no tokamak TCABR. PhD thesis, IFUSP, 2003.

[33] T. Dudok De Wit, J.B. Lister, B.P. Duval,B. Joye, P. Marmillod. Central mass feedback control using the discrete Alfvén wave spectrum. 1990 Nucl. Fusion 30 $1493,2006$.

[34] J B Lister, L Villard and G de Ridder. Measurement of the effective plasma ion mass in large tokamaks using global Alfvén eigenmodes. Plasma Phys. Control. Fusion 40 1635-1645, 1998. 
[35] P. G. P. P. Puglia, A. G. Elfimov, L. F. Ruchko, R. M. O. Galvão, Z. GuimarãesFilho, G. Ronchi and TCABR Team. Externally driven global Alfvén eigenmodes applied for effective mass number measurement on TCABR. Phys. Plasmas 21, 122509, 2014.

[36] Neil F. Cramer. The Physics of Alfvén Waves. Wiley-VHC.

[37] S . M. Mahajan. Spectrum of Alfvén waves, a brief review. Physica Scripta Vol. T60, 160-170, 1995.

[38] A. de Chambrier et. al. Target plasma conditions in TCA. LRP 241/84, 1984.

[39] I. H. Hutchinson. Principles of Plasma Diagnostics, 2nd edition. Cambridge University Press.

[40] A. G. Elfimov, L.F. Ruchko et al. Identification of Local Alfvén Wave Resonances With Reflectometry as a Diagnostic Tool in Tokamaks. Nucl. Fusion 46, S722, 2006.

[41] A. G. Elfimov; E. A. Lerche; R. M. O. Galvão; L. F. Ruchko; A. M. M. Fonseca; R. P. da Silva; V. Bellintani. Results of localized Alfvén wave heating in TCABR. Braz. J. Phys. vol.34 no.4b, 2004.

[42] J. P. Goedbloed et. al. MHD Spectroscopy. Plasma Physics and Controlled Fusion 35 B27r-B292, 1993.

[43] T. Dudok De Wit, B.P. Duval, B. Joye, J.B. Lister. Measurement of hydrogen transport in deuterium discharges using the dynamic response of the effective mass. Nucl. Fusion 31 359, 1991.

[44] G. A. Collins et. al. The effect of Lower Hybrid Current Drive on the discrete Alfvén wave spectrum. Plasma Phys. Control. Fusion 29 1631, 1987.

[45] P. Descamps, G. Van Wassenhove1, R. Koch, A.M. Messiaen, P.E. Vandenplas, J.B. Lister, Ph. Marmillod. Dermination of central q and effective mass on textor 
based on discrete Alfvén wave (DAW) spectrum measurements. Physics Letters A $143311-316,1990$.

[46] A. G. Elfimov. Kinetic effect on low frequency Alfvén continuum in tokamaks. Physics of Plasmas 15, 074503, 2008.

[47] S.E. Sharapov et. al. MHD spectroscopy through detecting toroidal Alfvén eigenmodes and Alfvén wave cascades. Physics Letters A 289, 127-134, 2001.

[48] Theodoros Panis. Direct Measurements of the Damping of Alfvén Eigenmodes for an Assessment of their Stability Limits in Tokamak Plasmas. PhD thesis, Thèse École polytechnique fédérale de Lausanne EPFL no 4940, 2010.

[49] P. G. P. P. Puglia A. G. Elfimov, L. F. Ruchko. Alfvén and Helicon Wave Resonances Measured with Demodulator Circuit in TCABR. J. Phys.: Conf. Ser. 511 012038, 2014.

[50] P. G. P. P. Puglia et. al. Excitation of Global Alfvén Waves by Low RF Power on TCABR. J. Phys.: Conf. Ser. 591 012002, 2015.

[51] L. Ruchko. Variable Frequency Generator. In Poster presented in Encontro Brasileiro de Física de Plasma, 2009.

[52] Victor Cominato Theodoro. Estudo espectral das instabilidades mhd no tokamak TCABR. Master's thesis, IFUSP, 2013.

[53] I.C. Nascimento J.I. Elizondo, D. Korneev and W.P. de Sa. Tcabr interferometer. Brazilian Journal of Physics, vol. 32, no. 1, March, 2002.

[54] M. E. Manso C. Laviron, A. J. H. Donné and J. Sanchez. Reflectometry techniques for density profile measurements on fusion plasmas. Plasma Phys. Control. Fusion, v. 38, p. 905,. 
[55] G.J.Kramer R.Nazikian and E.Valeo. A tutorial on the basic principles of microwave reflectometry applied to fluctuation measurements in fusion plasmas. Phys. Plasma, v. 5, p. 1840, 2001.

[56] J. D. Jackson. Classical Electrodynamics Third Edition. Wiley, 1998.

[57] Timothée Nicolas et. al. Particle Flow during Sawtooth Reconnection: Numerical Simulations of Experimental Observations . Plasma and Fusion Research Vol. 8, 2402131, 2013.

[58] C. De Micheli C. Breton and M. Maitio. Ionization Equilibrium and Radiative Cooling of a High Temperature Plasma. . Quant. Spectrosc. Radiat. Transfer, Vol.19, pp. 367-379.

[59] Naval Research Laboratory. NRL Plasma Formulary. United States Navy, 2009.

[60] 1 F. O. Borges J. I. Elizondo R. M. O. Galvão J. H. F. Severo O. C. Usuriaga L. A. Berni M. P. Alonso, A. C. A. Figueiredo and M. Machida. Comparative electron temperature measurements of Thomson scattering and electron cyclotron emission diagnostics in TCABR plasmas. Review of Scientific Instruments 81, 10D529, 2010.

[61] J.H.F. Severo, I.C. Nascimento, Yu.K. Kuznetsov, R.M.O. Galvão, Z.O. Guimarães-Filho, F.O. Borges1, O.C. Usuriaga, J.I. Elizondo, W.P. de Sá, E.K. Sanada and M. Tendler. Temporal behaviour of toroidal rotation velocity in the TCABR tokamak. Nucl. Fusion 49 115026, 2009.

[62] Yu. V. Gott. On Artsimovich's Formula. Plasma Physics Reports, 2007, Vol. 33, No. 10, p. 880, 2007.

[63] G. Fussman, A. R. Field, A. Kallenbach, K. Krieger, HK Steuer and the ASDEXTEAM. Impurity Transport and Neoclassical Predictions. Plasma Phys. Control. Fusion Vol. 33, No 15, 1991. 